\title{
EPIDEMIOLOGÍA DE LAS TRICHOSTRONGYLOSIS OVINAS EN EL SUR DE LA PROVINCIA DE CORRIENTES
}

Federico A. Illanes 2021
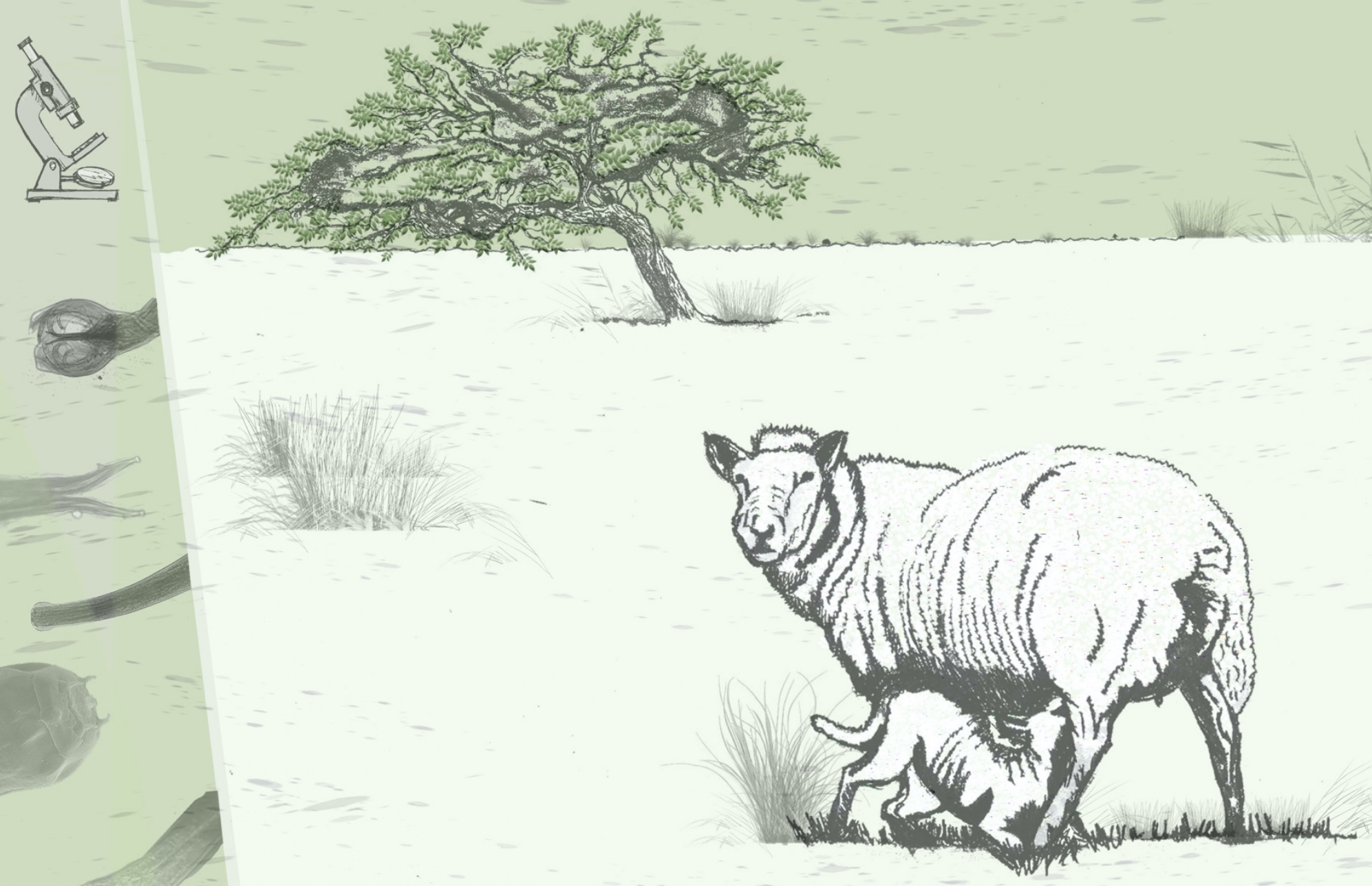


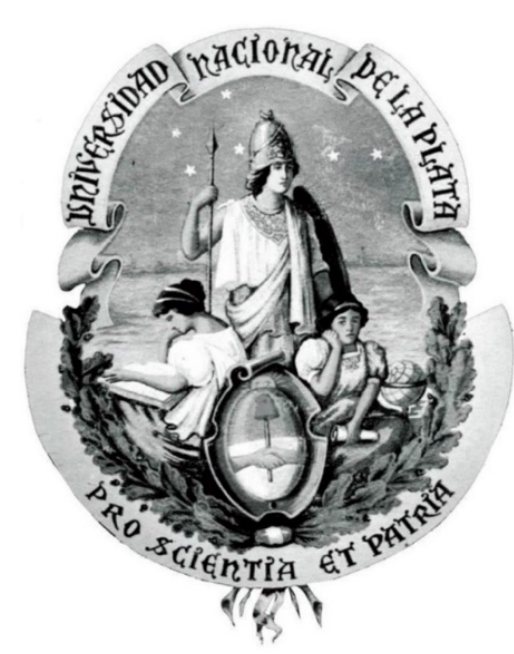

UNIVERSIDAD NACIONAL DE LA PLATA

FACULTAD DE CIENCIAS VETERINARIAS

Trabajo de Tesis realizado como requisito para optar al título de

DOCTOR EN CIENCIAS VETERINARIAS

"Epidemiología de las trichostrongylosis ovinas en el sur de la provincia de Corrientes"

AUTOR: ILLANES, Federico Adrián.

DIRECTOR: ROMERO, Jorge Roberto.

CODIRECTOR: SANABRIA, Rodrigo Eduardo Fabrizio.

LUGAR DE TRABAJO: Centro de Diagnóstico e Investigaciones

Veterinarias (CEDIVE).

Facultad de Ciencias Veterinarias. UNLP.

MIEMBROS DEL JURADO:

Prof. FIEL, Cesar

Dr. SPÄTH, Ernesto

Dr. UNZAGA, Juan Manuel.

AÑO 2021 
Dedicatoria

A mi familia, que siempre confió, me apoyó y apostó por la educación.

A la familia que fui eligiendo, esos amigos eternos que estuvieron, están y estarán siempre.

A mi compañera de vida, que incondicionalmente, me alienta y banca en todas. 


\section{Agradecimientos}

Fueron muchas las personas que colaboraron pero en primer lugar quiero agradecer a Jorge Romero por su dedicación, quien además de dirigir la investigación, fue de gran apoyo personal en el transcurso del trabajo.

A mi amigo y compañero de ruta Álvaro Niño Uribe, que afectuosamente se sumó a todas las rutinas de trabajo de campo, laboratorio y escritorio.

A la Facultad de Ciencias Veterinarias y a la Universidad Nacional de La Plata.

Al Centro de Diagnóstico e Investigaciones Veterinarias (CEDIVE), que tanto institucionalmente como las personas que allí trabajan hicieron posible y facilitaron directa o indirectamente el trabajo. Especialmente al grupo de parasitología, César Pruzzo, Catalina Lauroua, Héctor Falero y Martín Videla y a quienes desde otro lugar pudieron acompañarme en alguno de los muestreos como Magalí Romero y Carlos Cherrutti.

A la Dra. Alicia Antonini, que desinteresadamente brindó su tiempo, me asesoró y capacitó en el manejo de la información y procesamiento de datos.

Al M.V. Facundo Ramírez, que participó en muchas de las actividades de campo y facilitó el vínculo directo con productores y/o sus administraciones. A su papá Gerardo y a toda la familia, que nos recibieron siempre tan cálidamente.

A Montiel, César, Orlando Benta, German Romero, Juan Chavez, Emmanuel Jacobo, Hugo Fernández, propietarios, administración y a todo el personal de las Estancias "La Aurora"; "San Luis del Garabatá" y "Aguay". Todos colaboraron inmensamente en la ejecución día a día en cada una de las etapas de la investigación. iIncluso con clases de guaraní! 
A los más de 30 pasantes, alumnos y residentes que pudieron acompañarme en los viajes de campo.

A todo el personal de la EEA INTA Mercedes, Corrientes. Especialmente a los Ing. Agr. Susana Escalante, Diego Bendersky y equipo. A la M.V. Bibiana Cetrá y Marisa Pereira.

Al M.V. Luis Rivero de la agencia de extensión INTA Curuzú Cuatiá.

A la Lic. Fiorela Bertone del Centro de Información Meteorológica (CIM) del Servicio Meteorológico Nacional (SMN).

A la diseñadora Paola Moy y a la artista Ayelén Ponce Cativa por la confección, edición e ilustración de las imágenes de tapa. 


\section{Citas bibliográficas correspondientes a las publicaciones parciales relacionadas al trabajo de tesis}

Illanes, F.; Romero, J.; Ramírez, F.; Pruzzo, C.; Sanabria, R. Resultados preliminares de la epidemiología de las trichostrongylosis ovinas en el sur de Corrientes. 2014. XXIII Encuentro Rioplatense de Veterinarios Endoparasitólogos (ERVE) - Bariloche.

Illanes, F.; Romero, J. Estudio epidemiológico de las trichostrongylosis ovinas en la provincia de Corrientes. 2014. Jornadas de Ciencia y Técnica de la FCV; UNLP.

Illanes, F.; Niño Uribe, A.; Pruzzo, C.; Romero, J. Impacto del manejo de la majada en la transmisión de la Strongyloidosis ovina. Análisis de tres establecimientos del sur de Corrientes. 2017. VII Jornadas de Jóvenes Investigadores de la FCV; UBA.

Illanes, F.; Romero, J.; Niño Uribe, A.; Pruzzo, C. Epidemiología de las trichostrongylosis ovinas en el sur de la provincia de Corrientes. Resultado de dos años de sacrificio. 2018. XXVII Encuentro Rioplatense de Veterinarios Endoparasitólogos (ERVE) - Puerto Iguazú.

Illanes, F.; Romero, J.; Niño Uribe, A.; Pruzzo, C. Evaluación del impacto productivo de un método de control antihelmíntico en borregas de recría. 2019. XXVIII Encuentro Rioplatense de Veterinarios Endoparasitólogos (ERVE) - Termas de Arapey, URUGUAY. 


\section{Índice}

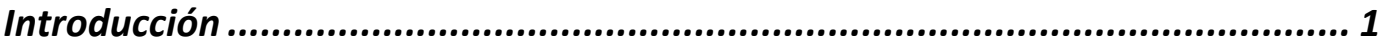

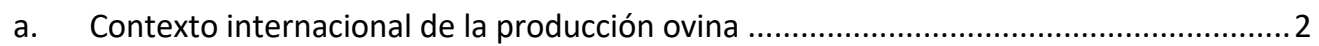

b. Producción ovina en la Argentina ........................................................................

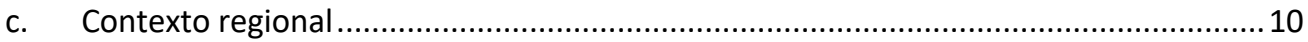

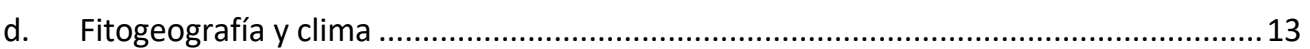

e. La enfermedad parasitaria como desequilibrio...........................................................16

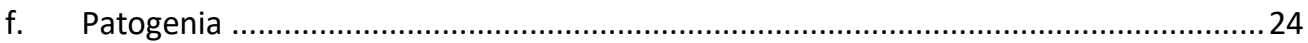

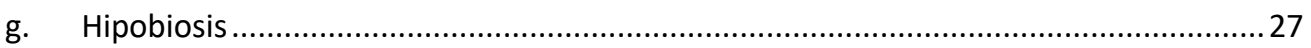

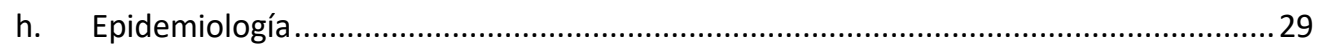

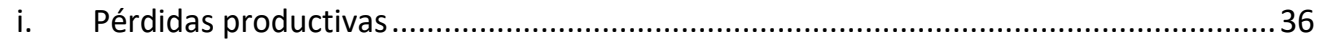

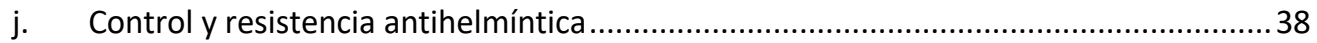

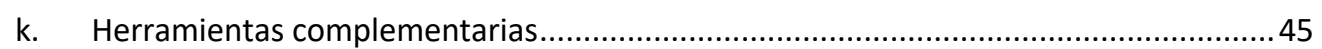

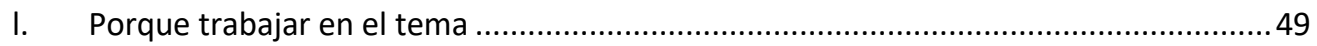

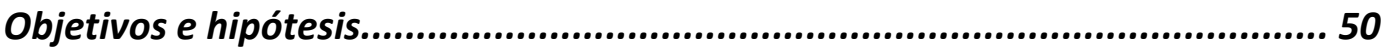

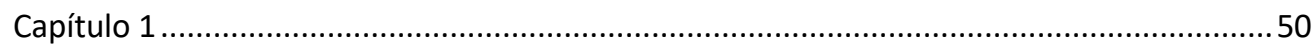

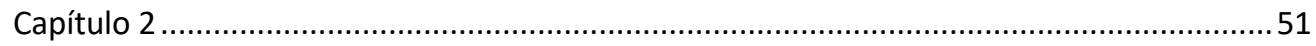

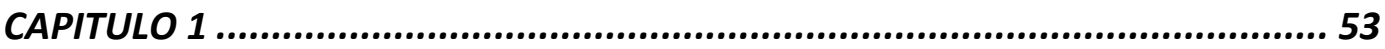

EPIDEMIOLOGIA DE LOS TRICHOSTRONGYLIDOS.................................... 53

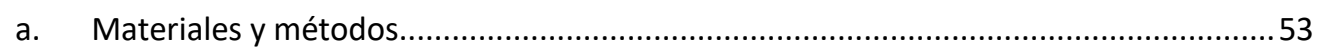

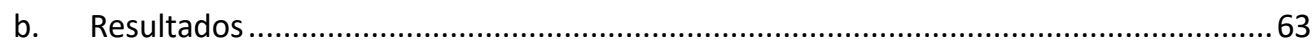

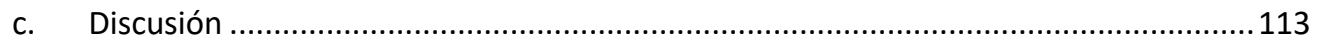

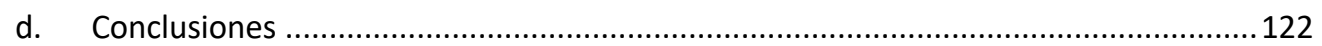

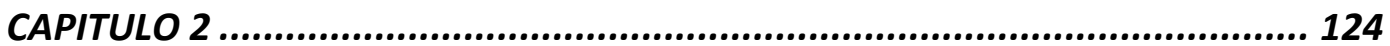

IMPACTO PRODUCTIVO DE UN MÉTODO DE CONTROL ............................... 124 


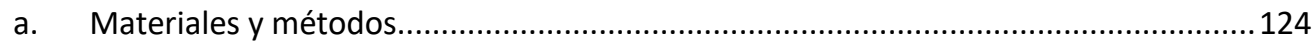

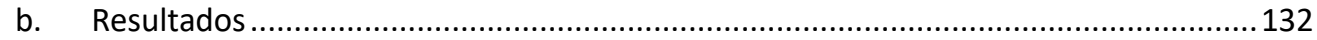

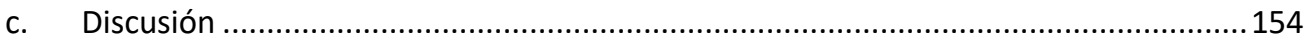

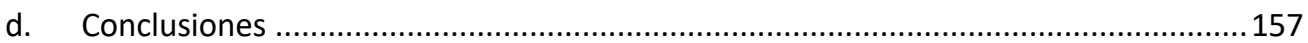

CONCLUSIONES GENERALES................................................................ 158

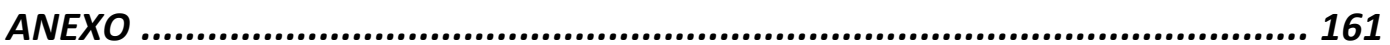

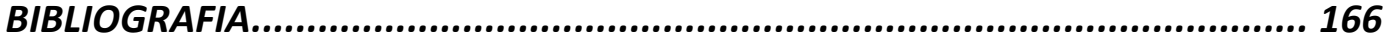




\section{Abreviaturas y símbolos}

${ }^{\circ} \mathrm{C}$ : grados Celsius.

ALmT: almacenaje total $(\mathrm{mm})$.

Animales permanentes: animales que pastorearon por un mínimo de 60 días luego del efecto residual de una droga utilizada en un tratamiento antihelmíntico.

Animales trazadores: animales que pastorearon por un máximo de 30 días luego de un tratamiento antihelmíntico realizado con drogas eficaces con bajo poder residual.

BHM: balance hídrico mensual $(\mathrm{mm})$.

CCK: colecistoquinina.

DP: días con precipitaciones acumulados.

DS: desvío estándar.

ETPA: evapotranspiración potencial acumulada ( $\mathrm{mm})$.

EV: equivalente vaca.

GC: grupo control.

GDP: ganancia diaria de peso.

GEV: gastroenteritis Verminosa.

Gr: gramo.

GS: grupo sistemático.

GT: grupo táctico.

Ha: hectárea.

HE: heliofania efectiva diaria (hs).

HEA: heliofania efectiva acumulada (hs).

HM: heladas meteorológicas acumuladas (días). 
HPG: huevos por gramo.

HRM: humedad relativa media (\%).

HRMax: humedad relativa máxima (\%).

HRMin: humedad relativa mínima (\%).

Kg: kilogramo.

Km: kilometro.

L1: larva 1.

L2: larva 2.

L3: larva 3.

L4: larva 4.

LI: límite inferior.

LS: límite superior.

Mg: miligramo.

Mm: milímetro.

MS: materia seca.

Oesoph. spp.: Oesophagostomum spp.

PA: precipitaciones acumuladas ( $\mathrm{mm})$.

PDP: precipitaciones diarias promedio.

TM: temperatura media ( $\left.{ }^{\circ} \mathrm{C}\right)$.

TMaxA: temperatura máxima absoluta $\left({ }^{\circ} \mathrm{C}\right)$.

TMinA: temperatura mínima absoluta $\left({ }^{\circ} \mathrm{C}\right)$.

TMMax: temperatura media máxima $\left({ }^{\circ} \mathrm{C}\right)$.

TMMin: temperatura media mínima $\left({ }^{\circ} \mathrm{C}\right)$.

TRCH: test de reducción del conteo de huevos.

Trichos. spp.: Trichostrongylus spp. 


\section{Resumen}

Título: Epidemiología de las trichostrongylosis ovinas en el sur de la provincia de Corrientes.

Se realizó un estudio epidemiológico de parasitosis gastrointestinales producidas por nematodes, sobre ovinos en el sur de la provincia de Corrientes. Resulta relevante por la importancia de la ovinicultura, por las condiciones propicias para presentaciones clínicas y por la escasa información sistemática. El entorno de resistencia a antiparasitarios exige fundamentos para desarrollar estrategias adecuadas. En este trabajo se evaluó la posibilidad de manejo, basado en datos epidemiológicos y vigilancia mensual.

Se realizó un seguimiento longitudinal durante dos años, de cargas parasitarias en ovejas y corderas de recría, mantenidas sin tratamientos (salvo salvataje) dentro de una majada comercial. La evaluación fue mediante la necropsia mensual de dos animales de cada categoría, reflejando la carga acumulada por "pastoreo permanente". Además, se estudiaron dos corderos "trazadores" que mostraron la infestación adquirida mensualmente.

Pudo demostrarse, que las mayores cargas se acumulan en ovejas en el periparto durante el invierno, con predominio de Haemonchus contortus y Trichostrongylus colubriformis, determinando también cualitativa y cuantitativamente el perfil de las cargas globales del campo. El balance hídrico y el almacenaje total de agua en el suelo y su gran variación interanual (especialmente en otoño), explican las cargas parasitarias de $H$. contortus, que determinan en gran medida la 
demanda de tratamientos. Estos, a su vez condicionan la oportunidad de Trichostrongylus spp. y de otros parásitos de menor representación para construir cargas hacia el invierno. Las borregas, siguen un patrón de acumulación desde el otoño hasta la primavera, mostrando un perfil más heterogéneo en la composición específica.

Las pérdidas productivas, resultan tan variables como la carga parasitaria, pudiendo presentarse en valores insignificantes como demuestra este trabajo. Una estrategia de control basada en datos epidemiológicos, seguimiento y registro mensual, permitiría detectarlas incluso cuando éstas fueran mínimas. Se destacan otros factores de pérdidas productivas (principalmente nutricionales) que suelen solaparse tras los trastornos de origen parasitario.

Palabras clave: Epidemiología. Parasitosis Gastrointestinal. Ovinos.

\section{Abstract}

Title: Epidemiology of ovine trichostrongylosis in the south of the province of Corrientes.

An epidemiological study of gastrointestinal parasitosis produced by nematodes was carried out on sheep in the south of the province of Corrientes. It is relevant due to the importance of sheep farming, due to the favorable conditions for clinical presentations and due to the scarce systematic information. The antiparasitic resistance environment requires a rationale for developing appropriate strategies. In this work, 
the possibility of management was evaluated, based on epidemiological data and monthly surveillance.

A longitudinal follow-up was carried out for two years, of parasite loads in rearing ewes and lambs, keepoing them without treatments (except salvage) within a commercial flock. The evaluation was done by means of the monthly necropsy of two animals of each category, reflecting the accumulated load due to "permanent grazing". In addition, two "tracer" lambs were studied that showed the infestation acquired on a monthly basis.

It could be demonstrated that the highest loads are accumulated in sheep in the peripartum during winter, with a predominance of Haemonchus contortus and Trichostrongylus colubriformis, also determining qualitatively and quantitatively the profile of global loads in the field. The water balance and the total storage of water in the soil and its great interannual variation (especially in autumn), explain the parasitic loads of $H$. contortus, which largely determine the demand for treatments. These, at the same time, are conditioning the opportunity of Trichostrongylus spp. and other minor parasites to build loads towards the winter. The sheep follow an accumulation pattern from autumn to spring, showing a more heterogeneous profile in the specific composition.

Productive losses are as variable as the parasitic load and can occur in insignificant values as this work shows. A control strategy based on epidemiological data, monitoring and monthly registration, allowed 
them to be detected even when they were minimal. Other factors of productive losses (mainly nutritional) that tend to overlap after disorders of parasitic origin are pointed out.

Keywords: Epidemiology; Gastrointestinal parasitosis; Sheep. 


\section{Introducción}

La ganadería ovina es una actividad de gran interés regional (Dutruel y De Caro, 2019), con poca competencia en zonas de producción marginal y complementándose en zonas con mayores exigencias (Mueller et al., 2015), representando un sector importante en la economía nacional.

Según los resultados en diferentes estudios de casuística (Lopez Saubidet, 1987; Robles y Olaechea, 2001; Miranda et al., 2002; Späth et al., 2009; Rissi et al., 2010; Suarez et al., 2010a y 2011a; INIA, 2013) podríamos clasificar las limitaciones de la producción ovina en:

- Problemas reproductivos: dependientes de la aptitud y sanidad de los reproductores (Fernandez Abella, 2011). Así mismo se asocian bajos índices de señalada a causas nutricionales y ambientales (Salgado, 2003).

- Problemas sanitarios: debido a la gran variación de los ambientes y regiones climáticas de producción pueden presentarse situaciones particulares. Sin embargo, la mayoría de los autores considera en las regiones templadas, a las enfermedades parasitarias (gastroenteritis verminosa particularmente) como una de las principales limitantes de la producción (Fernandez Abella et al., 2006; Suarez, 2010b y 2011b). 
El control de la gastroenteritis verminosa (GEV), debido al contexto mundial de resistencia antihelmíntica, actualmente debe basarse en datos epidemiológicos precisos, de manera de retrasar o mejorar dichas condiciones para su control farmacológico.

a. Contexto internacional de la producción ovina

El stock ovino mundial es de poco más de 1.363 millones de cabezas (Existencias ovinas FAO - Faostat, 2020), concentradas principalmente en países como China, Australia e India, que acumulan el $24,6 \%$ del total de ovinos. Argentina representa el $1,23 \%$ del stock mundial (puesto 27), con 14,78 millones de cabezas (SENASA, 2020) (Gráfico 1).

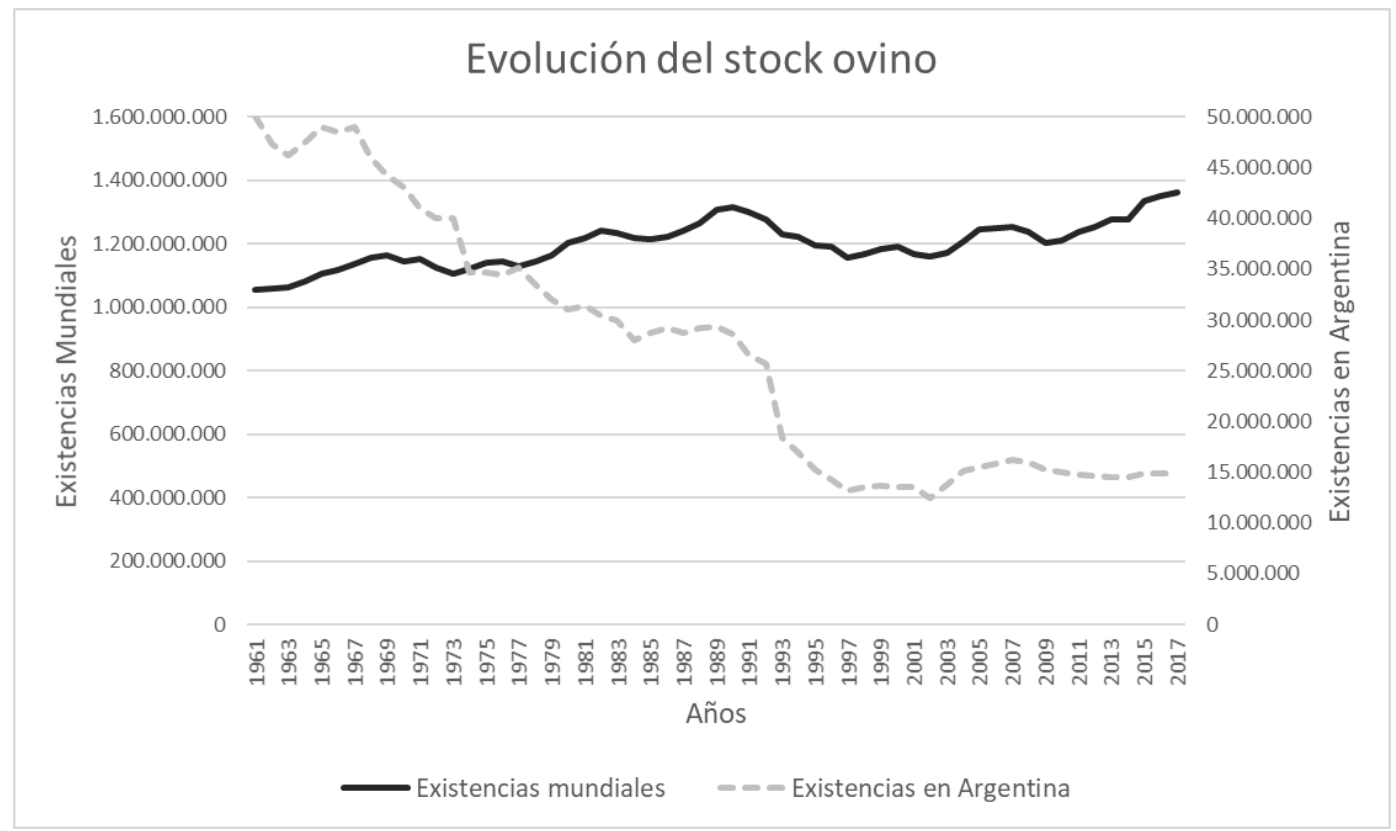

Gráfico 1: evolución del stock a nivel mundial (en aumento). Argentina expresa una tasa fuertemente negativa hasta el año 1997 (para el siglo XIX contaba con aproximadamente 74 millones de cabezas), que luego se sostuvo con variaciones, en los niveles actuales. 
Finalizando la década del '80, luego de la crisis más importante del sector (crisis lanera de Australia) (Producción Lana Grasa FAO Faostat, 2020), se redujo el stock mundial hasta principios de 2003, donde comenzó a recomponerse debido al crecimiento del stock de China. Este país, sostiene desde hace más de 50 años una tasa promedio de aumento del stock del 1,6\% anual, basada fundamentalmente en la producción carnicera. Estas tasas, mantuvieron estable la cantidad de ovinos a nivel mundial, absorbiendo las reducciones de los demás países, cambiando la intervención relativa en la producción mundial. Aumentó el valor relativo de la producción carnicera, desarrollándose genética (específica o doble propósito), mientras que la lana, fue refinando su mercado y uso, considerándose un producto Premium (Ministerio de Agroindustria, 2016).

En consecuencia, hubo una caída en la producción mundial de lana en los últimos 25 años cercana al 47\% (1,8 millones de toneladas en el 2013), casi exclusivamente a costa de lanas finas, mientras que la producción de lanas gruesas y medias se redujeron en menor medida (IWTO, 2018). El precio internacional de la lana, en los últimos 4 años tiende a aumentar (65\%) en lanas finas ( $<20$ micras), mientras que para lanas gruesas (>28 micras) mantiene su valor (+5\%) (AWEX 2019; AWI, 2019). Esta situación, se debe a los elevados precios de los productos que utilizan como materia prima, lanas finas y ultra finas (altísima calidad) y a su competencia con fibras de algodón y sintéticas. Entre otras variables (mercado/moda), el menor costo de estas últimas 
impulsó modificaciones en el hábito de vestimenta. El mercado consumidor de lana fue polarizando la producción hasta llegar a dos productos de venta: lanas finas con 19 micras en promedio y lanas con 28 micras o más. La importancia relativa de los dos grupos se fue invirtiendo con el tiempo, cobrando mayor importancia económica (y en aumento) las lanas finas (IWTO, 2018).

La producción mundial de leche ovina presenta tasas de crecimiento interanuales del $1,4 \%$. China se coloca como principal productor, siendo de importancia en otros países de Asia (Turquía, Siria, Irán e Irak principalmente) y Europa (Italia, Grecia, España, Rumania, Francia y Portugal). Una característica sobresaliente de esta industria es que su consumo, no fue afectado pese al incremento de otras producciones lácteas (vacuna, búfala, caprina). En Argentina es un tipo de producción relativamente nueva, con poca difusión y emprendimientos aislados, concentrados fundamentalmente en Buenos Aires y Patagonia. (Producción de leche ovina. FAO - Faostat, 2020; Suarez, 2004).

b. Producción ovina en la Argentina

En Argentina hay actualmente entre 14 y 15 millones de lanares en aproximadamente 92.000 establecimientos (Gráfico 2) ${ }^{1}$, que van

\footnotetext{
${ }^{1}$ El registro de información del sector suele estar sesgado, ya que son muchos los productores (chicos especialmente) que no están registrados, debiendo asumirse una subestimación de los datos.
} 
desde pequeñas empresas familiares con menos de 100 animales, hasta explotaciones grandes y extensivas con mas de 50.000 ovinos (SENASA, 2018). En los últimos 4 años hay una tendencia a favor de producciones chicas, en detrimento de grandes establecimientos sin alterar el número de cabezas. Esta atomización del sector en pequeños y medianos productores refleja la importancia social en las economías regionales de las distintas localidades (Hauck y Slukwa, 2013). El stock nacional concentra el $80 \%$ en 6 provincias (Gráfico 3).

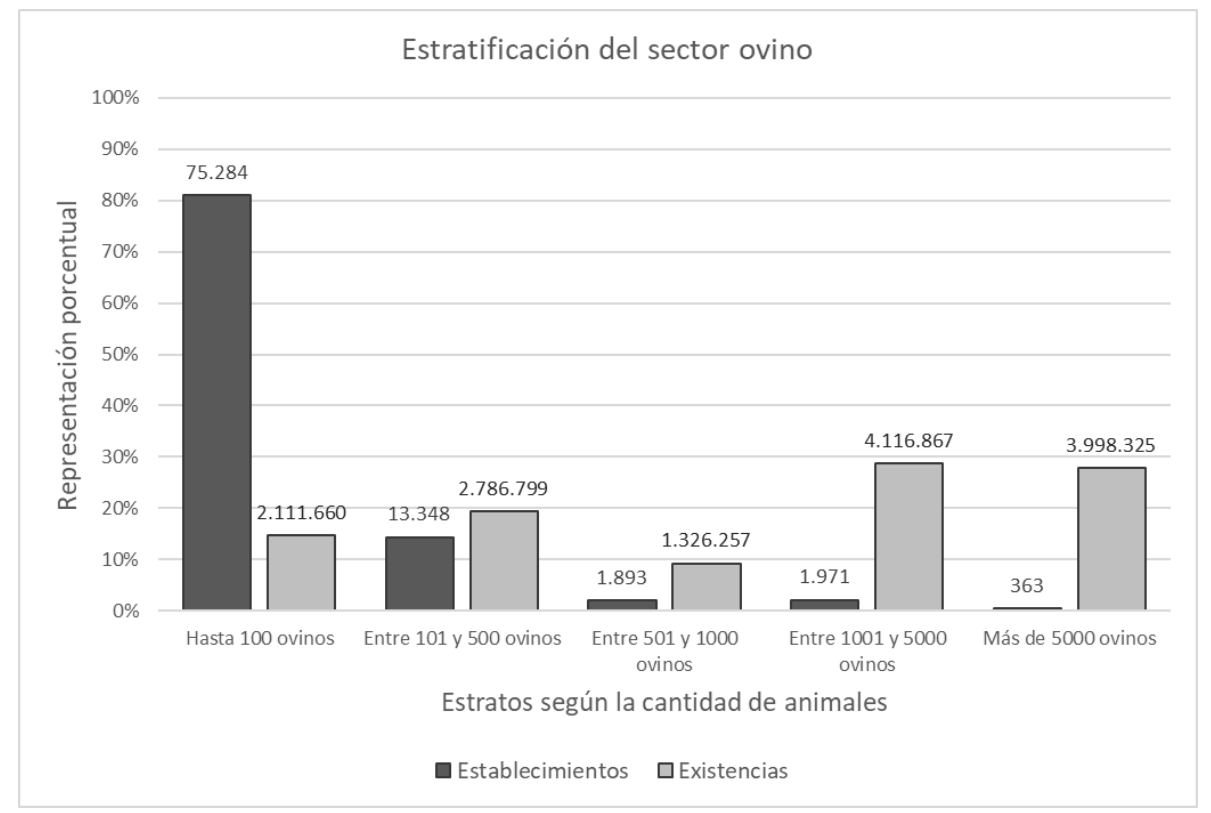

Gráfico 2: cantidad de establecimientos según su estrato, por cantidad de animales y su representación del stock nacional. 


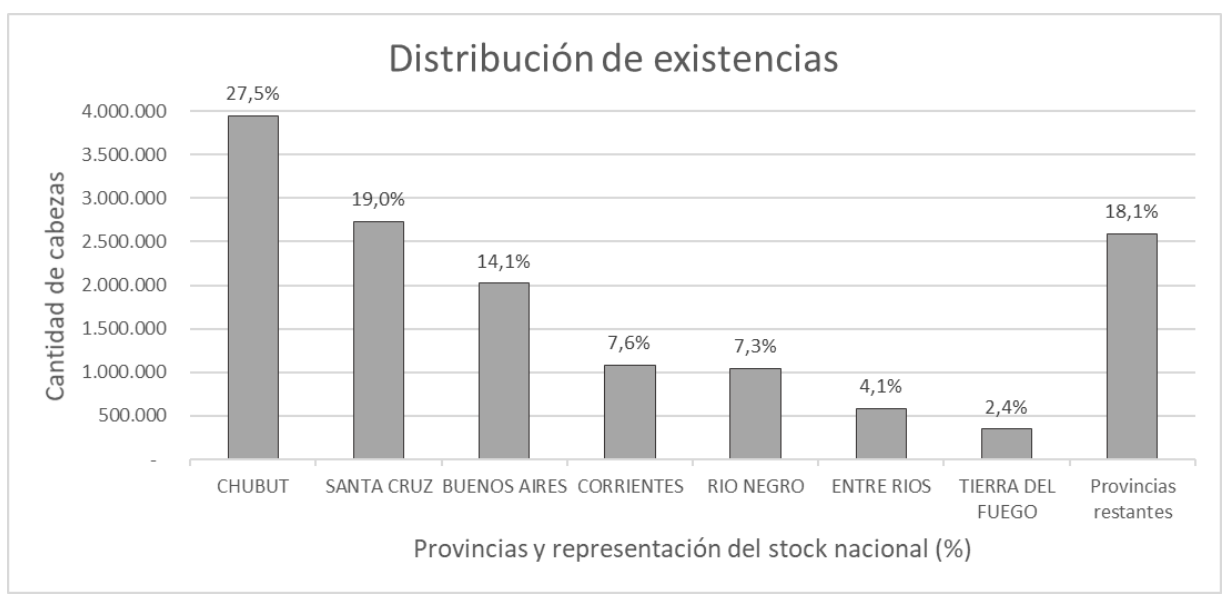

Gráfico 3: distribución del stock por provincia. El 56,4\% de la producción se ubica en Patagonia (Tierra del Fuego, Santa Cruz, Chubut y Río Negro). Mientras que el porcentaje restante lo hace principalmente en provincia de Buenos Aires, Corrientes y norte de Entre Ríos (25,9\%). El resto del stock esta repartido de forma más o menos variable en las demás provincias $(18,1 \%)$.

El sector podría dividirse en regiones, caracterizándose en Patagonia por ocupar áreas de monocultivo extensivo ( 1 a 0,2 animales/ha) con razas Merino y Corriedale, cuyo producto es fundamentalmente lana fina (19 a 23 micras), con pocas actividades en competencia (SENASA, 2018) y escasas posibilidades de manejo ya que se encierran pocas veces en el año (Mueller et al., 2015). La provincia de Buenos Aires, debido a las características climáticas y regionales, es donde mayor variedad de sistemas y razas encontramos, pudiendo observarse la actividad de forma complementaria a otras producciones, hasta sistemas ovinos puros. Concentra más de la mitad de los tambos ovinos del país, además de representar porcentajes importantes en la producción de carne y lana, con tendencia creciente del stock ovino (Gráfico 4). 
En la región mesopotámica la actividad resulta complementaria de la producción bovina, con un enfoque doble propósito (carnicera y lanera) con razas Corriedale, Romney Marsh e Ideal principalmente. La evolución de las existencias ovinas en Corrientes prácticamente no presentó variaciones en las existencias, mientras que Entre Ríos expresa una leve pero sostenida tasa positiva (Ministerio de Agroindustria, 2016).

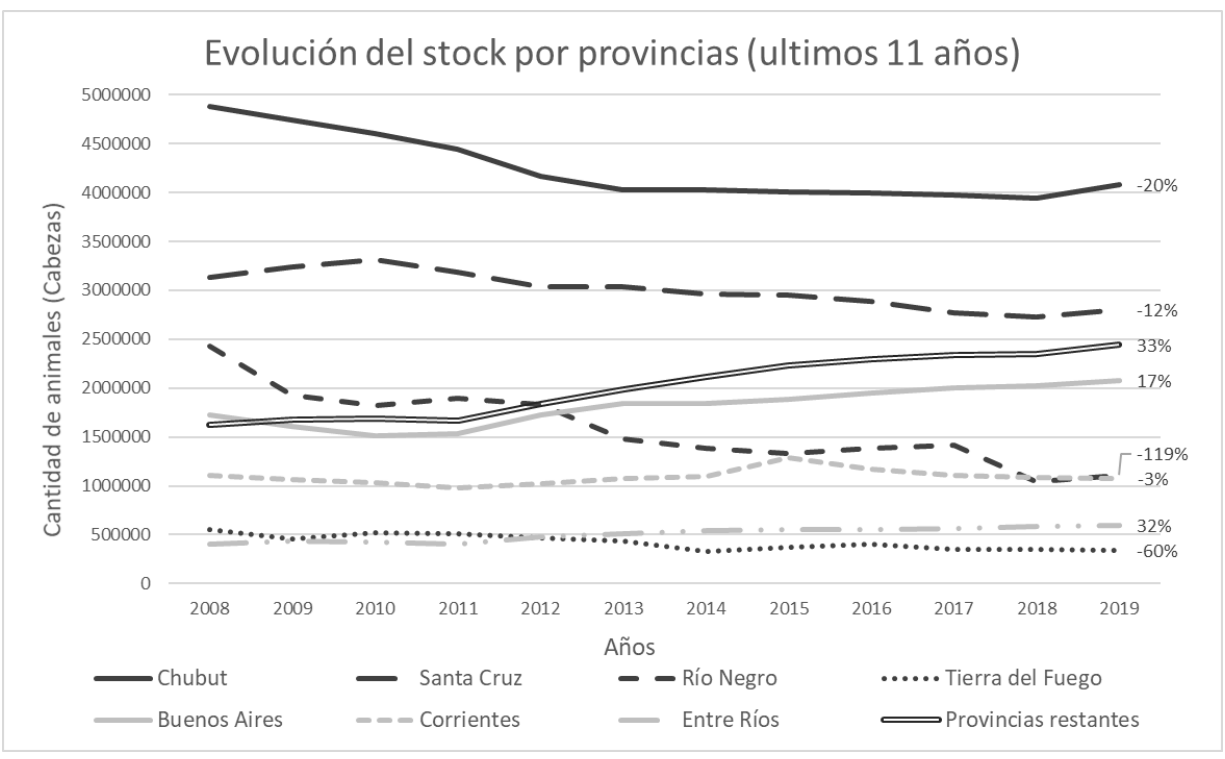

Gráfico 4: evolución del stock en las provincias con mayor participación, expresando el porcentaje de variación para el período (2008-2019). Las provincias Patagónicas, con actividad fundamentalmente lanera, fueron reduciendo las existencias, incluso drásticamente como la provincia de Río Negro (a menos de la mitad del stock en 11 años). Esta tendencia negativa es producto de un conjunto de situaciones, desde económicas propias del sector y del país, que se suman a factores ambientales de desertificación (sequías, grandes nevadas, erupciones volcánicas, incendios, etc.). También se observa la clara tendencia en aumento de la provincia de Buenos Aires, al igual que la de Entre Ríos, a las que se suman el resto de las provincias, todas con tasas positivas (en mayor o menor medida). 
A nivel nacional la conformación del stock, se basa en un planteo de cría, cuya categoría predominante son los vientres (57\%), los carneros representan menos del $4 \%$ y los corderos/as de recría cerca del $18 \%$, mientras que el porcentaje restante se reparte entre borregos $(13 \%)$ y capones $(8 \%)$ con una tendencia negativa (SENASA, 2018).

En Argentina, se generaban ingresos por exportaciones muy bajos debido al mal acondicionamiento de la lana. Intensos trabajos realizados desde 1994 en la esquila, clasificación y acondicionamiento bajo el sistema PROLANA, lograron cambiar el posicionamiento en el mercado internacional mejorando el precio de comercialización, y una mayor participación a partir del 2004-2005. En los últimos años se redujo casi en un $40 \%$ la producción de lana (de poco más de 70.000 toneladas en 2003-2004 a 40.695 toneladas en 2018-2019) (PROLANA 2017), generando ingresos por exportaciones de 252 millones de dólares (Federación Lanera Argentina, 2020) (Gráfico 6). 


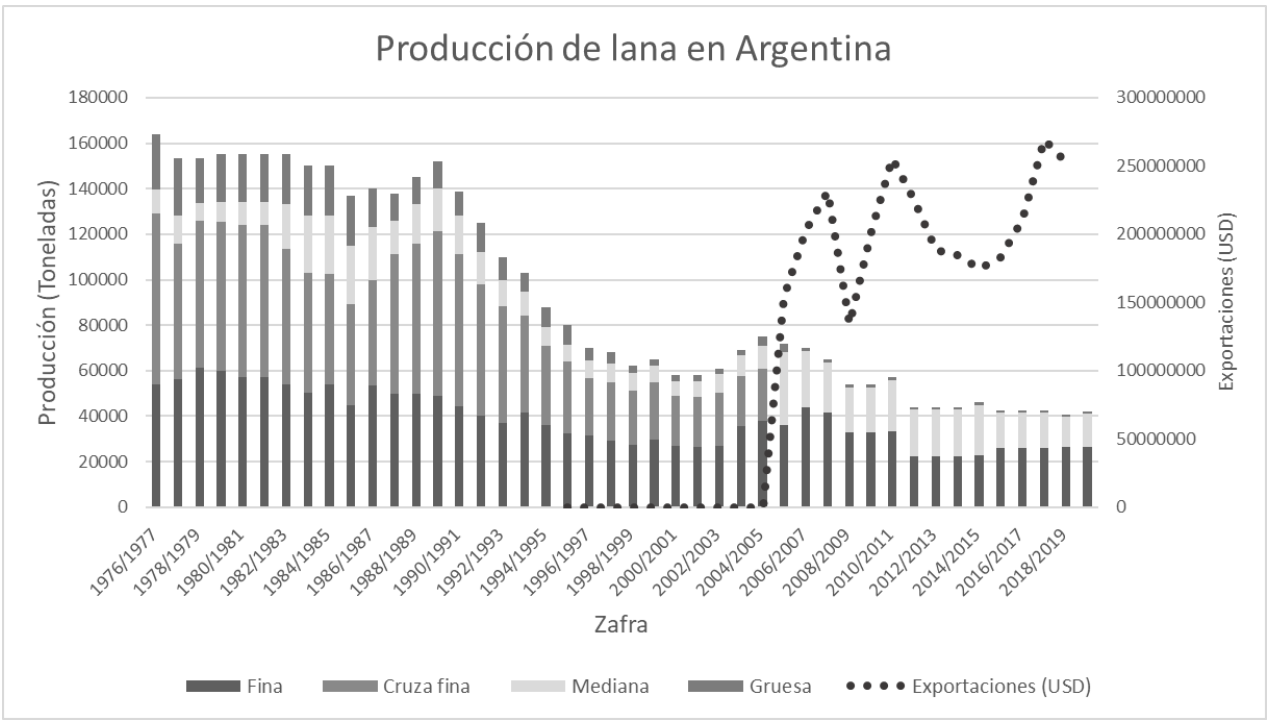

Gráfico 6: evolución de la producción lanera en Argentina, según la finura de la lana y los ingresos generados por las exportaciones.

La producción de carne no cuenta con el mismo nivel de información, debido a la falta entidades oficiales que lleven registros ordenados debiendo recurrirse a informes parciales del Ministerio de Agroindustria. La faena total estimada, se redujo en un $40 \%$, pasando de 4 millones de cabezas en 2004 a algo más de 2,5 millones en 2017. La faena con inspección sanitaria también expresó un descenso cercano al $40 \%$, con valores del $25 \%$ de la faena total. El peso al gancho (aunque con variaciones) presentó un aumento de 18,5 a 20,5 kg promedio sostenido en los años 2015-2016 (Ministerio de Agroindustria, 2017). El producto principal es el cordero liviano de estación y es casi nula la producción y faena de cordero pesado. En tanto el consumo per cápita para el mismo período, se redujo de 1,7 a $1,13 \mathrm{Kg} /$ habitante/año (Ministerio de Agroindustria, 2016). La importación de carne ovina es prácticamente nula, mientras que la exportación, que en 2005 llegó a 
las 15.000 toneladas (res con hueso), se redujo a 2.000 toneladas en 2017.

En este contexto internacional, nacional y regional de reducción de stock, los productores que permanecen en la actividad deben optimizar la producción. Esto implica, aumentar los índices y parámetros productivos intensificando cualquier tipo de producción (Montossi et al., 2011). Por ello, adquiere particular relevancia la presión sobre la sanidad de las majadas y su mejoramiento (Morris et al., 2012), entendida como uno de los tres pilares de la producción, junto con el manejo y la alimentación.

\section{c. Contexto regional}

El sur de la provincia de Corrientes y el norte de Entre Ríos, particularmente los departamentos de Mercedes, Curuzú Cuatiá, Paso de los Libres, Monte Caseros y Chajarí, constituyen una de las zonas del país más densamente poblada por ovinos, con más de 1 millón de lanares. Es una actividad socio-económica de gran importancia para la región (Dutruel y De Caro, 2019) y para el país, participando del 5\% de la producción nacional del sector (Gráfico 7). 


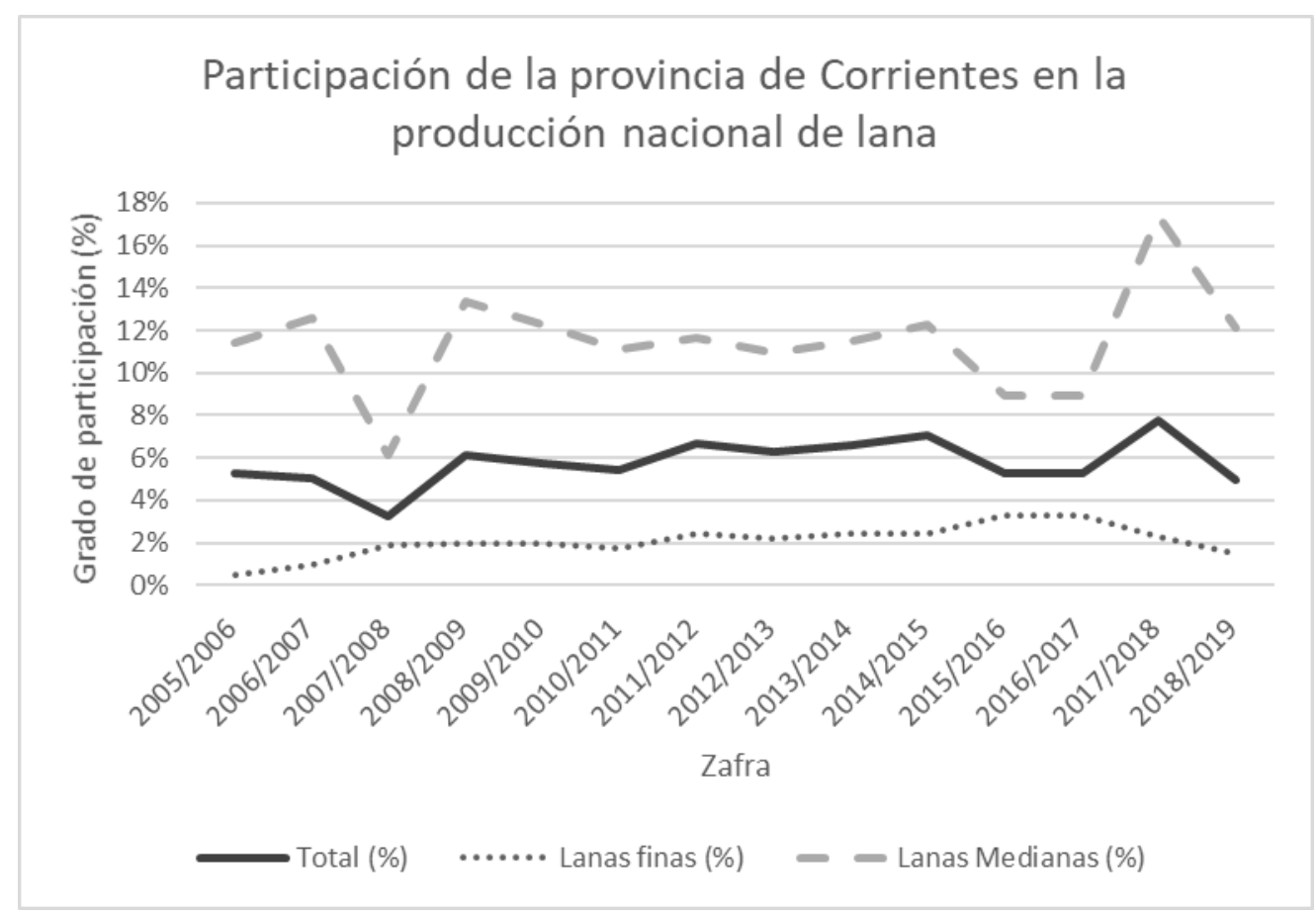

Gráfico 7: porcentaje de participación de la provincia de Corrientes en la producción nacional en los últimos 14 años. Actualmente representa en lanas finas el $2 \%$, mientras que en lanas medianas varía entre el $12 \%$ y el $17 \%$ (Federación Lanera Argentina, 2020).

La raza principal de la zona es la Corriedale (70\%) siguiendo en importancia la Ideal, de lana más fina debido a su mayor componente Merino, mejorando la calidad y precio de la lana (De Gea, 2007). En contraste, los vellones de lanas más finas tienden a reducir su peso debiendo considerarse al proyectar la facturación. La principal limitante en la introducción de esta raza fue la mayor susceptibilidad a enfermedades, planteando un desafío en la calidad del manejo sanitario. Otra raza introducida exitosamente en la región fue Romney Marsh, por su gran adaptación, aunque el pobre valor comercial de su lana limitó el crecimiento (Comisión Mixta Provincial del Ovino, 2004). En los últimos 
años ha aumentado la tendencia de introducción de razas fundamentalmente carniceras como Texel y Dorper, con mayores exigencias nutricionales. También hubo intentos con variedades Multipropósito de la raza Merino sin mucho éxito, debido a la falta de adaptación.

Los sistemas de producción presentan gran diversidad de cargas y estructuras de manejo, pudiendo variar desde 0,3 a 1,5 ov/ha y variando la relación en el pastoreo con bovinos desde 0,75 a 2 ov/bov, dependiendo el grado de intensificación del establecimiento. Lo más frecuente es que los lanares representen el $10-15 \%$ de la carga del establecimiento, que suele rondar en los 0,55 y 0,70 EV/ha (Montossi et al., 2013). Estas variaciones en el manejo presionan sobre los animales y ponen a prueba el status sanitario, tal como expresan la mayoría de los productores en el manejo parasitológico cuando se superan estos valores (Romero et al., 2013).

En la región, los servicios se realizan entre enero y mayo, según el establecimiento y la raza, con pariciones entre mayo y octubre. Los productores más organizados, concentran los servicios en 45 días desde principios de enero-febrero, en busca de corderos tempranos en primavera con mayor valor de venta. La raza Ideal, tiene una estacionalidad menos marcada, lo que permite este adelanto de las pariciones. 
d. Fitogeografía y clima

Esta región, considerada como la principal zona de producción ovina del Noreste Argentino, está ubicada entre los paralelos 28 y 32 y las isohietas de 1300 y $1500 \mathrm{~mm}$ de precipitaciones anuales, situada entre los ríos Paraná y Uruguay. Es caracterizada como una zona templada y húmeda, con verano lluvioso, definiéndose como subtropical sin estación seca (Acosta et al., 2009). Las precipitaciones resultan variables entre años, siendo el otoño la estación más variable (coeficiente de correlación 49\%). Los registros de datos meteorológicos de referencia se expresan en la Tabla 1 (Servicio Meteorológico Nacional, 2012). 


\begin{tabular}{|c|c|c|c|c|c|c|c|c|c|c|c|c|c|}
\hline VARIABLE & $\mathrm{E}$ & $\mathrm{F}$ & $M$ & A & M & $\mathrm{J}$ & $\mathrm{J}$ & A & $\mathrm{S}$ & 0 & $\mathrm{~N}$ & D & ANUAL \\
\hline $\operatorname{TMaxA}\left({ }^{\circ} \mathrm{C}\right)$ & 38,1 & 36,8 & 35,7 & 32,9 & 29,4 & 27,5 & 28,4 & 31,1 & 31,8 & 34,4 & 36,1 & 37,5 & 33,3 \\
\hline $\operatorname{TMMax}\left({ }^{\circ} \mathrm{C}\right)$ & 32,6 & 31,0 & 29,6 & 25,7 & 22,0 & 19,2 & 19,1 & 21,6 & 22,7 & 25,8 & 28,6 & 31,2 & 25,7 \\
\hline $\operatorname{TM}\left({ }^{\circ} \mathrm{C}\right)$ & 26,5 & 25,5 & 24,0 & 20,4 & 16,9 & 14,4 & 13,9 & 16,0 & 17,2 & 20,3 & 22,8 & 25,1 & 20,3 \\
\hline $\operatorname{TMMin}\left({ }^{\circ} \mathrm{C}\right)$ & 20,5 & 20,0 & 18,5 & 15,2 & 11,8 & 9,7 & 8,9 & 10,3 & 11,7 & 14,8 & 16,9 & 19,0 & 14,8 \\
\hline $\operatorname{TMin} A\left({ }^{\circ} \mathrm{C}\right)$ & 15,1 & 13,9 & 11,6 & 7,3 & 3,3 & 1,1 & 0,5 & 2,0 & 4,1 & 7,8 & 10,5 & 13,2 & 7,5 \\
\hline HM (días) & 0 & 0 & 0 & 0 & 0 & 1 & 1 & 0 & 0 & 0 & 0 & 0 & 2 \\
\hline PA (mm) & 100 & 149 & 151 & 148 & 111 & 76 & 50 & 47 & 101 & 140 & 105 & 107 & 1284 \\
\hline DP (días) & 7 & 8 & 8 & 8 & 8 & 8 & 7 & 6 & 8 & 9 & 8 & 7 & 92 \\
\hline HRMax (\%) & 86,7 & 90,2 & 91,3 & 93,4 & 94,3 & 95,0 & 93,5 & 91,1 & 90,5 & 89,9 & 88,0 & 86,2 & 90,8 \\
\hline HRM (\%) & 66,1 & 71,0 & 72,0 & 75,3 & 76,4 & 78,6 & 75,8 & 71,6 & 71,7 & 70,7 & 68,0 & 65,4 & 71,9 \\
\hline HRMin (\%) & 45,4 & 51,5 & 52,3 & 56,9 & 58,5 & 62,4 & 57,8 & 52,5 & 52,6 & 52,3 & 47,6 & 45,0 & 52,9 \\
\hline $\mathrm{HE}(\mathrm{Hs})$ & 7,9 & 7,3 & 6,1 & 5,4 & 5,0 & 3,8 & 4,9 & 5,2 & 4,7 & 6,1 & 7,7 & 7,5 & 5,9 \\
\hline HEA (Hs) & 245 & 211 & 188 & 163 & 155 & 113 & 151 & 161 & 140 & 188 & 230 & 233 & 2177 \\
\hline ETPA $(\mathrm{mm})$ & 164 & 128 & 111 & 72 & 45 & 33 & 40 & 63 & 80 & 120 & 139 & 164 & 1161 \\
\hline ALmT (mm) & 104,7 & 121,7 & 129,9 & 144,2 & 149,2 & 153,5 & 150,5 & 140,3 & 137,9 & 139,4 & 130,7 & 115,1 & 134,8 \\
\hline
\end{tabular}

Tabla 1: registros meteorológicos promedio desde el año 1981-2012, para la localidad de Paso de los Libres (la más cercana con información completa). TMaxA: temperatura máxima absoluta $\left({ }^{\circ} \mathrm{C}\right)$; TMMax: temperatura media máxima $\left({ }^{\circ} \mathrm{C}\right)$; TM: temperatura media $\left({ }^{\circ} \mathrm{C}\right)$; TMMin: temperatura media mínima $\left({ }^{\circ} \mathrm{C}\right)$; TMinA: temperatura mínima absoluta $\left({ }^{\circ} \mathrm{C}\right) ; \mathrm{HM}$ : heladas meteorológicas acumuladas (días); PA: precipitaciones acumuladas (mm); DP: días con precipitaciones acumulados. HRMax: humedad relativa máxima (\%); HRM: humedad relativa media (\%); HRMin: humedad relativa mínima (\%); HE: heliofania efectiva diaria (hs); HEA: heliofania efectiva acumulada (hs); ETPA: evapotranspiración potencial acumulada (mm); ALmT: almacenaje total $(\mathrm{mm})$. 
Constituye la ecorregión del Espinal, distrito Ñandubay (Burkart et al., 1999), que se caracteriza por bosques abiertos de 6 a 12 metros de altura de plantas de ñandubay (Prosopis affinis) y espinillo o aromito (Acacia coeven), pudiendo ser más variado dependiendo la zona con estrato arbustivo pobre o nulo. Cerca del $60 \%$ de la superficie está cubierta por cuerpos de agua de tamaño variable, de lo que depende el forraje predominante. Los campos naturales se caracterizan por su diversidad, llegando a describirse más de 100 especies de diferentes familias, aunque sólo unas pocas aportan el mayor volumen de pasto forrajero.

Se describen 3 tipos de pastizales, pastos en matas dominantes (pajonales o espartillar), pastos cortos (duros o tiernos) y mosaico de pajonales y pastos cortos. El ambiente de pajonal es el más difundido en la provincia, pudiendo estar formado por varias especies siendo Andropogon lateralis (paja colorada) la de mayor distribución (Pizzio et al., 2021). El estado y la composición del pastizal varía de acuerdo a los antecedentes del potrero según describe Bendersky (et al., 2017).

La digestibilidad y concentración de proteína de los pastizales es variable y se las considera máxima en primavera $(11 \%$ y $8 \%$ respectivamente). En la medida que avanza el verano, disminuyen los niveles de proteína hasta llegar a valores extremos del 3\% en otoño, mientras que la digestibilidad llega a su mínimo (5\%) en invierno, debido a la pérdida de follaje por las bajas temperaturas. Los porcentajes documentados, definen a los pastizales como deficientes de 
proteína durante todo el año, con excepción de algún período variable en primavera (Pizzio et al., 2006).

Por otro lado, los suelos de la región son carentes de fósforo y sodio (Mufarrege et al., 2005), siendo recomendable la suplementación oral durante todo el año.

\section{e. La enfermedad parasitaria como desequilibrio}

La parasitosis es una interacción biológica heterotípica negativa unilateral, temporal o permanente, externa o interna, en la cual la especie parásita (de menor nivel zoológico) depende, se beneficia y genera daño de gravedad variable en el huésped o especie parasitada (de mayor tamaño y organización biológica).

En la GEV (como en otras parasitosis), la sola presencia del parásito no condiciona la aparición de enfermedad parasitaria. La misma se presenta cuando hay un desequilibrio en dicha interacción ("huésped" $\Leftrightarrow$ "parásito"), no siendo deseable para ninguno de los dos simbiontes², ya que si se profundiza se verían perjudicados ambos (Cordero del Campillo y Rojo Vázquez, 1999). Esta situación se da en todos los sistemas en diferente medida (según el grado de intensificación), modificando la ecología parasitaria dependiente de tres factores:

I. Agente etiológico: conocerlo y caracterizarlo permite desarrollar herramientas y fundar criterio que argumente los sistemas de

\footnotetext{
${ }^{2}$ Simbiosis: (del griego syn= juntos; biosis= vivir) interacción biológica entre especies (simbiontes), la cual puede ser positiva o negativa.
} 
vigilancia y control. Es importante definir los géneros y las especies involucradas, su comportamiento epidemiológico (cantidad y proporciones), dinámica anual, potencial biótico y particularidades de su ciclo biológico (períodos de latencia o hipobiosis).

La GEV es una afección gastrointestinal producida por un grupo de nematodes que afectan a los rumiantes, en particular a bovinos jóvenes y ovinos y caprinos en todas las categorías.

En ovinos de regiones templadas, el parásito más documentado y que mayores problemas ocasiona es el Haemonchus contortus, seguido por Trichostrongylus spp. (Castells et al., 1995). Es la endoparasitosis de mayor importancia, causada por una infección mixta de un conjunto de nematodes (superfamilia: Trychostrongyloidea), los parásitos asociados pertenecen a las familias: Trichostrongylidae (Haemonchus spp.; Ostertagia spp.; Teladorsagia spp.; Trichostrongylus spp.; Marshallagia spp.; Cooperia spp.); Molineidae (Nematodirus spp.); Strongyloididae (Strongyloides spp.); Strongylidae (Oesophagostomum spp.; Chabertia spp.); Trichuridae (Trichuris spp.); Ancylostomatidae (Bunostomum spp.) (Newton et al., 1998; Cordero del Campillo y Rojo Vazquez, 1999; Suarez, 2007a; Giudici et al., 2013). El predominio de una especie sobre otra depende de diversas condiciones ambientales y la inmunidad de los animales. 
Los estrongilidos tienen un ciclo directo, en el cual luego de la cópula (reproducción sexual), eliminan con la materia fecal de su huésped, huevos morulados. En el medio ambiente maduran, eclosionando la larva de primer estado (L1), que luego de una muda pasa a L2, que vuelve a mudar a L3, conservando la cutícula de la L2, dando lugar a una L3 envainada, que la hace más resistente a factores ambientales. Los estados de L1 y L2 tienen hábitos bacteriófagos, mientras que la L3, que es el estado infectante y muy móvil, no se alimenta consumiendo la energía acumulada en sus células intestinales. Su sobrevida en el ambiente depende fundamentalmente de la especie y situaciones ambientales, especialmente la desecación. El tiempo que transcurre para la maduración de la L3, ronda entre los 7-10 días en condiciones favorables, pudiendo durar hasta 45 días (fase de vida libre). Una vez ingerida la L3 por el huésped, pasa por una etapa histotrófica, en el estado de L4 que puede durar desde pocos días (14-28 días) a 2-3 meses (según el género, época del año, región, etc.) para luego continuar su desarrollo preadulto, que alcanza su ubicación y madurez definitiva (fase parasitaria). El período prepatente p $^{3}$ y el potencial biótico son características

3 Período prepatente: tiempo transcurrido desde la infección (ingreso del parásito en el huésped) hasta que éste produce descendencia.

Tiempo generacional: duración de un ciclo completo, desde que nace un individuo hasta que nace su descendencia. 
que varían según la especie y deben ser tenidos en cuenta en estudios epidemiológicos y en el manejo clínico, ya que inciden en la expresión y comportamiento de cada parásito (Tabla 2).

\begin{tabular}{lcc}
\hline \multicolumn{1}{c}{ GÉNERO } & $\begin{array}{c}\text { PRODUCCIÓN DE } \\
\text { HUEVOS/DÍA }\end{array}$ & $\begin{array}{c}\text { PERÍODO PREPATENTE } \\
\text { (días) }\end{array}$ \\
\hline $\begin{array}{lcc}\text { Haemonchus spp. } \\
\text { Ostertagia spp. }\end{array}$ & $5.000-10.000$ & $14-28$ \\
Trichostrongylus spp. & $200-250$ & $18-23$ \\
Cooperia spp. & $100-2.000$ & $15-21$ \\
Nematodirus spp. & $50-100$ & $11-22$ \\
Bunostomum spp. & - & $21-26$ \\
Oesophagostomum spp. & $5.000-10.000$ & $52-56$ \\
Strongyloides papillosus & - & $35-41$ \\
\hline
\end{tabular}

Tabla 2: detalle de la puesta de huevos y período prepatente por género. (adaptado de Giudici et al., 2013).

II. Huésped: la acumulación del agente etiológico en el huésped depende, entre otros factores, de la inmunidad (Brunsdon, 1966; Clerebout y Vercruysse, 2000) que está influida por:

- Especie/categoría: según el manejo de la región, raza o establecimiento, predominarán diferentes categorías a lo largo del ciclo productivo. Éste, puede asociarse a la expresión estacional de determinados parásitos, al combinarse factores favorables para el parásito con la presencia de categorías o especies susceptibles (Michel et al., 1979). Según el grado de afinidad a sus huéspedes, 
hay parásitos generalistas y otros especialistas (Archie y Ezenwa, 2011) que inciden en las expresiones epizootiológicas. Dichas condiciones, están sujetas a la inmunidad del huésped y su respuesta frente a las diferentes especies (Giudici, 1999). Barger (1988) afirma que la inmunidad generada por la experiencia inmune (edad) en corderos, para los géneros Ostertagia spp. y Trichostrongylus spp., se logra en torno a los 8 meses de edad, mientras que para Haemonchus contortus más tempranamente (4 meses). Los tratamientos antihelmínticos influyen negativamente en su consolidación, al mismo tiempo que la inmunidad adquirida no es sólida y puede quebrarse frente a diferentes situaciones del huésped o del ambiente, considerándose susceptibles todas las categorías (con consideraciones).

- Estado fisiológico: hay determinadas situaciones que generan inmunosupresión, favoreciendo la acumulación de parásitos. Ejemplos de esto son el destete en los corderos y el periparto para los vientres ("Spring rise") (Nari et al., 1977b).

- Estado nutricional y de salud: ambos factores inciden directamente en el estado inmunológico del huésped. Un huésped sano y bien nutrido, tiene menos probabilidades de expresar un desequilibrio huésped-parásito (Coop y Holmes, 1996; Coop y Kyriazakis, 1999). 
- Genética: los huéspedes pueden clasificarse como susceptibles o resistentes, según la predisposición individual a acumular parásitos y que estos desarrollen. Dentro del grupo de animales resistentes se encuentran los resilientes, en donde los parásitos logran establecerse sin provocar daños clínicos (Albers et al., 1987; Castells, 2002; Zvinorova et al., 2016). Actualmente, muchas líneas de trabajo se basan en la detección de estos animales (resistentes e incluso resilientes) como parámetro mejorador de la población.

III. Ambiente: todo lo que rodea al huésped y al agente etiológico, modifica su interacción. Conocer el ambiente (y definir las variables) permite plantear estrategias de control. La combinación de los factores tiempo y espacio, determinará el encuentro del parásito y su huésped y condicionará su equilibrio:

Tiempo: (tiempo cronológico) la permanencia de los animales en las pasturas y los períodos de descanso, están influenciados por las condiciones meteorológicas y sus combinaciones (clima). Las tecnologías de manejo apuntan a optimizar el pastoreo y aumentar la carga, mientras que las condiciones meteorológicas son ingobernables, pudiendo sufrir variaciones de dos tipos:

- Estacionales: períodos estables de duración variable (3 meses aproximadamente) con condiciones climáticas 
similares, que puede favorecer o retrasar el desarrollo de poblaciones de un agente etiológico o su cuadro clínico (Niec et al., 1966; Suarez, 1990a; Ferreyra et al., 2002; Pereira et al., 2006). Las precipitaciones favorecen la migración larvaria, permitiendo que las larvas salgan de la materia fecal en 1 semana en veranos lluviosos (con más de $69 \%$ de humedad y temperatura entre $19^{\circ} \mathrm{C}$ y $42^{\circ} \mathrm{C}$ ), mientras en estaciones más secas la materia fecal actúa como reservorio (en menor medida que en bovinos) y las larvas se mantienen mayormente en la base del pasto (Santos et al., 2012).

- Interanuales: relacionadas con el fenómeno del Niño y la Niña (OMM, 2014), registran años de sequía o inundaciones, según las precipitaciones se sucedan por debajo o superen los valores históricos para la región. Romero (et al., 2013) considera que las variaciones interanuales (especialmente de temperatura y precipitaciones) influyen en la presentación de casos clínicos.

\section{Espacio:}

- Región geográfica: las condiciones meteorológicas (clima) están relacionadas con la ubicación y características del suelo, que determinan la receptividad y la aptitud de los forrajes que pueden ofrecerse a los animales. Estos factores, en conjunto condicionan el tipo de problemas 
parasitarios que se presentan. En la bibliografía parasitológica sobre ovinos, en Australia predomina información sobre Haemonchus spp. (Gordon, 1948), mientras que en estudios realizados en Escocia (Hammer et al., 2019), el género predominante fue Trichostrongylus spp. El estudio detallado de la epidemiología en cada región resulta ineludible para establecer programas de control (Armour, 1980).

- Establecimiento productivo: los antecedentes y características de explotación pueden condicionar la epidemiología y las posibilidades de control (resistencia), existiendo diferencias entre campos e incluso entre potreros. Situaciones geográfico-ambientales como cursos de agua y tipos de pastos naturales, manejo de la carga animal, antecedentes de desparasitaciones (carga parasitaria), especies que pastorearon anteriormente, etc. (Bairden et al., 1995).

- Sistema de producción: las diferentes especies productivas (y su proporción), razas, manejo (sistemas extensivos; intensivos e intermedios), épocas de servicio/parto, rotación con otras explotaciones y producto de venta (corderos livianos, pesados, reproductores). Dentro de este punto, puede citarse al pastoreo mixto como un condicionante de la expresión parasitaria (Barger y Southcott, 1975). 
- Rotación de potreros: depende de la velocidad de crecimiento del forraje. En la medida que las tecnologías mejoran en este aspecto, se reduce el tiempo entre los ciclos de pastoreo (período de descanso), favoreciéndose el ciclo parasitario (intensificación). La utilización del recurso forrajero con otras especies o categorías puede aumentar los intervalos de exposición frente a parásitos específicos, al intercalar turnos de pastoreo reduciendo los riesgos de expresiones clínicas.

- Producción de materia seca: la cantidad y calidad determina la carga animal (animales/hectárea). El riesgo de un potrero está basado en la cantidad de larvas por $\mathrm{Kg}$ de materia seca (dilución de larvas). Cuando se utilizan pasturas de alta calidad y productividad, se aumenta la carga para optimizar su uso, acelerando la contaminación (cuando no hay control) y el riesgo epidemiológico por acumulación de larvas. La producción de materia seca es estacional y relacionada a las variables meteorológicas que condicionan los ciclos de crecimiento (curva de producción forrajera) y por lo tanto de aprovechamiento y restricción.

\section{f. Patogenia}

El daño que producen los parásitos varía según el género, ubicación, modo de alimentación, tamaño y reacción local o general. 
Estas características, determinan su capacidad de daño potencial y nivel de tolerancia por el huésped.

$H$. contortus es fundamentalmente hematófago, pudiendo absorber una hembra adulta entre 40-67 $\mu$ l de sangre por día, dependiendo la carga parasitaria (Clarke, 1963). Los signos están relacionados con anemia e hipoproteinemia (edema submandibular, palidez de mucosas), estando asociada la muerte con entre $1.000 \mathrm{y}$ 10.000 parásitos adultos. Dergie y Allonby (1974) describieron la fisiopatología de cuadros de anemia, como así también procesos de autocura con base inmune vinculado a reinfecciones.

Las especies de Trichostronylus spp. que predominan en ovinos, ocupan fundamentalmente la primera porción del intestino delgado ( $T$. colubriformis), en galerías debajo de la mucosa. Provocan atrofia de las vellosidades, que derivan en un síndrome malabsortivo que cursa con diarrea oscura. Las infecciones por Cooperia spp. y Nematodirus spp., producen una enteritis, que en infestaciones severas puede producir una diarrea profusa.

En el caso de Ostertagia spp., cuando las larvas ingresan se localizan en las glándulas fúndicas del cuajo, provocando la pérdida de células parietales. Estas, son reemplazadas por otras menos diferenciadas engrosando la mucosa. En consecuencia, hay una menor secreción de ácido clorhídrico, aumentando el pH de la luz y del contenido gástrico. Se reduce la activación del pepsinógeno (a pepsina), absorbiéndose y aumentando la concentración plasmática (al igual que otras hormonas como la gastrina). La falta de pepsina activa dificulta la 
digestión y absorción de proteínas, cuya presencia estimula células zimógenas, produciendo aún más pepsinógeno. Las lesiones generadas en la mucosa se observan macroscópicamente en el cuajo como nódulos de 2-3 mm (aspecto de "cuero de marroquí") (Armour et al., 1979). Para sobrepasar condiciones ambientales desfavorables, las larvas detienen su desarrollo en la submucosa, período denominado hipobiosis (ver adelante). Cuando finaliza, éstas salen a la luz masivamente (oleadas) y producen una hiperplasia con engrosamiento de la mucosa y edema submucoso.

Alteración del apetito: aunque hay varias hipótesis de la causa, el mecanismo por el que se reduce la ingesta, aún no está del todo esclarecido. Se sabe que intervienen factores físicos, químicos y hormonales. Debido al daño en la mucosa del tubo digestivo o los cambios en su contenido, hay un aumento de la colecistoquinina (CCK), la cual se ha relacionado (incluso experimentalmente) con una reducción en la ingesta (Symons y Hennessey, 1981). El grado de anorexia es variable según el estado inmunitario y género involucrado, pudiendo ser desde 20 al 55\% para Ostertagia spp. y Trichostrongylus spp. respectivamente.

Alteración de la función (digestión y absorción): hay especies que pueden disminuir el tránsito (Teladorsagia circumcincta) mientras que otras pueden acelerarlo (Trichostrongylus axei y Chabertia ovina) (Bueno et al., 1975). Junto con estas alteraciones en la motilidad, se dan cambios estructurales y funcionales que provocan cuadros de 
diarrea. Estos están relacionados a la mayoría de los géneros con la excepción del Haemonchus spp.

Alteraciones metabólicas: se produce un reemplazo de células funcionales diferenciadas, por otras indiferenciadas inmaduras (no funcionales), con complejos de unión intercelular imperfectamente formados. Esto provoca una pérdida de proteínas por la luz del intestino, que puede terminar en hipoproteinemia (principalmente albúmina) y aumenta el pasaje de pepsinógeno a través de la lámina propia a la circulación, demostrado en cuadros de ostertagiasis (Armour et al., 1979).

Alteraciones del metabolismo mineral: el aumento del $\mathrm{pH}$ y la hipoalbuminemia disminuyen la absorción de calcio y aumentan las pérdidas de fósforo. Los cuadros de diarrea están relacionados con pérdida de potasio, sodio, cloruro y bicarbonato, que en casos extremos terminan en acidosis metabólica, deshidratación y muerte por falla renal.

g. Hipobiosis

Es un fenómeno que demuestra la adaptación del parásito al ambiente (principalmente al clima). En nematodes estrongylidos se manifiesta en poblaciones genéticamente aptas y por la selección que ejerce el ambiente sobre los estados de vida libre. La estacionalidad climática de cada región define períodos desfavorables para la viabilidad de los huevos eliminados, que aseguran su sobrevida (o predominio) de los genotipos más adaptados, mediante este mecanismo (Gibbs, 1986). 
Consiste en detener el desarrollo (L4) por un período de tiempo variable hasta que las condiciones ambientales (al momento de la reanudación) sean favorables.

Fenómeno ampliamente estudiado en diferentes condiciones para Ostertagia ostertagi en bovinos (Fiel et al., 1988; Suarez, 1990c; Fernández et al., 1999; Dopchiz et al., 2000), mientras que en ovinos se ha descripto fundamentalmente en $H$. contortus (Nari et al., 1982) y Trichostrongylus spp. (Ogunsusi y Eysker 1979). Las condiciones determinantes de hipobiosis en el género Haemonchus sp. se vinculan a climas con temporadas frías (Balbi, 1993) o bien a condiciones de sequía (Hart, 1964; de Melo, 1977). Las precipitaciones presentan mayor fluctuación que la temperatura, por lo que Michel (1969) sugiere que dichas variaciones, cuando están en los límites, pueden ser determinantes en las tendencias parasitarias entre años. En tanto, las variaciones de temperatura, difícilmente se sostengan en magnitudes suficientes que alteren el comportamiento parasitario.

El fenómeno de hipobiosis también se ha descripto en los géneros Nematodirus sp. y Cooperia $s p$. aunque con menor relevancia epidemiológica (Abbot et al., 2007). 


\section{h. Epidemiología 4}

Debido a que numerosos factores ambientales la hacen variable, no alcanza con conocer el comportamiento de los parásitos en los animales (interacción global), sino que es necesaria su descripción en el ambiente y en relación con los sistemas de manejo. En este sentido, primero Vlassoff (1982) y luego Mc Ewan (1994), propusieron un modelo según el cual, se explica el alza del periparto en los recuentos de huevos de las ovejas, que genera la base de la contaminación primaveral y que constituye la primo infección de los corderos al pie. A su vez, en estudios de vida libre, Rossanigo y Gruner (1995) y O'Conor (et al., 2006) evaluaron la influencia de la humedad y la temperatura, considerando estos factores, como los limitantes para el desarrollo parasitario. Coincidiendo, en Nueva Zelanda, se demostraron patrones de desarrollo estacional fundamentalmente en Haemonchus contortus (más que en otros géneros estudiados - $T$. circumcincta), con predominio entre primavera-otoño (Waghorn et al., 2011). Esto demuestra la predilección de $H$. contortus a climas templados y húmedos, mientras que $T$. circumcincta se adapta mejor a temperaturas más bajas. En cuanto a los factores meteorológicos Reynecke (et al., 2011), demostró que las

\footnotetext{
${ }^{4}$ Epidemiología: estudio de la distribución y los determinantes de estados o eventos (en particular de enfermedades), aplicándolos al control de las mismas, promoviendo la salud. Hay diversos métodos para llevar a cabo investigaciones epidemiológicas: la vigilancia y los estudios descriptivos se pueden utilizar para analizar la distribución y los estudios analíticos permiten analizar los factores determinantes (OMS).
} 
bajas temperaturas son la principal limitante para el desarrollo de los estados de vida libre. La humedad también lo fue para $H$. contortus (especialmente en los primeros 14 días de desarrollo), mientras que especies como T. circumcincta y $T$. colubriformis toleran mejor la desecación. Numerosos estudios en todo el mundo describen a estos tres géneros como los principales en ovinos (Nari et al., 1977; Vlassoff et al., 2001; Morgan y van Dijk, 2012) con predominio de $H$. contortus en regiones templadas.

Desde hace tiempo se han realizado estudios de descripciones epidemiológicas, en diferentes regiones del mundo donde la producción ovina es relevante.

En Australia Gordon (1948), describió los máximos recuentos para $H$. contortus en verano (extendiéndose desde la primavera al otoño), mientras que Trichostrongylus spp. fue más frecuente (aunque variable) en invierno.

Brunsdon (1970) en Nueva Zelanda, demostró predominio de $H$. contortus, Ostertagia spp. y Trichostrongylus spp. en otoño.

En Brasil y Sudáfrica $H$. contortus es el principal género, con predominio desde finales de primavera hasta principios de invierno (especialmente en verano), cuando las temperaturas superan los $15^{\circ} \mathrm{C}$ y las precipitaciones son superiores a $50 \mathrm{~mm}$. (Santiago et al., 1976; Ramos et al., 2004; Maciel et al., 2014; Viljoen, 1964). Otros estudios realizados en México, Colombia, Venezuela, Cuba y Asia son consecuentes con lo hasta acá descripto (Martinez, 1987; Gonzalez 
Garduño et al., 2011; Pinilla et al., 2018; Morales et al., 2006; Arece García, 2006, Sani et al., 2004).

En Chile y en diferentes regiones de Europa (Escocia y España) las descripciones epidemiológicas son similares a las de la Patagonia Argentina que se detalla más adelante (Nitor Torres, 2006; Zúñiga Loaiza, 2003; Hamer et al., 2019; Ballesteros, 2018).

En Uruguay, Nari et al. (1977) describió las siguientes prevalencias: H. contortus $(43 \%) ; T$. colubriformis $(26 \%) ;$ T. axei (12\%); Nematodirus spp. ( $N$. filicolis y spathiger) (11\%); en menor proporción (3\%), se describieron ejemplares de los géneros Ostertagia spp.; Cooperia spp.; Oesophagostomum spp.; Strongyloides papillosus y Trichuris ovis. Una actualización reciente realizada por Castells (et al., 2011) demostró frecuencias similares: $H$. contortus $(35,1 \%) ; T$. colubriformis $(31,9 \%) ;$ T. axei $(10,3 \%) ; \quad$. spathiger $(7,7 \%) ; T$. circumcincta $(4,8 \%)$ y $(4,3 \%)$ para otros géneros (Cooperia spp.; Strongyloides papillosus; Trichuris ovis y Oesophagostomum venulosum). Ambos autores, describieron para $H$. contortus, un período de hipobiosis entre marzo y septiembre (otoño-invernal), con porcentajes que pueden llegar hasta el 50\% de la carga de este parásito.

Los primeros estudios sobre epidemiología en ovinos en América fueron realizados en Argentina por Johnstone (1971). Se enfocaron en la Patagonia, citando como género dominante a Ostertagia spp. (Teladorsagia circumcincta). En segundo lugar, se citan varias especies del género Trichostrongylus spp., según zona e influencia climática (Olaechea y Suarez, 1984; 1985). Ambos géneros, presentan un pico 
invernal que luego disminuye, presentando las mayores tasas de infección en primavera. Nematodirus spp. fue descripto con mayor prevalencia en animales jóvenes, cuyas cargas aumentan desde el destete (verano) hasta el año de edad (verano siguiente). En animales adultos, tiene un comportamiento otoño-invernal que luego declina. Según la región (regímenes de precipitaciones), pueden observarse estacionalmente Chabertia ovina y Oesophagostomum venulosum y de forma más o menos constante Trichuris ovis (con poca importancia). Ocasionalmente, pueden producirse brotes de haemonchosis (debido a su rápida propagación) en zonas de mallines, cuando los veranos son Iluviosos y con temperaturas elevadas.

Estudios realizados en La Pampa (Suárez, 1985a; 1985b; 1986; Suarez et al., 1990b), sugieren un predominio de $H$. contortus entre enero y junio, con presentación de hipobiosis entre abril y junio (entre el 20 y $75 \%$ ). Se observó un pico de Trichostrongylus spp. (T. axei, T. colubriformis y T. vitrinus) y Nematodirus spp. hacia fines de invierno y principios de primavera. Teladorsagia circumcincta y Ostertagia ostertagi tuvieron una prevalencia menor que los anteriores. Las presentaciones de Trichuris ovis, Oesophagostomum spp. y de Dictyocaulus filaria fueron esporádicas y escasas. Estos resultados, son coincidentes con lo descripto en provincia de Buenos Aires por Sánchez y Romero (2005), con la salvedad que la magnitud de hipobiosis observada fue menor y en un período más concreto ( $40 \%$ entre mayo y junio). Esto sugiere, que las cargas halladas entre agosto y septiembre 
provendrían de la desinhibición más que de reinfección con larvas que hubieran sobrevivido en el pasto durante el invierno.

En el Noroeste Argentino, $H$. contortus es el género más importante (incluso en bovinos), seguido por Trichostrongylus spp. y Cooperia spp. En zonas de mayor altura aparece Ostertagia spp. y Teladorsagia circumcincta. Con menor importancia aparecen los géneros Oesophagostomum spp.; Nematodirus spp.; Bunostomum spp. y Chabertia spp. El pico de eliminación de huevos descripto es durante el verano-otoño (Aguirre et al., 2000; Suarez et al., 2013).

En Corrientes, los primeros estudios programados sobre la epidemiología de nematodos ovinos fueron realizados a comienzos de la década del '70, por Rosa (et al., 1973) y Lombardero (et al., 1976). Estos estudios, estuvieron basados en recuento de huevos por gramo (HPG) de materia fecal y su coprocultivo y en necropsias en diferentes épocas del año provenientes de frigorífico. Establecieron que el $85 \%$ de la carga parasitaria de corderos sacrificados entre diciembre y mayo correspondía a $H$. contortus, coincidiendo con la mayor prevalencia de Cooperia spp. (probablemente en pastoreo conjunto de con bovinos). El segundo género en importancia fue Trichostrongylus spp. ( $T$. colubriformis y T. vitrinus), con mayor abundancia entre los meses de agosto y noviembre (también para Nematodirus spp. y Oesophagostomum colombianum). En tanto que Trichuris ovis, de escasa prevalencia, se observó entre junio y septiembre. Las infestaciones por Moniezia spp., tuvieron una clara estacionalidad en verano y otoño, especialmente en corderos. Ostertagia spp. se encontró 
con mayor frecuencia en otoño-invierno, mientras que Cooperia spp., presentó menor estacionalidad. Ambos géneros se asociaron al pastoreo con bovinos.

La información posterior sobre epidemiología en la zona surge de observaciones dispersas en torno a trabajos de manejo, evaluaciones de medicamentos y la casuística de algunos laboratorios o centros de diagnóstico, sugiriendo un patrón otoñal para $H$. contortus, asociado a las precipitaciones y a la temperatura con un segundo pico de Trichostrongylus spp. para el final de la primavera (Romero et al., 1998; Romero y Boero, 2001). Considerando las condiciones climáticas más benignas para las parasitosis que en otras regiones, es posible que $H$. contortus exprese el patrón de inhibición menos marcado.

De lo descripto hasta este momento, se destaca la estacionalidad del parasitismo (Fiel et al., 1988) y las condiciones ambientales determinantes de humedad y temperatura para el desarrollo y sobrevida de estados de vida libre (O'Connor et al., 2006). La construcción de bioclimatogramas (gráficos que cruzan datos de temperatura media mensual y precipitación mensual acumulada) reafirma estas teorías. Estos gráficos, fueron muy utilizados en la década del '50 en Australia, Canadá y Estados Unidos por diferentes autores, para la interpretación de datos epidemiológicos. En Argentina Johnstone (1971), los utilizó en Ios estudios en la Patagonia, teniendo como referencia los informes de Gordon (1948) y Levine (1963) que consideraron que los límites para el desarrollo de $H$. contortus están en $50 \mathrm{~mm}$ de precipitación mensual y temperaturas medias entre 15 y $37^{\circ} \mathrm{C}$ (Gráfico 8 a 12). Recientemente 
O’Connor (et al., 2006), reafirma dichos parámetros y agrega que deben tenerse en cuenta modificaciones del microambiente (microclima) de los estados de vida libre. En los Gráficos 8 a 12 se observan los bioclimatogramas que caracterizan las diferentes regiones de interés.
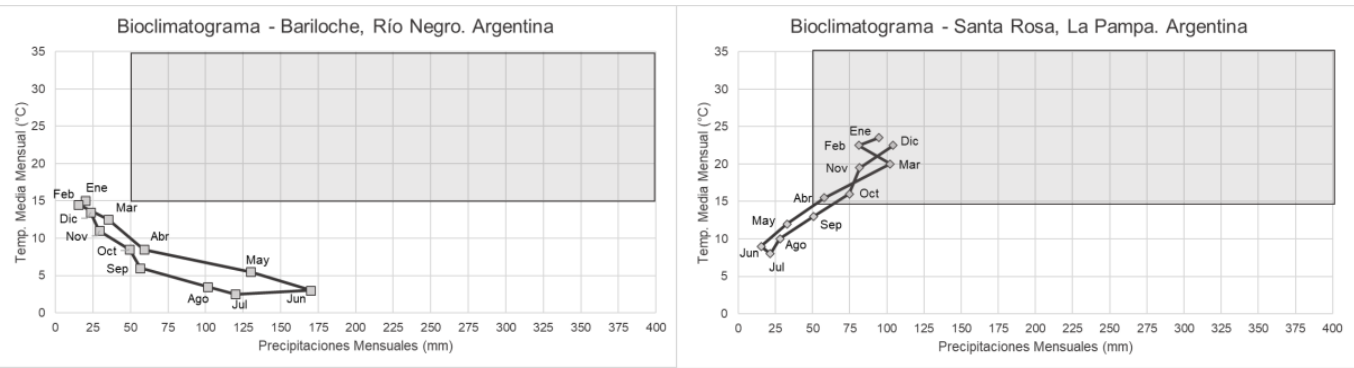

Gráfico 8 y 9.
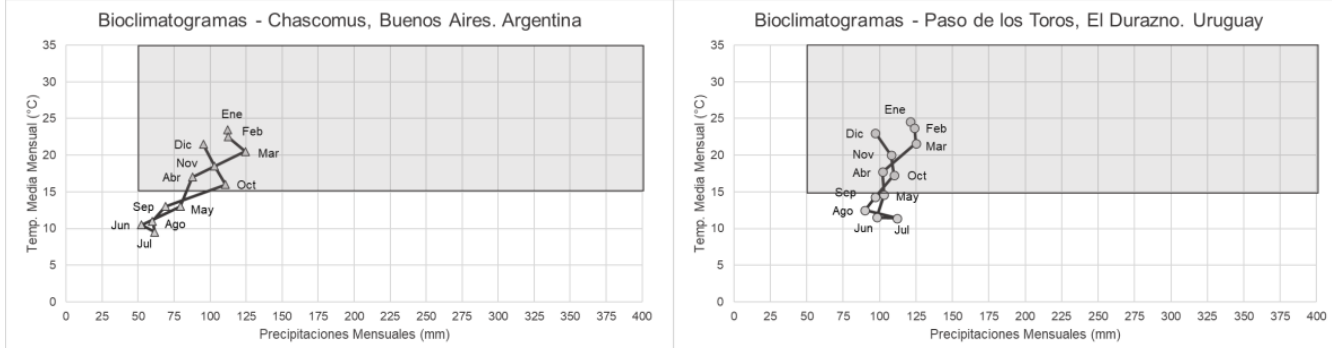

Gráfico 10 y 11.

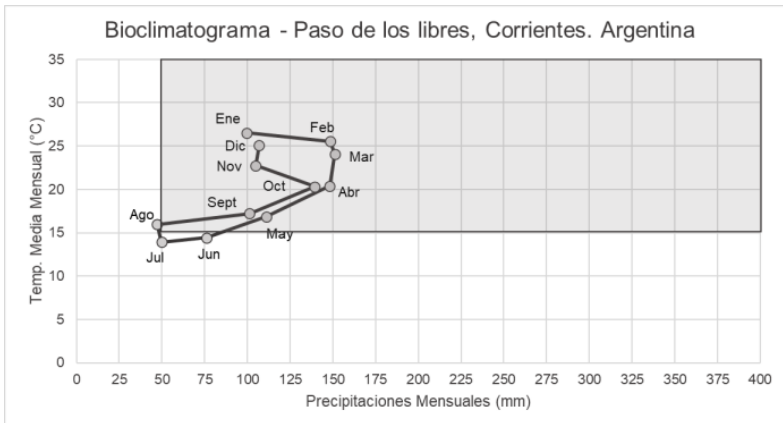

Gráfico 12.

Gráfico 8 a 12: bioclimatograma para las diferentes regiones donde se caracterizó la epidemiología en el país, incluyendo la descripción de Uruguay por cercanía a la región en estudio. Se utilizaron registros históricos (promedio) de los años 1981-2012, obtenidos del Servicio Meteorológico Nacional (SMN, 2020) y de los años 1961-1990, obtenidos del Instituto 
Uruguayo de Meteorología (INUMET, 2020). El área delimitada en gris, abarca las condiciones consideradas favorables para el desarrollo de $H$. contortus según la bibliografía consultada. En la región a estudiar los parámetros resultan favorables durante todo el año, mientras que en las demás regiones analizadas presentan al menos tres meses, fuera de la zona de confort, que es consistente con epidemiología y estacionalidad parasitaria descripta para cada zona.

La observación de casuística clínica sugiere inconsistencias con lo hasta acá expresado y demanda mayores detalles sobre la epidemiología.

\section{i. Pérdidas productivas}

La GEV es considerada una de las limitantes más severas de la producción bovina y ovina. Se ha intentado realizar estimaciones globales de las pérdidas y fijarlas en valores monetarios, que resultan por lo menos contrafácticas y menosprecian las producidas por otros factores (Bulman, 2015). El potencial productivo de un sistema depende de numerosas variables (características agroclimáticas, culturales, socioeconómicas, etc.) a los que se subordinan las pérdidas por problemas sanitarios específicos. Los casos clínicos son relativamente menos frecuentes (pero más llamativos) que las pérdidas subclínicas, siendo estas más difíciles de evaluar y diagnosticar en contextos de resistencia. En ese sentido, cualquier estrategia de control debe estar enmarcada en la neutralización de las pérdidas producidas, en este caso por parásitos. 
En ovinos, las alteraciones producidas por la GEV son más marcadas en regiones templadas y húmedas y se asocian fundamentalmente a $H$. contortus desestimando a otros géneros (Clarke, 1963).

Las pérdidas observadas, se asocian a menor ganancia de peso (hasta $15-25 \%$ del PV en animales en crecimiento), menor condición corporal, pérdida de calidad y peso del vellón (hasta el 10-29\%), menor producción de leche (hasta el 22\%), menor porcentaje de señalada y aumento de la mortandad (Brunsdon, 1964; Rosa y Lukovich, 1974; Castells et al., 1995; Suarez et al., 1990; Suarez, 2007c; Mavrot et al., 2015). Nari (et al., 1983) demostró que cuando se realiza el destete tempranamente, las pérdidas en GDP pueden llegar hasta el 56,8\% si no se aplican medidas de control. Mejores niveles nutricionales pueden anular los efectos de bajas cargas parasitarias ( $<1800$ parásitos totales y con predominio de Nematodirus spp.).

En bovinos, las pérdidas de peso y retraso en el crecimiento se asociaron con un menor desarrollo del aparato reproductivo (tanto en machos como en hembras), prolongando el período de crecimiento con el consiguiente costo (Ambrústolo et al., 1990; Steffan, 1991; Steffan y Fiel, 1994; Bulman, 2012), pudiendo este efecto replicarse en ovinos.

Las mortandades son variables, llegando hasta el 50\% anual en las categorías más susceptibles (Castells et al., 1995). Cabe destacar que en los sistemas de producción de Argentina, la mayoría de los productores no realiza rutinariamente análisis por necropsia, 
adjudicando su causa de forma subjetiva. Lo mismo, sucede con las pérdidas cuando no se encuentran causas evidentes.

Respecto de los daños producidos por Moniezia expansa (Filo: Plathelminthes; Clase: Cestoda), Brunsdon (1966) no halló pérdidas con y sin asociación a trichostrongylidos.

En Corrientes es limitada la información disponible sobre las pérdidas en sistemas de producción, siendo estas variables entre años.

\section{j. Control y resistencia antihelmíntica}

Hasta la década del '60 el control era prácticamente nulo y empírico. Los tratamientos se realizaban con químicos poco eficaces o con frecuentes efectos colaterales indeseables. En adelante, el desarrollo masivo de la industria farmacéutica generó oferta de drogas que sirvieron (y aún lo hacen) como herramientas eficaces para el control de los parásitos gastrointestinales, al extremo de ser la única medida de control utilizada. En tanto, las mejoras en la precisión, calidad y utilidad diagnóstica para las indicaciones de tratamientos y manejo comenzaron a desarrollarse cuando la resistencia a las drogas fue evidente.

Una encuesta realizada en Corrientes por Vazquez (en comunicación personal, durante el trabajo realizado por FAO en 1994), demostró que los productores adoptaron métodos de control sin conocimiento de la epidemiología, ni asesoramiento profesional, basándose en la disponibilidad de medicamentos a bajo costo, realizando tratamientos masivos ante cualquier situación que 
consideraran de riesgo. Los productores declararon un promedio de 4,54 tratamientos antihelmínticos (entre 3 y 8 ) en ovejas adultas y 3,8 en corderos (entre 1-8). La decisión la toman según se presenten signos clínicos que a su modo de ver impliquen daño causado por parásitos, como la clásica anemia producida por Haemonchus spp., reblandecimiento de heces, mal estado general, situaciones que consideran críticas por experiencia (destete en corderas e incluso en ovejas y preservicio y preparto en reproductores). Muchas veces son pocos los animales afectados y se trata toda la majada y en otras, se definen por signos inespecíficos de mal estado general, que pueden no responder a cargas parasitarias (déficit nutricional). En esas situaciones, el refugio, posiblemente sea reducido acelerando el proceso de presión de selección eficaz e innecesariamente (especialmente si ya existe genética de resistencia en la población parasitaria).

Hay evidencias de como las variaciones anuales, inciden sobre las poblaciones parasitarias y sus consecuencias. Romero (et al., 2013), demostró durante el seguimiento de una majada con igual manejo, durante cuatro años consecutivos, la necesidad de distintos tratamientos en cada ciclo $(2,3,3$ y 1 tratamientos/año) y al mismo tiempo la variabilidad en los momentos de aplicación. Estas experiencias, demuestran que la falta de información técnica se suple con un mayor número de tratamientos que pueden resultar innecesarios.

La calidad y variedad de las drogas fue en aumento en lo que respecta a seguridad, eficacia, poder residual y espectro, a la vez que 
se redujeron los precios relativos facilitando la aplicación masiva. Los antihelmínticos disponibles en el mercado para ovinos corresponden a 7 grupos químicos: 1) Benzimidazoles, 2) Imidazotiazoles, 3) Lactonas macrocíclicas, 4) Amino acetronitrilo derivados, 5) Espiroindoles, 6) Salicilanilidas y 7) Organofosforados. Considerando a los principios activos como un recurso no renovable ( $y$ una herramienta), por lo que su uso requiere de capacitación adecuada y permanente por parte de los veterinarios y productores.

La resistencia a los principios activos se describe como la disminución heredable de la eficacia de un antihelmíntico frente a poblaciones parasitarias que a una dosis determinada son susceptibles (Prichard et al., 1980; Sangster y Gill, 1999). Las poblaciones que sobreviven (resistentes) son las que se multiplican y tienen más posibilidades de dominar en el ambiente. Coles (et al., 1992) y Fiel (et al., 2001) sugieren la presencia de resistencia antihelmíntica cuando la reducción de los conteos es menor al $95 \%$ y $90 \%$ en ovinos y bovinos respectivamente, teniendo en cuenta que las fallas clínicas se observan con valores de eficacia cercanos o menores al 80\% (Nari, 2011).

Para el diagnóstico de resistencia, existen tres tipos de pruebas (Prichard, 1990; Coles et al., 2006), in vivo (test de eficacia controlada y test de reducción del conteo de huevos), in vitro (test de eclosión de huevos y test de desarrollo larval) y técnicas moleculares (por detección de genes o mutaciones específicas) (Castaño Zubieta et al., 2005; Guzmán, 2014). Según Caracostantogolo (et al., 2013), desde el punto de vista práctico, la prueba que mejor se adaptó y difundió en el campo 
con excelentes resultados, fue el test de reducción del conteo de huevos $(\mathrm{TRCH})$. Pese a utilizar animales, no tiene mayores implicancias en su bienestar, que las propias rutinas de manejo de campo (encierre, identificación, dosificación y muestreo). Desde el punto de vista técnico, deben considerarse las características de los parásitos y fármacos para su correcta interpretación. Hoy en día es la más utilizada y recomendada por la WAAVP (World Association for the Advancement of Veterinary Parasitology). No obstante, la tecnología y el diagnóstico molecular avanzan rápidamente y con un futuro prometedor.

La expresión de determinados genes en una población está condicionada a la capacidad de sobrevivir a la exposición a una droga (tratamiento). Los mecanismos por los cuales lo logra podrían clasificarse como específicos cuando están relacionados con el mecanismo de acción del principio activo, o inespecíficos cuando dependen de una respuesta física (Wolstenholme et al., 2004). La población de parásitos que no fue seleccionada (no expuesta al tratamiento) se la considera en refugio (van Wyk et al., 2001) y constituye el banco de genes (variabilidad genética de una población). La frecuencia de tratamientos es inversamente proporcional a la variabilidad genética y por lo tanto un catalizador de la resistencia (Barton, 1983).

La exposición de los parásitos a dosis inferiores a las recomendadas (subdosificación) puede facilitar la expresión de genes de resistencia (incluso en heterocigosis). Al tratar los animales debe 
prestarse especial atención al peso de los animales, formulación de los medicamentos y funcionamiento de las herramientas (jeringas).

Lloberas (2018), afirma que la vía de administración juega un rol importante en la eficacia, sugiriendo que la administración oral la mejora parcialmente. Por otro lado, el ayuno previo a la administración de benzimidazoles orales mejora la absorción, lo que puede verse reflejado en mejoras parciales de eficacia. Este efecto, también se observó en aplicaciones de benzimidazoles orales versus ricobendazol inyectable en bovinos (Cristel et al., 2017). Las diferencias de pequeña magnitud cobran más importancia en casos de resistencia incipiente (detección temprana).

La vida media de las diferentes drogas incide en la expresión de resistencia. Dobson (et al., 1996) propone un modelo que divide la vida media en dos etapas de actividad frente a nuevas reinfecciones. En la primera, todas las larvas ingeridas mueren, mientras que la segunda etapa, la subdivide en 3 niveles, donde sobreviven larvas homocigotas dominantes (resistentes), heterocigotas (resistentes) y homocigotas recesivas (susceptibles). Dicha hipótesis, justifica la preferencia de drogas de una segunda etapa corta, exponiendo al menor número de larvas posible.

La primera comunicación de resistencia fue realizada en 1914 sobre artrópodos, en pesticidas agrícolas (Melander, 1914), mientras que se reportaron casos de resistencia poco después del lanzamiento de los primeros antihelmínticos (Love, 2011). Se sumaron los reportes de 
Druge (et al., 1964) frente a benzimidazoles, Le Jambre (et al., 1976) para levamisol/morantel y Carmichel (et al., 1987) para ivermectina.

En Argentina los primeros antecedentes fueron realizados por Entrocasso (et al., 1988); Romero (et al., 1992) y Eddi (et al., 1996). Publicaciones de diferentes partes del mundo demuestran la amplitud e incremento de la problemática (Rialch et al., 2013; Domke et al., 2012; Artho et al., 2007; Bakunzi et al., 2013; Tsotetsi et al., 2013; McMahon et al., 2013; Voigt et al., 2012; Čerňanská et al., 2006; McKenna, 2010; Webb y Ottaway, 1986), situación que no sólo se da en explotaciones ovinas y que llega a amenazar la sustentabilidad de la actividad en algunas regiones (Kaplan, 2004).

En un relevamiento del MERCOSUR (Waller et al., 1996; Echevarria et al., 1996; Nari et al., 1996; Maciel et al., 1996 y Eddi et al., 1996), se expresa la grave situación regional respecto del problema de resistencia antihelmíntica, cuya prevalencia resulta variable según la droga y región, siendo la Mesopotamia una de las más comprometidas. Entre 1994 y 1995 fueron relevados 22 establecimientos ovinos de la provincia de Corrientes y Entre Ríos, donde la eficacia de ivermectina y closantel era importante en sus espectros específicos, pero sólo el $5 \%$ de los establecimientos relevados presentaba eficacia a todos los grupos químicos con una distribución variable de resistencia a benzimidazoles, levamisol y otros principios (Romero et al., 1998). Un nuevo relevamiento 10 años más tarde, muestra que el 64\% de los 26 establecimientos relevados presentaba resistencia, mientras que en la provincia de Corrientes, el $100 \%$ expresó resistencia a por lo menos un 
grupo químico (Caracostantogolo et al., 2005). En contraparte, un informe reciente realizado en bovinos por Cristel (et al., 2017) expresa como el conocimiento epidemiológico detallado, junto con una correcta evaluación diagnóstica, pueden revalorizar y dar precisión al uso de drogas que aún mantienen eficacia frente a algún género o especie, como es el caso de la ivermectina frente a Ostertagia spp. en bovinos (Anziani et al.; 2000; Fiel et al., 2000).

Drogas relativamente nuevas como el monepantel, acumulan reportes de resistencia en diferentes países (Scott et al., 2013; Van den Brom et al., 2015; Cintra et al., 2016; Raza et al., 2016), inclusive con esquemas de tratamientos selectivos (Mederos et al. 2014). También en Argentina, con un primer reporte en 2015 (Illanes et al., 2018). El derquantel (presentación combinada con abamectina) en su corto tiempo en el mercado, ya presenta casos de reducción en la eficacia (Sales y Love, 2016). En cuanto al naftalofos, que tiene alguna comunicación de resistencia en Australia (Lyndal-Murphy et al., 2014), en Uruguay (pese a su intenso) hasta el momento no han registrado casos.

Hay principios activos que presentan mayor facilidad para generar resistencia, pero todos los medicamentos podrían desarrollarla (Prichard, 1999). Conceptualmente, cuanto mayor es el éxito de un tratamiento, mayor es el riesgo de desarrollar resistencia, por ello es necesario adoptar medidas de manejo superadoras, basadas en el conocimiento epidemiológico y que no dependan exclusivamente de tratamientos farmacológicos (Nari et al., 2013). 


\section{k. Herramientas complementarias}

En el marco de resistencia como problema actual y futuro, están en desarrollo y son motivo de diferentes líneas de trabajo, técnicas para mejorar la calidad diagnóstica, las expectativas y precisión de los tratamientos, los márgenes de decisión y la capacidad de la majada para resistir o tolerar el efecto de las parasitosis. Las propuestas, orientan a combinar estrategias para reducir el número de tratamientos y administrarlos en los momentos más oportunos, resaltando la premisa de "primero el diagnóstico y luego el tratamiento". El diagnóstico debe basarse en datos concretos, resultando el HPG (hasta el momento) el mejor indicador (Steffan y Fiel, 2018), mientras que los tratamientos tienden a estar dirigidos a los animales y situaciones que lo requieran.

Tratamientos selectivos: el método FAMACHA ${ }^{\odot}$ es muy utilizado en ovinos y caprinos por su practicidad y está orientado a dosificar únicamente los animales que lo necesitan clínicamente. Desde 1990 y con apoyo de la FAO, se desarrolló un proyecto dirigido a ganaderos y profesionales en Sudáfrica, que permitió sintetizar en un método práctico la decisión de tratar un animal individualmente según su nivel de adaptación a la carga parasitaria que soporta. El principal problema son cuadros producidos por $\mathrm{H}$. contortus (hematófago), por lo que este método se basó en la correlación de los valores de hematocrito, coloración de las mucosas (especialmente la del párpado inferior) y recuentos de HPG. Se describió como el método FAMACHA ${ }^{\odot}$ (nombre derivado de su creador Francois -apodado Faffa- Malan Chart). Dicha 
tabla crea una escala de 1 a 5 según la coloración de la mucosa del tercer párpado (Bath et al., 1996). Los grados 1 y 2 (rosados fuertes) se asocian a hematocritos mayores a $30 \%$, mientras que los grados 4 y 5 (rosa pálido) a hematocritos menores a 24\%. El grado 3, con hematocrito entre $24 \%$ y $30 \%$, es el que mayor variabilidad y controversias genera entre los técnicos al momento de realizar el diagnóstico (Romero en comunicación personal). Otros autores (Suarez et al., 2014 y Rossanigo y Page, 2017) en trabajos realizados en Argentina sobre caprinos, demostraron que el grado 3 varía entre valores de hematocrito de 30 y $21 \%$, mientras que los grados 4 y 5 resultaron en valores menores. Si bien su correlación con el hematocrito ya fue validada (van Wyk y Bath, 2002), resta por conocer como impacta su aplicación en las pérdidas productivas, según controversias expresadas en trabajos realizados en Uruguay (Salles et al., 2002). Kaplan (et al., 2004) en Estados Unidos, evaluó dos valores de corte de hematocrito $(19 \%-15 \%)$ y como influyen en la especificidad y sensibilidad del método. Demostró que aunque un número importante de animales sin anemia fueran tratados (por fallas en la sensibilidad), aumenta de forma significativa la cantidad total de animales sin tratar.

Rotación anual de grupos químicos y combinaciones: no debe presionarse sobre las cepas que portan genes de resistencia, sino por el contrario evitar su multiplicación evitando cargas residuales luego de cada tratamiento. Hay varios modelos sobre el enfoque estratégico de rotación y uso de drogas, pero todos coinciden en partir del 
conocimiento del estatus de eficacia de los principios activos en cada establecimiento y alternarlos (Nari, 2011).

Selección de individuos resistentes: Le Jambre (1978) en Australia, fue uno de los pioneros en profundizar esta línea de trabajo, a los que se sumaron diferentes autores en distintas partes del mundo (Albers et al., 1987; Woolaston, 1994; Baker, 1997; Eady, 1998). En la región, uno de los primeros en formalizar la selección genética fue Cardelino (et al., 1994) en Uruguay. En Argentina Romero (et al., 1999; et al., 2011), seleccionó animales por su comportamiento fenotípico, mientras que Poli (et al., 2015) realizó estimaciones de la heredabilidad. Hoy en día continúan estas líneas de trabajo con resultados alentadores.

Manejo del pastoreo: existen diferentes alternativas, como son pastoreo alterno con otras especies o categorías menos susceptibles, rotación de parcelas y manejo de cargas (Castells et al., 2013). En todos los casos el objetivo es regular el refugio de manera de mantener una población heterogénea, dentro de niveles que no representen un problema para los animales. Hay mucho por dilucidar al respecto, desde la supervivencia de los parásitos en el ambiente (Pereira et al., 2006; Niño Uribe et al., 2019), la dilución de los mismos en el volumen de forraje (muy variable entre años, potreros y recurso forrajero) y como inciden e interactúan estos factores en la dinámica de infestación.

Reversión de resistencia: diferentes estudios demuestran que es posible establecer protocolos de inserción de cepas susceptibles de diferentes géneros en bovinos y ovinos con el objetivo de recuperar la 
susceptibilidad del refugio y mejorando la eficacia de los tratamientos (van Wyk y Schalkwyk, 1990; Fiel et al., 2017; Muchiut et al., 2019).

Partículas de cobre: el cobre y su efecto antiparasitario fue descubierto antes que los primeros antihelmínticos, indicado específicamente para el control de $H$. contortus. Debido a que los ovinos presentan mayor susceptibilidad a las intoxicaciones con este mineral, sumado a la amplia difusión y mejor eficacia de los antihelmínticos modernos, fue desplazado del mercado. Sin embargo, la creciente resistencia motivó a retomar estudios de su aplicación con resultados favorables (Vatta et al., 2012).

Vacunas: los trabajos con inmunógenos se basaron en la producción de dos tipos de antígenos (naturales y ocultos). Si bien el mecanismo de acción de los antígenos naturales es más simple, los avances más próximos a la obtención de una vacuna comercial están en referencia a los antígenos ocultos, teniendo como principal inconveniente la producción en escala industrial (Castells et al., 2013).

Nutracéuticos: se basa en sustancias presentes en las pasturas, con efecto sobre los parásitos. En las investigaciones de los últimos años, se ha puesto especial interés en las plantas forrajeras con alto contenido de taninos (Schapiro et al., 2015).

Inmunoestimulación por nutrición (proteína): los sistemas de producción ovina suelen ser extensivos a semiextensivos en zonas marginales, donde son frecuentes las carencias nutricionales, especialmente proteicas. Las proteínas en la dieta impactan por acción directa sobre la salud del animal mejorando la respuesta inmune, que 
se ve reflejada en una mejor respuesta clínica a un mismo desafío parasitario (Coop y Holmes, 1996). La corrección de este desbalance sugiere una mejor respuesta a las infestaciones por parásitos (Houdijk et al., 2001), además de mejorar el desempeño productivo y acelerar la recuperación clínica (Torres-Acosta et al., 2004).

Hongos nematófagos: el control biológico es otra de las posibilidades en las investigaciones modernas. Hongos de los géneros Artrobotris y Duddingtonia son ingeridos por los animales y luego eliminados con la materia fecal, afectando el desarrollo de las larvas. Se demostró el efecto en diferentes géneros, pero presenta muchas variabilidades en cuanto a la adaptación del hongo en los diferentes climas (Sagues et al., 2011). Teniendo en cuenta que actúan reduciendo el refugio, el uso combinado con tratamientos antihelmínticos debe ser monitoreado.

\section{Porque trabajar en el tema}

Para aplicar este conjunto de herramientas en una región tan favorable para los parásitos y lograr su integración en los resultados, es imprescindible contar con información precisa sobre la dinámica de los parásitos y sobre los puntos críticos de afectación de los huéspedes, información que hasta el momento no está disponible en la región.

En Corrientes no se han estudiado con la precisión suficiente las tendencias en composición, variedad e intensidad de las cargas parasitarias en las distintas categorías de lanares en pastoreo, ni su vínculo con variables de contexto que expliquen un patrón de 
comportamiento epidemiológico. Este último, en la GEV responde a un sistema de variables definidas (o un gran número de ellas) que se asocian según sean sus componentes y cuyos vínculos e interrelaciones determinan las diferencias en el comportamiento.

Para dar un paso adelante en los sistemas de control profesional, debe integrarse el conocimiento epidemiológico definiendo propuestas con mínimos tratamientos. Al mismo tiempo deben definirse criterios de evaluación para los sistemas de control propuestos. Hoy desconocemos los márgenes tolerables de pérdidas no evitables y los costos que suponen la sostenibilidad de las propuestas estratégicas, al utilizar el diagnóstico a nivel predial para la toma de decisiones sobre la implementación de tratamientos en majadas de la región. Esto resulta indispensable para la posterior incorporación sistemática de herramientas complementarias.

\section{Objetivos e hipótesis}

\section{Capítulo 1}

Objetivos:

- Describir la distribución estacional y composición de la carga parasitaria en dos establecimientos de la región, su variación entre categorías (ovejas y corderas de recría) y el fenómeno de hipobiosis en Haemonchus contortus.

- Describir tendencias sobre la variación en las tasas de infección para las distintas especies. 
- Estudiar factores concomitantes y asociaciones entre variables ambientales (meteorológicas) que expliquen el comportamiento epidemiológico (según las precisiones del primer objetivo).

Hipótesis

- La composición específica de las poblaciones parasitarias y su dinámica en un mismo ambiente podría ser diferente según las categorías afectadas (corderas y ovejas).

- El esquema de influencia de factores climáticos considerado hasta ahora, no explicaría totalmente el patrón de infectividad en la zona.

- La importancia de Trichostrongylus colubriformis en la carga de los ovinos en distintos momentos del año, podría estar subestimada en estudios basados en análisis coproparasitológicos.

- El fenómeno de hipobiosis de Haemonchus contortus, se expresaría con menor intensidad que en otras regiones estudiadas.

\section{Capítulo 2}

Objetivo

- Evaluar una estrategia de control antihelmíntico a campo y su efecto en el comportamiento de variables parasitarias y desempeño productivo/reproductivo de la majada. 
- Estudiar la relación entre el comportamiento productivo de la majada con la producción de forraje medida a través del índice verde.

Hipótesis

- El patrón de comportamiento epidemiológico del parasitismo gastrointestinal en el sur de la provincia de Corrientes permitiría ajustar estrategias de control antihelmíntico.

- Una estrategia de monitoreo y control con intervenciones mensuales podría tener la sensibilidad suficiente para minimizar riesgos, evitando el uso excesivo de medicamentos y las posibles pérdidas producidas por parásitos. 


\section{CAPITULO 1}

\section{EPIDEMIOLOGIA DE LOS TRICHOSTRONGYLIDOS}

a. Materiales y métodos

Se realizó un estudio longitudinal de evolución de cargas parasitarias naturalmente adquiridas en establecimientos comerciales sobre ovejas y corderas de recría.

1. Lugar de trabajo

El trabajo se realizó en los años 2014 y 2015, en dos establecimientos comerciales próximos (menos de $40 \mathrm{~km}$ de distancia entre ellos) entre las localidades de Curuzú Cuatiá (departamento Curuzú Cuatiá) y Bonpland (departamento Paso de los Libres), Corrientes, Argentina, con animales raza Ideal. El pastoreo fue sobre campo natural en un sistema mixto con bovinos.

- Establecimiento "La Aurora" - año 2014 (2180 ha): latitud 2950'29"S; longitud 5724'36"W. Por la alta frecuencia de abigeato, los animales se encerraban todas las noches en piquetes cercanos a la casa, haciendo variable y condicionada la ocupación de los potreros y cargas relativas.

\footnotetext{
${ }^{5}$ Estaba planificado realizar el ensayo en el mismo establecimiento por 2 años, pero por robos reiterados el dueño decidió la venta del establecimiento teniendo que trasladar el segundo año de ensayo.
} 
- Establecimiento "San Luis del Garabatá" - año 2015 (4900 ha): latitud 2955'32"S; longitud 5747'55"O.

\begin{tabular}{lcc}
\hline \multicolumn{1}{c}{ DETALLE } & La Aurora & San Luis del Garabatá \\
\hline Caballos (Cabezas) & 15 & 220 \\
Bovinos (Cabezas) & 1400 & 4700 \\
Ovinos (Cabezas) & 1050 & 2700 \\
Superficie (ha) & 2180 & 4900 \\
\hline Relación Ov/bov & 0,75 & 0,57 \\
Relación Ov/ha & 0,48 & 0,55 \\
Carga animal (EV/ha) & 0,75 & 1,14 \\
\hline Carga ovina/carga total & $\mathbf{1 2 , 9 \%}$ & $\mathbf{9 , 7 \%}$ \\
\hline
\end{tabular}

Tabla 3: relación de existencias y cargas relativas.

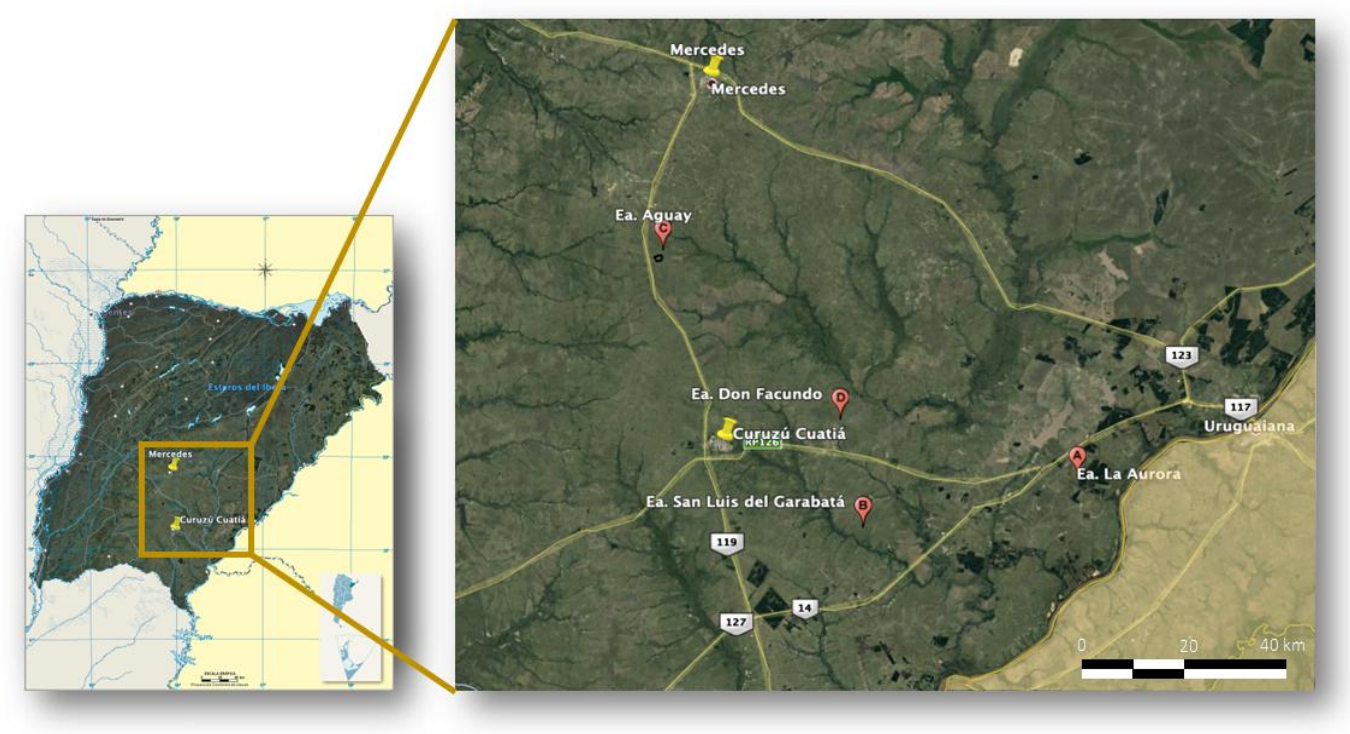

Imagen 1: mapa de la provincia de Corrientes, Argentina, ampliando la región de estudio e indicando la ubicación de los establecimientos donde se realizaron los ensayos (incluyendo establecimientos que se mencionarán más adelante). 


\section{Variables meteorológicas}

Considerando $150 \mathrm{Km}$, como el radio de alcance confiable para una estación meteorológica en zonas sin montañas, se solicitaron datos al Servicio Meteorológico Nacional (SMN), para la estación de Paso de los Libres, Corrientes, generando el expediente Nro. 149.472.

Los períodos consultados fueron los siguientes:

- Serie histórica: se utilizó como referencia de la región y para las comparaciones, calculándose con el promedio (para cada variable) entre los años 1981 y 2012.

- Años de estudio: registros de los años 2014 y 2015.

Las variables consideradas fueron las siguientes:

- Temperatura máxima absoluta (TMaxA): temperatura máxima registrada para el período en estudio.

- Temperatura media máxima (TMMax): promedio de temperatura máxima en un período determinado.

- Temperatura media (TM): promedio de temperatura máxima y mínima en un período determinado.

- Temperatura media mínima (TMMin): promedio de temperatura mínima en un período determinado.

- Temperatura mínima absoluta (TMinA): temperatura mínima registrada para el período en estudio. Los días con heladas (heladas meteorológicas), refieren a temperaturas igual o inferior a $0,0^{\circ} \mathrm{C}$ a $1,5 \mathrm{mts}$. 
- Precipitaciones diarias promedio (PDP): promedio diario del volumen $(\mathrm{mm})$ de precipitaciones para un período determinado.

- Precipitaciones acumuladas (PA): volumen $(\mathrm{mm})$ de precipitaciones para un período determinado.

- Frecuencia de precipitaciones: cantidad de días en los que sucedieron las precipitaciones.

- Humedad relativa (máxima; media y mínima): cantidad de vapor de agua en el aire, promediando valores máximos, mínimos o ambos (media) para un período determinado.

- Heliofania efectiva acumulada (HEA): tiempo (hs) de radiación solar directa en un período determinado.

- Evapotranspiración potencial acumulada (ETPA): demanda atmosférica de agua acumulada en un período determinado. Surge de la evaporación directa desde el suelo más la transpiración de las plantas (Fernández-Long et al., 2012).

- Balance hídrico mensual (BHM): calculado por la sustracción de la evapotranspiración potencial mensual a las precipitaciones mensuales (Pizzio et al., 2021).

- Almacenaje total (ALmT): agua almacenada en el suelo en un período determinado luego del balance hídrico mensual, resultante de la interacción entre la oferta de agua (por precipitaciones, infiltración y escurrimiento del suelo) y la demanda por evapotranspiración (Fernández-Long et al., 2012). 


\section{Majada de entorno}

Los animales del estudio se mantuvieron dentro de la majada comercial general del campo, que tuvo su propia demanda de control antihelmíntico:

a. Elección de las drogas: según un TRCH (Coles et al., 1992) previo para cada establecimiento.

b. Criterio de tratamientos: se prefijaron previo al parto en ovejas y al destete en las recrías. El resto del año fue según consideración clínica, teniendo en cuenta los valores de HPG mensuales para cada categoría, tomando como referencia ${ }^{6}$ los trabajos de Morales (et al., 2013) y Nari (2011). En cada ocasión se muestrearon 10-12 animales por categoría (Love, 2007; Castells et al., 2013):

- Valores de HPG promedio menores o iguales a 800: fueron considerados bajos, sugiriendo no aplicar ningún tratamiento.

- Valores de HPG promedio entre 801 y 1500 : se consideraron moderados, sugiriendo tratamiento selectivo por FAMACHA ${ }^{\odot}$, tratando scores 4 y 5 únicamente.

- Valores de HPG promedio mayores o iguales a 1501: se consideraron elevados, sugiriendo tratamiento poblacional.

\footnotetext{
${ }^{6}$ Los siguientes parámetros son sólo orientativos y sujetos a ajuste por criterio clínico-parasitológico.
} 
4. Estudio de cargas parasitarias acumuladas, mediante necropsias mensuales

El estudio se realizó en un lote de animales para cada una de las dos categorías más relevantes, a los que llamamos permanentes y que pastorearon en las mismas condiciones que la majada de entorno, constituida en el caso de las corderas de recría por 100 animales y 150 para las ovejas. Todos los animales (los del estudio y los de la majada de entorno) se identificaron con caravana.

Se estudiaron ovejas (de segundo parto en adelante), las que recibieron servicio de verano (febrero-marzo) y diagnóstico ecográfico a los 30 días de finalizado el servicio, eliminando de la cohorte a las hembras vacías. Un segundo grupo de estudio fueron corderas de recría, destetadas en diciembre (4-5 meses de edad) que se monitorearon hasta los 17-18 meses de vida.

Las recomendaciones de la CICUAL (Comité Institucional para el Cuidado y Uso de Animales de Laboratorio o Experimentación), de la Facultad de Ciencias Veterinarias (FCV), Universidad Nacional de La Plata (UNLP), exigieron limitar el riesgo clínico de los animales por lo que fueron indicados, incluso en estos lotes, algunos tratamientos aislados. No obstante, el criterio de inclusión en los animales a sacrificar fue de un período de pastoreo mínimo de 60 días luego del efecto residual de las drogas eventualmente utilizadas. Este límite se estableció según lo informado por Barger (et al., 1985), que demostró en condiciones de reinfecciones, que las poblaciones tienden a estabilizarse 
en ese período (6-8 semanas). Se aseguraron 20 animales, como mínimo, en cada período y para cada categoría, que cumplieran con este criterio de tiempo mínimo de pastoreo.

Dentro del grupo de animales permanentes, se realizaron monitoreos de cargas parasitarias mensuales de HPG en materia fecal, no considerándose los huevos del género Strongyloides spp. (Roberts y O’Sullivan, 1949). La caracterización cualitativa se realizó por coprocultivo del pool para cada categoría (Henriksen y Korsholm, 1983; Niec, 1968). Para esto se tomaron muestras individuales de 10-12 animales, en cada categoría, de los cuales se eligieron $\underline{2}$ animales por mes ( 2 ovejas y 2 corderas) que tuvieran carga de HPG cercana al promedio para su sacrificio (Nari et al., 1977; Suárez et al., 1985-a y b; Fiel et al.; 1988; Sánchez et al., 2005).

Los animales sacrificados (utilizados para consumo interno en la estancia) se estudiaron por necropsia realizando el conteo e identificación de los parásitos gastrointestinales (Lukovich, 1985; Ueno y Gonçalves, 1988; Fiel et al., 2011). El contenido de las vísceras se lavó y filtró por separado, extrayendo alícuotas y recuperando el $10 \%$ del lavado de abomaso, intestino delgado e intestino grueso y el $100 \%$ del lavaje broncopulmonar. Además, se realizó digestión pépsica de la pared abomasal para reconocimiento de nematodes inmaduros. La identificación de las especies se realizó sobre los ejemplares machos, asumiendo igual proporción para las hembras (Muller, 1968; Jacquiet et al., 1997). 
5. Estimación de tasas de infestación

Se evaluó mediante la utilización de dos corderas trazadoras a intervalos mensuales. La preparación consistió en la desparasitación con una droga eficaz y sin poder residual (monepantel), exponiéndolos a la infestación natural durante un período no mayor a 4-5 semanas, luego del cual fueron sacrificados $\underline{2}$ animales por mes y procesados con el protocolo antes mencionado (Suarez, 1990a).

6. Evaluación de la presentación del fenómeno de hipobiosis

Para definir los momentos en que Haemonchus contortus expresa el fenómeno de hipobiosis (tasas de inhibición y desinhibición) y teniendo en cuenta el carácter regional de esta condición, se utilizaron animales de dos establecimientos con el siguiente criterio de inclusión:

- Encierre previo al sacrificio por 14 días (mínimo). Tiempo considerado suficiente para que maduren las larvas provenientes de infecciones recientes, interpretando como larvas inhibidas los estados inmaduros presentes tanto en la luz del órgano, como en la mucosa (Nari et al., 1977; Castells et al., 2011)

- Se sacrificaron ovejas y corderas permanentes y corderas trazadoras (según el criterio antes mencionando).

- El material de necropsia se procesó con el protocolo descripto anteriormente. 
Se registraron según el mes en que fueron encerrados y los resultados se expresaron en porcentaje sobre la carga total de parásitos del género.

El encierre se realizó en el campo de origen, en una jaula techada y elevada con piso enrejado de madera, que impedía la acumulación de materia fecal y las reinfecciones. Durante el encierre se alimentaron con pellets de alfalfa (70\%) y maíz entero (30\%) como dieta de mantenimiento a razón del $1,5-2 \%$ del peso vivo en materia seca por día (CSIRO, 2007). Agua fresca disponible ad libitum mediante bebedero automático.

\section{Análisis estadístico}

Para ambas categorías (ovejas y corderas), se realizó una descripción epidemiológica durante dos años consecutivos a intervalos mensuales, de valores absolutos y relativos (respecto de otros géneros). Para ello se utilizaron los resultados de estudios coprológicos (HPG y cultivo de larvas) y de recuentos parasitarios obtenidos por necropsia.

Las variables cuantitativas con distribución normal se procesaron por análisis de varianza (ANOVA).

Las variables que no presentaron distribución normal (incluso después de una transformación - Log10) se analizaron los datos originales por el método de Kruskal-Wallis utilizando la prueba de Bonferroni como post-hoc, cuando hubo más de dos grupos.

Se compararon las tendencias de las variables parasitarias y meteorológicas agrupándolas en períodos trimestrales (promediando o 
sumando los valores según la variable). La agrupación de los trimestres fue la siguiente:

o Trimestres: 1 (enero, febrero y marzo); 2 (abril, mayo y junio); 3 (julio, agosto y septiembre); 4 (octubre, noviembre y diciembre).

Se utilizó un modelo de regresión lineal simple para analizar la relación entre:

- La carga parasitaria de cada género obtenida por necropsia con cada una de las variables meteorológicas antes mencionadas.

- La carga parasitaria de cada género obtenida por necropsia con los recuentos de HPG por género.

- La carga parasitaria obtenida de cada género obtenida por necropsia en animales permanentes con la carga parasitaria de los trazadores.

El software utilizado fue Statistics Base Grad Pack Student IBM SPSS, 12 month Grad Pack Base v26. Código de autorización: 452d5700b97a35e28071. 


\section{b. Resultados}

Los resultados se presentaran exhaustivamente (dada la característica de este informe) detallando las relaciones en diversas tablas y gráficos.

\section{Majada de entorno}

Los resultados de los $\mathrm{TRCH}^{7}$ realizados en cada establecimiento y sobre los cuales se definieron las drogas a utilizar se expresan en las tablas 4 y 5 . Los porcentajes de reducción globales, no superaron para ninguna de las drogas y/o combinaciones utilizadas el $84 \%$, por lo que se recurrió a nuevas combinaciones según la eficacia por especie. En dichas pruebas, no se incluyeron drogas como monepantel y derquantel (presentación con abamectina) debido a su reciente lanzamiento y/o disponibilidad posterior al inicio de la investigación. Los géneros evaluados fueron Haemonchus spp., Trichostrongylus spp. y Oesophagostomum spp. (este último únicamente en el año 2014), debido a que no se hallaron larvas de otros géneros en los cultivos pretratamiento.

\begin{tabular}{cccccc}
\hline DROGA & DETALLE & \% DE EFICACIA TOTAL & Haemonchus spp. & Trichos. spp. & Oesoph. spp. \\
\hline \multirow{2}{*}{$\begin{array}{c}\text { Ivermectina 1\% } \\
\text { \% RCH }\end{array}$} & $12 \%$ & $0 \%$ & $100 \%$ & $34 \%$ \\
& IC95\% (LI-LS) & $0-70$ & $0-50$ & $0-100$ & $0-78$ \\
\hline \multirow{2}{*}{ Closantel } & $\%$ RCH & $67 \%$ & $67 \%$ & $77 \%$ & $50 \%$ \\
& IC95\% (LI-LS) & $44-80$ & $43-81$ & $61-86$ & $16-71$ \\
\hline
\end{tabular}

${ }^{7}$ Se realizaron sobre corderas de recría luego del destete, utilizando 10 animales por droga a evaluar. 


\begin{tabular}{|c|c|c|c|c|c|}
\hline \multirow{3}{*}{ Levamisol } & $\% \mathrm{RCH}$ & $33 \%$ & $10 \%$ & $72 \%$ & $66 \%$ \\
\hline & & & & & \\
\hline & IC95\% (LI-LS) & $0-69$ & $0-59$ & $39-87$ & $27-85$ \\
\hline \multirow{2}{*}{$\begin{array}{c}\text { Albendazol + } \\
\text { Levamisol }\end{array}$} & $\% \mathrm{RCH}$ & $76 \%$ & $98 \%$ & $52 \%$ & $100 \%$ \\
\hline & IC95\% (LI-LS) & $57-86$ & $97-99$ & $14-73$ & $0-100$ \\
\hline \multirow{3}{*}{ Albendazol } & $\% \mathrm{RCH}$ & $38 \%$ & $15 \%$ & $73 \%$ & $100 \%$ \\
\hline & & & & & \\
\hline & IC95\% (LI-LS) & $22-82$ & $0-47$ & $57-83$ & $0-100$ \\
\hline \multirow{3}{*}{ Moxidectin } & $\% \mathrm{RCH}$ & $81 \%$ & $68 \%$ & $100 \%$ & $100 \%$ \\
\hline & & & & & \\
\hline & IC95\% (LI-LS) & $65-90$ & $39-83$ & $0-100$ & $0-100$ \\
\hline \multirow{3}{*}{ Triclorfon } & $\% \mathrm{RCH}$ & $77 \%$ & $80 \%$ & $83 \%$ & $26 \%$ \\
\hline & & & & & \\
\hline & IC95\% (LI-LS) & $52-89$ & $59-91$ & $63-92$ & $0-65$ \\
\hline \multirow{2}{*}{$\begin{array}{c}\text { Albendazol + } \\
\text { Closantel }\end{array}$} & $\% \mathrm{RCH}$ & $77 \%$ & $85 \%$ & $72 \%$ & $89 \%$ \\
\hline & IC95\% (LI-LS) & $55-88$ & $72-92$ & $47-85$ & $79-94$ \\
\hline
\end{tabular}

Tabla 4: TRCH para el establecimiento "La Aurora". LI: límite inferior; LS: límite superior.

\begin{tabular}{|c|c|c|c|c|}
\hline DROGA & DETALLE & \% DE EFICACIA TOTAL & Haemonchus spp. & Trichos. spp. \\
\hline & $\% \mathrm{RCH}$ & $15 \%$ & $0 \%$ & $80 \%$ \\
\hline \multicolumn{5}{|l|}{ Ivermectina 1\% } \\
\hline & IC95\% (LI-LS) & $0-49$ & $0-36$ & $66-88$ \\
\hline & $\% \mathrm{RCH}$ & $82 \%$ & $85 \%$ & $82 \%$ \\
\hline \multicolumn{5}{|l|}{ Closantel } \\
\hline & IC95\% (LI-LS) & $58-92$ & $65-93$ & $60-92$ \\
\hline & $\% \mathrm{RCH}$ & $84 \%$ & $78 \%$ & $99 \%$ \\
\hline \multicolumn{5}{|l|}{ Levamisol } \\
\hline & IC95\% (LI-LS) & $62-93$ & $50-91$ & $98-100$ \\
\hline \multirow{2}{*}{$\begin{array}{c}\text { Fenbendazol + } \\
\text { Levamisol }\end{array}$} & $\% \mathrm{RCH}$ & $74 \%$ & $66 \%$ & $97 \%$ \\
\hline & IC95\% (LI-LS) & $51-86$ & $82-37$ & $94-98$ \\
\hline & $\% \mathrm{RCH}$ & $0 \%$ & $0 \%$ & $36 \%$ \\
\hline \multicolumn{5}{|l|}{ Fenbendazol } \\
\hline & IC95\% (LI-LS) & $0-28$ & $0-18$ & $0-65$ \\
\hline
\end{tabular}

Tabla 5: TRCH para el establecimiento "San Luis del Garabatá". 
En las tablas 6 a 9 se expresan los recuentos de HPG de la majada de entorno para las diferentes categorías y años.

\begin{tabular}{|c|c|c|c|c|c|c|c|c|c|c|c|c|}
\hline GENEROS & $E$ & $\mathrm{~F}$ & M & A & M & J & J & $A$ & $S$ & $\mathrm{O}$ & $\mathrm{N}$ & D \\
\hline \multicolumn{13}{|l|}{ OVEJAS 2014} \\
\hline HPG total (promedio) & 1100 & 169 & 2500 & 608 & 1121 & 820 & 3233 & 1744 & 1133 & 1630 & 1960 & - \\
\hline Mínimo & 0 & 0 & 0 & 0 & 0 & 0 & 0 & 0 & 0 & 0 & 100 & \\
\hline Máximo & 8900 & 1100 & 12600 & 3400 & 12200 & 3700 & 7300 & 5400 & 4600 & 11300 & 6500 & \\
\hline Haemonchus spp. & 979 & 164 & 2125 & 596 & 1098 & 754 & 3072 & 1726 & 680 & 1581 & 1960 & - \\
\hline $\begin{array}{l}\text { Trichostrongylus spp. } \\
\text { (Trichos. spp.) }\end{array}$ & 77 & 3 & 175 & 12 & 11 & 66 & 129 & 0 & 79 & 49 & 0 & - \\
\hline Ostertagia. spp. & 0 & 0 & 0 & 0 & 0 & 0 & 0 & 0 & 0 & 0 & 0 & - \\
\hline Cooperia spp. & 22 & 2 & 125 & 0 & 0 & 0 & 32 & 0 & 147 & 0 & 0 & - \\
\hline Nematodirus spp. & 22 & 0 & 75 & 0 & 11 & 0 & 0 & 17 & 227 & 0 & 0 & - \\
\hline $\begin{array}{l}\text { Oesophagostomum. } \\
\text { spp. (Oesoph. spp.) }\end{array}$ & 0 & 0 & 0 & 0 & 0 & 0 & 0 & 0 & 0 & 0 & 0 & - \\
\hline
\end{tabular}

Tabla 6: promedio de recuentos de HPG del muestreo mensual (detallando valores mínimos y máximos) y estimaciones proporcionales para cada género según los resultados de los coprocultivos en ovejas para los años 2014.

\begin{tabular}{|c|c|c|c|c|c|c|c|c|c|c|c|c|c|}
\hline GENEROS & $\mathrm{E}$ & $\mathrm{F}$ & $M$ & A & $M$ & $\mathrm{~J}$ & J & A & $S$ & 0 & $\mathrm{~N}$ & D & $\mathrm{E}$ \\
\hline \multicolumn{14}{|l|}{ OVEJAS 2015} \\
\hline HPG total (promedio) & - & 821 & 225 & 700 & 1300 & 1032 & 1000 & 458 & 1559 & 280 & 75 & 217 & 408 \\
\hline Mínimo & & 0 & 0 & 0 & 400 & 0 & 100 & 0 & 0 & 0 & 0 & 0 & c \\
\hline Máximo & & 8300 & 800 & 1700 & 2300 & 4400 & 2800 & 1400 & 3700 & 1100 & 200 & 700 & 2900 \\
\hline Haemonchus spp. & - & & 189 & 546 & 1183 & 607 & 730 & & 1213 & 243 & 53 & 43 & 408 \\
\hline Trichos. spp. & - & & 23 & 105 & 117 & 389 & 200 & & 299 & 25 & 21 & 150 & 0 \\
\hline Ostertagia. spp. & - & & 2 & 35 & 0 & 0 & 40 & & 16 & 0 & 0 & 0 & 0 \\
\hline Cooperia spp. & - & & 5 & 7 & 0 & 37 & 30 & & 16 & 0 & 0 & 0 & 0 \\
\hline Nematodirus spp. & - & & 0 & 0 & 0 & 0 & 0 & & 0 & 0 & 0 & 0 & 0 \\
\hline Oesoph. spp. & - & & 7 & 7 & 0 & 0 & 0 & & 16 & 12 & 1 & 24 & 0 \\
\hline
\end{tabular}


Tabla 7: promedio de recuentos de HPG del muestreo mensual (detallando valores mínimos y máximos) y estimaciones proporcionales para cada género según los resultados de los coprocultivos en ovejas para los años 2015. En los meses de febrero y agosto no se recuperaron larvas en los coprocultivos.

\begin{tabular}{|c|c|c|c|c|c|c|c|c|c|c|c|c|}
\hline GENEROS & E & $\mathrm{F}$ & M & A & M & J & J & $A$ & $S$ & 0 & $\mathrm{~N}$ & D \\
\hline \multicolumn{13}{|l|}{ CORDERAS 2014} \\
\hline HPG total (promedio) & 500 & 1067 & 573 & 937 & 910 & 1129 & 1070 & 638 & 300 & 125 & 2500 & - \\
\hline Mínimo & 0 & 0 & 0 & 0 & 0 & 0 & 100 & 0 & 0 & 0 & 0 & - \\
\hline Máximo & 2100 & 3600 & 2600 & 2900 & 2900 & 2600 & 2500 & 3600 & 1100 & 400 & 6500 & \\
\hline Haemonchus spp. & & 971 & 435 & 899 & 864 & 1073 & 1017 & 626 & 297 & & 1825 & - \\
\hline Trichos. spp. & & 21 & 92 & 9 & 27 & 23 & 32 & 13 & 0 & & 550 & - \\
\hline Ostertagia. spp. & & 0 & 0 & 0 & 0 & 0 & 0 & 0 & 0 & & 0 & - \\
\hline Cooperia spp. & & 75 & 34 & 28 & 18 & 11 & 22 & 0 & 3 & & 0 & - \\
\hline Nematodirus spp. & & 0 & 11 & 0 & 0 & 11 & 0 & 0 & 0 & & 125 & - \\
\hline Oesoph. spp. & & 0 & 0 & 0 & 0 & 11 & 0 & 0 & 0 & & 0 & - \\
\hline
\end{tabular}

Tabla 8: promedio de recuentos de HPG del muestreo mensual (detallando valores mínimos y máximos) y estimaciones proporcionales para cada género según los resultados de los coprocultivos en corderas del año 2014. En los meses de enero y octubre no se recuperaron larvas en los coprocultivos.

\begin{tabular}{lccccccccccccc}
\hline \multicolumn{1}{c}{ GENEROS } & E & $\mathrm{F}$ & $\mathrm{M}$ & $\mathrm{A}$ & $\mathrm{M}$ & $\mathrm{J}$ & $\mathrm{J}$ & $\mathrm{A}$ & $\mathrm{S}$ & $\mathrm{O}$ & $\mathrm{N}$ & $\mathrm{D}$ & $\mathrm{E}$ \\
\hline CORDERAS 2015 & & & & & & & & & & & & \\
\hline HPG total (promedio) & 2423 & 655 & 5808 & 1427 & 330 & 442 & 450 & 481 & 164 & 530 & 488 & 4306 & 8217 \\
\multicolumn{1}{c}{ Mínimo } & 300 & 0 & 1500 & 100 & 100 & 0 & 0 & 0 & 0 & 0 & 0 & 0 & 700 \\
\multicolumn{1}{c}{ Máximo } & 8200 & 2000 & 16500 & 4900 & 2200 & 1200 & 1500 & 900 & 700 & 3800 & 1800 & 15100 & 18400 \\
\hline Haemonchus spp. & 2108 & 531 & 5634 & 899 & 267 & 387 & 394 & 416 & 82 & 270 & 280 & 3961 & 6820 \\
Trichos. spp. & 291 & 118 & 174 & 528 & 63 & 55 & 56 & 65 & 70 & 223 & 198 & 172 & 1397 \\
Ostertagia. spp. & 24 & 0 & 0 & 0 & 0 & 0 & 0 & 0 & 3 & 24 & 5 & 43 & 0
\end{tabular}


Cooperia spp.

Nematodirus spp.

$0 \quad 0 \quad 0$

0

0

0

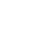

0

$0 \quad 0 \quad 0$

Oesoph. spp.

0
0

0

$\begin{array}{lllllll}0 & 0 & 0 & 0 & 0 & 0 & 0\end{array}$

$\begin{array}{llllllllllllll}0 & 7 & 0 & 0 & 0 & 0 & 0 & 0 & 8 & 13 & 5 & 129 & 0\end{array}$

Tabla 9: promedio de recuentos de HPG del muestreo mensual (detallando valores mínimos y máximos) y estimaciones proporcionales para cada género según los resultados de los coprocultivos en corderas del año 2015.

Los tratamientos aplicados en la majada de entorno se describen en el Gráfico 13. En ovejas en el primer año, se realizaron 3 tratamientos selectivos $\left(\mathrm{FAMACHA}^{\odot}\right)$ y 4 poblacionales, mientras que para el segundo año se aplicó 1 tratamiento selectivo $\left(\mathrm{FAMACHA}^{\circ}\right)$ y 3 poblacionales. En corderas, se realizaron en el primer año 4 tratamientos selectivos y 4 poblacionales, mientras que en el segundo 1 tratamiento selectivo y 4 poblacionales.

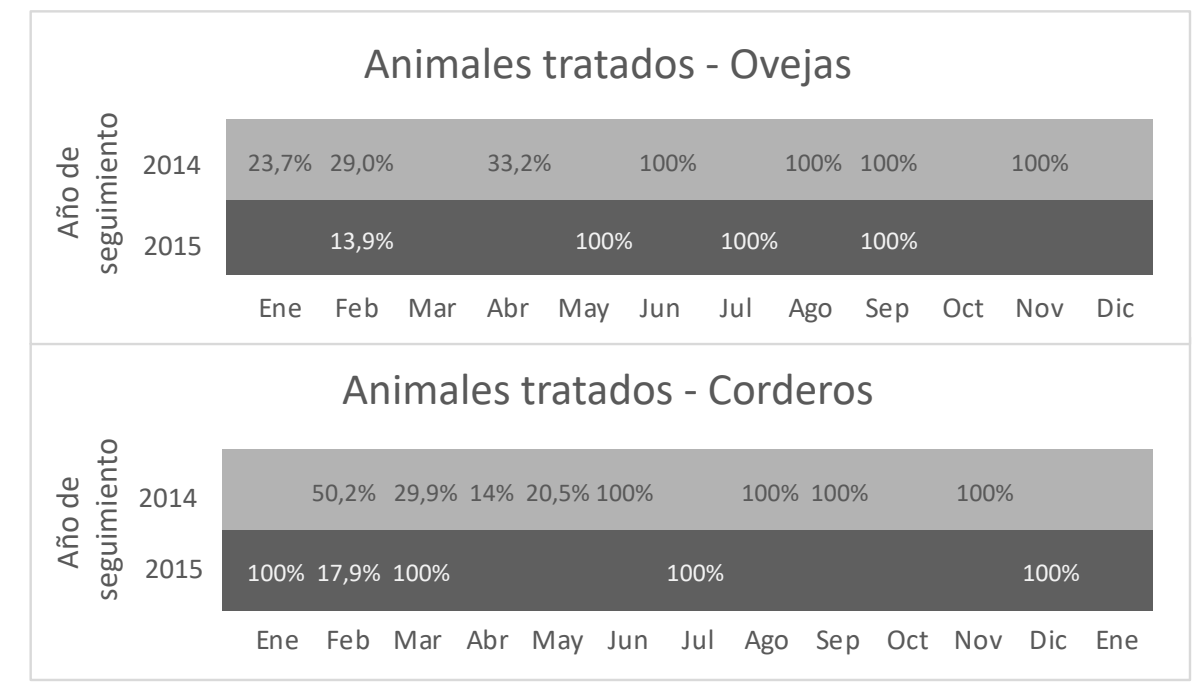

Gráfico 13: detalle mensual de los tratamientos para cada categoría y año, indicando el porcentaje de animales tratados en cada ocasión.

En la tabla 10, se muestran los resultados de los tratamientos por FAMACHA $^{\odot}$, donde se expresan las cantidades relativas para cada score. 


\begin{tabular}{|c|c|c|c|c|c|c|}
\hline \multirow{2}{*}{$\begin{array}{c}\text { AÑO Y } \\
\text { CATEGORÍA }\end{array}$} & \multirow{2}{*}{ MES } & \multicolumn{5}{|c|}{ ESCALA DE FAMACHA ${ }^{\odot}$} \\
\hline & & 1 & 2 & 3 & 4 & 5 \\
\hline \multirow{3}{*}{$\begin{array}{c}2014 \\
\text { Ovejas }\end{array}$} & Enero & $5,0 \%$ & $30,1 \%$ & $41,2 \%$ & $22,2 \%$ & $1,5 \%$ \\
\hline & Febrero & $0,4 \%$ & $13,1 \%$ & $57,5 \%$ & $29,0 \%$ & $0,0 \%$ \\
\hline & Abril & $1,2 \%$ & $15,4 \%$ & $50,2 \%$ & $32,0 \%$ & $1,2 \%$ \\
\hline \multirow{4}{*}{$\begin{array}{c}2014 \\
\text { Corderas }\end{array}$} & Febrero & $0,8 \%$ & $8,7 \%$ & $40,4 \%$ & $50,2 \%$ & $0,0 \%$ \\
\hline & Marzo & $1,1 \%$ & $19,4 \%$ & $49,6 \%$ & $29,5 \%$ & $0,4 \%$ \\
\hline & Abril & $4,0 \%$ & $27,6 \%$ & $54,4 \%$ & $14,0 \%$ & $0,0 \%$ \\
\hline & Mayo & $3,5 \%$ & $24,3 \%$ & $51,8 \%$ & $18,7 \%$ & $1,8 \%$ \\
\hline 2015 Ovejas & Febrero & $3,6 \%$ & $24,2 \%$ & $58,3 \%$ & $13,9 \%$ & $0,0 \%$ \\
\hline 2015 Corderas & Febrero & $0,2 \%$ & $20,6 \%$ & $61,3 \%$ & $17,2 \%$ & $0,7 \%$ \\
\hline
\end{tabular}

Tabla 10: distribución de animales según escala de $\mathrm{FAMACHA}^{\odot}$, resaltando los porcentajes de animales que recibieron tratamiento (score 4 y 5 ). Porcentajes aplicados sobre un lote de base de 100 corderas de recría y 150 ovejas para cada año.

\section{Variables meteorológicas}

El Gráfico 14 permite visualizar y comparar las precipitaciones y temperatura media de los dos años en estudio y del promedio histórico, mientras que en el gráfico 15 se observa el balance hídrico. 


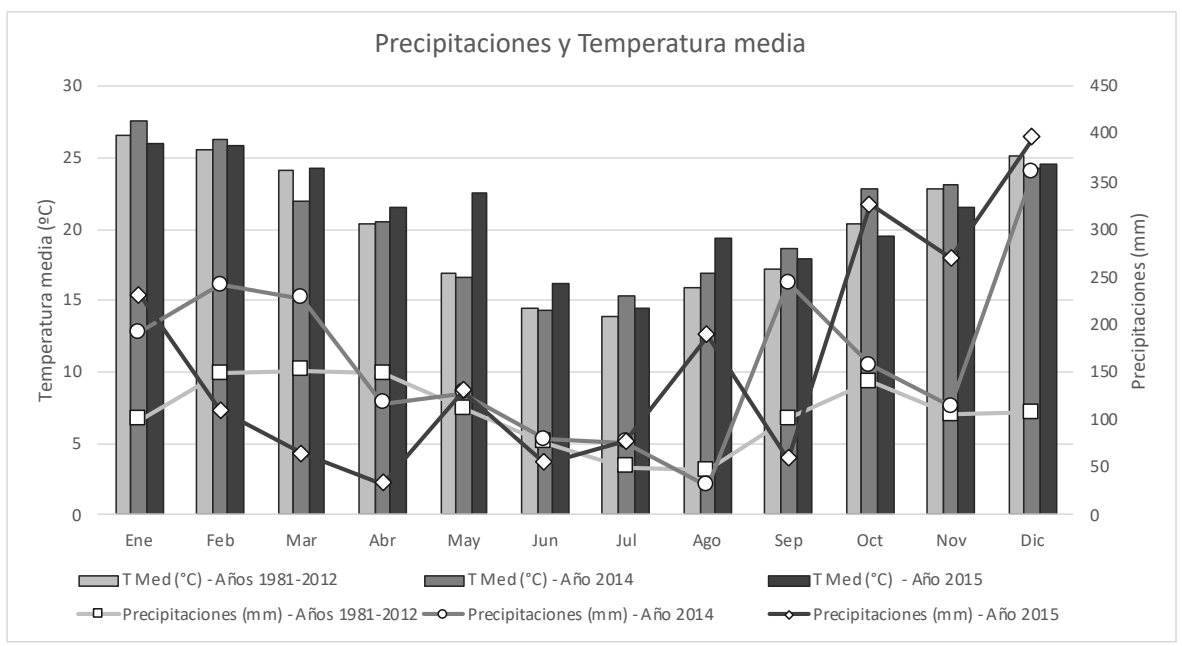

Gráfico 14: temperatura media y precipitaciones acumuladas para los dos años en estudio y la serie histórica.

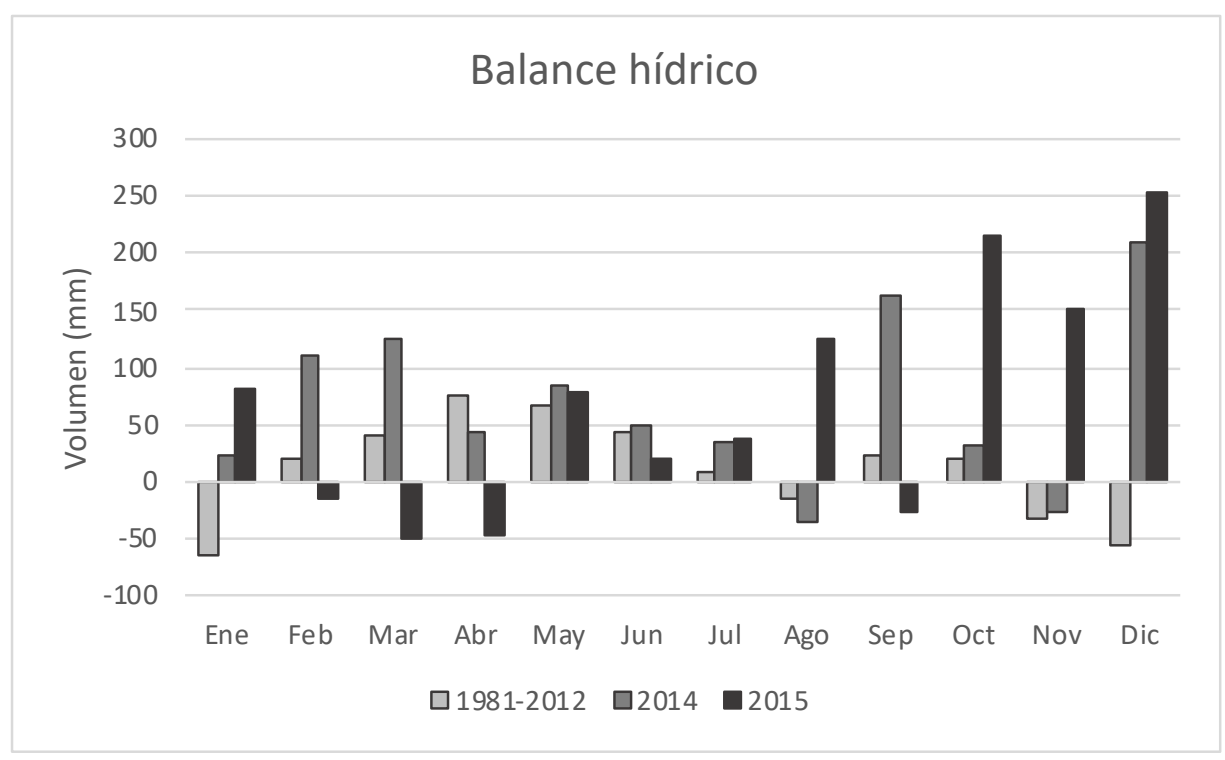

Gráfico 15: resultado del balance hídrico acumulado para los dos años en estudio y la serie histórica. Las mayores diferencias se observan en el primer y último cuatrimestre, con balances negativos y positivos respectivamente para el 2015.

Los registros meteorológicos completos de los años 2014 y 2015 se expresan en las tablas 11 y 12 respectivamente. 


\begin{tabular}{|c|c|c|c|c|c|c|c|c|c|c|c|c|c|}
\hline VARIBALE & $\mathrm{E}$ & $F$ & $M$ & A & $M$ & J & J & A & $S$ & 0 & $\mathrm{~N}$ & D & ANUAL \\
\hline $\begin{array}{l}\text { TMaxA } \\
\left({ }^{\circ} \mathrm{C}\right)\end{array}$ & 38,6 & 38,3 & 34,7 & 33,6 & 26,8 & 27,0 & 27,0 & 31,3 & 32,4 & 36,5 & 35,6 & 36,0 & 33,2 \\
\hline $\begin{array}{l}\text { TMMax } \\
\left({ }^{\circ} \mathrm{C}\right)\end{array}$ & 33,6 & 31,4 & 27,3 & 25,6 & 21,0 & 18,5 & 20,0 & 23,1 & 23,4 & 27,7 & 29,1 & 29,4 & 25,8 \\
\hline $\operatorname{TM}\left({ }^{\circ} \mathrm{C}\right)$ & 27,6 & 26,2 & 21,9 & 20,6 & 16,6 & 14,4 & 15,3 & 17,0 & 18,7 & 22,9 & 23,2 & 24,2 & 20,7 \\
\hline $\begin{array}{l}\text { TMMin } \\
\left({ }^{\circ} \mathrm{C}\right)\end{array}$ & 21,7 & 21,0 & 16,6 & 15,5 & 12,2 & 10,2 & 10,6 & 10,9 & 14,0 & 18,0 & 17,2 & 19,1 & 15,6 \\
\hline $\operatorname{TMin} A\left({ }^{\circ} \mathrm{C}\right)$ & 14,2 & 14,0 & 8,8 & 7,5 & 4,0 & 1,6 & 2,4 & 1,0 & 10,0 & 12,5 & 11,8 & 14,8 & 8,6 \\
\hline HM (días) & 0 & 0 & 0 & 0 & 0 & 0 & 0 & 0 & 0 & 0 & 0 & 0 & 0 \\
\hline PA (mm) & 191 & 241 & 227 & 118 & 128 & 79 & 76 & 31 & 244 & 157 & 114 & 360 & 1964 \\
\hline DP (días) & 8 & 9 & 9 & 9 & 9 & 9 & 9 & 4 & 14 & 10 & 5 & 12 & 107 \\
\hline $\begin{array}{l}\text { HRMax } \\
(\%)\end{array}$ & 93,0 & 92,8 & 94,6 & 94,9 & 97,4 & 97,1 & 96,3 & 92,5 & 95,2 & 91,9 & 93,0 & 93,7 & 94,4 \\
\hline HRM (\%) & 70,2 & 72,9 & 74,4 & 77,1 & 82,4 & 82,5 & 79,9 & 70,6 & 77,1 & 75,0 & 70,5 & 74,7 & 75,6 \\
\hline HRMin (\%) & 47,3 & 53,1 & 54,2 & 59,3 & 67,3 & 67,8 & 63,5 & 48,7 & 59,0 & 58,0 & 47,9 & 55,6 & 56,8 \\
\hline $\mathrm{HE}(\mathrm{Hs})$ & 8,1 & 7,3 & 6,5 & 6,3 & 4,8 & 3,6 & 4,9 & 7,5 & 4,8 & 5,9 & 8,3 & 6,8 & 6,2 \\
\hline HEA (Hs) & 252 & 205 & 201 & 188 & 149 & 109 & 152 & 234 & 143 & 182 & 248 & 212 & 2275 \\
\hline $\begin{array}{l}\text { ETPA } \\
(\mathrm{mm})\end{array}$ & 168 & 130 & 103 & 73 & 43 & 31 & 40 & 67 & 80 & 124 & 140 & 149 & 1152 \\
\hline $\begin{array}{l}\text { ALmT } \\
(\mathrm{mm})\end{array}$ & 94,8 & 150,7 & 151,0 & 147,5 & 159,2 & 158,5 & 156,1 & 142,5 & 154,1 & 149,1 & 123,1 & 153,8 & 145,0 \\
\hline $\mathrm{BHM}(\mathrm{mm})$ & 23 & 111 & 124 & 44 & 84 & 48 & 36 & -37 & 164 & 33 & -26 & 211 & 811 \\
\hline
\end{tabular}

Tabla 11: registros meteorológicos para el año 2014, departamento de Paso de los Libres, Corrientes, Argentina. 


\begin{tabular}{|c|c|c|c|c|c|c|c|c|c|c|c|c|c|}
\hline VARIABLE & $E$ & $F$ & M & A & $\mathrm{M}$ & J & J & A & $S$ & $\mathrm{O}$ & $N$ & D & ANUAL \\
\hline $\begin{array}{l}\text { TMaxA } \\
\left({ }^{\circ} \mathrm{C}\right)\end{array}$ & 36,3 & 34,8 & 34,5 & 32,3 & 29,2 & 29,0 & 30,4 & 35,3 & 31,6 & 33,6 & 31,3 & 34,5 & 32,7 \\
\hline $\begin{array}{l}\text { TMMax } \\
\left({ }^{\circ} \mathrm{C}\right)\end{array}$ & 31,0 & 30,9 & 29,9 & 27,8 & 23,0 & 21,1 & 18,7 & 24,1 & 23,8 & 24,1 & 25,9 & 29,1 & 25,8 \\
\hline $\operatorname{TM}\left({ }^{\circ} \mathrm{C}\right)$ & 26,0 & 25,8 & 24,3 & 21,5 & 22,5 & 16,3 & 14,5 & 19,4 & 17,9 & 19,5 & 21,5 & 24,5 & 21,1 \\
\hline $\begin{array}{l}\text { TMMin } \\
\left({ }^{\circ} \mathrm{C}\right)\end{array}$ & 21,0 & 20,7 & 18,7 & 15,1 & 8,3 & 11,4 & 10,3 & 15,0 & 11,9 & 14,6 & 17,1 & 20,0 & 15,4 \\
\hline $\operatorname{TMin} \mathrm{A}\left({ }^{\circ} \mathrm{C}\right)$ & 14,9 & 16,1 & 11,8 & 10,2 & 7,9 & $-0,2$ & 2,0 & 8,5 & 1,0 & 7,6 & 12,2 & 14,0 & 8,8 \\
\hline HM (días) & 0 & 0 & 0 & 0 & 0 & 1 & 0 & 0 & 0 & 0 & 0 & 0 & 1 \\
\hline $\mathrm{PA}(\mathrm{mm})$ & 231 & 110 & 64 & 33 & 130 & 54 & 77 & 188 & 59 & 325 & 269 & 396 & 1935 \\
\hline DP (días) & 13 & 7 & 5 & 2 & 5 & 9 & 7 & 12 & 4 & 13 & 13 & 11 & 101 \\
\hline HRMax (\%) & 94,4 & 94,4 & 93,2 & 93,3 & 96,5 & 96,1 & 96,6 & 92,9 & 92,2 & 92,0 & 92,0 & 94,7 & 94,0 \\
\hline HRM (\%) & 75,8 & 75,3 & 73,2 & 69,7 & 78,8 & 78,4 & 82,3 & 77,1 & 71,0 & 75,7 & 75,7 & 77,4 & 75,8 \\
\hline HRMin (\%) & 57,2 & 56,1 & 53,3 & 46,0 & 61,0 & 60,8 & 67,9 & 61,3 & 49,8 & 59,3 & 59,3 & 60,2 & 57,7 \\
\hline $\mathrm{HE}(\mathrm{Hs})$ & 7,6 & 8,0 & 7,2 & 8,0 & 5,2 & 4,2 & 3,4 & 4,6 & 5,4 & 4,9 & 7,1 & 6,1 & 6,0 \\
\hline HEA (Hs) & 237 & 223 & 222 & 241 & 162 & 126 & 104 & 141 & 161 & 152 & 207 & 188 & 2163 \\
\hline $\begin{array}{l}\text { ETPA } \\
(\mathrm{mm})\end{array}$ & 151 & 126 & 113 & 81 & 51 & 35 & 39 & 65 & 85 & 111 & 117 & 143 & 1119 \\
\hline $\begin{array}{l}\text { ALmT } \\
(\mathrm{mm})\end{array}$ & 152,3 & 130,3 & 124,3 & 108,9 & 142,3 & 153,6 & 156,4 & 154,6 & 123,7 & 157,8 & 156,4 & 159,3 & 143,3 \\
\hline $\mathrm{BHM}(\mathrm{mm})$ & 80 & -16 & -49 & -48 & 79 & 19 & 38 & 123 & -26 & 214 & 152 & 253 & 817 \\
\hline
\end{tabular}

Tabla 12: registros meteorológicos para el año 2015, departamento de Paso de los Libres, Corrientes, Argentina.

Se realizaron comparaciones, considerando como factor el año y el trimestre y como variables dependientes a los diferentes parámetros meteorológicos.

En el análisis anual se observaron diferencias significativas $(p<0,05)$ para la temperatura mínima, humedad (en todas las mediciones) y almacenaje total, registrando mayores valores en los 
años de estudio respecto a la serie histórica. El resto de los parámetros estudiados no mostró diferencias significativas.

El análisis trimestral demostró estacionalidad con diferencias estadísticas $(p<0,05)$, para la temperatura (todas las mediciones), humedad (todas las mediciones) y heliofania acumulada. La evapotranspiración expresó estacionalidad en los dos años de estudios y no en la serie histórica. El almacenaje total y las precipitaciones mostraron estacionalidad únicamente en el año 2015.

Cuando comparamos los diferentes trimestres entre años (Tabla 13), observamos diferencias significativas $(p<0,05)$ en todos los trimestres, para la humedad y almacenaje total. En los trimestres 2 y 3 para la temperatura (máxima y mínima respectivamente) y la heliofania y en el trimestre 4 la temperatura (media, media mínima y media máxima) y la evapotranspiración. 


\begin{tabular}{|c|c|c|c|c|c|c|c|c|c|c|c|c|}
\hline \multicolumn{13}{|c|}{ COMPARACIÓN DE VARIABLES METEOROLÓTICAS ENTRE AÑOS PARA CADA TRIMESTRE } \\
\hline \multirow{2}{*}{ VARIABLE } & \multicolumn{3}{|c|}{ TRIMESTRE 1} & \multicolumn{3}{|c|}{ TRIMESTRE 2} & \multicolumn{3}{|c|}{ TRIMESTRE 3} & \multicolumn{3}{|c|}{ TRIMESTRE 4} \\
\hline & 1981 & 2014 & 2015 & 1981 & 2014 & 2015 & 1981 & 2014 & 2015 & 1981 & 2014 & 2015 \\
\hline TMMax $\left({ }^{\circ} \mathrm{C}\right)$ & $31,1 \mathrm{a}$ & $30,7 \mathrm{a}$ & 30,6 a & 22,3 a & 21,7 a & $24 \mathrm{~b}$ & $21,1 \mathrm{a}$ & $22,2 \mathrm{a}$ & $22,2 \mathrm{a}$ & 28,5 a & 28,7 a & $26,3 \mathrm{~b}$ \\
\hline $\operatorname{TM}\left({ }^{\circ} \mathrm{C}\right)$ & $25,4 \mathrm{a}$ & $25,2 \mathrm{a}$ & $25,4 \mathrm{a}$ & 17,2 a & $17,2 \mathrm{a}$ & $18,6 \mathrm{~b}$ & $15,7 \mathrm{a}$ & $17 \mathrm{~b}$ & $17,3 \mathrm{~b}$ & 22,7 a & 23,4 a & $21,8 \mathrm{~b}$ \\
\hline $\operatorname{TMMin}\left({ }^{\circ} \mathrm{C}\right)$ & $19,7 \mathrm{a}$ & $19,7 \mathrm{a}$ & $20,1 \mathrm{a}$ & $12,2 \mathrm{a}$ & $12,6 \mathrm{a}$ & $13 \mathrm{a}$ & $10,3 \mathrm{a}$ & $11,8 \mathrm{~b}$ & $12,4 \mathrm{~b}$ & $16,9 \mathrm{a}$ & $18,1 \mathrm{~b}$ & $17,3 \mathrm{a}$ \\
\hline HM (días) & $0 \mathrm{a}$ & $0 \mathrm{a}$ & $0 \mathrm{a}$ & $0,5 \mathrm{a}$ & $0 \mathrm{a}$ & $1 \mathrm{a}$ & $1,2 \mathrm{a}$ & $0 \mathrm{a}$ & $0 \mathrm{a}$ & $0 \mathrm{a}$ & $0 \mathrm{a}$ & $0 \mathrm{a}$ \\
\hline $\mathrm{PA}(\mathrm{mm})$ & 399 a & $660 \mathrm{a}$ & $405 \mathrm{a}$ & $336 a$ & 325 a & $218 \mathrm{a}$ & $198 \mathrm{a}$ & $351 \mathrm{a}$ & 325 a & $351 \mathrm{a}$ & $630 \mathrm{a}$ & $991 \mathrm{a}$ \\
\hline DP (días) & $23,4 \mathrm{a}$ & $26 a$ & $25 \mathrm{a}$ & $23,7 a$ & $27 a$ & $16 \mathrm{a}$ & $20,8 \mathrm{a}$ & $27 a$ & $23 \mathrm{a}$ & $24,4 \mathrm{a}$ & $27 a$ & $37 a$ \\
\hline HRMax (\%) & 89,4 a & $93,5 \mathrm{~b}$ & $94,0 \mathrm{~b}$ & $94,2 \mathrm{a}$ & $96,5 \mathrm{c}$ & $95,3 \mathrm{~b}$ & 91,7 a & $94,7 \mathrm{~b}$ & $93,9 \mathrm{~b}$ & $88,0 \mathrm{a}$ & $92,9 \mathrm{~b}$ & $92,9 \mathrm{~b}$ \\
\hline HRM (\%) & 69,6 a & $72,5 \mathrm{~b}$ & $74,7 \mathrm{c}$ & 76,7 a & 80,7 b & 75,6 a & $73,1 \mathrm{a}$ & $75,9 \mathrm{~b}$ & $76,8 \mathrm{~b}$ & $68,0 a$ & $73,4 \mathrm{~b}$ & $76,2 \mathrm{c}$ \\
\hline HRMin (\%) & $49,7 \mathrm{a}$ & 51,5 a & $55,5 \mathrm{~b}$ & 59,2 a & $64,8 \mathrm{~b}$ & 56,0 a & 54,3 a & $57,0 \mathrm{ab}$ & $59,8 \mathrm{~b}$ & $48,3 a$ & $53,9 \mathrm{~b}$ & $59,6 \mathrm{c}$ \\
\hline HEA (Hs) & $215 \mathrm{a}$ & $219 a$ & $227 a$ & 144 a & 149 a & $176 \mathrm{~b}$ & 150 a & $176 \mathrm{~b}$ & $135 a$ & $217 a$ & $214 \mathrm{a}$ & $182 \mathrm{a}$ \\
\hline ETPA (mm) & $403 a$ & $402 \mathrm{a}$ & $390 \mathrm{a}$ & $150 \mathrm{a}$ & $148 a$ & $167 a$ & $183 \mathrm{a}$ & $187 a$ & $188 \mathrm{a}$ & $423 \mathrm{~b}$ & $413 \mathrm{~b}$ & 371 a \\
\hline $\operatorname{ALmT}(\mathrm{mm})$ & 119 a & $132 \mathrm{~b}$ & $136 \mathrm{~b}$ & $149 \mathrm{~b}$ & $155 \mathrm{c}$ & 135 a & 143 a & $151 \mathrm{~b}$ & $145 \mathrm{a}$ & 128 a & 142 b & $158 \mathrm{c}$ \\
\hline
\end{tabular}

Letras diferentes expresan diferencias significativas $(p<0,05)$.

Tabla 13: comparación estadística de los parámetros meteorológicos entre años para los diferentes trimestres.

Comparando los dos años de estudio, el 2015 presentó temperaturas más altas y bajas en la primera y segunda mitad del año respectivamente. Las precipitaciones del primer trimestre en el año 2014 registraron valores mínimos en agosto, mientras que en el 2015 fueron en marzo y abril. En tanto, el balance hídrico resultó negativo entre febrero y abril de 2015, a diferencia del año anterior para ese período. Las abundantes precipitaciones de primavera del 2015 invierten esta tendencia para finalizar el año con valores anualizados similares. 
Cuando se construyeron los bioclimatogramas (gráfico 15 y 16), se observó en los años 2014 y 2015, que agosto y abril respectivamente, presentaron condiciones fuera de los parámetros considerados favorables para $H$. contortus, por bajas precipitaciones (que en el 2015 se potencian con los meses previos de balance hídrico negativo) y los extremos de temperatura se observaron en enero y febrero 2014 (superando los $25^{\circ} \mathrm{C}$ de temperatura media). Se observan valores elevados de precipitaciones en los meses diciembre en ambos años y en el 2015 también para octubre, noviembre y enero.
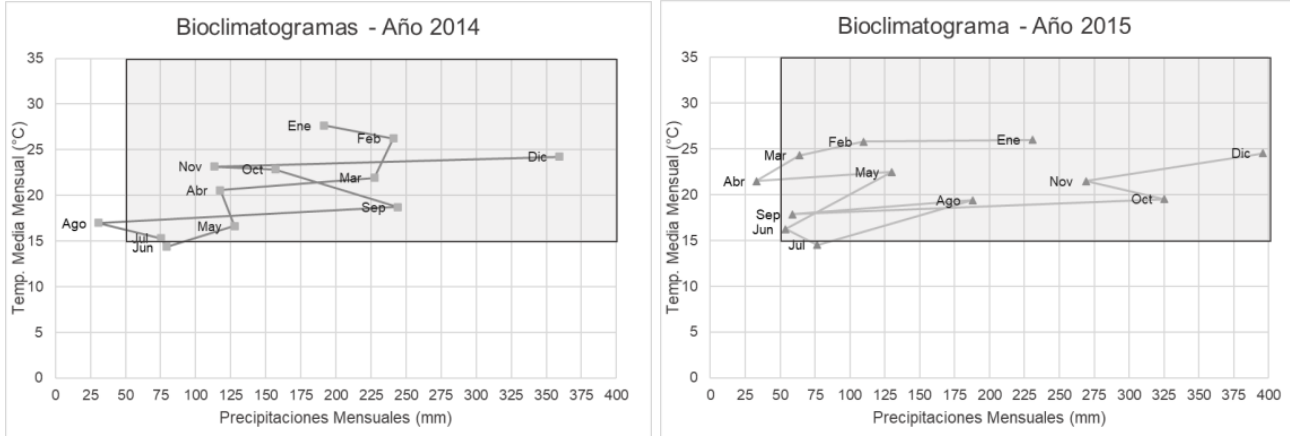

Gráfico 15 y 16: bioclimatogramas comparados para los dos años de estudio, marcando el límite descripto para precipitaciones y temperatura. 
3. Estudio de cargas parasitarias

En la tabla 14 se presenta un esquema de los animales sacrificados por categoría.

\begin{tabular}{|c|c|c|c|c|c|c|c|c|c|c|c|c|c|c|}
\hline \multirow{2}{*}{$\begin{array}{c}\text { ESTABLECIMIENTO Y } \\
\text { AÑO }\end{array}$} & \multirow{2}{*}{ CATEGORÍA } & \multicolumn{13}{|c|}{ CANTIDAD DE ANIMALES SACRIFICADOS } \\
\hline & & $\mathrm{E}$ & $\mathrm{F}$ & M & A & M & J & $\mathrm{J}$ & $A$ & $S$ & 0 & $\mathrm{~N}$ & D & $\mathrm{E}$ \\
\hline \multirow{4}{*}{$\begin{array}{l}\text { La Aurora } \\
2014\end{array}$} & Oveja & 2 & 2 & 2 & 2 & 2 & 2 & 2 & 2 & 2 & 2 & 2 & 1 & 0 \\
\hline & & & & & & & & & & & & & & \\
\hline & ovicto & 2 & 2 & 2 & 2 & 2 & 2 & 2 & 2 & 2 & 2 & 2 & 0 & 0 \\
\hline & Trazador & 2 & 2 & 2 & 2 & 2 & 2 & 1 & 2 & 2 & 2 & 2 & 2 & 0 \\
\hline \multirow{4}{*}{$\begin{array}{c}\text { San Luis } \\
2015\end{array}$} & Oveja & 0 & 2 & 2 & 2 & 2 & 2 & 2 & 2 & 2 & 2 & 2 & 2 & 2 \\
\hline & & & & & & & & & & & & & & \\
\hline & & & & & & & & & & & & & & \\
\hline & Trazador & 0 & 2 & 2 & 2 & 2 & 2 & 2 & 2 & 1 & 2 & 2 & 2 & 2 \\
\hline
\end{tabular}

Tabla 14: detalle de animales sacrificados por categoría y por mes para cada año de estudio.

En el año 2014, los meses de julio y diciembre (trazadores y ovejas), hubo faltantes para el protocolo descripto debido al robo de los animales seleccionados e identificados para tal fin. En el año 2015 en el mes de septiembre se murió uno de los animales preparados como trazadores para ese período. Por otro lado, el cambio de campo implicó faltantes de animales en el final del primer año (corderos permanentes) e inicio del segundo año (ovejas permanentes y trazadores), por esto, en el segundo año de estudio, se extendieron por un mes las observaciones (hasta enero 2016). 
4. Recuentos parasitarios por necropsia en animales permanentes

Los recuentos parasitarios en ovejas y corderas se observan en los gráficos 17 y 18 y en las tablas 15 a 18.

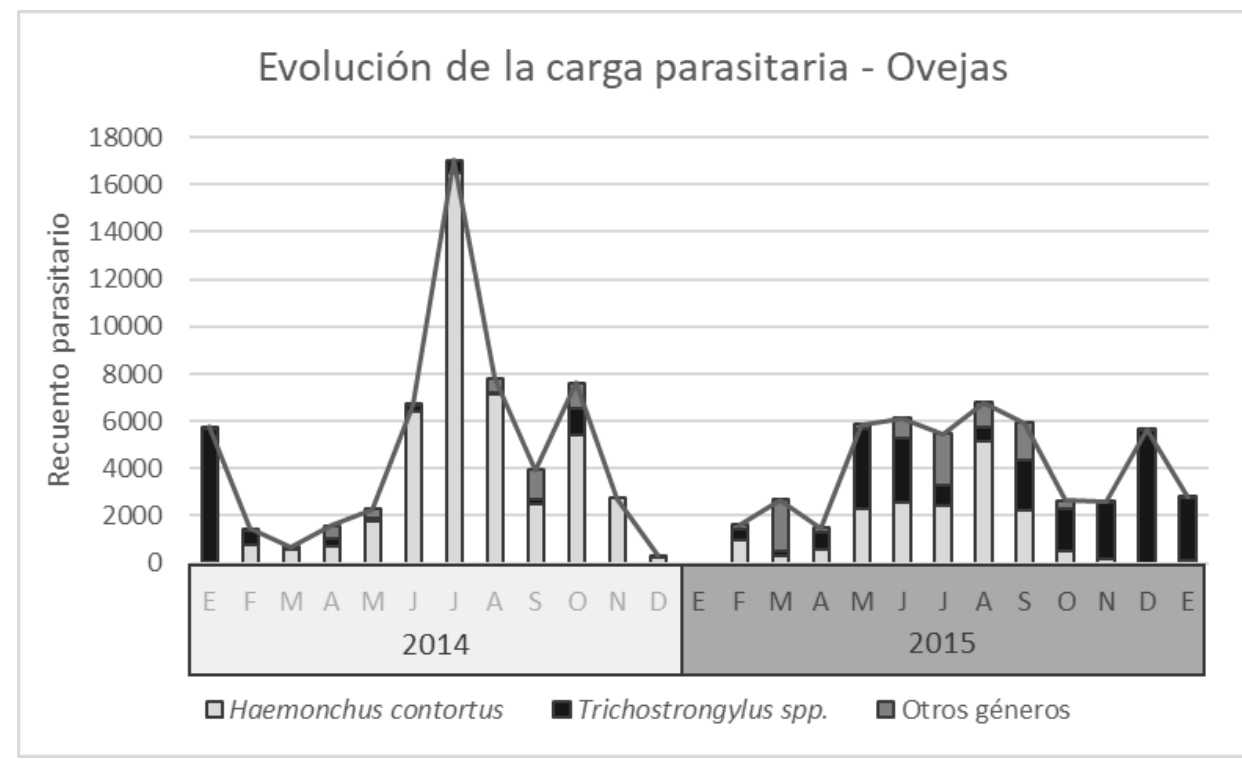

Gráfico 17: distribución anual de los recuentos parasitarios mensuales acumulados, para los diferentes géneros, en ovejas para los años 2014 y 2015. Sólo se detallan los géneros principales ( $H$. contortus y $T$. colubriformis) agrupando los demás géneros para la representación gráfica.

\begin{tabular}{|c|c|c|c|c|c|c|c|c|c|c|c|c|}
\hline GENEROS & $\mathrm{E}$ & $\mathrm{F}$ & $M$ & $A$ & $M$ & J & J & A & $S$ & 0 & $\mathrm{~N}$ & D \\
\hline \multicolumn{13}{|l|}{ OVEJAS 2014} \\
\hline Parásitos totales & 5750 & 1445 & 700 & 1575 & 2285 & 6700 & 17025 & 7815 & 3952 & 7600 & 2745 & 319 \\
\hline H. contortus & 50 & 770 & 575 & 700 & 1775 & 6375 & 16475 & 7133 & 2526 & 5400 & 2745 & 269 \\
\hline Trichos. spp. & 5625 & 575 & 25 & 325 & 155 & 275 & 550 & 50 & 200 & 1125 & 0 & 0 \\
\hline T. colubriformis & 5625 & 538 & 25 & 175 & 155 & 200 & 400 & 50 & 200 & 1125 & 0 & 0 \\
\hline T. axei & 0 & 38 & 0 & 150 & 0 & 75 & 150 & 0 & 0 & 0 & 0 & 0 \\
\hline T. circumcincta & 0 & 0 & 0 & 0 & 0 & 0 & 0 & 0 & 0 & 0 & 0 & 0 \\
\hline S. papillosus & 0 & 100 & 100 & 375 & 180 & 50 & 0 & 17 & 50 & 0 & 0 & 50 \\
\hline Cooperia spp. & 0 & 0 & 0 & 175 & 10 & 0 & 0 & 17 & 201 & 225 & 0 & 0 \\
\hline C. punctata & 0 & 0 & 0 & 175 & 10 & 0 & 0 & 17 & 151 & 113 & 0 & 0 \\
\hline
\end{tabular}




$\begin{array}{lcccccccccccc}\quad \text { C. pectinata } & 0 & 0 & 0 & 0 & 0 & 0 & 0 & 0 & 51 & 113 & 0 & 0 \\ \text { N. spathiger } & 75 & 0 & 0 & 0 & 165 & 0 & 0 & 599 & 975 & 850 & 0 & 0 \\ \text { Trichuris ovis } & 0 & 0 & 0 & 0 & 0 & 0 & 0 & 0 & 0 & 0 & 0 & 0 \\ \text { Oesoph. spp. } & 0 & 0 & 0 & 0 & 0 & 0 & 0 & 0 & 0 & 0 & 0 & 0 \\ \text { O. venulosum } & 0 & 0 & 0 & 0 & 0 & 0 & 0 & 0 & 0 & 0 & 0 & 0 \\ \text { O. radiatum } & 0 & 0 & 0 & 0 & 0 & 0 & 0 & 0 & 0 & 0 & 0 & 0\end{array}$

Tabla 15: promedio de los recuentos parasitarios obtenidos por necropsia en los animales sacrificados para cada mes en ovejas durante el año 2014.

\begin{tabular}{|c|c|c|c|c|c|c|c|c|c|c|c|c|}
\hline GENEROS & $\mathrm{F}$ & $M$ & $A$ & $M$ & J & J & A & $S$ & 0 & $\mathrm{~N}$ & D & $\mathrm{E}$ \\
\hline \multicolumn{13}{|l|}{ OVEJAS 2015} \\
\hline Parásitos totales & 1625 & 2675 & 1480 & 5855 & 6126 & 5475 & 6775 & 5925 & 2630 & 2565 & 5638 & 2785 \\
\hline H. contortus & 975 & 275 & 550 & 2305 & 2550 & 2450 & 5175 & 2250 & 525 & 175 & 0 & 125 \\
\hline Trichos. spp. & 450 & 225 & 780 & 3375 & 2700 & 820 & 575 & 2075 & 1780 & 2365 & 5613 & 2620 \\
\hline T. colubriformis & 450 & 225 & 775 & 3375 & 2525 & 500 & 525 & 2000 & 825 & 1175 & 5500 & 2525 \\
\hline T. axei & 0 & 0 & 5 & 0 & 175 & 320 & 50 & 75 & 955 & 1190 & 113 & 95 \\
\hline T. circumcincta & 0 & 0 & 0 & 0 & 50 & 30 & 700 & 25 & 150 & 0 & 0 & 0 \\
\hline S. papillosus & 0 & 0 & 25 & 0 & 0 & 0 & 0 & 0 & 0 & 0 & 0 & 0 \\
\hline Cooperia spp. & 125 & 2150 & 100 & 125 & 751 & 2175 & 300 & 1500 & 175 & 25 & 0 & 0 \\
\hline C. punctata & 125 & 2075 & 34 & 113 & 582 & 1961 & 300 & 1048 & 175 & 25 & 0 & 0 \\
\hline C. pectinata & 0 & 75 & 67 & 13 & 169 & 215 & 0 & 452 & 0 & 0 & 0 & 0 \\
\hline N. spathiger & 75 & 25 & 25 & 50 & 25 & 0 & 0 & 0 & 0 & 0 & 0 & 0 \\
\hline Trichuris ovis & 0 & 0 & 0 & 0 & 0 & 0 & 25 & 0 & 0 & 0 & 0 & 25 \\
\hline Oesoph. spp. & 0 & 0 & 0 & 0 & 50 & 0 & 0 & 75 & 0 & 0 & 25 & 15 \\
\hline O. venulosum & 0 & 0 & 0 & 0 & 50 & 0 & 0 & 75 & 0 & 0 & 25 & 5 \\
\hline O. radiatum & 0 & 0 & 0 & 0 & 0 & 0 & 0 & 0 & 0 & 0 & 0 & 10 \\
\hline
\end{tabular}

Tabla 16: promedio de los recuentos parasitarios obtenidos por necropsia en los animales sacrificados para cada mes en ovejas durante el año 2015. 


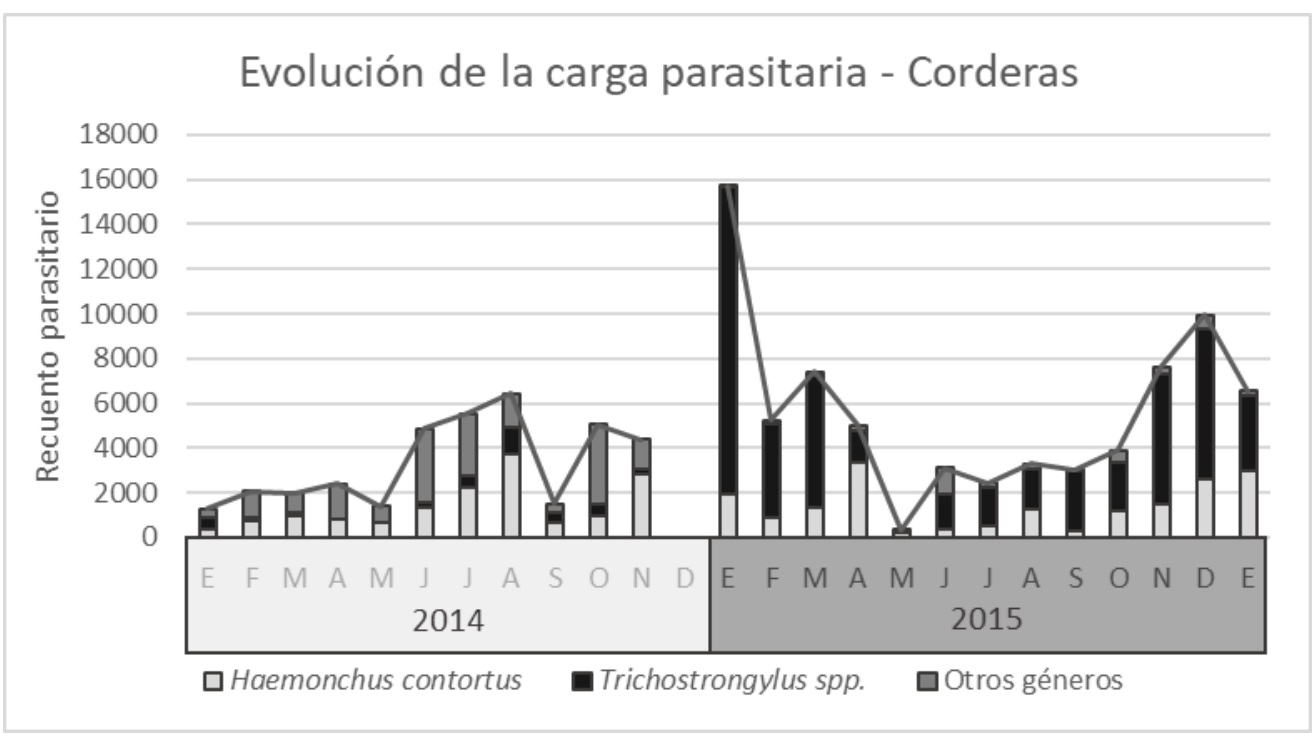

Gráfico 18: distribución anual de los recuentos parasitarios mensuales acumulados, para los diferentes géneros, en corderas para los años 2014 y 2015. Sólo se detallan los géneros principales ( $H$. contortus y $T$. colubriformis) agrupando los demás géneros para la representación gráfica.

\begin{tabular}{|c|c|c|c|c|c|c|c|c|c|c|c|c|}
\hline GENEROS & $E$ & $\mathrm{~F}$ & $M$ & A & $M$ & J & J & A & $S$ & 0 & $\mathrm{~N}$ & $\mathrm{D}$ \\
\hline \multicolumn{13}{|l|}{ CORDERAS 2014} \\
\hline Parásitos totales & 1270 & 2075 & 1975 & 2400 & 1400 & 4875 & 5551 & 6450 & 1500 & 5060 & 4375 & - \\
\hline H. contortus & 360 & 750 & 950 & 775 & 650 & 1300 & 2251 & 3750 & 675 & 960 & 2850 & - \\
\hline Trichos. spp. & 500 & 125 & 150 & 0 & 25 & 250 & 475 & 1175 & 450 & 525 & 200 & - \\
\hline T. colubriformis & 500 & 125 & 150 & 0 & 25 & 250 & 475 & 1175 & 425 & 525 & 200 & - \\
\hline T. axei & 0 & 0 & 0 & 0 & 0 & 0 & 0 & 0 & 25 & 0 & 0 & \\
\hline T. circumcincta & 0 & 0 & 0 & 0 & 0 & 0 & 0 & 0 & 0 & 0 & 0 & - \\
\hline S. papillosus & 300 & 375 & 775 & 700 & 625 & 2600 & 1875 & 1000 & 375 & 500 & 50 & - \\
\hline Cooperia spp. & 0 & 675 & 100 & 825 & 50 & 300 & 625 & 0 & 0 & 200 & 475 & - \\
\hline C. punctata & 0 & 129 & 100 & 763 & 25 & 300 & 278 & 0 & 0 & 200 & 475 & - \\
\hline C. pectinata & 0 & 547 & 0 & 63 & 25 & 0 & 348 & 0 & 0 & 0 & 0 & \\
\hline N. spathiger & 50 & 100 & 0 & 75 & 50 & 400 & 325 & 525 & 0 & 2875 & 800 & - \\
\hline Trichuris ovis & 60 & 50 & 0 & 25 & 0 & 25 & 0 & 0 & 0 & 0 & 0 & - \\
\hline Oesoph. spp. & 0 & 0 & 0 & 0 & 0 & 0 & 0 & 0 & 0 & 0 & 0 & - \\
\hline
\end{tabular}


O. venulosum

O. radiatum

Tabla 17: promedio de los recuentos parasitarios obtenidos por necropsia en los animales sacrificados para cada mes en corderas durante el año 2014.

\begin{tabular}{|c|c|c|c|c|c|c|c|c|c|c|c|c|c|}
\hline GENEROS & $E$ & $F$ & M & A & $\mathrm{M}$ & $\mathrm{J}$ & J & $A$ & $\mathrm{~S}$ & $\mathrm{O}$ & $\mathrm{N}$ & D & $E$ \\
\hline \multicolumn{14}{|l|}{ CORDERAS 2015} \\
\hline Parásitos totales & 15725 & 5255 & 7400 & 5010 & 355 & 3110 & 2420 & 3292 & 3020 & 3880 & 7615 & 9960 & 6550 \\
\hline H. contortus & 1955 & 905 & 1350 & 3350 & 200 & 350 & 530 & 1265 & 280 & 1200 & 1510 & 2585 & 3010 \\
\hline Trichos. spp. & 13690 & 4200 & 5900 & 1435 & 50 & 1550 & 1730 & 1760 & 2715 & 2180 & 5830 & 6710 & 3340 \\
\hline T. colubriformis & 13675 & 4200 & 5900 & 1435 & 25 & 1550 & 1580 & 1685 & 2665 & 2075 & 5755 & 6700 & 3255 \\
\hline T. axei & 15 & 0 & 0 & 0 & 25 & 0 & 150 & 75 & 50 & 105 & 75 & 10 & 85 \\
\hline T. circumcincta & 55 & 50 & 125 & 0 & 5 & 310 & 0 & 142 & 0 & 25 & 75 & 615 & 100 \\
\hline S. papillosus & 0 & 0 & 0 & 75 & 50 & 0 & 100 & 0 & 13 & 0 & 0 & 0 & 0 \\
\hline Cooperia spp. & 0 & 50 & 0 & 0 & 50 & 800 & 30 & 75 & 0 & 450 & 125 & 0 & 0 \\
\hline C. punctata & 0 & 50 & 0 & 0 & 50 & 578 & 24 & 75 & 0 & 450 & 125 & 0 & 0 \\
\hline C. pectinata & 0 & 0 & 0 & 0 & 0 & 222 & 7 & 0 & 0 & 0 & 0 & 0 & 0 \\
\hline N. spathiger & 0 & 0 & 0 & 0 & 0 & 0 & 5 & 0 & 13 & 25 & 50 & 0 & 0 \\
\hline Trichuris ovis & 0 & 50 & 0 & 25 & 0 & 100 & 0 & 50 & 0 & 0 & 25 & 50 & 100 \\
\hline Oesoph. spp. & 25 & 0 & 25 & 125 & 0 & 0 & 25 & 0 & 0 & 0 & 0 & 0 & 0 \\
\hline O. venulosum & 25 & 0 & 25 & 125 & 0 & 0 & 25 & 0 & 0 & 0 & 0 & 0 & 0 \\
\hline O. radiatum & 0 & 0 & 0 & 0 & 0 & 0 & 0 & 0 & 0 & 0 & 0 & 0 & 0 \\
\hline
\end{tabular}

Tabla 18: promedio de los recuentos parasitarios obtenidos por necropsia en los animales sacrificados para cada mes en corderas durante el año 2015.

Para el análisis estadístico ${ }^{8}$ se realizaron comparaciones estadísticas para los recuentos parasitarios, considerando como

${ }^{8}$ En todos los análisis estadísticos se utilizaron los valores individuales de la medición. En el caso de los animales se tomaron los valores de cada uno y en 
factor la categoría (ovejas y corderas de recría), el año (2014 y 2015) y los trimestres (tablas 19 a 26).

\begin{tabular}{|c|c|c|c|c|}
\hline \multicolumn{5}{|c|}{ COMPARACIÓN ENTRE CATEGORÍAS PARA CADA AÑO } \\
\hline \multirow[b]{2}{*}{ GENEROS } & \multicolumn{2}{|c|}{2014} & \multicolumn{2}{|c|}{2015} \\
\hline & OVEJAS & CORDERAS & OVEJAS & CORDERAS \\
\hline Parásitos totales & $4828 \mathrm{a}$ & 3357 a & $4130 \mathrm{a}$ & 5661 a \\
\hline H. contortus & $3733 a$ & $1388 \mathrm{a}$ & 1446 a & $1422 \mathrm{a}$ \\
\hline Trichos. spp. & $742 \mathrm{a}$ & 352 a & 1948 a & $3930 \mathrm{a}$ \\
\hline T. colubriformis & 708 a & $350 \mathrm{a}$ & $1700 \mathrm{a}$ & 3885 a \\
\hline T. axei & $34 \mathrm{~b}$ & $2 \mathrm{a}$ & 248 b & 45 a \\
\hline T. circumcincta & $0-$ & $0-$ & $80 \mathrm{a}$ & $116 a$ \\
\hline S. papillosus & 77 a & $834 \mathrm{~b}$ & $2 a$ & $18 \mathrm{~b}$ \\
\hline Cooperia spp. & 54 a & $295 \mathrm{~b}$ & $619 \mathrm{~b}$ & 122 a \\
\hline C. punctata & $40 a$ & $206 \mathrm{~b}$ & $536 \mathrm{~b}$ & 104 a \\
\hline C. pectinata & $14 \mathrm{a}$ & $89 a$ & $83 \mathrm{~b}$ & $18 \mathrm{a}$ \\
\hline N. spathiger & 222 a & $473 \mathrm{~b}$ & $17 \mathrm{a}$ & $7 a$ \\
\hline Trichuris ovis & $0 \mathrm{a}$ & $15 \mathrm{~b}$ & $4 a$ & $31 \mathrm{~b}$ \\
\hline Oesoph. spp. & $0-$ & $0-$ & $14 a$ & 15 a \\
\hline O. venulosum & $0-$ & $0-$ & $13 a$ & 15 a \\
\hline O. radiatum & 0 - & 0 - & $1 \mathrm{a}$ & $0 \mathrm{a}$ \\
\hline
\end{tabular}

Letras diferentes expresan diferencias significativas $(p<0,05)$.

el caso de las variables meteorológicas las de cada unidad de tiempo, salvo para los períodos acumulados, en los que se tomó la sumatoria para dicho período.

Las tablas muestran valores promedio con el objetivo de simplificar la presentación e interpretación de resultados. 
Tabla 19: promedio anual de los recuentos parasitarios de los diferentes géneros indicando las diferencias significativas entre categorías para cada año.

\begin{tabular}{|c|c|c|c|c|}
\hline \multicolumn{5}{|c|}{ COMPARACIÓN ENTRE AÑOS PARA CADA CATEGORÍA } \\
\hline \multirow[b]{2}{*}{ GENEROS } & \multicolumn{2}{|c|}{ OVEJAS } & \multicolumn{2}{|c|}{ CORDERAS } \\
\hline & 2014 & 2015 & 2014 & 2015 \\
\hline Parásitos totales & $4828 \mathrm{a}$ & $4130 \mathrm{a}$ & 3357 a & $5661 \mathrm{a}$ \\
\hline H. contortus & $3733 a$ & 1446 a & $1388 \mathrm{a}$ & $1422 \mathrm{a}$ \\
\hline Trichos. spp. & 742 a & 1948 b & 352 a & $3930 \mathrm{~b}$ \\
\hline T. colubriformis & 708 a & $1700 \mathrm{~b}$ & $350 a$ & $3885 \mathrm{~b}$ \\
\hline T. axei & 34 a & $248 \mathrm{~b}$ & $2 a$ & $45 \mathrm{~b}$ \\
\hline T. circumcincta & $0 \mathrm{a}$ & $80 \mathrm{~b}$ & $0 \mathrm{a}$ & $116 \mathrm{~b}$ \\
\hline S. papillosus & $77 \mathrm{~b}$ & $2 \mathrm{a}$ & 834 b & $18 a$ \\
\hline Cooperia spp. & 54 a & $619 \mathrm{~b}$ & $295 \mathrm{a}$ & $122 \mathrm{a}$ \\
\hline C. punctata & $40 a$ & $536 \mathrm{~b}$ & $206 a$ & $104 \mathrm{a}$ \\
\hline C. pectinata & $14 \mathrm{a}$ & $83 a$ & $89 a$ & $18 \mathrm{a}$ \\
\hline N. spathiger & $222 \mathrm{a}$ & $17 \mathrm{a}$ & $473 \mathrm{~b}$ & $7 \mathrm{a}$ \\
\hline Trichuris ovis & $0 \mathrm{a}$ & $4 \mathrm{a}$ & $15 \mathrm{a}$ & $31 \mathrm{a}$ \\
\hline Oesoph. spp. & $0 \mathrm{a}$ & $14 \mathrm{~b}$ & $0 \mathrm{a}$ & $15 \mathrm{~b}$ \\
\hline O. venulosum & $0 \mathrm{a}$ & $13 \mathrm{~b}$ & $0 \mathrm{a}$ & $15 \mathrm{~b}$ \\
\hline O. radiatum & $0 \mathrm{a}$ & $1 \mathrm{a}$ & $0-$ & $0-$ \\
\hline
\end{tabular}

Letras diferentes expresan diferencias significativas $(p<0,05)$.

Tabla 20: promedio anual de los recuentos parasitarios de los diferentes géneros indicando las diferencias significativas entre años para cada categoría. 


\begin{tabular}{|c|c|c|c|c|}
\hline \multicolumn{5}{|c|}{ COMPARACIÓN TRIMESTRAL PARA LA CARGA PARASITARIA DE OVEJAS DEL 2014} \\
\hline GENEROS & TRIMESTRE 1 & TRIMESTRE 2 & TRIMESTRE 3 & TRIMESTRE 4 \\
\hline Parásitos totales & $2633 a$ & 3521 a & 9598 a & 3556 a \\
\hline H. contortus & 465 a & $2950 \mathrm{ab}$ & $8711 \mathrm{~b}$ & $2805 a b$ \\
\hline Trichos. spp. & 2076 a & $252 \mathrm{a}$ & 267 a & 375 a \\
\hline T. colubriformis & $2063 \mathrm{a}$ & 177 a & 217 a & 375 a \\
\hline T. axei & $13 a$ & $75 a$ & $50 a$ & $0 \mathrm{a}$ \\
\hline T. circumcincta & $0-$ & $0-$ & $0-$ & $0-$ \\
\hline S. papillosus & $67 a$ & $202 \mathrm{a}$ & $22 \mathrm{a}$ & $17 \mathrm{a}$ \\
\hline Cooperia spp. & $0 \mathrm{a}$ & $62 \mathrm{a}$ & $73 a$ & $76 a$ \\
\hline C. punctata & $0 \mathrm{a}$ & $62 \mathrm{a}$ & $56 a$ & $38 a$ \\
\hline C. pectinata & $0 \mathrm{a}$ & $0 \mathrm{a}$ & $17 a$ & $38 a$ \\
\hline N. spathiger & $25 \mathrm{a}$ & $55 a$ & $525 a$ & $283 a$ \\
\hline Trichuris ovis & $0-$ & $0-$ & $0-$ & $0-$ \\
\hline Oesoph. spp. & $0-$ & $0-$ & $0-$ & $0-$ \\
\hline O. venulosum & $0-$ & 0 - & $0-$ & $0-$ \\
\hline O. radiatum & 0 - & 0 - & $0-$ & 0 - \\
\hline
\end{tabular}

Letras diferentes expresan diferencias significativas $(p<0,05)$.

Tabla 21: comparación trimestral de las cargas parasitarias obtenidas por necropsia en ovejas para el año 2014.

\begin{tabular}{|c|c|c|c|c|}
\hline \multicolumn{5}{|c|}{ COMPARACIÓN TRIMESTRAL PARA LA CARGA PARASITARIA DE OVEJAS DEL 2015} \\
\hline GENEROS & TRIMESTRE 1 & TRIMESTRE 2 & TRIMESTRE 3 & TRIMESTRE 4 \\
\hline Parásitos totales & $2150 \mathrm{a}$ & 4487 a & 6058 a & 3611 a \\
\hline H. contortus & $625 a b$ & $1802 \mathrm{ab}$ & $3292 \mathrm{~b}$ & 233 a \\
\hline Trichos. spp. & 337 a & $2285 a b$ & $1156 a b$ & $3253 \mathrm{~b}$ \\
\hline T. colubriformis & $337 a$ & 2225 a & $1008 \mathrm{a}$ & $2500 \mathrm{a}$ \\
\hline T. axei & $0 \mathrm{a}$ & $60 a$ & $148 a$ & $753 a$ \\
\hline T. circumcincta & $0 \mathrm{a}$ & $17 \mathrm{a}$ & $252 \mathrm{a}$ & $50 a$ \\
\hline
\end{tabular}




\begin{tabular}{|c|c|c|c|c|}
\hline S. papillosus & $0 \mathrm{a}$ & $8 a$ & $0 \mathrm{a}$ & $0 \mathrm{a}$ \\
\hline Cooperia spp. & $1138 a b$ & $325 a b$ & $1325 \mathrm{~b}$ & $67 a$ \\
\hline C. punctata & $1100 \mathrm{a}$ & $242 a$ & 1103 a & $67 a$ \\
\hline C. pectinata & $38 \mathrm{a}$ & $83 a$ & $222 \mathrm{a}$ & $0 \mathrm{a}$ \\
\hline N. spathiger & $50 a$ & $33 \mathrm{a}$ & $0 \mathrm{a}$ & $0 \mathrm{a}$ \\
\hline Trichuris ovis & $0 \mathrm{a}$ & $0 \mathrm{a}$ & $8 a$ & $0 \mathrm{a}$ \\
\hline Oesoph. spp. & $0 \mathrm{a}$ & $17 \mathrm{a}$ & $25 \mathrm{a}$ & $8 a$ \\
\hline O. venulosum & $0 \mathrm{a}$ & $17 \mathrm{a}$ & $25 \mathrm{a}$ & $8 a$ \\
\hline O. radiatum & 0 - & 0 - & 0 - & 0 - \\
\hline
\end{tabular}

Letras diferentes expresan diferencias significativas $(p<0,05)$.

Tabla 22: comparación trimestral de las cargas parasitarias obtenidas por necropsia en ovejas para el año 2015.

COMPARACIÓN TRIMESTRAL PARA LA CARGA PARASITARIA DE CORDERAS DEL 2014

\begin{tabular}{|c|c|c|c|c|}
\hline GENEROS & TRIMESTRE 1 & TRIMESTRE 2 & TRIMESTRE 3 & TRIMESTRE 4 \\
\hline Parásitos totales & $1773 \mathrm{a}$ & $2892 \mathrm{a}$ & $4500 \mathrm{a}$ & 4718 a \\
\hline H. contortus & $687 a$ & $908 a$ & $2225 \mathrm{a}$ & $1905 \mathrm{a}$ \\
\hline Trichos. spp. & $258 a b$ & 92 a & $700 \mathrm{~b}$ & $362 a b$ \\
\hline T. colubriformis & $258 \mathrm{ab}$ & 92 a & $692 b$ & $362 a b$ \\
\hline T. axei & $0 \mathrm{a}$ & $0 \mathrm{a}$ & $8 a$ & $0 \mathrm{a}$ \\
\hline T. circumcincta & $0-$ & $0-$ & $0-$ & $0-$ \\
\hline S. papillosus & $483 a$ & $1308 \mathrm{a}$ & $1083 \mathrm{a}$ & $275 a$ \\
\hline Cooperia spp. & $258 a$ & 392 a & $209 a$ & $338 a$ \\
\hline C. punctata & $76 a$ & $363 a$ & $93 a$ & $338 a$ \\
\hline C. pectinata & $182 \mathrm{a}$ & $29 a$ & $116 a$ & $0 \mathrm{a}$ \\
\hline N. spathiger & 50 a & $175 a b$ & $283 a b$ & $1838 \mathrm{~b}$ \\
\hline Trichuris ovis & $37 a$ & $17 \mathrm{a}$ & $0 \mathrm{a}$ & $0 \mathrm{a}$ \\
\hline
\end{tabular}




\begin{tabular}{llccc}
$\begin{array}{l}\text { Oesoph. spp. } \\
\text { O. venulosum }\end{array}$ & $0-$ & $0-$ & $0-$ & $0-$ \\
O. radiatum & $0-$ & $0-$ & $0-$ & $0-$ \\
\hline & $0-$ & $0-$ & $0-$ \\
\hline
\end{tabular}

Tabla 23: comparación trimestral de las cargas parasitarias obtenidas por necropsia en corderas para el año 2014.

\begin{tabular}{|c|c|c|c|c|}
\hline \multicolumn{5}{|c|}{ COMPARACIÓN TRIMESTRAL PARA LA CARGA PARASITARIA DE CORDERAS DEL 2015} \\
\hline GENEROS & TRIMESTRE 1 & TRIMESTRE 2 & TRIMESTRE 3 & TRIMESTRE 4 \\
\hline Parásitos totales & 9461 a & $2825 a$ & 2912 a & 7151 a \\
\hline H. contortus & 1403 a & $1300 \mathrm{a}$ & $692 \mathrm{a}$ & $1765 a$ \\
\hline Trichos. spp. & 7930 a & $1011 \mathrm{a}$ & 2069 a & 4906 a \\
\hline T. colubriformis & 7925 a & 1003 a & 1977 a & $4843 \mathrm{a}$ \\
\hline T. axei & $5 a$ & $8 a$ & $92 \mathrm{a}$ & $63 a$ \\
\hline T. circumcincta & 77 a & $105 a$ & $47 a$ & $238 a$ \\
\hline S. papillosus & $0 \mathrm{a}$ & $42 \mathrm{a}$ & $38 \mathrm{a}$ & $0 \mathrm{a}$ \\
\hline Cooperia spp. & $17 \mathrm{a}$ & $283 a$ & $35 \mathrm{a}$ & $192 \mathrm{a}$ \\
\hline C. punctata & $17 \mathrm{a}$ & 209 a & $33 \mathrm{a}$ & 192 a \\
\hline C. pectinata & $0 \mathrm{a}$ & 74 a & $2 a$ & $0 \mathrm{a}$ \\
\hline N. spathiger & $0 \mathrm{a}$ & $0 \mathrm{a}$ & $6 a$ & $25 \mathrm{a}$ \\
\hline Trichuris ovis & $17 \mathrm{a}$ & $42 \mathrm{a}$ & $17 \mathrm{a}$ & $25 \mathrm{a}$ \\
\hline Oesoph. spp. & $17 \mathrm{a}$ & $42 \mathrm{a}$ & $8 a$ & $0 \mathrm{a}$ \\
\hline O. venulosum & $17 \mathrm{a}$ & $42 \mathrm{a}$ & $8 a$ & $0 \mathrm{a}$ \\
\hline O. radiatum & $0-$ & $0-$ & $0-$ & $0-$ \\
\hline
\end{tabular}

Letras diferentes expresan diferencias significativas $(p<0,05)$.

Tabla 24: comparación trimestral de las cargas parasitarias obtenidas por necropsia en corderas para el año 2015. Los recuentos elevados de $T$. colubriformis del primer trimestre están traccionados por altos recuentos (18650) de un animal. 


\begin{tabular}{|c|c|c|c|c|c|c|c|c|}
\hline \multicolumn{9}{|c|}{ COMPARACIÓN ENTRE AÑOS PARA CADA TRIMESTRE EN OVEJAS } \\
\hline \multirow{2}{*}{ GENEROS } & \multicolumn{2}{|c|}{ TRIMESTRE 1} & \multicolumn{2}{|c|}{ TRIMESTRE 2} & \multicolumn{2}{|c|}{ TRIMESTRE 3} & \multicolumn{2}{|c|}{ TRIMESTRE 4} \\
\hline & 2014 & 2015 & 2014 & 2015 & 2014 & 2015 & 2014 & 2015 \\
\hline Parásitos totales & $2633 a$ & $2150 \mathrm{a}$ & 3521 a & 4487 a & 9598 a & $6058 \mathrm{a}$ & 3556 a & $3611 a$ \\
\hline H. contortus & $465 \mathrm{a}$ & $625 a$ & 2950 a & $1802 \mathrm{a}$ & 8711 a & 3292 a & $2805 \mathrm{~b}$ & $233 a$ \\
\hline Trichos. spp. & $2076 \mathrm{a}$ & $337 a$ & $252 a$ & $2285 b$ & $267 a$ & $1156 \mathrm{a}$ & 375 a & $3253 \mathrm{~b}$ \\
\hline T. colubriformis & 2063 a & $337 a$ & 177 a & $2225 b$ & $217 \mathrm{a}$ & $1008 \mathrm{a}$ & $375 a$ & $2500 a$ \\
\hline T. axei & $13 \mathrm{a}$ & $0 \mathrm{a}$ & $75 a$ & $60 \mathrm{a}$ & $50 a$ & $148 \mathrm{a}$ & $0 \mathrm{a}$ & $753 b$ \\
\hline T. circumcincta & $0-$ & $0-$ & $0 \mathrm{a}$ & $17 \mathrm{a}$ & $0 \mathrm{a}$ & 252 b & $0 \mathrm{a}$ & $50 a$ \\
\hline S. papillosus & $67 a$ & $0 \mathrm{a}$ & 202 b & $8 a$ & $22 \mathrm{a}$ & $0 \mathrm{a}$ & $17 \mathrm{a}$ & $0 \mathrm{a}$ \\
\hline Cooperia spp. & $0 \mathrm{a}$ & $1138 \mathrm{~b}$ & $62 \mathrm{a}$ & $325 a$ & $73 \mathrm{a}$ & $1325 \mathrm{~b}$ & $76 a$ & $67 a$ \\
\hline C. punctata & $0 \mathrm{a}$ & $1100 \mathrm{~b}$ & $62 a$ & $242 a$ & $56 a$ & $1103 \mathrm{~b}$ & $38 \mathrm{a}$ & $67 a$ \\
\hline C. pectinata & $0 \mathrm{a}$ & $38 a$ & $0 \mathrm{a}$ & $83 a$ & $17 \mathrm{a}$ & $222 \mathrm{a}$ & $38 \mathrm{a}$ & $0 \mathrm{a}$ \\
\hline N. spathiger & $25 \mathrm{a}$ & $50 a$ & $55 \mathrm{a}$ & $33 a$ & $525 a$ & $0 \mathrm{a}$ & $283 a$ & $0 \mathrm{a}$ \\
\hline Trichuris ovis & $0-$ & $0-$ & $0-$ & $0-$ & $0 \mathrm{a}$ & $8 a$ & $0-$ & $0-$ \\
\hline Oesoph. spp. & $0-$ & $0-$ & $0 \mathrm{a}$ & $17 \mathrm{a}$ & $0 \mathrm{a}$ & $25 \mathrm{a}$ & $0 \mathrm{a}$ & $8 a$ \\
\hline O. venulosum & $0-$ & $0-$ & $0 \mathrm{a}$ & $17 \mathrm{a}$ & $0 \mathrm{a}$ & $25 \mathrm{a}$ & $0 \mathrm{a}$ & $8 a$ \\
\hline O. radiatum & 0 - & $0-$ & $0-$ & $0-$ & $0-$ & $0-$ & $0-$ & $0-$ \\
\hline
\end{tabular}

Letras diferentes expresan diferencias significativas $(p<0,05)$.

Tabla 25: comparación entre años para cada trimestre de las cargas parasitarias obtenidas por necropsia en ovejas. 


\begin{tabular}{|c|c|c|c|c|c|c|c|c|}
\hline \multicolumn{9}{|c|}{ COMPARACIÓN ENTRE AÑOS PARA CADA TRIMESTRE EN CORDERAS } \\
\hline \multirow{2}{*}{ GENEROS } & \multicolumn{2}{|c|}{ TRIMESTRE 1} & \multicolumn{2}{|c|}{ TRIMESTRE 2} & \multicolumn{2}{|c|}{ TRIMESTRE 3} & \multicolumn{2}{|c|}{ TRIMESTRE 4} \\
\hline & 2014 & 2015 & 2014 & 2015 & 2014 & 2015 & 2014 & 2015 \\
\hline Parásitos totales & 1773 a & 9461 a & $2892 \mathrm{a}$ & 2825 a & 4500 a & 2912 a & 4718 a & $7151 \mathrm{a}$ \\
\hline H. contortus & $687 \mathrm{a}$ & $1403 \mathrm{a}$ & 908 a & $1300 \mathrm{a}$ & $2225 \mathrm{a}$ & $692 \mathrm{a}$ & $1905 \mathrm{a}$ & $1765 a$ \\
\hline Trichos. spp. & $258 a$ & $7930 \mathrm{~b}$ & $92 \mathrm{a}$ & $1011 \mathrm{a}$ & $700 \mathrm{a}$ & 2069 a & 362 a & $4906 a$ \\
\hline T. colubriformis & $258 a$ & 7925 b & $92 \mathrm{a}$ & 1003 a & $692 a$ & 1977 a & 362 a & $4843 a$ \\
\hline T. axei & $0 \mathrm{a}$ & $5 a$ & $0 \mathrm{a}$ & $8 a$ & $8 a$ & $92 \mathrm{a}$ & $0 \mathrm{a}$ & $63 a$ \\
\hline T. circumcincta & $0 \mathrm{a}$ & $77 \mathrm{~b}$ & $0 \mathrm{a}$ & $105 a$ & $0 \mathrm{a}$ & $47 a$ & $0 \mathrm{a}$ & $238 a$ \\
\hline S. papillosus & $483 \mathrm{~b}$ & $0 \mathrm{a}$ & $1308 \mathrm{~b}$ & $42 a$ & $1083 \mathrm{~b}$ & $38 a$ & $275 b$ & $0 \mathrm{a}$ \\
\hline Cooperia spp. & $258 \mathrm{a}$ & $17 \mathrm{a}$ & 392 a & $283 a$ & 209 a & $35 \mathrm{a}$ & 338 a & $192 \mathrm{a}$ \\
\hline C. punctata & $76 a$ & $17 \mathrm{a}$ & 363 a & $209 a$ & 93 a & 33 a & 338 a & $192 \mathrm{a}$ \\
\hline C. pectinata & $182 \mathrm{a}$ & $0 \mathrm{a}$ & $29 a$ & $74 \mathrm{a}$ & $116 \mathrm{a}$ & $2 a$ & $0-$ & $0-$ \\
\hline N. spathiger & $50 a$ & $0 \mathrm{a}$ & $175 b$ & $0 \mathrm{a}$ & $283 a$ & $6 a$ & $1838 \mathrm{~b}$ & $25 \mathrm{a}$ \\
\hline Trichuris ovis & $37 a$ & $17 \mathrm{a}$ & $17 \mathrm{a}$ & $42 \mathrm{a}$ & $0 \mathrm{a}$ & $17 \mathrm{a}$ & $0 \mathrm{a}$ & $25 \mathrm{a}$ \\
\hline Oesoph. spp. & $0 \mathrm{a}$ & $17 \mathrm{a}$ & $0 \mathrm{a}$ & $42 \mathrm{a}$ & $0 \mathrm{a}$ & $8 a$ & $0-$ & $0-$ \\
\hline O. venulosum & $0 \mathrm{a}$ & $17 \mathrm{a}$ & $0 \mathrm{a}$ & $42 \mathrm{a}$ & $0 \mathrm{a}$ & $8 a$ & $0-$ & $0-$ \\
\hline O. radiatum & 0 - & $0-$ & 0 - & $0-$ & $0-$ & 0 - & $0-$ & $0-$ \\
\hline
\end{tabular}

Letras diferentes expresan diferencias significativas $(p<0,05)$.

Tabla 26: comparación entre años para cada trimestre de las cargas parasitarias obtenidas por necropsia en corderas.

Parásitos totales: en los dos años de observaciones, las ovejas presentaron valores máximos para invierno-primavera coincidiendo con la parición. Esto fue más marcado en el primer año, al igual que el predominio de $H$. contortus, seguido en importancia, por Trichostrongylus spp.; S. papillosus; N. spathiger y Cooperia spp. Para el segundo año, la composición de la carga parasitaria resulta más 
variada, con Trichostrongylus spp. como el género más relevante, seguido por H. contortus y luego Cooperia spp. En primavera se observó T. circumcincta, mientras que fueron esporádicos los hallazgos de Trichuris ovis y S. papillosus y N. spathiger. Los resultados de la regresión con las variables meteorológicas para los parásitos totales en esta categoría no presentaron significancia estadística $(p<0,05)$, con excepción de la temperatura y la evapotranspiración que expresan una relación negativa (beta: $<-0,4$ y $R^{2}:<0,2$ ), situación que coincide con los máximos recuentos de invierno.

Las corderas, expresan una tendencia más marcada hacia veranootoño, siendo los géneros principales $H$. contortus; S. papillosus y $T$. colubriformis para el primer año y $T$. colubriformis y $H$. contortus para segundo. La relación entre las variables meteorológicas estudiadas y los recuentos de parásitos totales, para los diferentes períodos no presentaron significancia estadística $(p<0,05)$.

Haemonchus contortus: en ovejas los mayores recuentos se observaron en el 3er trimestre, coincidiendo con el parto, llegando a valores cercanos al $90 \%$ y $60 \%$ de la carga para el primer y segundo año respectivamente. Los recuentos se reducen significativamente al finalizar la lactancia. Esta reducción de verano (representando hasta el $5 \%$ de la carga), fue menos evidente en corderas de recría que llegó a ocupar hasta $15 \%$ del total de los parásitos. En corderas, no hubo un patrón que diferenciara los trimestres.

En ovejas $H$. contortus presentó relación con las variables meteorológicas únicamente en el segundo trimestre y aisladamente en 
el tercero $(p<0,05)$. Las variables con relación negativa fueron la temperatura, heliofania y evapotranspiración (beta: $<-0,5$ y $R^{2}:>0,5$ ), mientras que la humedad (mínima y media) presentó relación positiva (beta: $>0,6$ y $\mathrm{R}^{2}:>0,3$ ). Las otras variables meteorológicas analizadas para los diferentes períodos en ovejas no presentaron significancia estadística $(p<0,05)$ con los recuentos parasitarios del género, mientras que en corderas no la hubo en ningún caso.

Trichostrongylus spp.: el comportamiento de este parásito fue similar en ambas categorías y describió el mismo patrón en los dos años, aunque en el segundo año con mayor magnitud ( 3 veces mas en ovejas y 10 veces más en corderas). Las cargas se incrementan hacia fines de invierno, alcanzando su máximo en verano. La principal especie fue $T$. colubriformis y en segundo lugar T. axei., este último, observado con mayor frecuencia en ovejas en torno al parto y con mayores recuentos en el año 2015.

Fue significativamente mayor durante el año 2015 en ambas categorías, con mayores recuentos en el trimestre 2 y 4 en ovejas y en el 1 en corderas. En ovejas los valores máximos se observaron en el trimestre 4 y los mínimos en el 1, mientras que en corderas los mayores y menores recuentos se observaron en el trimestre 3 y 2 respectivamente. Los demás trimestres en ambas categorías resultaron intermedios.

En ovejas presentó asociación positiva entre la carga parasitaria del género en el primer trimestre con la temperatura (en todas sus 
mediciones) y heliofania (beta: $<0,9$ y $\mathrm{R}^{2}$ : $<0,7$ ) y en el cuarto con la humedad (media y mínima) y almacenaje total (beta: $<0,7$ y $R^{2}:<0,8$ ). Las otras variables meteorológicas analizadas en los diferentes períodos en ovejas no presentaron significancia estadística $(p<0,05)$ con los recuentos parasitarios del género, mientras que en corderas no la hubo en ningún caso.

Teladorsagia circumcincta: única especie hallada del género. Ausente en el primer año, siendo significativamente mayor en el segundo, donde se halló en las dos categorías. Presentó un patrón más definido en ovejas que en corderas, donde llegó a representar hasta un $17 \%$ de la carga total. En ambas categorías no se observó significancia estadística $(p<0,05)$ en la relación de las variables meteorológicas analizadas en los diferentes períodos con la carga parasitaria del género.

Cooperia spp.: las principales especies halladas fueron $C$. punctata y en segundo lugar $C$. pectinata. Se observó más constante en las ovejas del segundo año, llegando a representar el $85 \%$ de la carga en el mes de marzo. En el primer año fue más variable y en menor magnitud (hasta el $29 \%$ de la carga), con recuentos significativamente mayores en el 2015 para los trimestres 1 y 3 . El comportamiento fue similar al de $H$. contortus, con valores máximos en otoño-invierno y mínimos en verano. En las corderas del año 2014 representó cerca del 45\% de la carga siendo significativamente mayores estos recuentos. 
En ovejas se observó asociación negativa con la temperatura, heliofania, precipitaciones y evapotranspiración (beta: $<-0,3$ y $R^{2}$ : $<0,1)$. Las otras variables meteorológicas analizadas en los diferentes períodos en ovejas no presentaron significancia estadística $(p<0,05)$ con los recuentos parasitarios del género, mientras que en corderas no la hubo en ningún caso.

Nematodirus spathiger: mas constante y en mayor magnitud durante el primer año de trabajo, con diferencias significativas en los trimestres 2 y 4. Los recuentos en corderos fueron significativamente mayores que en ovejas y presentaron valores máximos en el trimestre 4 y mínimos en el 1 (siendo los trimestres 2 y 3 intermedios). No obstante, el comportamiento de invierno-primavera se observó en ambas categorías, llegando a representar valores cercanos al $19 \%$ y $52 \%$ en ovejas y corderas respectivamente. No se observó significancia estadística $(p<0,05)$ en la relación de las variables meteorológicas analizadas en los diferentes períodos con la carga parasitaria del género.

Oesophagostomum spp.: solo presente en el segundo año, en ambas categorías, aunque en escasa cantidad ( $<4 \%$ de la carga parasitaria), donde se observó una tendencia invernal. La especie predominante fue O. venulosum, hallándose aisladamente en ovejas en el mes de enero ejemplares de $O$. radiatum en igual proporción que el anterior. No se observó significancia estadística $(p<0,05)$ en la relación de las variables 
meteorológicas analizadas en los diferentes períodos con la carga parasitaria del género.

Strongyloides papillosus: de patrón otoño-invernal y mayor prevalencia en corderas en el primer año (en los 4 trimestres), con 15 y $50 \%$ de la carga en ovejas y corderas respectivamente (diferencias significativas). En el segundo, la carga relativa fue significativamente menor con apenas el $1 \%$ en ovejas y hasta el $7 \%$ en las corderas de recría.

En corderas se observó asociación negativa con la temperatura y evapotranspiración (beta: $<-0,4$ y $R^{2}:<0,1$ ) y asociación positiva con la humedad relativa máxima (beta: 0,3 y $R^{2}: 0,1$ ). Las otras variables meteorológicas analizadas en los diferentes períodos en corderas no presentaron significancia estadística $(p<0,05)$ con los recuentos parasitarios del género, mientras que en ovejas no la hubo en ningún caso.

Trichuris ovis: este parásito se encontró ocasionalmente en ovejas $(<1 \%)$ mientras que en corderas fue más constante, en valores del 2 y $1 \%$ para el primer y segundo año respectivamente. No se observó significancia estadística $(p<0,05)$ en la relación de las variables meteorológicas analizadas en los diferentes períodos con la carga parasitaria del género. 
Además, aisladamente se encontraron ejemplares de:

- Moniezia expanza especialmente en ovejas (en mayor proporción en el 2014), aunque también se observó en corderas. No presentó un patrón estacional (observaciones en los meses de enero, febrero, abril, julio, septiembre y diciembre).

- Thysanosoma actinoides en ovejas y corderas de ambos años, con mayor prevalencia durante el invierno (observado en los meses de abril, junio, julio y agosto fundamentalmente).

- Oestrus ovis (un ejemplar) en un sólo animal (oveja) en enero de 2014.

- Quistes hidatídicos de observación frecuente y únicamente en ovejas y durante el año 2014. Localización hepática principalmente y en algunos individuos se observaron múltiples quistes.

- Cisticerco tenuicollis esporádico en serosas de cuajo, rumen e intestino (mesogastrio, omento y mesenterio). Se observaron en dos animales (1 oveja y 1 cordero) en el año 2015 en enero.

5. Patrón de infestación obtenida por animales Trazadores Los recuentos parasitarios hallados en corderas trazadoras se observan detallados en el gráfico 19 , tabla 27 y 28. 


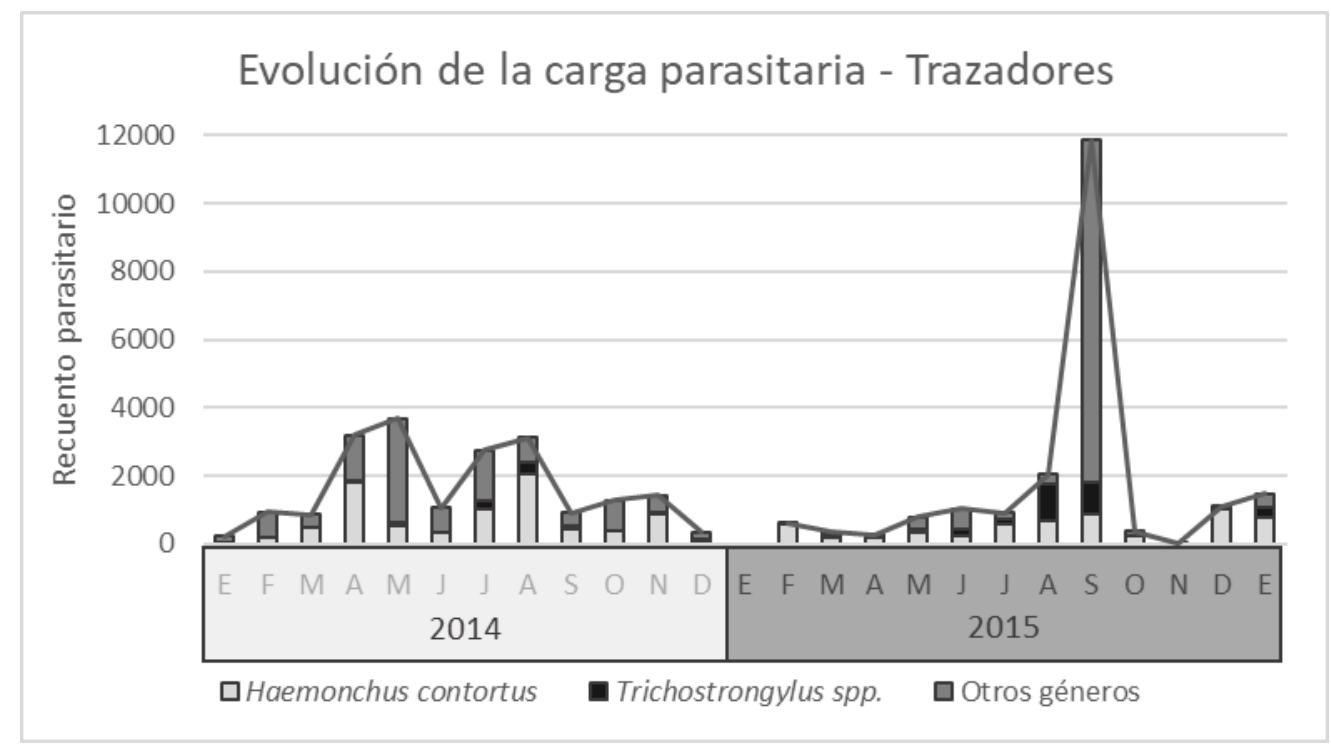

Gráfico 19: evolución anual de los recuentos parasitarios obtenidos por necropsia de las corderas trazadoras para los años 2014 y 2015. El pico de septiembre de 2015 está compuesto principalmente por Cooperia spp. (6000) y $T$. circumcincta (3850).

\begin{tabular}{|c|c|c|c|c|c|c|c|c|c|c|c|c|}
\hline GENEROS & $E$ & $\mathrm{~F}$ & $M$ & A & $M$ & J & J & A & $S$ & 0 & $\mathrm{~N}$ & $\mathrm{D}$ \\
\hline \multicolumn{13}{|l|}{ TRAZADORES 2014} \\
\hline Parásitos totales & 235 & 950 & 875 & 3200 & 3675 & 1051 & 2750 & 3125 & 925 & 1285 & 1425 & 356 \\
\hline H. contortus & 30 & 200 & 475 & 1825 & 525 & 326 & 1050 & 2075 & 450 & 410 & 875 & 106 \\
\hline Trichos. spp. & 5 & 0 & 17 & 50 & 100 & 25 & 200 & 300 & 100 & 0 & 50 & 50 \\
\hline T. colubriformis & 5 & 0 & 17 & 50 & 100 & 25 & 200 & 300 & 100 & 0 & 50 & 50 \\
\hline T. axei & 0 & 0 & 0 & 0 & 0 & 0 & 0 & 0 & 0 & 0 & 0 & 0 \\
\hline T. circumcincta & 0 & 0 & 1 & 0 & 0 & 0 & 0 & 0 & 0 & 0 & 0 & 0 \\
\hline S. papillosus & 25 & 300 & 200 & 1000 & 2475 & 325 & 1450 & 425 & 325 & 550 & 500 & 75 \\
\hline Cooperia spp. & 0 & 425 & 75 & 100 & 250 & 175 & 0 & 0 & 0 & 0 & 0 & 50 \\
\hline C. punctata & 0 & 425 & 0 & 100 & 100 & 175 & 0 & 0 & 0 & 0 & 0 & 0 \\
\hline C. pectinata & 0 & 0 & 75 & 0 & 150 & 0 & 0 & 0 & 0 & 0 & 0 & 50 \\
\hline N. spathiger & 150 & 0 & 108 & 150 & 300 & 150 & 50 & 325 & 50 & 325 & 0 & 75 \\
\hline Trichuris ovis & 25 & 25 & 0 & 75 & 25 & 50 & 0 & 0 & 0 & 0 & 0 & 0 \\
\hline
\end{tabular}


Oesoph. spp.

$\begin{array}{llllllllllll}0 & 0 & 0 & 0 & 0 & 0 & 0 & 0 & 0 & 0 & 0 & 0 \\ 0 & 0 & 0 & 0 & 0 & 0 & 0 & 0 & 0 & 0 & 0 & 0 \\ 0 & 0 & 0 & 0 & 0 & 0 & 0 & 0 & 0 & 0 & 0 & 0\end{array}$

Tabla 27: recuentos parasitarios obtenidos por necropsia en corderas trazadoras para el año 2014.

\begin{tabular}{|c|c|c|c|c|c|c|c|c|c|c|c|c|}
\hline GENEROS & $\mathrm{F}$ & M & $A$ & M & J & J & $A$ & $S$ & 0 & $\mathrm{~N}$ & $\mathrm{D}$ & $E$ \\
\hline \multicolumn{13}{|l|}{ TRAZADORES 2015} \\
\hline Parásitos totales & 590 & 340 & 280 & 800 & 1030 & 915 & 2045 & 11860 & 375 & 25 & 1100 & 1475 \\
\hline H. contortus & 575 & 175 & 175 & 350 & 255 & 580 & 685 & 880 & 225 & 0 & 1025 & 775 \\
\hline Trichos. spp. & 0 & 115 & 0 & 75 & 175 & 160 & 1100 & 930 & 0 & 0 & 25 & 300 \\
\hline T. colubriformis & 0 & 115 & 0 & 75 & 175 & 160 & 1100 & 930 & 0 & 0 & 25 & 300 \\
\hline T. axei & 0 & 0 & 0 & 0 & 0 & 0 & 0 & 0 & 0 & 0 & 0 & 0 \\
\hline T. circumcincta & 0 & 0 & 0 & 0 & 0 & 0 & 150 & 3850 & 0 & 0 & 0 & 0 \\
\hline S. papillosus & 0 & 30 & 75 & 50 & 0 & 0 & 75 & 0 & 125 & 25 & 25 & 25 \\
\hline Cooperia spp. & 0 & 20 & 25 & 275 & 500 & 175 & 0 & 6000 & 0 & 0 & 0 & 0 \\
\hline C. punctata & 0 & 20 & 25 & 163 & 500 & 175 & 0 & 5678 & 0 & 0 & 0 & 0 \\
\hline C. pectinata & 0 & 0 & 0 & 113 & 0 & 0 & 0 & 322 & 0 & 0 & 0 & 0 \\
\hline N. spathiger & 0 & 0 & 0 & 25 & 0 & 0 & 0 & 0 & 0 & 0 & 0 & 0 \\
\hline Trichuris ovis & 15 & 0 & 5 & 25 & 100 & 0 & 30 & 200 & 25 & 0 & 0 & 375 \\
\hline Oesoph. spp. & 0 & 0 & 0 & 0 & 0 & 0 & 5 & 0 & 0 & 0 & 25 & 0 \\
\hline O. venulosum & 0 & 0 & 0 & 0 & 0 & 0 & 5 & 0 & 0 & 0 & 25 & 0 \\
\hline O. radiatum & 0 & 0 & 0 & 0 & 0 & 0 & 0 & 0 & 0 & 0 & 0 & 0 \\
\hline
\end{tabular}

Tabla 28: recuentos parasitarios obtenidos por necropsia en corderas trazadoras para el año 2015.

Se realizaron comparaciones estadísticas para los recuentos parasitarios, considerando como factor el año (2014 y 2015) y los trimestres (tablas 29 a 32). También se realizaron regresiones 
entre las variables meteorológicas (informadas previamente) y los recuentos parasitarios de cada género.

\begin{tabular}{|c|c|c|}
\hline \multicolumn{3}{|c|}{ COMPARACIÓN ENTRE AÑOS DE TRAZADORES } \\
\hline GENEROS & 2014 & 2015 \\
\hline Parásitos totales & 1655 a & $1737 \mathrm{a}$ \\
\hline H. contortus & $696 a$ & $475 \mathrm{a}$ \\
\hline Trichos. spp. & 75 a & $240 \mathrm{a}$ \\
\hline T. colubriformis & $75 \mathrm{a}$ & $240 \mathrm{a}$ \\
\hline T. axei & $0 \mathrm{a}$ & $0 \mathrm{a}$ \\
\hline T. circumcincta & $0,04 \mathrm{a}$ & $333 \mathrm{a}$ \\
\hline S. papillosus & $637,96 \mathrm{~b}$ & 36 a \\
\hline Cooperia spp. & $90 \mathrm{a}$ & $583 a$ \\
\hline C. punctata & 67 a & $547 a$ \\
\hline C. pectinata & $23 \mathrm{a}$ & $36 a$ \\
\hline N. spathiger & $140 \mathrm{~b}$ & $2 a$ \\
\hline Trichuris ovis & $17 \mathrm{a}$ & $65 a$ \\
\hline Oesoph. spp. & $0 \mathrm{a}$ & $3 a$ \\
\hline O. venulosum & $0 \mathrm{a}$ & $3 a$ \\
\hline O. radiatum & $0 \mathrm{a}$ & $0 \mathrm{a}$ \\
\hline
\end{tabular}

Letras diferentes expresan diferencias significativas $(p<0,05)$.

Tabla 29: comparaciones interanuales de las cargas parasitarias por necropsia de los trazadores.

\begin{tabular}{lcccc}
\hline \multicolumn{5}{c}{ COMPARACIÓN TRIMESTRAL EN TRAZADORES DEL AÑO 2014} \\
\hline \multicolumn{1}{c}{ GENEROS } & TRIMESTRE 1 & TRIMESTRE 2 & TRIMESTRE 3 & TRIMESTRE 4 \\
\hline Parásitos totales & $687,2 \mathrm{a}$ & $2642 \mathrm{a}$ & $2267 \mathrm{a}$ & $1022 \mathrm{a}$ \\
\hline H. contortus & $235 \mathrm{a}$ & $892 \mathrm{a}$ & $1192 \mathrm{a}$ & $464 \mathrm{a}$ \\
Trichos. spp. & $\mathbf{7 ~ a}$ & $\mathbf{5 8 ~ a b}$ & $\mathbf{2 0 0} \mathbf{~ b}$ & $\mathbf{3 3} \mathbf{~ a b}$
\end{tabular}




\begin{tabular}{|c|c|c|c|c|}
\hline T. colubriformis & $7 a$ & $58 a b$ & $200 \mathrm{~b}$ & $33 a b$ \\
\hline T. axei & $0-$ & 0 - & $0-$ & $0-$ \\
\hline T. circumcincta & $0,2 \mathrm{a}$ & $0 \mathrm{a}$ & $0 \mathrm{a}$ & $0 \mathrm{a}$ \\
\hline S. papillosus & $175 a$ & $1267 \mathrm{a}$ & $733 a$ & $375 a$ \\
\hline Cooperia spp. & $167 a$ & $175 a$ & $0 \mathrm{a}$ & $17 a$ \\
\hline C. punctata & $142 \mathrm{a}$ & $125 \mathrm{a}$ & $0 \mathrm{a}$ & $0 \mathrm{a}$ \\
\hline C. pectinata & $25 a$ & $50 a$ & $0 \mathrm{a}$ & $17 a$ \\
\hline N. spathiger & $86 a$ & $200 \mathrm{a}$ & $142 \mathrm{a}$ & $133 a$ \\
\hline Trichuris ovis & $17 \mathrm{a}$ & $50 a$ & $0 \mathrm{a}$ & $0 \mathrm{a}$ \\
\hline Oesoph. spp. & $0-$ & $0-$ & $0-$ & $0-$ \\
\hline O. venulosum & $0-$ & $0-$ & $0-$ & 0 - \\
\hline O. radiatum & 0 - & 0 - & $0-$ & 0 - \\
\hline
\end{tabular}

Letras diferentes expresan diferencias significativas $(p<0,05)$.

Tabla 31: comparaciones trimestrales de las cargas parasitarias obtenidas por necropsia de animales trazadores para el año 2014.

\begin{tabular}{|c|c|c|c|c|}
\hline \multicolumn{5}{|c|}{ COMPARACIÓN TRIMESTRAL EN TRAZADORES DEL AÑO 2015} \\
\hline GENEROS & TRIMESTRE 1 & TRIMESTRE 2 & TRIMESTRE 3 & TRIMESTRE 4 \\
\hline Parásitos totales & $466 \mathrm{a}$ & $703 \mathrm{a}$ & 4940 a & 499 a \\
\hline H. contortus & $375 a$ & $260 \mathrm{a}$ & $715 \mathrm{a}$ & 417 a \\
\hline Trichos. spp. & $58 \mathrm{a}$ & $83 a$ & $730 \mathrm{a}$ & $8 a$ \\
\hline T. colubriformis & $58 \mathrm{a}$ & $83 a$ & $730 \mathrm{a}$ & $8 a$ \\
\hline T. axei & $0-$ & 0 - & $0-$ & $0-$ \\
\hline T. circumcincta & $0 \mathrm{a}$ & $0 \mathrm{a}$ & $1333 \mathrm{a}$ & $0 \mathrm{a}$ \\
\hline S. papillosus & $15 \mathrm{a}$ & $42 \mathrm{a}$ & $25 a$ & $58 a$ \\
\hline Cooperia spp. & $10 \mathrm{a}$ & $267 a b$ & $2058 \mathrm{~b}$ & $0 \mathrm{a}$ \\
\hline C. punctata & $10 \mathrm{a}$ & $229 a$ & 1951 a & $0 \mathrm{a}$ \\
\hline C. pectinata & $0 \mathrm{a}$ & $38 a$ & $107 a$ & $0 \mathrm{a}$ \\
\hline N. spathiger & $0 \mathrm{a}$ & $8 a$ & $0 \mathrm{a}$ & $0 \mathrm{a}$ \\
\hline
\end{tabular}




\begin{tabular}{lcccc} 
Trichuris ovis & $8 \mathrm{a}$ & $43 \mathrm{a}$ & $77 \mathrm{a}$ & $8 \mathrm{a}$ \\
Oesoph.spp. & $0 \mathrm{a}$ & $0 \mathrm{a}$ & $2 \mathrm{a}$ & $8 \mathrm{a}$ \\
& $0 \mathrm{a}$ & $0 \mathrm{a}$ & $2 \mathrm{a}$ & $8 \mathrm{a}$ \\
& O. venulosum & $0-$ & $0-$ & $0-$ \\
\hline
\end{tabular}

Letras diferentes expresan diferencias significativas $(p<0,05)$.

Tabla 31: comparaciones trimestrales de las cargas parasitarias obtenidas por necropsia de animales trazadores para el año 2015.

\begin{tabular}{|c|c|c|c|c|c|c|c|c|}
\hline \multirow{3}{*}{ GENEROS } & \multicolumn{8}{|c|}{ COMPARACIÓN ENTRE AÑOS PARA CADA TRIMESTRE EN TRAZADORES } \\
\hline & \multicolumn{2}{|c|}{ TRIMESTRE 1} & \multicolumn{2}{|c|}{ TRIMESTRE 2} & \multicolumn{2}{|c|}{ TRIMESTRE 3} & \multicolumn{2}{|c|}{ TRIMESTRE 4} \\
\hline & 2014 & 2015 & 2014 & 2015 & 2014 & 2015 & 2014 & 2015 \\
\hline Parásitos totales & $687,2 \mathrm{a}$ & 466 a & $2642 \mathrm{a}$ & $703 \mathrm{a}$ & 2267 a & $4940 \mathrm{a}$ & $1022 \mathrm{a}$ & $499 \mathrm{a}$ \\
\hline H. contortus & $235 a$ & $375 a$ & 892 a & $260 \mathrm{a}$ & $1192 \mathrm{a}$ & 715 a & 464 a & $417 a$ \\
\hline Trichos. spp. & $7 a$ & $58 \mathrm{a}$ & $58 a$ & $83 a$ & $200 \mathrm{a}$ & $730 a$ & $33 a$ & $8 a$ \\
\hline T. colubriformis & $7 a$ & $58 \mathrm{a}$ & $58 a$ & $83 a$ & $200 \mathrm{a}$ & $730 \mathrm{a}$ & $33 \mathrm{a}$ & $8 a$ \\
\hline T. axei & $0 \mathrm{a}$ & $0 \mathrm{a}$ & $0 \mathrm{a}$ & $0 \mathrm{a}$ & $0 \mathrm{a}$ & $0 \mathrm{a}$ & $0 \mathrm{a}$ & $0 \mathrm{a}$ \\
\hline T. circumcincta & $0,2 \mathrm{a}$ & $0 \mathrm{a}$ & $0 \mathrm{a}$ & $0 \mathrm{a}$ & $0 \mathrm{a}$ & $1333 \mathrm{a}$ & $0 \mathrm{a}$ & $0 \mathrm{a}$ \\
\hline S. papillosus & $175 a$ & $15 \mathrm{a}$ & $1267 \mathrm{~b}$ & $42 a$ & $733 \mathrm{~b}$ & 25 a & $375 a$ & $58 a$ \\
\hline Cooperia spp. & $167 \mathrm{a}$ & $10 \mathrm{a}$ & $175 a$ & $267 a$ & $0 \mathrm{a}$ & 2058 a & $17 \mathrm{a}$ & $0 \mathrm{a}$ \\
\hline C. punctata & $142 \mathrm{a}$ & $10 \mathrm{a}$ & $125 a$ & $229 a$ & $0 \mathrm{a}$ & 1951 a & $0 \mathrm{a}$ & $0 \mathrm{a}$ \\
\hline C. pectinata & $25 \mathrm{a}$ & $0 \mathrm{a}$ & $50 a$ & $38 \mathrm{a}$ & $0 \mathrm{a}$ & 107 a & $17 \mathrm{a}$ & $0 \mathrm{a}$ \\
\hline N. spathiger & $86 a$ & $0 \mathrm{a}$ & $200 \mathrm{~b}$ & $8 a$ & $142 \mathrm{~b}$ & $0 \mathrm{a}$ & $133 a$ & $0 \mathrm{a}$ \\
\hline Trichuris ovis & $17 \mathrm{a}$ & $8 a$ & $50 a$ & $43 \mathrm{a}$ & $0 \mathrm{a}$ & $77 a$ & $0 \mathrm{a}$ & $8 a$ \\
\hline Oesoph. spp. & $0 \mathrm{a}$ & $0 \mathrm{a}$ & $0 \mathrm{a}$ & $0 \mathrm{a}$ & $0 \mathrm{a}$ & $2 a$ & $0 \mathrm{a}$ & $8 a$ \\
\hline O. venulosum & $0 \mathrm{a}$ & $0 \mathrm{a}$ & $0 \mathrm{a}$ & $0 \mathrm{a}$ & $0 \mathrm{a}$ & $2 a$ & $0 \mathrm{a}$ & $8 a$ \\
\hline O. radiatum & $0 \mathrm{a}$ & $0 \mathrm{a}$ & $0 \mathrm{a}$ & $0 \mathrm{a}$ & $0 \mathrm{a}$ & $0 \mathrm{a}$ & $0 \mathrm{a}$ & $0 \mathrm{a}$ \\
\hline
\end{tabular}

Letras diferentes expresan diferencias significativas $(p<0,05)$.

Tabla 32: comparaciones trimestrales entre años de las cargas parasitarias en trazadores. 
Las comparaciones globales realizadas entre los dos años del estudio revelan, que tanto S. papillosus como $N$. spathiger expresaron mayores cargas en el año 2014.

Cuando se analizaron los datos trimestrales, en el primer año se observaron diferencias significativas para el género Trichostrongylus spp. con valores máximos en el trimestre 3 y mínimos en el 1 (trimestre 2 y 4 intermedios). En el segundo año, únicamente se observaron diferencias significativas entre el trimestre 1 y 2 para el género Cooperia spp. siendo los demás trimestres intermedios.

Se realizó la comparación entre años para los diferentes trimestres, observando diferencias significativas únicamente en los trimestres 2 y 3 para $S$. papillosus y $N$. spathiger, con mayores recuentos en el año 2014. Aunque los recuentos para $H$. contortus y Trichostrongylus spp. fueron mayores en el primer y segundo año respectivamente para los trimestres 2 y 3 no se observaron diferencias significativas, las que pudieron detectarse al realizar una comparación bimestral (debiendo considerarse el reducido número de animales en este último análisis).

La regresión (lineal simple) con las variables meteorológicas expresa una relación negativa en Trichostrongylus spp. con la temperatura en todas sus mediciones (beta: $<-0,31$ y $\left.R^{2}: 0,1\right)$ y evapotranspiración (beta: $-0,38$ y $\mathrm{R}^{2}: 0,13$ ). Haemonchus contortus expresó relación negativa con los días de precipitaciones (beta: -0,29 y $\left.\mathrm{R}^{2}: 0,06\right)$ y positiva con las precipitaciones -30 (beta: 0,32 y $\mathrm{R}^{2}: 0,08$ ). 
Cooperia spp. expresó relación negativa con temperatura mínima y mínima absoluta (beta: $<-0,36$ y $\mathrm{R}^{2}:<0,1$ ), heliofania acumulada (beta: $-0,29$ y $R^{2}: 0,07$ ) y evapotranspiración (beta: $-0,4$ y $R^{2}: 0,2$ ) y relación positiva con humedad máxima y días con heladas (beta: 0,33 y $R^{2}$ : $<0,1)$. Nematodirus spathiger relación negativa con temperatura (beta: $-0,29$ y $R^{2}:<0,01$ ), evapotranspiración (beta: $-0,29$ y $R^{2}:<0,01$ ) y relación positiva con la humedad relativa máxima (beta: 0,32 y $R^{2}$ : $<0,01$ ). Trichuris ovis relación positiva con días con heladas (beta: 0,31 y $\mathrm{R}^{2}$ : $\left.<0,01\right)$. Teladorsagia cricumcincta; Strongyloides papillosus y Oesophagostomum spp. no presentaron relación estadísticamente significativa $(p<0,05)$ para las variables analizadas.

\section{Hipobiosis}

Se sacrificaron 96 animales que se detallan en la Tabla 33. También se muestran los resultados de animales sin encerrar (86 entre los tres grupos) que facilitan la interpretación de los niveles de infestación. 


\begin{tabular}{lllllllllllllll}
\hline \multicolumn{10}{c}{ CANTIDAD DE ANIMALES SACRIFICADOS } \\
\hline CONDICIÓN & CATEGORÍA & E & F & M & A & M & J & J & A & S & O & N & D & Total \\
\hline \multirow{2}{c}{$\begin{array}{c}\text { Con } \\
\text { Encierre }\end{array}$} & Ovejas & 2 & 3 & 2 & 4 & 2 & 3 & 1 & & 1 & 2 & 4 & 3 & $\mathbf{2 7}$ \\
& Trazadores & 2 & 2 & 2 & 4 & 2 & 3 & 3 & & 4 & 1 & 4 & 4 & $\mathbf{3 1}$ \\
\hline & Corderas & 2 & 2 & 2 & 2 & 2 & 2 & 2 & 2 & 4 & 2 & 2 & 2 & $\mathbf{2 6}$ \\
Sin Encierre & Ovejas & 2 & 3 & 2 & 2 & 2 & 3 & 5 & 2 & 5 & 2 & 2 & 2 & $\mathbf{3 2}$ \\
& Trazadores & 2 & 2 & 2 & 2 & 2 & 3 & 2 & 4 & 2 & 3 & 2 & 2 & $\mathbf{2 8}$ \\
\hline
\end{tabular}

Tabla 33: detalle de los animales sacrificados en cada mes para cada categoría.

En la Tabla 34 se presenta un resumen de los animales sacrificados y sus proporciones de L4 consideradas hipobióticas (respecto de la carga total para el género). Los valores máximos se hallaron para fines de invierno en los meses de julio y agosto y los porcentajes no superan el $4,5 \%$ de larvas inhibidas.

\begin{tabular}{|c|c|c|c|c|c|c|c|c|c|c|c|c|c|}
\hline \multicolumn{14}{|c|}{ CARGA RELATIVA DE L4 DE $H$. contortus (L4/total de $H$. contortus hallados) } \\
\hline CONDICIÓN & CATEGORÍA & $\mathrm{E}$ & $\mathrm{F}$ & M & A & M & J & J & A & S & $\mathrm{O}$ & $\mathrm{N}$ & D \\
\hline \multirow{3}{*}{$\begin{array}{c}\text { Carga de } H . \\
\text { contortus }\end{array}$} & Corderas & 1775 & 795 & 1150 & 1967 & 425 & 1408 & 2510 & 2525 & 1008 & 948 & 2180 & 2585 \\
\hline & Ovejas & 88 & 1298 & 425 & 1392 & 2040 & 3075 & 7778 & 5175 & 2359 & 2963 & 973 & 474 \\
\hline & Trazadores & 403 & 388 & 325 & 1308 & 438 & 202 & 502 & 1380 & 530 & 318 & 325 & 635 \\
\hline \multirow{3}{*}{ Con Encierre } & Corderas & $0 \%$ & $0 \%$ & $0 \%$ & $0 \%$ & $0 \%$ & $0,3 \%$ & $2,9 \%$ & $4,4 \%$ & $0 \%$ & $1,2 \% *$ & $0 \%$ & $0 \%$ \\
\hline & Ovejas & $0 \%$ & $0,2 \%$ & $0 \%$ & $1,00 \%$ & $0 \%$ & $0 \%$ & $0 \%$ & & $0 \%$ & $0 \%$ & $0 \%$ & $0 \%$ \\
\hline & Trazadores & $0 \%$ & $0 \%$ & $0 \%$ & $0 \%$ & $0 \%$ & $0 \%$ & $1,6 \%$ & & $0 \%$ & $0 \%$ & $1,19 \%$ & $0 \%$ \\
\hline
\end{tabular}




\begin{tabular}{|c|c|c|c|c|c|c|c|c|c|c|c|c|c|}
\hline & Corderas & $21,4 \%$ & $18,5 \%$ & $1,0 \%$ & $0,7 \%$ & $30,0 \%$ & $3,8 \%$ & $9,4 \%$ & $4,5 \%$ & $27,6 \%$ & $9,6 \%$ & $9,8 \%$ & $9,4 \%$ \\
\hline \multirow[t]{2}{*}{ Sin Encierre } & Ovejas & $9,3 \%$ & $14,0 \%$ & $0 \%$ & $0 \%$ & $1,0 \%$ & $5,3 \%$ & $0,9 \%$ & $10,8 \%$ & $3,3 \%$ & $0 \%$ & $25,0 \%$ & $0 \%$ \\
\hline & Trazadores & $0 \%$ & $25,4 \%$ & $45,8 \%$ & $0 \%$ & $0 \%$ & $31,5 \%$ & $43,3 \%$ & $18,0 \%$ & $15,3 \%$ & $44,2 \%$ & $0 \%$ & $63,5 \%$ \\
\hline
\end{tabular}

* En el mes de octubre se excluyó una de las corderas, ya que presentó un solo $H$. contortus y en estado de $L 4$, no siendo representativo.

Tabla 34: promedio de la carga parasitaria total de $H$. contortus para cada categoría y carga porcentual de larvas inhibidas en animales encerrados y larvas halladas en animales sin encierre previo al sacrificio.

En el análisis por regresión se observó asociación entre los porcentajes de larvas hipobióticas con las precipitaciones acumuladas (Beta: $-0,697$ y $\left.R^{2}: 0,434\right)$ y con los días de precipitaciones (Beta: 0,613 y $\left.R^{2}: 0,313\right)$.

\section{Integración de los resultados}

El último cuatrimestre del año 2013 termina con un balance hídrico negativo, que se observa acumulado en bajos valores de almacenaje total (debajo de $130 \mathrm{~mm}$ ). Comenzando el 2014, el balance se hace positivo y se sostiene así durante todo el año (almacenaje total por encima de $130 \mathrm{~mm}$ ). En ovejas comienzan a acumularse $H$. contortus, que alcanza el máximo al momento del parto, que avanzada la lactancia y hasta el destete decae. En tanto Trichostrongylus spp., más allá de los altos recuentos iniciales, se observa en menor proporción sin sobresaltos en todo el año. En el segundo año, el balance hídrico resulta crítico en el primer cuatrimestre debido a tres meses consecutivos con valores negativos, invirtiéndose luego. La carga de $H$. 
contortus, aunque nuevamente máxima al momento del parto, evidencia menores recuentos que el año anterior. Por el contrario, Trichostrongylus spp. va en aumento hasta el momento del parto, donde se reduce y comienza un período de acumulación hasta el verano. Debe destacarse que las cargas parasitarias registradas por los animales (permanentes y trazadores), reflejan la oferta de un entorno en el que los animales de majada general fueron tratados mucho más intensamente en 2014 que los de 2015, como consecuencia de ese desafío mayor por $H$. contortus. Esos tratamientos influyeron también en la oportunidad de T. colubriformis de acumular larvas en el pasto, mientras que no impidieron a $H$. contortus, de mayor tasa reproductiva, generar en los intervalos una importante siembra de huevos.

Las corderas en el primer año muestran cargas crecientes hasta la primavera-verano. Durante el segundo, se observan cargas altas de Trichostrongylus spp. durante el primer cuatrimestre (coincidiendo con el período de balance hídrico negativo y bajos valores de almacenaje total) que hacia mitad de año se reducen para nuevamente comenzar a acumularse y llegar al verano. $H$. contortus muestra pendientes menores, alcanzando los máximos recuentos a principios de otoño, que luego decaen recuperándose hacia fin de año cuando el balance hídrico es fuertemente positivo.

Los otros géneros, se observan en ovejas durante el primer año fundamentalmente en primavera $y$ en el segundo durante el primer trimestre y en el parto. En corderas se observan mayores recuentos 
durante el primer año (tener en cuenta la carga de Strongyloides papillosus), mientras que, en el segundo ocupan un lugar menor.

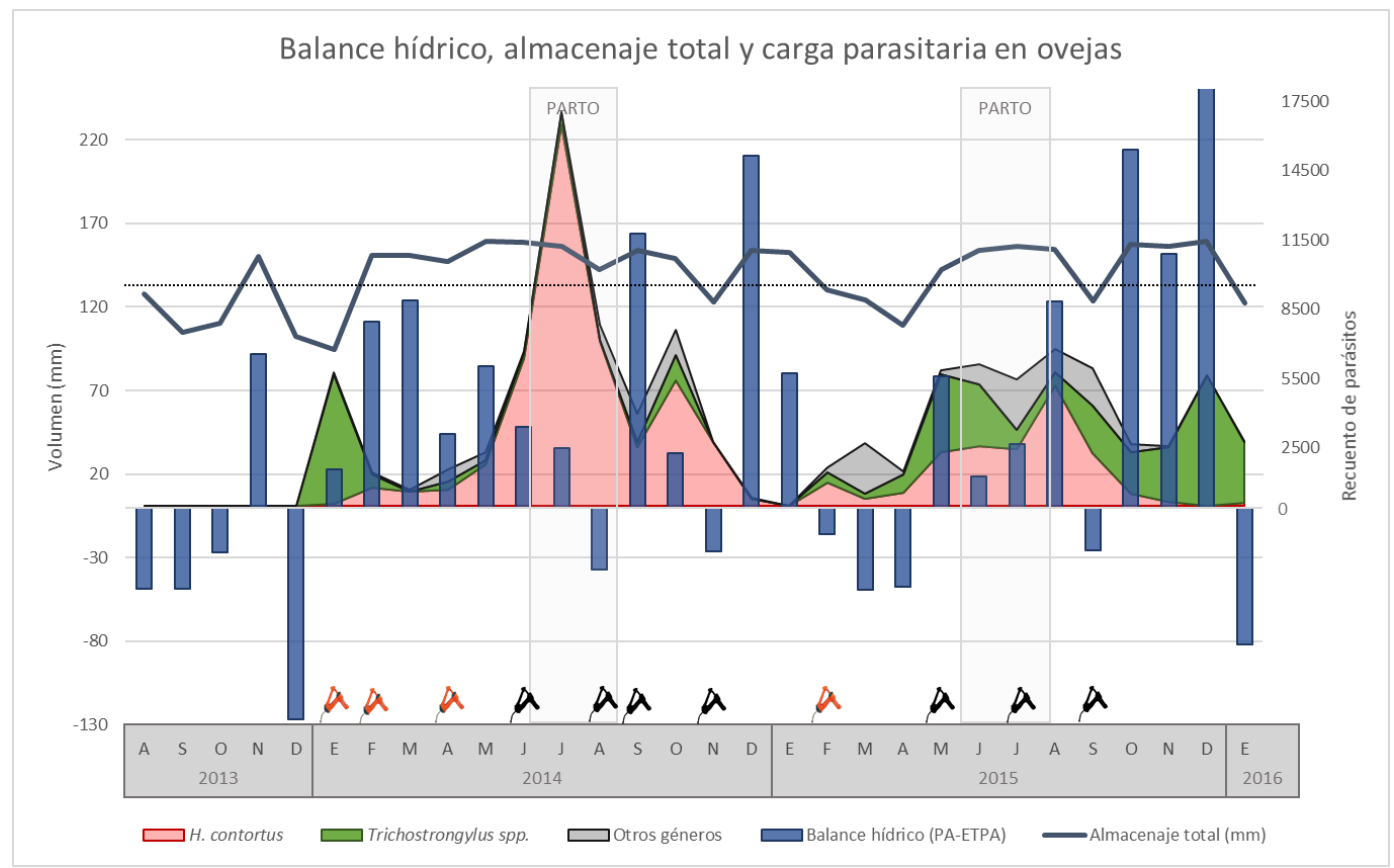

Gráfico 20: relación de cargas parasitarias y resultados de balance hídrico y almacenaje total en ovejas durante los dos años de estudio, indicando los momentos de parición. Se indican los tratamientos de la majada de entorno (en naranja tratamientos FAMACHA ${ }^{\odot}$ y en negro los poblacionales), que aunque no afectaron directamente lo expresado por los animales sacrificados modifican el contexto de contaminación. Se añadieron datos del año anterior al estudio para observar la evolución de las variables meteorológicas. 


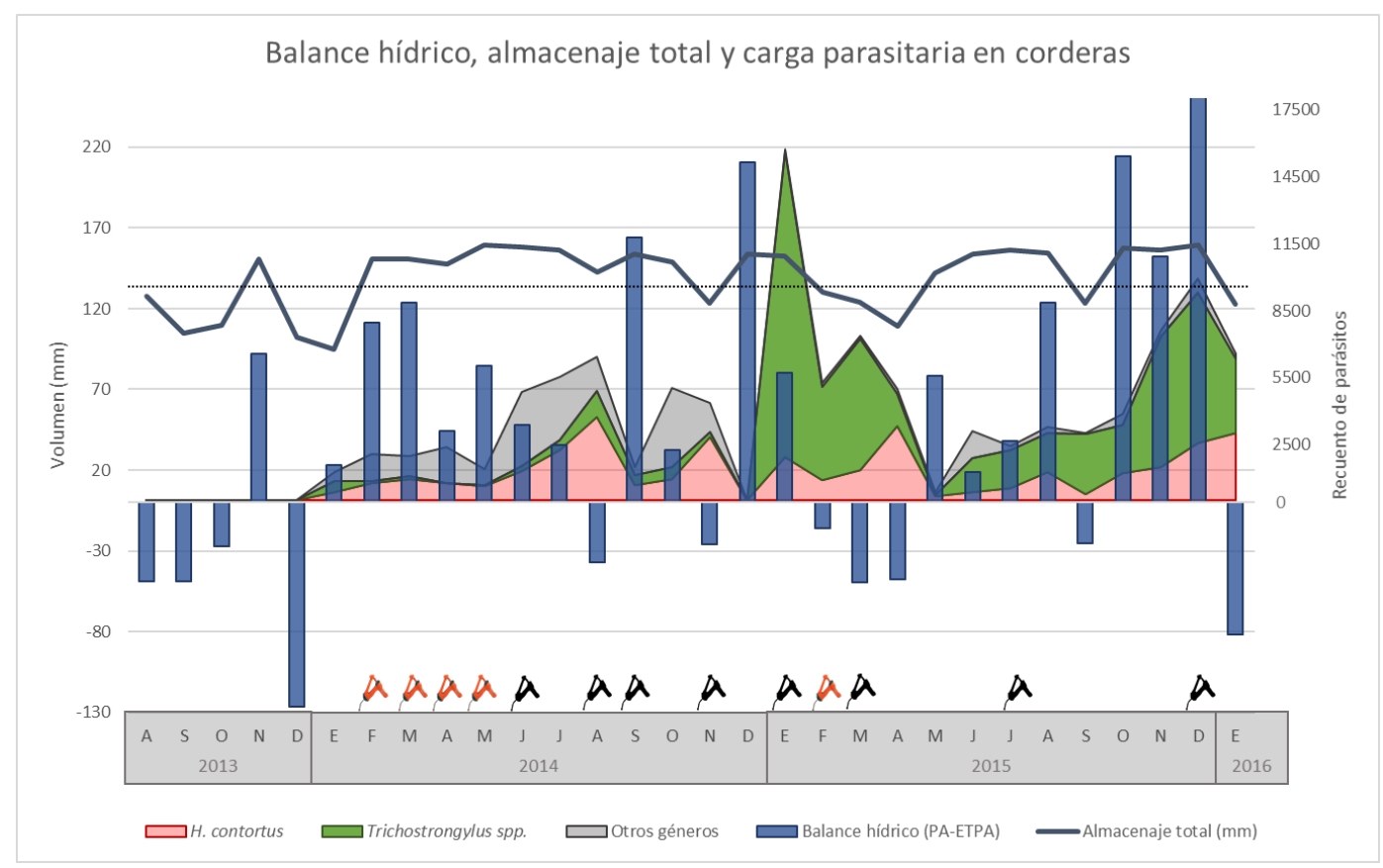

Gráfico 21: relación de cargas parasitarias y resultados de balance hídrico y almacenaje total en corderas de recría durante los dos años de estudio. Se indican los tratamientos de la majada de entorno (en naranja tratamientos FAMACHA $^{\odot}$ y en negro los poblacionales), que aunque no afectaron directamente lo expresado por los animales sacrificados modifican el contexto de contaminación. Se añadieron datos del año anterior al estudio para observar la evolución de las variables meteorológicas. 


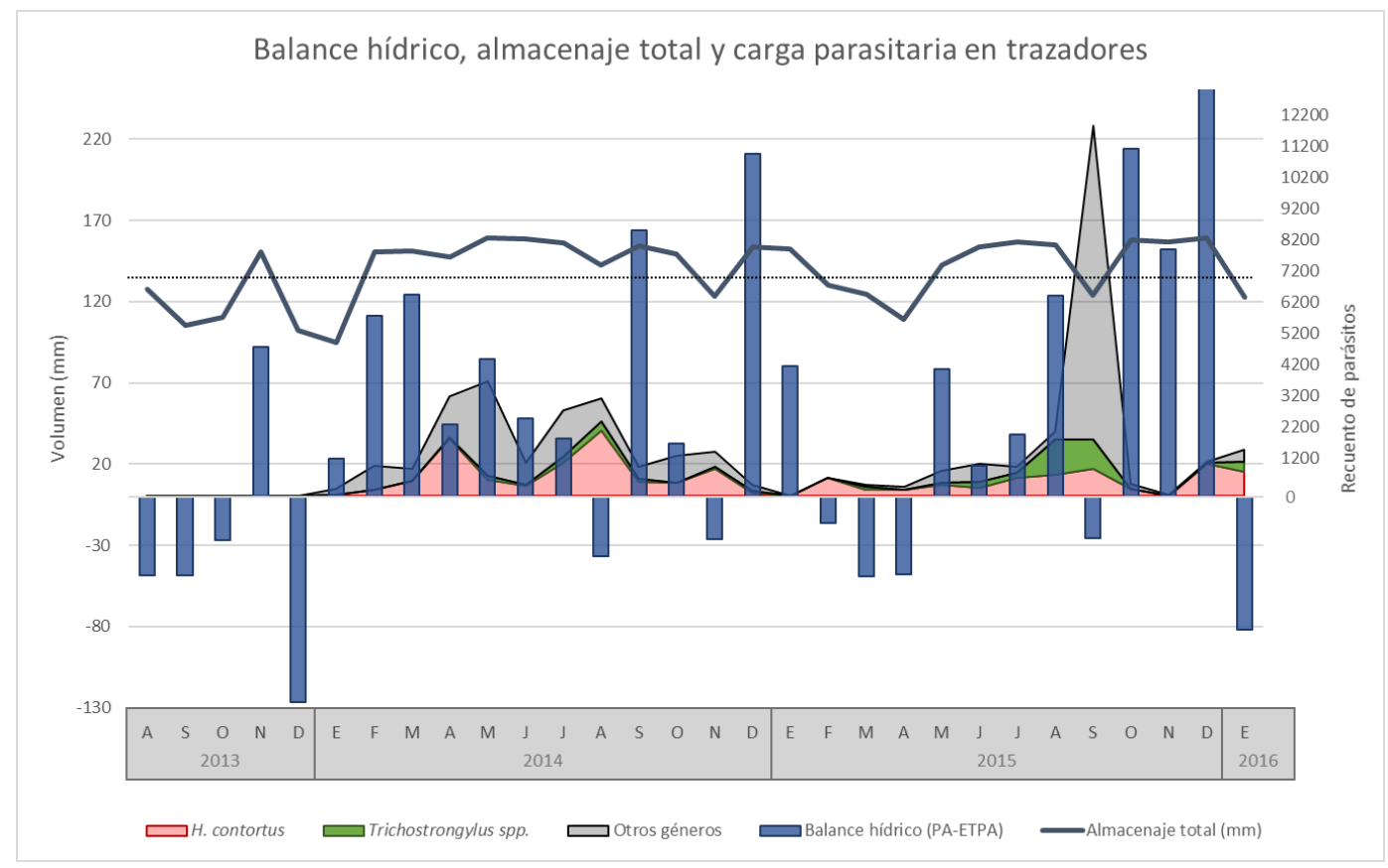

Gráfico 22: relación de cargas parasitarias y resultados de balance hídrico y almacenaje total en trazadores durante los dos años de estudio. Se añadieron datos del año anterior al estudio para observar la evolución de las variables meteorológicas.

8. Estudios coproparasitológicos de los animales sacrificados (según Tabla 14)

En las ovejas la dinámica mensual de eliminación de huevos (Tabla 35 y 36 ) tiende a consolidarse hacia el invierno, coincidiendo con lo observado en las necropsias. El género predominante es Haemonchus spp. con valores en los cultivos mensuales mayores a 50\% (con excepción de diciembre del segundo año que alcanzó el 20\%). El segundo género en importancia es Trichostrongylus spp. con mayor prevalencia en el segundo año. Mientras que el género Cooperia spp. estuvo presente en ambos años observándose mayores recuentos en invierno. En tanto la presencia de Nematodirus spp. y 
Oesophagostomum spp. fue prácticamente exclusiva del primer y segundo año respectivamente. A este último se le sumó Ostertagia spp. con predominio en verano.

\begin{tabular}{lccccccccccccc}
\hline \multicolumn{1}{c}{ GENEROS } & E & $\mathrm{F}$ & $\mathrm{M}$ & $\mathrm{A}$ & $\mathrm{M}$ & $\mathrm{J}$ & $\mathrm{J}$ & $\mathrm{A}$ & $\mathrm{S}$ & $\mathrm{O}$ & $\mathrm{N}$ & $\mathrm{D}$ & $\mathrm{E}$ \\
\hline OVEJAS 2014 & & & & & & & & & & & & \\
\hline HPG total & 100 & 2100 & 2400 & 7600 & 2100 & 11600 & 4800 & 9150 & 2500 & 3550 & 400 & - & - \\
\hline Haemonchus spp. & 89 & 2037 & 2040 & 7448 & 2058 & 10672 & 4560 & 9059 & 1500 & 3444 & 400 & - & - \\
Trichos. spp. & 7 & 42 & 168 & 152 & 21 & 928 & 192 & 0 & 175 & 107 & 0 & - & - \\
Ostertagia. spp. & 0 & 0 & 0 & 0 & 0 & 0 & 0 & 0 & 0 & 0 & 0 & - & - \\
Cooperia spp. & 2 & 21 & 120 & 0 & 0 & 0 & 48 & 0 & 325 & 0 & 0 & - & - \\
Nematodirus spp. & 2 & 0 & 72 & 0 & 21 & 0 & 0 & 92 & 500 & 0 & 0 & - & - \\
Oesoph. spp. & 0 & 0 & 0 & 0 & 0 & 0 & 0 & 0 & 0 & 0 & 0 & - & - \\
\hline
\end{tabular}

Tabla 35: promedio de recuentos de HPG proporcionales para cada género según los resultados de los coprocultivos en ovejas sacrificadas en el año 2014.

\begin{tabular}{|c|c|c|c|c|c|c|c|c|c|c|c|c|c|}
\hline GENEROS & $E$ & $F$ & $M$ & A & $M$ & J & J & A & $S$ & 0 & $\mathrm{~N}$ & D & $\mathrm{E}$ \\
\hline \multicolumn{14}{|l|}{ OVEJAS 2015} \\
\hline HPG total & - & 950 & 600 & 850 & 1550 & 1598 & 1300 & 1050 & 1535 & 599 & 100 & 300 & 600 \\
\hline Haemonchus spp. & - & & 504 & 663 & 1411 & 939 & 949 & & 1194 & 521 & 71 & 60 & 600 \\
\hline Trichos. spp. & - & & 60 & 128 & 140 & 602 & 260 & & 295 & 53 & 28 & 207 & 0 \\
\hline Ostertagia. spp. & - & & 6 & 43 & 0 & 0 & 52 & & 16 & 0 & 0 & 0 & 0 \\
\hline Cooperia spp. & - & & 12 & 9 & 0 & 58 & 39 & & 16 & 0 & 0 & 0 & 0 \\
\hline Nematodirus spp. & - & & 0 & 0 & 0 & 0 & 0 & & 0 & 0 & 0 & 0 & 0 \\
\hline Oesoph. spp. & - & & 18 & 9 & 0 & 0 & 0 & & 16 & 26 & 1 & 33 & 0 \\
\hline
\end{tabular}

Tabla 36: promedio de recuentos de HPG proporcionales para cada género según los resultados de los coprocultivos en ovejas sacrificadas en el año 2015. En los meses de febrero y agosto no se pudieron recuperar larvas en los coprocultivos. 
En el caso de las corderas de recría (Tabla 37 y 38), los recuentos de huevos tienden a aumentar hacia el verano, fenómeno más marcado en el segundo año, mientras que la composición genérica no presenta grandes variaciones respecto de lo descripto para las ovejas.

\begin{tabular}{|c|c|c|c|c|c|c|c|c|c|c|c|c|c|}
\hline GENEROS & $\mathrm{E}$ & $\mathrm{F}$ & $M$ & A & $M$ & J & J & $A$ & $S$ & 0 & $\mathrm{~N}$ & D & $E$ \\
\hline \multicolumn{14}{|l|}{ CORDERAS 2014} \\
\hline HPG total & 3550 & 600 & 4100 & 1300 & 4200 & 3350 & 1750 & 3400 & 1400 & 3400 & 4550 & - & - \\
\hline Haemonchus spp. & & 546 & 3116 & 1248 & 3990 & 3183 & 1663 & 3332 & 1386 & & 3322 & - & - \\
\hline Trichos. spp. & & 12 & 656 & 13 & 126 & 67 & 53 & 68 & 0 & & 1001 & - & - \\
\hline Ostertagia. spp. & & 0 & 0 & 0 & 0 & 0 & 0 & 0 & 0 & & 0 & - & - \\
\hline Cooperia spp. & & 42 & 246 & 39 & 84 & 34 & 36 & 0 & 14 & & 0 & - & - \\
\hline Nematodirus spp. & & 0 & 82 & 0 & 0 & 34 & 0 & 0 & 0 & & 228 & - & - \\
\hline Oesoph. spp. & & 0 & 0 & 0 & 0 & 34 & 0 & 0 & 0 & & 0 & - & - \\
\hline
\end{tabular}

Tabla 37: promedio de recuentos de HPG proporcionales para cada género según los resultados de los coprocultivos para corderas sacrificadas en el año 2014. En los meses de enero y octubre no se recuperaron larvas en los coprocultivos.

\begin{tabular}{lccccccccccccc}
\hline \multicolumn{1}{c}{ GENEROS } & E & $\mathrm{F}$ & $\mathrm{M}$ & $\mathrm{A}$ & $\mathrm{M}$ & $\mathrm{J}$ & $\mathrm{J}$ & $\mathrm{A}$ & $\mathrm{S}$ & $\mathrm{O}$ & $\mathrm{N}$ & $\mathrm{D}$ & $\mathrm{E}$ \\
\hline CORDERAS 2015 & & & & & & & & & & & & \\
\hline HPG total & 3450 & 750 & 6050 & 1600 & 350 & 550 & 850 & 842 & 200 & 606 & 909 & 3850 & 6550 \\
\hline Haemonchus spp. & 3002 & 608 & 5869 & 1008 & 284 & 482 & 744 & 729 & 100 & 309 & 522 & 3542 & 5437 \\
Trichos. spp. & 414 & 135 & 182 & 592 & 67 & 68 & 106 & 113 & 86 & 255 & 369 & 154 & 1114 \\
Ostertagia. spp. & 35 & 0 & 0 & 0 & 0 & 0 & 0 & 0 & 4 & 27 & 9 & 39 & 0 \\
Cooperia spp. & 0 & 0 & 0 & 0 & 0 & 0 & 0 & 0 & 0 & 0 & 0 & 0 & 0 \\
Nematodirus spp. & 0 & 0 & 0 & 0 & 0 & 0 & 0 & 0 & 0 & 0 & 0 & 0 & 0 \\
Oesoph. spp. & 0 & 8 & 0 & 0 & 0 & 0 & 0 & 0 & 10 & 15 & 9 & 116 & 0 \\
\hline
\end{tabular}


Tabla 38: promedio de recuentos de HPG proporcionales para cada género según los resultados de los coprocultivos para corderas sacrificadas en el año 2015.

Se analizó por regresión los recuentos de HPG y coprocultivo de Ios animales sacrificados con los recuentos parasitarios de cada género obtenidos por necropsia para cada categoría, en cada trimestre.

Tanto en ovejas, como en corderas se observa relación positiva entre los HPG de los animales sacrificados y los recuentos de necropsia para los parásitos totales, para $H$. contortus y $N$. spathiger. En ovejas además se observa para Cooperia spp., mientras que en corderas para Trichostrongylus spp. (Tabla 39). Así mismo se observó asociación positiva para los recuentos de HPG totales con la carga parasitaria de $H$. contortus en ambas categorías.

\begin{tabular}{|c|c|c|c|c|c|c|c|c|}
\hline VARIABLE & ESTADISTICO & $\begin{array}{c}\text { Parásitos } \\
\text { totales }\end{array}$ & $\begin{array}{c}H . \\
\text { contortus }\end{array}$ & $\begin{array}{c}\text { Trichos. } \\
\text { spp. }\end{array}$ & $\begin{array}{c}T . \\
\text { circumcincta }\end{array}$ & $\begin{array}{c}\text { Cooperia } \\
\text { spp. }\end{array}$ & N. spathiger & $\begin{array}{c}\text { Oesoph. } \\
\text { spp. }\end{array}$ \\
\hline \multirow{3}{*}{$\begin{array}{c}\text { HPG de } \\
\text { Ovejas } \\
(n=47)\end{array}$} & Valor-P & 0,001 & 0,001 & & & 0,001 & 0,044 & \multirow{3}{*}{ NS } \\
\hline & $\begin{array}{l}\text { Coeficiente de } \\
\text { correlación }\end{array}$ & 0,594 & 0,803 & NS & NS & 0,503 & 0,316 & \\
\hline & $\mathrm{R}^{2}$ & 0,339 & 0,636 & & & 0,234 & 0,077 & \\
\hline \multirow{3}{*}{$\begin{array}{l}\text { HPG de } \\
\text { Corderas } \\
(n=48)\end{array}$} & Valor-P & 0,037 & 0,001 & 0,019 & \multirow{3}{*}{ NS } & & 0,017 & \multirow{3}{*}{ NS } \\
\hline & $\begin{array}{l}\text { Coeficiente de } \\
\text { correlación }\end{array}$ & 0,302 & 0,549 & 0,353 & & NS & 0,359 & \\
\hline & $\mathrm{R}^{2}$ & 0,071 & 0,284 & 0,104 & & & 0,108 & \\
\hline
\end{tabular}

Tabla 39: regresión simple entre los recuentos de HPG y coprocultivo de los animales sacrificados con los recuentos parasitarios obtenidos por necropsia en ovejas y corderas. NS: No Significativo $(p<0,05)$. 
9. Proporción de los recuentos parasitarios

La cantidad total de parásitos en ovejas para cada año fue de 57.910 y 49.553 , mientras que en corderas fueron 36.931 y 73592 para el 2014 y 2015 respectivamente. Las proporciones detalladas a continuación se expresan en porcentaje sobre estos valores (hallados en los animales sacrificados según Tabla 14).

Los promedios anualizados de los recuentos parasitarios obtenidos por necropsia revelan en el primer año de seguimiento que el principal parásito es $H$. contortus con 63,8 y $34,4 \%$ para ovejas y corderas respectivamente. El segundo género hallado en ovejas es Trichostrongylus spp. (principalmente T. colubriformis) con 27,6\%, mientras que en corderas S. papillosus y Trichostrongylus spp. se hallaron en valores de 20,7 y $20,4 \%$ respectivamente. Los demás géneros hallados en ambas categorías son principalmente Cooperia spp. (C. punctata y C. pectinata) y N. spathiger. En menor proporción S. papillosus en ovejas y Trichuris ovis en corderas (ausente en animales adultos).

En el segundo año de seguimiento, el principal parásito resultó ser Trichostrongylus spp. (principalmente $T$. colubriformis) en ambas categorías ( 56,3 y $77,8 \%$ para ovejas y corderas respectivamente), estando en segundo lugar $H$. contortus $(20,9 \%$ y $12,8 \%$ para ovejas y corderas respectivamente). En ovejas Cooperia spp. representó el $18,9 \%$ del total de parásitos y $T$. circumcincta el 2,9\%. En corderas se hallaron Cooperia spp. y $T$. circumcincta con $4,1 \%$ y $4,3 \%$ 
respectivamente. Los géneros $N$. spathiger; Oesophagostomum spp.; Trichuris ovis y S. papillosus acumulan $1 \%$ en ambas categorías.

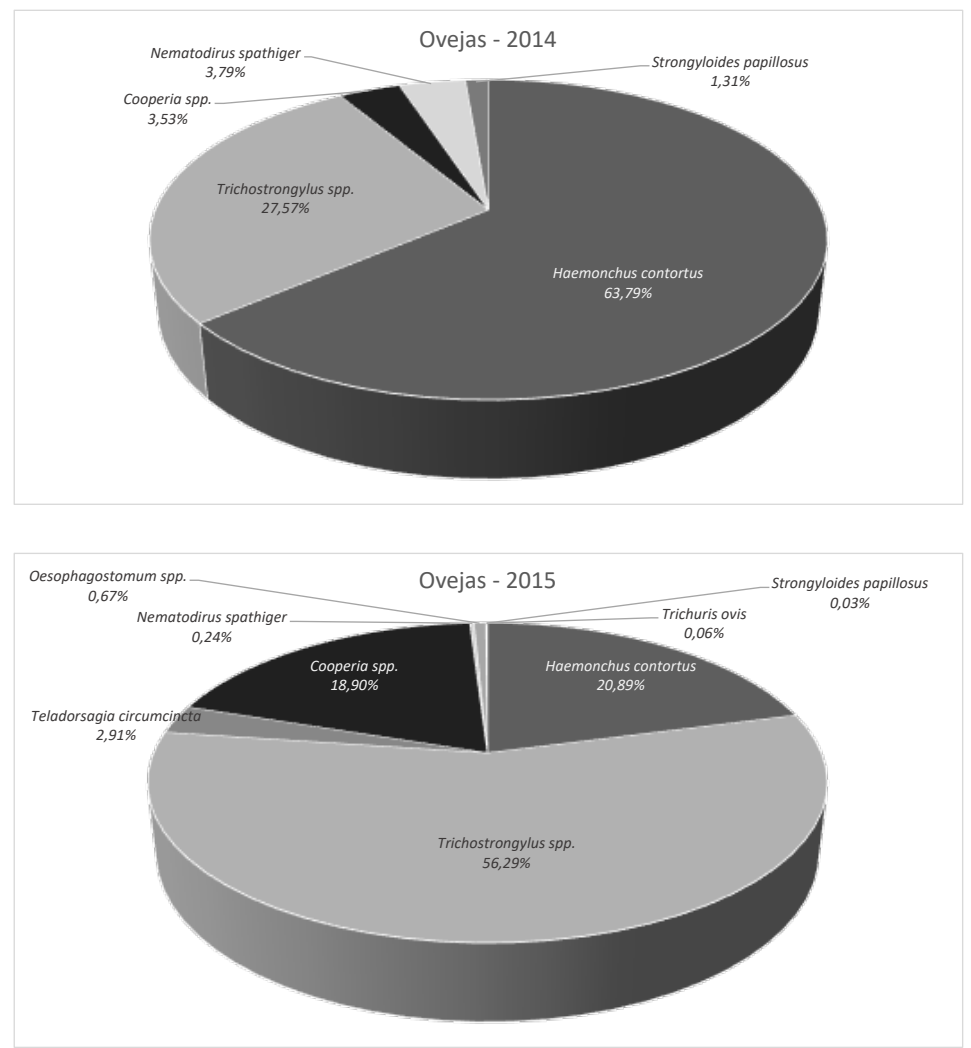

Gráfico 23 y 24: proporción de recuentos parasitarios acumulados anualmente, obtenidos por necropsia para los diferentes géneros en ovejas sacrificadas.

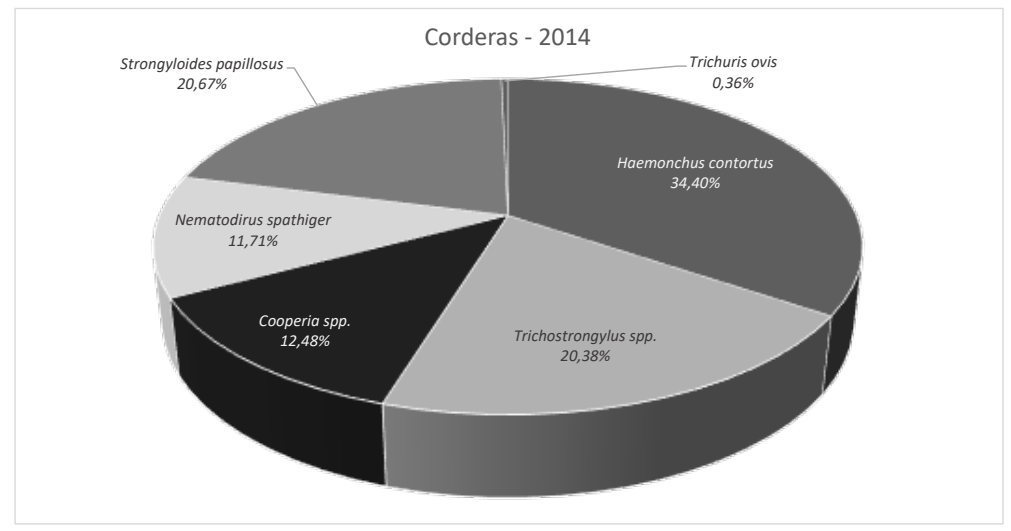




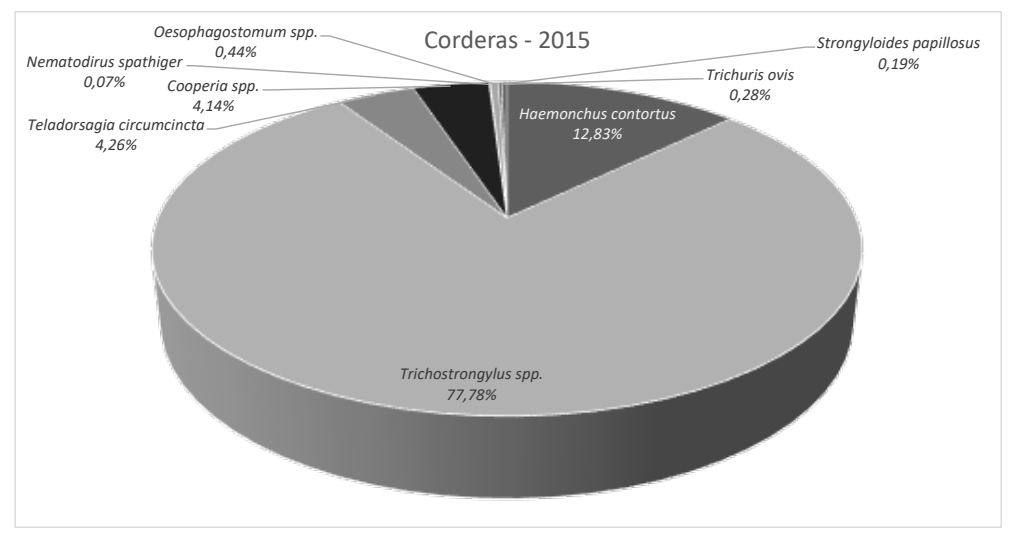

Gráfico 25 y 26: proporción de recuentos parasitarios acumulados anualmente, obtenidos por necropsia para los diferentes géneros en corderas sacrificadas.

Fueron ajustados proporcionalmente los recuentos parasitarios a la cantidad de animales para cada categoría (7,7 ovejas/2,3 corderas) y resulta evidente la mayor representatividad de la composición parasitaria de las ovejas en el total de los parásitos del campo (siembra). Así como también, los momentos en que las cargas de las corderas cobran mayor importancia (primavera-verano) y la importancia relativa de los diferentes géneros (Gráfico 27). 


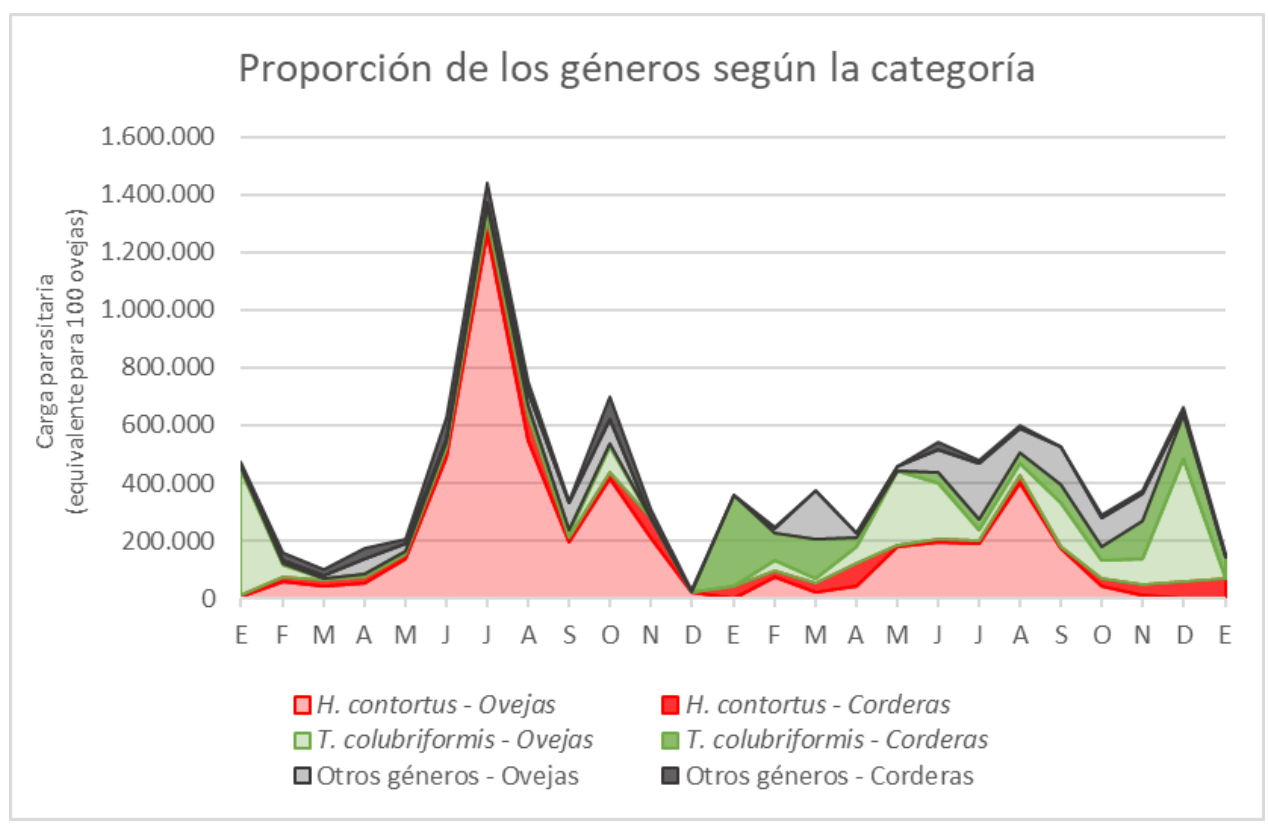

Gráfico 27: cantidad de parásitos aportados por 100 animales por cada categoría para cada género.

La mayor cantidad de parásitos en ambos años está dada por las ovejas y corresponde a $H$. contortus, especialmente en invierno. En el verano el aporte de las corderas puede ser más variable y siempre con predominio de Trichostrongylus spp.

Por otro lado los recuentos de HPG, tanto en ovejas como en corderas, expresan en ambos años un predominio de Haemonchus spp. $(89,5 \% ; 88,5 \% ; 76,7 \%$ y $85,8 \%$ para ovejas 2014 , corderas 2014 , ovejas 2015 y corderas 2015 respectivamente). El segundo en importancia es el Trichostrongylus spp. con mayores valores en el segundo año $(6,3 \% ; 8,1 \% ; 19,5 \%$ y $13,1 \%$ para ovejas 2014, corderas 2014, ovejas 2015 y corderas 2015 respectivamente). Los demás géneros no resultan representativos observándose en valores menores al $2,2 \%$ y acumulando en total $4,2 \% ; 3,4 \% ; 3,8 \%$ y $1,1 \%$ 
para ovejas 2014, corderas 2014, ovejas 2015 y corderas 2015 respectivamente.

\section{c. Discusión}

Como producto de este apartado surgen nuevas teorías, expresadas gráficamente, que motivan al desarrollo de nuevas investigaciones.

Los resultados obtenidos demuestran que el principal género parasitario en los ovinos de la región es $H$. contortus, coincidiendo con lo documentado en otras partes del mundo por otros autores (Nari et al., 1977; Vlassoff et al., 2001; Morgan y van Dijk, 2012; Castells et al., 1995). Sin embargo, T. colubriformis puede alcanzar cargas suficientes para convertirse en el principal género en ambas categorías (efecto más marcado en corderas).

La evolución de la carga parasitaria presentó un patrón diferente entre categorías. En ovejas, el momento de mayor carga está asociado al parto, mientras que las corderas son susceptibles hasta el año, aunque su inmunidad progrese (Michel et al., 1979; Barger, 1988) y la carga refleja lo acumulado en las pasturas, producto de lo que eliminan las ovejas, coincidiendo con el modelo propuesto por Vlassoff (et al., 1982).

El parto es el factor con mayor impacto en la carga parasitaria, expresando la composición presente en el campo. Por lo tanto, es el otoño y su gran variabilidad donde tal vez se defina la magnitud del pico 
(Gráfico 28). Una siembra suficiente en ese período asegura la disponibilidad para el invierno y basta con que las ovejas comiencen la parición para multiplicarlos. En el primer año el menor aporte de otros géneros ( $T$. colubriformis fundamentalmente), facilitó el predominio de $H$. contortus en grandes magnitudes, mientras que, en el segundo año la carga fue más variada.

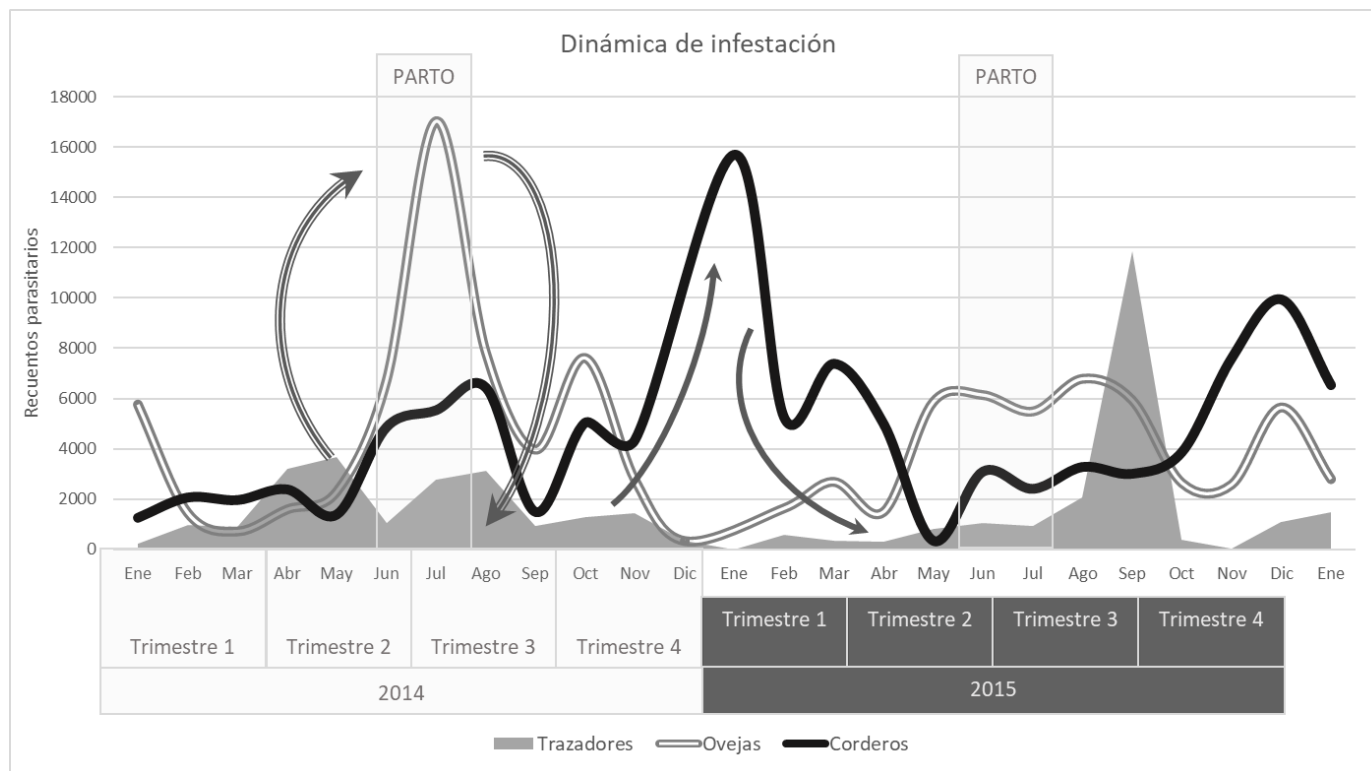

Gráfico 28: dinámica del comportamiento epidemiológico de infestación en ovejas y corderas para los parásitos totales. El mismo sugiere, que la carga acumulada en los trazadores en otoño, justificaría el pico del periparto en las ovejas, que generarán el pie de infección sobre el cual acumularán las corderas recién destetadas. Pese a tratarse de campos diferentes, los resultados son consistentes y muestran una continuidad conceptual.

Haemonchus contortus: alcanza su pico durante el inviernoprimavera (asociado al parto), observando los menores recuentos durante el verano, a diferencia de lo informado por Romero y Boero (2001) (sobre la base de estudios coprológicos), por Castells (et al., 
2011) y Sanchez y Romero (2005) que señalan picos de verano-otoño. Esos picos, responden seguramente a otoños con condiciones favorables para la traslación de L3, que son frecuentes e impactan más en las casuísticas clínicas de los servicios de diagnóstico, pero que no resultan necesariamente la regla a generalizar.

El fenómeno de hipobiosis se presenta durante los períodos desfavorables a la maduración y traslación de larvas en el ambiente. A diferencia de lo descripto por otros autores en distintas regiones (Suarez, 1986, Sanchez y Romero, 2005; Castells et al., 2011), en Corrientes revela una baja magnitud $(<5 \%)$ para $H$. contortus, aunque con la misma dinámica, asociada a los menores registros de precipitaciones (que suelen ser suficientes), considerándose este fenómeno de poca importancia epidemiológica.

En la región, las temperaturas mínimas no resultan limitantes y en ese contexto, encontramos los mayores recuentos de parásitos en los animales (ovejas periparto) en los momentos con menores precipitaciones y temperaturas. Estas condiciones menos extremas y la disponibilidad de huéspedes susceptibles se asocian, reduciendo la presión de selección por esta característica. Dicho comportamiento no ajusta al modelo propuesto en los bioclimatogramas por Gordon (1948) y Levine (1963), que no explican la dinámica de este parásito. Esto ocurre en animales permanentes como en trazadores y afirma que los clásicos modelos de bioclimatogramas proponen valores de corte, pero no sugieren tendencias o asociaciones de las variables con el sujeto de estudio. 
Trichostrongylus spp.: género representado fundamentalmente por Trichostrongylus colubriformis en ambas categorías. Las tasas de infestación aumentan hacia fines de invierno, acumulándose en animales permanentes hasta diciembre, cuando la temperatura es máxima, ya que toleran mejor la desecación que el $H$. contortus (Rosa et al., 1973 y Lombardero et al., 1976). La temperatura no se presenta como limitante (ni por alta ni por baja). Cuando se aumentó el intervalo entre tratamientos, potenciado por la falla en la eficacia de las drogas, este género pudo alcanzar cargas considerables especialmente en corderas.

Strongyloides papillosus: debe considerarse (especialmente en corderas) en condiciones de manejo de alta carga o hacinamiento, como las observadas durante el primer año de estudio. En coincidencia con Onyali (et al., 1989), fue observado con mayor prevalencia en otoñoinvierno, pero sumamente condicionado a la oportunidad de infecciones percutáneas, favorecidas ampliamente por las condiciones del encierre diario. Aunque es un parásito poco patógeno, hay estudios que lo asocian con un mayor daño oxidativo en el huésped (Dimitrijevic et al., 2012) o con muerte súbita en terneros (Taira et al., 1992). 


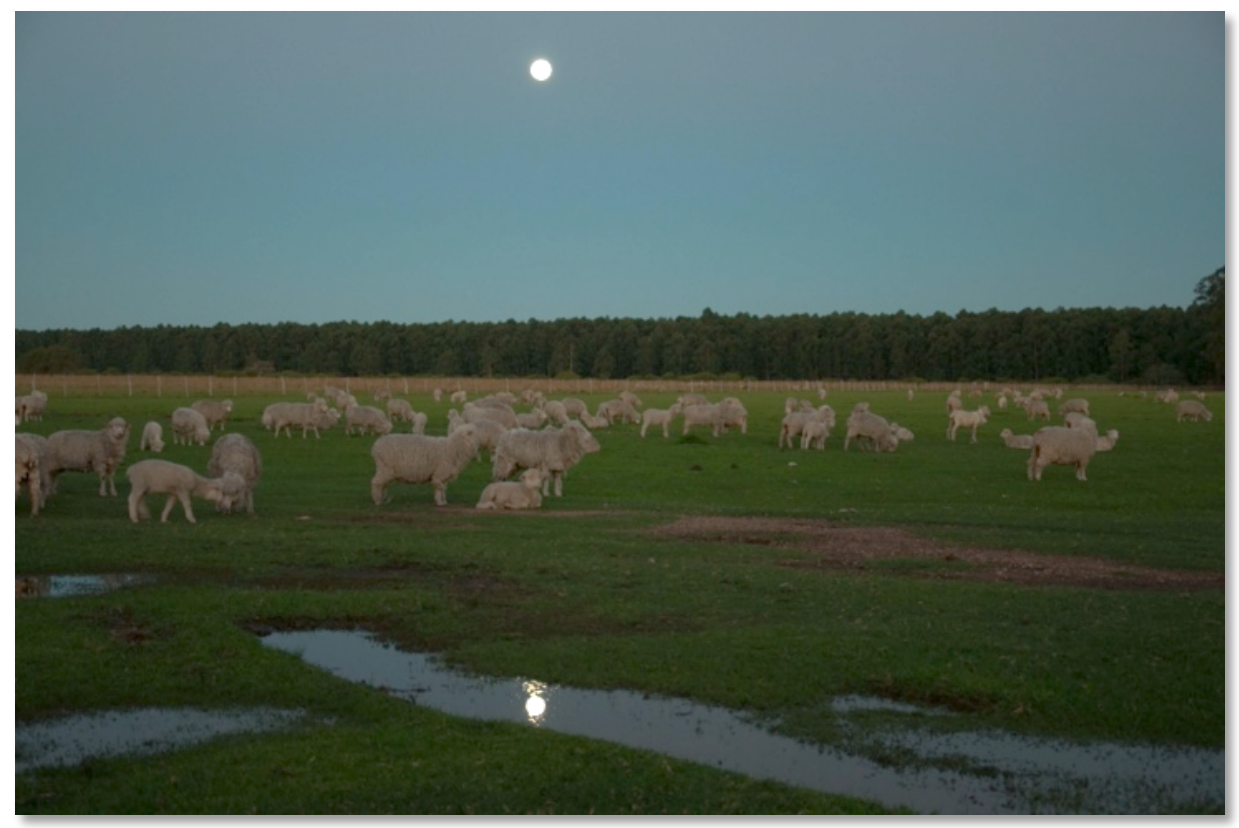

Imagen 2: encierre nocturno en parcelas cercanas a la casa para reducir el riesgo de abigeato.

Cooperia spp. presentó un patrón otoño-invernal, especialmente en el segundo año, asociándose a mayores cargas de bovinos. Las especies halladas fueron C. punctata y en segundo lugar $C$. pectinata.

Nematodirus spathiger fue descripto especialmente en el primer año (asociado a condiciones intensivas) con predominio en corderas y patrón de invierno-primavera, con mayores tasas de infección en otoñoinvierno.

Teladorsagia circumcincta se observó únicamente en el segundo año, en ovejas en época de parición. Las corderas de recría presentaron un patrón menos definido.

Las observaciones de Oesophagostomum spp. fueron exclusivas del segundo año de estudio (asociándolo a la mayor carga de bovinos). En ovejas se observó en invierno-primavera, junto con las tasas de 
infección (trazadores), mientras que en corderas de recría, predominó durante el primer semestre. La especie predominante fue Oesophagostomum venulosum con hallazgos ocasionales de Oesophagostomum radiatum.

Trichuris ovis puede ser considerado un parásito de baja incidencia, más constante en corderas que en ovejas. Las tasas de infección para este género, van en aumento desde el destete hasta entrado el invierno.

\section{Diferencias entre establecimientos y entre años}

El cambio de establecimiento plantea un problema en la interpretación de las causas de las diferencias asociadas por año o establecimiento.

En términos generales, las diferencias entre establecimientos están en la relación ov/bov y en las rutinas de encierre nocturno. Consideramos que ahí reside buena parte de la diferencia de presentación de la strongyloidiosis y la mayor frecuencia de Cooperia spp., T. circumcincta y Oesophagostomum spp. donde claramente la proporción de bovinos era mayor $(0,75$ y 0,57 ov/bov en 2014 y 2015 respectivamente).

Siguiendo ese análisis, una mayor proporción de bovinos facilita la expresión de géneros más adaptados a ésta especie, como es el caso de Cooperia spp. y Oesophagostomum spp. y puede observarse en el segundo año de estudio cuando la carga de vacunos fue mayor. La carga animal instantánea y relativa sugieren efectos similares en la expresión 
de Nematodirus spp. y S. papillosus, según expresan las diferencias cualitativas observadas en los dos años de estudio (Barger y Southcott, 1975).

En adelante, la discusión en la interpretación del efecto del clima y los tratamientos en las majadas de entorno esta por encima de la consideración de diferencias entre establecimientos, dándole mayor peso a las variaciones entre años.

La cantidad de animales para cada categoría, condiciona la dinámica y composición parasitaria. Puesto que las ovejas resultan casi 3,5 veces más cantidad que las corderas, es lógico suponer, que la cantidad de parásitos, su siembra de huevos, momentos de susceptibilidad, composición y tratamientos condicionan la dinámica del establecimiento y año.

Las abundantes precipitaciones, facilitan la salida de larvas de la materia fecal hacia el pasto, que si no encuentran huéspedes susceptibles, mueren rápidamente especialmente cuando la temperatura y la radiación son elevadas (Rossanigo y Gruner, 1995). Esto explica los mínimos recuentos de verano y justifica la mayor viabilidad en otoño (Pereira et al., 2006; Niño Uribe et al., 2018).

El balance hídrico primero y luego el almacenaje total (que resume el nivel de agua acumulada luego del balance hídrico) contribuyen al microclima en el que se producen la sobrevida y traslación de larvas de trichostrongylidos (Santos et al., 2012). Considerando que las larvas de $H$. contortus son sensibles a la 
desecación, las diferencias de carga parasitaria entre años (Gráficos 20 a 22), pueden asociarse con el balance hídrico y el almacenaje total de agua. Este efecto se ve más marcado durante el otoño, que resulta con grandes variaciones entre años (Pizzio et al., 2021), observándose que valores de balance hídrico negativos y de almacenaje total inferiores a $140 \mathrm{~mm}$ afectan negativamente las cargas de los trazadores en 2015. La carga acumulada en los animales permanentes es dependiente de las tasas de infección que reflejan los trazadores y condicionada por el almacenaje total, afectando su magnitud y composición de la carga parasitaria (Gráfico 29).

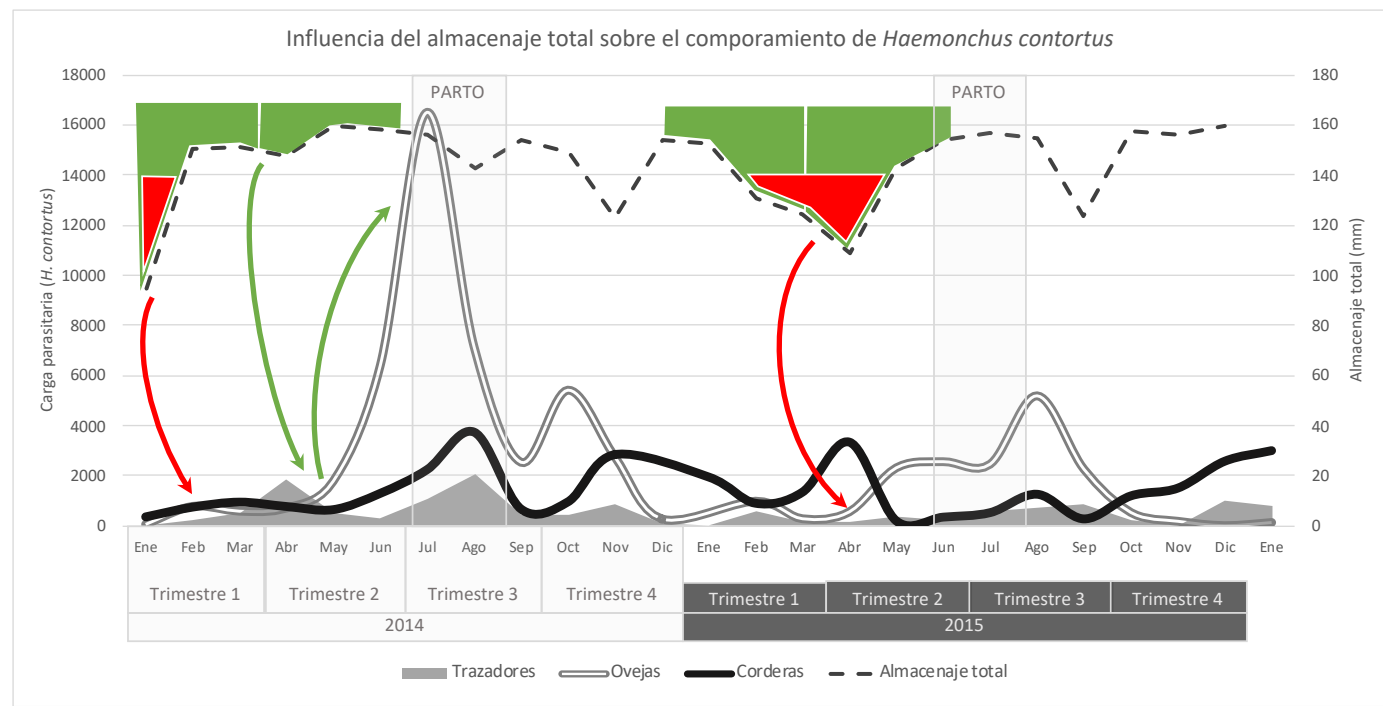

Gráfico 29: efecto del almacenaje total de agua en el suelo (Fernández-Long et al., 2012) sobre la dinámica parasitaria. Se observa una diferencia marcada entre años para el segundo trimestre, con un período sostenido de cuatro meses para el 2015, por debajo de los $140 \mathrm{~mm}$ en el almacenaje total (indicada en rojo). Esto permitiría inferir que este parámetro se asocia con las cargas parasitarias de los animales trazadores (flechas), que reflejarían lo que posteriormente se acumulará en los animales permanentes. Las observaciones de almacenaje total de valores similares, pero de forma aislada, parecieran no ser suficientes para afectar el comportamiento de $H$. contortus, ya que en el corto plazo podrían compensarse. 
Por otro lado, $H$. contortus construye rápidamente cargas elevadas, mientras que los géneros con menor potencial biótico ( $T$. colubriformis, Cooperia spp., T. circumcincta), requieren mayor tiempo de acumulación. Este último concepto, se puede asociar a la frecuencia y cantidad de tratamientos diferentes entre años (en ovejas 3 y 1 tratamientos $\mathrm{FAMACHA}^{\circledR}$ en los años 2014 y 2015 respectivamente para el primer cuatrimestre), que permitió una mayor expresión en el segundo año de T. colubriformis (también T. axei, Cooperia spp. y T. circumcincta). Este, no sólo compuso buena parte de la carga, sino que en corderas superó ampliamente los recuentos de $H$. contortus. En el primer año, la siembra de huevos de $H$. contortus generó una gran oferta de larvas, que sobrepasó a parásitos que requieren mayor tiempo, acumulándose así, en el campo y en los animales potenciado por la susceptibilidad de estos (Mc Ewan, 1994; Nari et al., 1977b). Puede decirse entonces, que la carga de $H$. contortus, "gatilla" la decisión de tratar, condicionando por ello la expresión de otras especies.

La asociación entre la carga parasitaria por necropsia y los recuentos de HPG para los parásitos totales, $H$. contortus y $N$. spathiger en ambas categorías, sostienen la confiabilidad en los diagnósticos coprológicos para esos géneros (Steffan y Fiel, 2018). En tanto Trichostrongylus spp. (con asociación solo en corderas), sugiere una subestimación del mismo en ovejas. Así es que la interpretación de los coprocultivos tiende a subestimar especies con menor capacidad de postura de huevos. 


\section{d. Conclusiones}

Los datos obtenidos aportan al conocimiento epidemiológico y permiten afirmar que la región es una de las más aptas del mundo para el desarrollo de trichostrongylidos de lanares. Los principales parásitos son Haemonchus contortus y Trichostrongylus colubriformis. Así mismo, el género Strongyloides papillosus puede cobrar importancia en determinadas condiciones de manejo, especialmente en corderas.

La expresión epidemiológica de las trichostrongylosis ovinas depende de numerosos factores, y sólo puede simplificarse cuando hay limitantes concretas (bajas temperaturas o precipitaciones), ya que sólo explican parcialmente los efectos del medioambiente. Esto expone la influencia de la combinación de diversos factores, parasitarios, del huésped y ambientales y en estos últimos, como influye la variabilidad climática entre las diferentes estaciones y entre años.

La carga en ovejas y corderas de recría (cuali y cuantitativamente) depende del nivel de susceptibilidad, pero está condicionada a la oferta de larvas que se hayan acumulado durante el otoño. Tal es así, que lo que pase del invierno en adelante, depende en gran parte de los recuentos de otoño. A su vez, las tendencias epidemiológicas interanuales se ven afectadas por la mayor variabilidad climática estacional del otoño. 
Así como el periparto aumenta la susceptibilidad de las ovejas, el destete es el fenómeno opuesto, y facilita la reducción de cargas parasitarias naturalmente.

El balance hídrico y el almacenaje total, parecieran reflejar mejor el efecto sobre los parásitos en estados de vida libre que mediciones de humedad, temperatura, precipitaciones y evapotranspiración frecuentemente estudiadas. Al depender y estar relacionados con éstos, permiten definir situaciones favorables para la acumulación, supervivencia y traslación de larvas, que sus relaciones aisladas. No obstante, deben estudiarse específicamente estos indicadores y su asociación, ajustándose la escala al microambiente parasitario. Resta aún conocer más detalles entre la asociación de todos los factores que intervienen en el comportamiento parasitario como conjunto y sus variaciones.

Los estudios basados en análisis coproparasitológicos han deformado relativamente la valoración de los parásitos dominantes y no logran evidenciar exactamente el comportamiento de las cargas parasitarias, especialmente por géneros diferentes a $H$. contortus. 


\section{CAPITULO 2}

\section{IMPACTO PRODUCTIVO DE UN MÉTODO DE}

\section{CONTROL}

a. Materiales y métodos

Se evaluaron los parámetros productivos y parasitológicos bajo condiciones naturales de infestación, sometidas a un método de control en ovejas de cría (hembras luego del primer parto) durante 2016 (desde el servicio enero hasta el destete en noviembre), y en corderas de recría, desde que fueron destetadas hasta su primer parto (febrero de 2018 a agosto de 2019).

El método de control debe cumplir como mínimo las siguientes condiciones:

- Tender a las mínimas pérdidas productivas (que no quiere decir que no existan).

- Justificación técnica de cada tratamiento.

- Conocer la eficacia de los medicamentos disponibles y sostenerla en el tiempo.

Se utilizaron animales raza Ideal realizando el trabajo con una cohorte de la majada total del campo, de aproximadamente 200-250 animales para cada categoría. El protocolo de trabajo tuvo en cuenta recomendaciones propuestas por la CICUAL de la Facultad de Cs. Veterinarias - UNLP.

Se crearon al inicio diferentes grupos de 50 animales cada uno: 
Grupo sistemático: recibió tratamiento mensual y fue considerado "libre de parásitos".

Grupo táctico: recibió tratamientos prefijados al destete en corderas y previo al parto en ovejas. El resto del ciclo estuvo condicionado por evaluación clínica y parasitológica mensual.

Previo al ensayo se realizó un diagnóstico de la situación mediante un TRCH (Coles et al., 1992) en cada establecimiento.

Con esta base, se estableció un Sistema de Control Vigilado, en función de los recuentos de HPG mensuales (10-12 muestras según Love, 2007; Castells et al., 2013), con el siguiente criterio general para definir tratamientos (Morales et al., 2013; Nari, 2011):

- Valores de HPG promedio menores o iguales a 800: no recibieron tratamiento.

- Valores de HPG promedio entre 801 y 1500: se aplicó tratamiento selectivo por $\mathrm{FAMACHA}^{\odot}$, tratando scores $4 \mathrm{y}$ 5 únicamente.

- Valores de HPG promedio mayores o iguales a 1501: se aplicó un tratamiento poblacional a todo el lote.

Grupo control: este grupo no recibió ningún tratamiento ${ }^{9}$ y se utilizó únicamente para la evaluación en corderas.

\footnotetext{
${ }^{9}$ La CICUAL recomendó tratamientos de salvataje cuando los animales presentaran signos clínicos.
} 
Todos los grupos se trataron al inicio del ensayo para neutralizar diferencias y se identificaron los animales con caravana doble. La majada general, dentro de la cual se encontraban se manejó según el criterio de decisión del grupo táctico.

\section{Lugar de trabajo ${ }^{10}$}

Se trabajó en dos establecimientos (a $60 \mathrm{~km}$ de distancia) entre las localidades de Curuzú Cuatiá (departamento Curuzú Cuatiá) y Mercedes (departamento Mercedes), Corrientes, Argentina. En ambos casos, se utilizaron ovinos raza Ideal, en pastoreo sobre campo natural en un sistema mixto con bovinos (ver Imagen 1 en página 54).

- Establecimiento "San Luis del Garabatá" - año 2017 (4900 ha): latitud $29^{\circ} 55^{\prime} 32.18^{\prime \prime}$; l longitud 57047'55.97"O. Majada de 1700 ovejas, 500 corderas de recría (más capones, carneros y animales de consumo), más de 4100 bovinos reproductores (más recrías) y 220 caballos (diferentes categorías). Relación de 0,57 ov/bov y 0,55 ov/ha. Para el ensayo se utilizaron ovejas, con servicio de verano (diciembre-enero).

\footnotetext{
${ }^{10}$ El ensayo de evaluación de impacto productivo en corderas se había iniciado en simultáneo y en el mismo establecimiento que el de las ovejas ("San Luis del Garabatá" en el 2016). Por una decisión de la administración de la firma, se vendió la totalidad de las corderas de recría de ese año, lo que obligó a tener que reiniciar el ensayo al año siguiente en otro establecimiento.
} 
- Establecimiento "Aguay" - año 2018-2019 (15626 ha): latitud

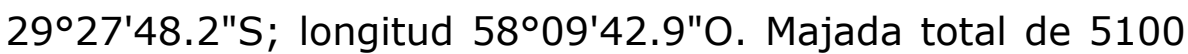
ovejas, 900 corderas de recría, 7500 bovinos y 660 caballos. Con una relación de 0,8 ov/bov y 0,38 y ov/ha. Para el ensayo se utilizaron corderas de recría, que fueron destetadas en diciembre con 4-5 meses de edad y se recriaron durante el año 2018. Recibieron servicio en febrero y marzo 2019.

\begin{tabular}{lcc}
\hline \multicolumn{1}{c}{ DETALLE } & San Luis del Garabatá & Aguay \\
\hline Caballos (Cabezas) & 220 & 660 \\
Bovinos (Cabezas) & 4700 & 7500 \\
Ovinos (Cabezas) & 2700 & 6000 \\
Superficie (ha) & 4900 & 15626 \\
\hline Relación Ov/bov & 0,57 & 0,80 \\
Relación Ov/ha & 0,55 & 0,38 \\
Carga animal (EV/ha) & 1,14 & 0,62 \\
Carga ovina/carga total & $\mathbf{9 , 7 \%}$ & $\mathbf{1 2 , 3 \%}$ \\
\hline
\end{tabular}

Tabla 40: relación de existencias y cargas relativas.

\section{Seguimiento}

De forma individual, se midieron y evaluaron diferentes variables parasitológicas y productivas a intervalos mensuales (exceptuando el muestreo en el pico de parición $\left.{ }^{11}\right)$ :

${ }^{11}$ En la región, al tratarse de majadas grandes no es posible encerrar los animales en parición. 
- Variables parasitológicas:

- Carga parasitaria: HPG y coprocultivo (Roberts y O'Sullivan, 1949; Henriksen y Korsholm, 1983; Niec, 1968).

- Grados de FAMACHA ${ }^{\circ}$ : independientemente de la indicación de tratamiento.

- Tratamientos aplicados.

- Parámetros de producción física

- Peso y condición corporal: se realizaron controles mensuales calculando la ganancia acumulada (peso del período - peso inicial).

- Producción de lana: calculado como la diferencia del peso previo y posterior a la esquila. Adicionalmente en el establecimiento "Aguay" (corderas) se evaluó el peso del vellón y calidad de lana individual ${ }^{12}$.

- Peso del destete: se midió el peso de los corderos destetados. Este parámetro se evaluó en ovejas, ya que en corderas de recría se finalizó el ensayo con los resultados de la parición.

- Mortalidad: animales muertos/animales que iniciaron el ensayo.

${ }^{12}$ El análisis de calidad de lana fue realizado por INTA Bariloche (OFDA 2000). 
- Performance reproductiva (Soto et al., 2020):

○ Índice de preñez: animales preñados/animales en servicio. Parámetro medido por ecografía a los 30 días de retirados los carneros, detallando las gestaciones múltiples.

- Índice de parición: animales paridos/animales en servicio. Para evaluar la parición se realizó observación de ubre en la señalada, clasificando los animales como: "con cría" (animales con cordero al pie); "parió y perdió" (animales que parieron, pero perdieron el cordero); "seca" (animales que perdieron el cordero tempranamente o no presentaron parición).

- Índice de señalada: corderos señalados/corderos nacidos.

- Mortalidad neonatal: corderos muertos/corderos nacidos. 


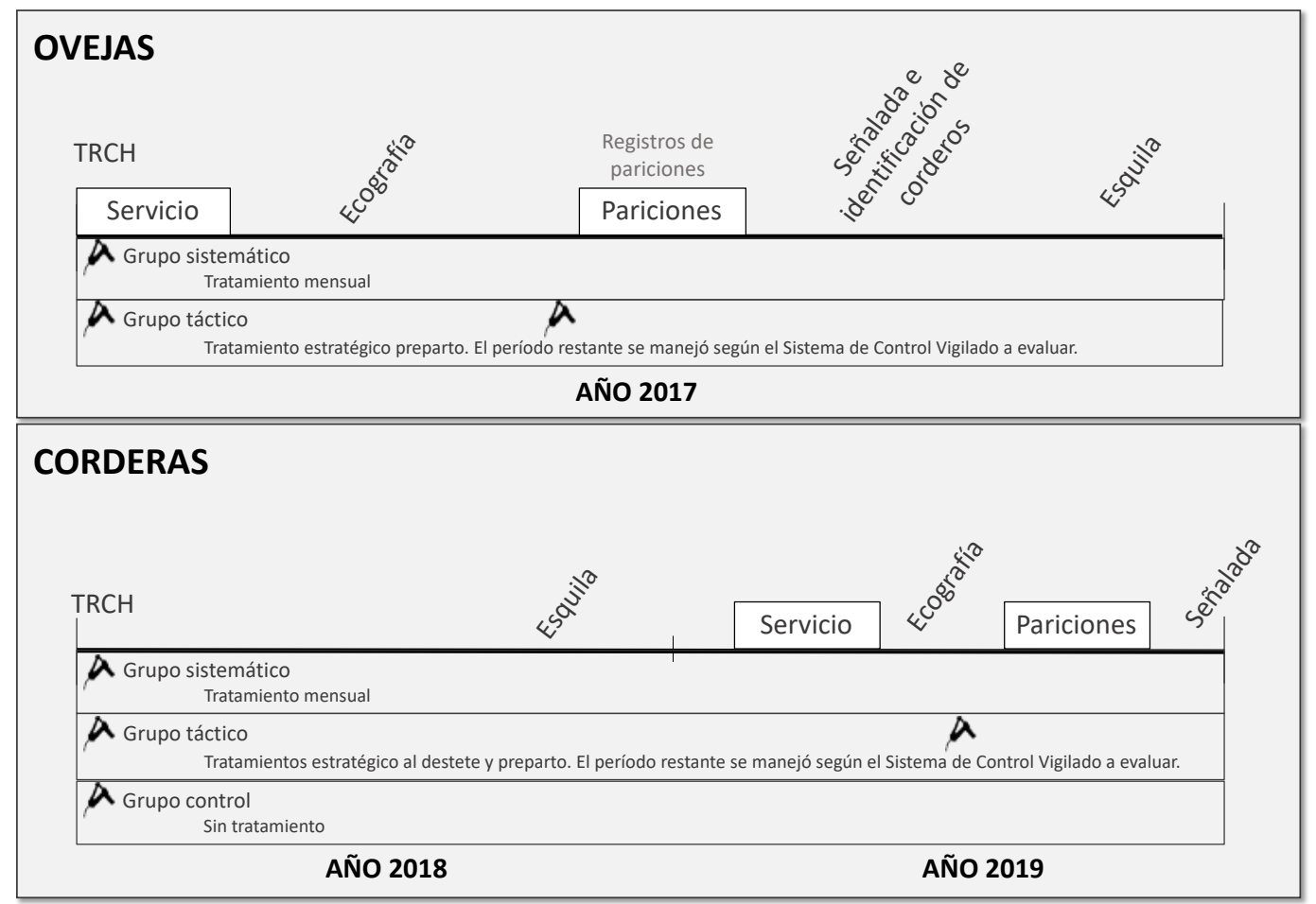

Gráfico 30: representación esquemática del plan de trabajo propuesto en cada categoría. En ambas categorías mensualmente se midió: recuento de HPG individual y coprocultivo por grupo; peso vivo individual; score de condición corporal; score de FAMACHA ${ }^{\odot}$ y únicamente en las ovejas, el peso vivo individual de los corderos (luego de la parición). En todos los grupos se aplicó un tratamiento al inicio del ensayo.

\section{3. Índice verde}

En el establecimiento Aguay, se estimaron los valores de producción de forraje en el potrero 14C (Latitud 29028'27"S; Longitud $\left.58^{\circ} 10^{\prime} 14^{\prime \prime} \mathrm{O}\right)$ donde pastorearon los animales durante todo el ensayo (2018-2019). Se calculó por interpretación de la Radiación fotosintéticamente activa absorbida (RFAA) por la vegetación, obtenida de información satelital, la cual tiene relación directa con la productividad de la vegetación (Monteith, 1972; Grigera et al., 2007). 
Se seleccionaron pixeles MODIS (https://modis.ornl.gov/cgibin/MODIS/global/subset.pl) para el potrero en estudio y la RFAA se calculó a partir del índice verde normalizado (IVN) del sensor MODIS (Moderate Resolution Imaging Spectroradiometer) y la radiación incidente obtenida del Centro de Datos Científicos Atmosféricos de Agencia Espacial Estadounidense (https://power.larc.nasa.gov). Se utilizaron calibraciones realizadas por Bendersky (et al.,2016) como referencia, obteniendo un estimado de productividad de materia seca $(\mathrm{Kg} / \mathrm{Ha})$ del potrero para un período determinado (Piñeiro et al., 2006). Del mismo modo se calculó la productividad promedio mensual de los últimos 10 años para tomar de referencia.

Se realizó una evaluación del potrero mediante el método BOTANAL ${ }^{13}$ (Tothill et al., 1978), que es una estimación visual que determina la composición botánica de la pastura.

\section{Análisis estadístico}

Se realizó una descripción epidemiológica a intervalos mensuales de valores absolutos y relativos para estudios coprológicos y de recuento de huevos.

Las variables cuantitativas con distribución normal se analizaron por análisis de varianza. Las variables que no presentaron distribución normal se analizaron por el método de Kruskal-Wallis utilizando la prueba de Bonferroni como post-hoc.

${ }^{13}$ Ing. Agro. Diego Bendersky y equipo, EEA INTA Mercedes. 
Se calculó el porcentaje del peso vivo que representaba la ganancia de peso mensual (tasa de ganancia de peso) para análisis por regresión con los resultados de producción de materia seca por índice verde.

Las variables cualitativas (frecuencias de FAMACHA ${ }^{\odot}$; condición corporal; índices de preñez, parición y mortalidad) se analizaron por el método de $\chi^{2}$. Para comparar frecuencias se agruparon del siguiente modo:

- FAMACHA $^{\odot}$ : score 1 y 2 ; score 3 y score 4 y 5 .

- Condición corporal: score menor o igual a 2; score mayor a 2 y menor a 3 y score mayor a 3.

Para el análisis de productividad de materia seca se agruparon los trimestres con el mismo criterio que en el capítulo anterior (trimestre 1: enero, febrero y marzo; trimestre 2: abril, mayo y junio; trimestre 3 : julio, agosto y septiembre y trimestre 4: octubre, noviembre y diciembre).

El software utilizado fue Statistics Base Grad Pack Student IBM SPSS, al igual que en el capítulo anterior.

b. Resultados

1) Datos preliminares

El estudio realizado en el establecimiento "San Luis del Garabatá", fue realizado al año siguiente del ensayo de epidemiología, tomándose de referencia el $\mathrm{TRCH}$ realizado anteriormente e informado en la Tabla 5. 
Para el ensayo realizado en la estancia "Aguay", durante el 2017 se realizó un $\mathrm{TRCH}$, cuyos resultados se expresan en la tabla 41 .

\begin{tabular}{|c|c|c|c|c|c|}
\hline DROGA & DETALLE & \% DE EFICACIA TOTAL & Haemonchus. spp. & Trichos. spp. & Cooperia spp \\
\hline \multirow{3}{*}{ Ivermectina $1 \%$} & $\% \mathrm{RCH}$ & $0 \%$ & $0 \%$ & $0 \%$ & $0 \%$ \\
\hline & & & & & \\
\hline & IC95\% (LI-LS) & $0-23$ & $0-34$ & $0-0$ & $0-0$ \\
\hline \multirow{3}{*}{ Closantel } & $\% \mathrm{RCH}$ & $94 \%$ & $97 \%$ & $39 \%$ & $100 \%$ \\
\hline & & & & & \\
\hline & IC95\% (LI-LS) & $86-97$ & $94-99$ & $0-73$ & $0-100$ \\
\hline \multirow{3}{*}{ Levamisol } & $\% \mathrm{RCH}$ & $75 \%$ & $92 \%$ & $0 \%$ & $100 \%$ \\
\hline & & & & & \\
\hline & IC95\% (LI-LS) & $40-89$ & $81-97$ & $0-0$ & $0-100$ \\
\hline \multirow{2}{*}{$\begin{array}{c}\text { Albendazol + } \\
\text { Levamisol }\end{array}$} & $\% \mathrm{RCH}$ & $80 \%$ & $78 \%$ & $100 \%$ & $100 \%$ \\
\hline & IC95\% (LI-LS) & $0-96$ & $0-96$ & $0-100$ & $0-100$ \\
\hline \multirow{3}{*}{ Albendazol } & $\% \mathrm{RCH}$ & $69 \%$ & $71 \%$ & $100 \%$ & $0 \%$ \\
\hline & & & & & \\
\hline & IC95\% (LI-LS) & $24-87$ & $30-80$ & $0-100$ & $0-0$ \\
\hline \multirow{3}{*}{ Moxidectin } & $\% \mathrm{RCH}$ & $16 \%$ & $96 \%$ & $16 \%$ & $100 \%$ \\
\hline & & & & & \\
\hline & IC95\% (LI-LS) & $0-43$ & $85-99$ & $0-43$ & $0-100$ \\
\hline \multirow{2}{*}{$\begin{array}{l}\text { Ivermectina } 1 \% \\
\quad+\text { Levamisol }\end{array}$} & $\% \mathrm{RCH}$ & $77 \%$ & $77 \%$ & $81 \%$ & $77 \%$ \\
\hline & IC95\% (LI-LS) & $43-91$ & $42-91$ & $53-93$ & $43-91$ \\
\hline \multirow{2}{*}{$\begin{array}{c}\text { Albendazol + } \\
\text { Closantel }\end{array}$} & $\% \mathrm{RCH}$ & $96 \%$ & $15 \%$ & $93 \%$ & $100 \%$ \\
\hline & IC95\% (LI-LS) & $85-99$ & $0-42$ & $75-98$ & $0-100$ \\
\hline \multirow{3}{*}{ Monepantel } & $\% \mathrm{RCH}$ & $99 \%$ & $100 \%$ & $100 \%$ & $100 \%$ \\
\hline & & & & & \\
\hline & IC95\% (LI-LS) & $94-100$ & $0-100$ & $0-100$ & $0-100$ \\
\hline \multirow{2}{*}{$\begin{array}{l}\text { Derquantel + } \\
\text { Abamectina }\end{array}$} & $\% \mathrm{RCH}$ & $99 \%$ & $100 \%$ & $100 \%$ & $100 \%$ \\
\hline & IC95\% (LI-LS) & $94-100$ & $0-100$ & $0-100$ & $0-100$ \\
\hline
\end{tabular}

Tabla 41: resultados del $\mathrm{TRCH}$, con el que se seleccionaron las drogas a utilizar. 
2) Seguimiento del control en ovejas

Del lote inicial fueron descartados por otras enfermedades (principalmente complicaciones por miiasis resultantes de afecciones podales) 3 animales, 1 del grupo sistemático y 2 del grupo táctico (trabajándose en el grupo sistemático con $\mathrm{N}=49$ y en el grupo táctico con $\mathrm{N}=48)$.

La carga parasitaria durante el año de seguimiento presentó valores considerados bajos. Los recuentos de HPG entre grupos expresan diferencias significativas con menores recuentos en el grupo sistemático durante todo el período de estudio (Gráfico 31 y Tabla 42). Al discriminar la eliminación de huevos por condición fisiológica, se observó el impacto de la parición en la eliminación de huevos con diferencias significativas únicamente entre paridas y vacías en el mes de junio (no por grupo de tratamiento), que se fueron reduciendo en la medida que avanzó la lactancia. Cabe aclarar que en el grupo táctico hubo un sólo animal sin preñez, no pudiéndose analizar por separado (Grupo de tratamiento y condición fisiológica). 


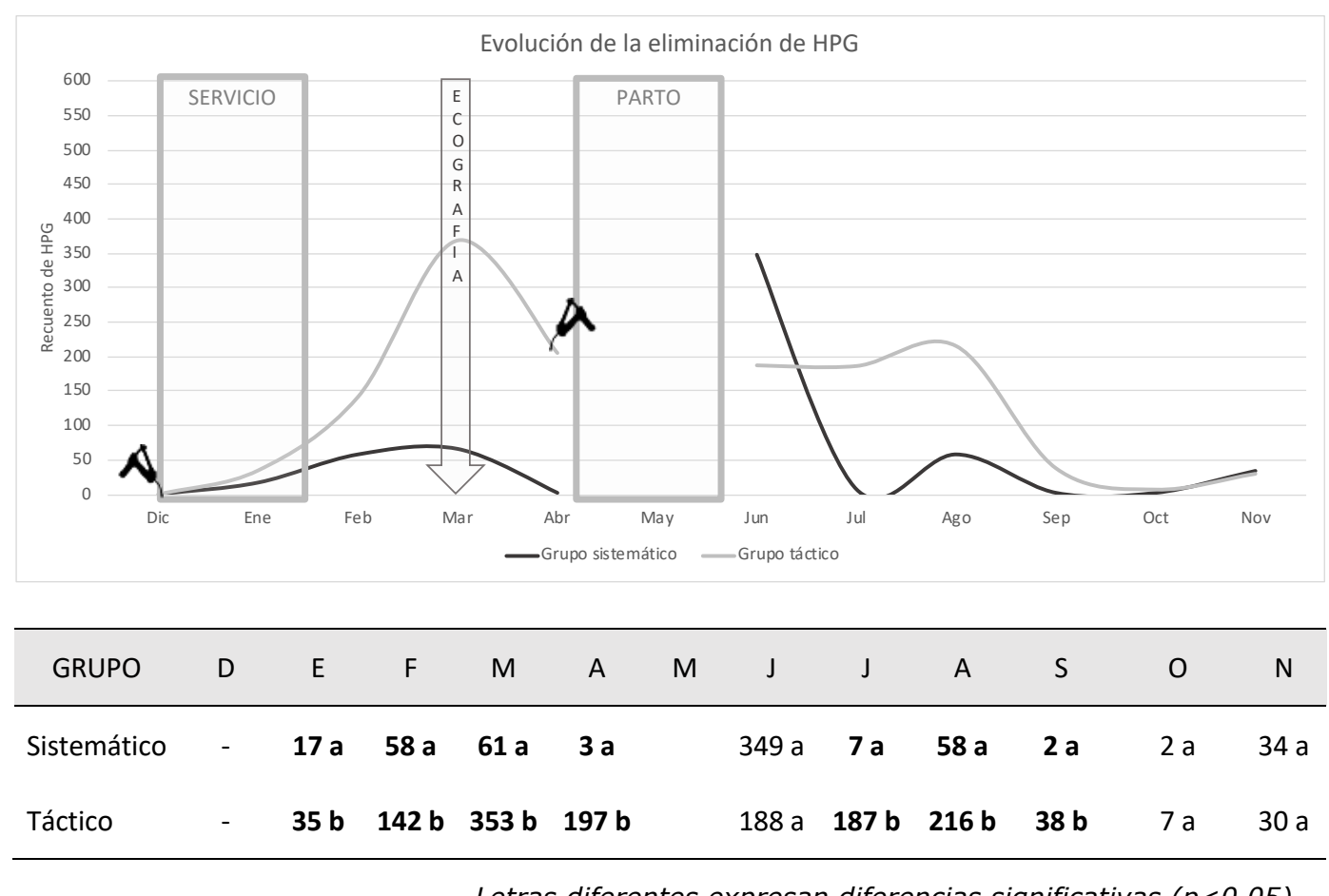

Letras diferentes expresan diferencias significativas $(p<0,05)$.

Gráfico 31 y Tabla 42: evolución de HPG promedio para cada grupo indicando los tratamientos del grupo táctico. Se observan diferencias significativas en todos los meses, con excepción al inicio, al mes siguiente al parto y al final del ensayo.

La dinámica parasitaria coincide con lo descripto en el capítulo anterior (coprocultivos), con un pico otoño-invernal y predominio en los coprocultivos de $H$. contortus, siguiendo en importancia Trichostrongylus spp. Oesophagostomum spp. se encontró relativamente constante, aunque en pequeña escala, con valores máximos en verano (11\%). Los demás géneros (Ostertagia spp. y Cooperia spp.), salvo excepciones se presentan en valores mucho menores, con predominio durante el otoño-invierno (Gráfico 32 y 33 y Tabla 43 y 44). 


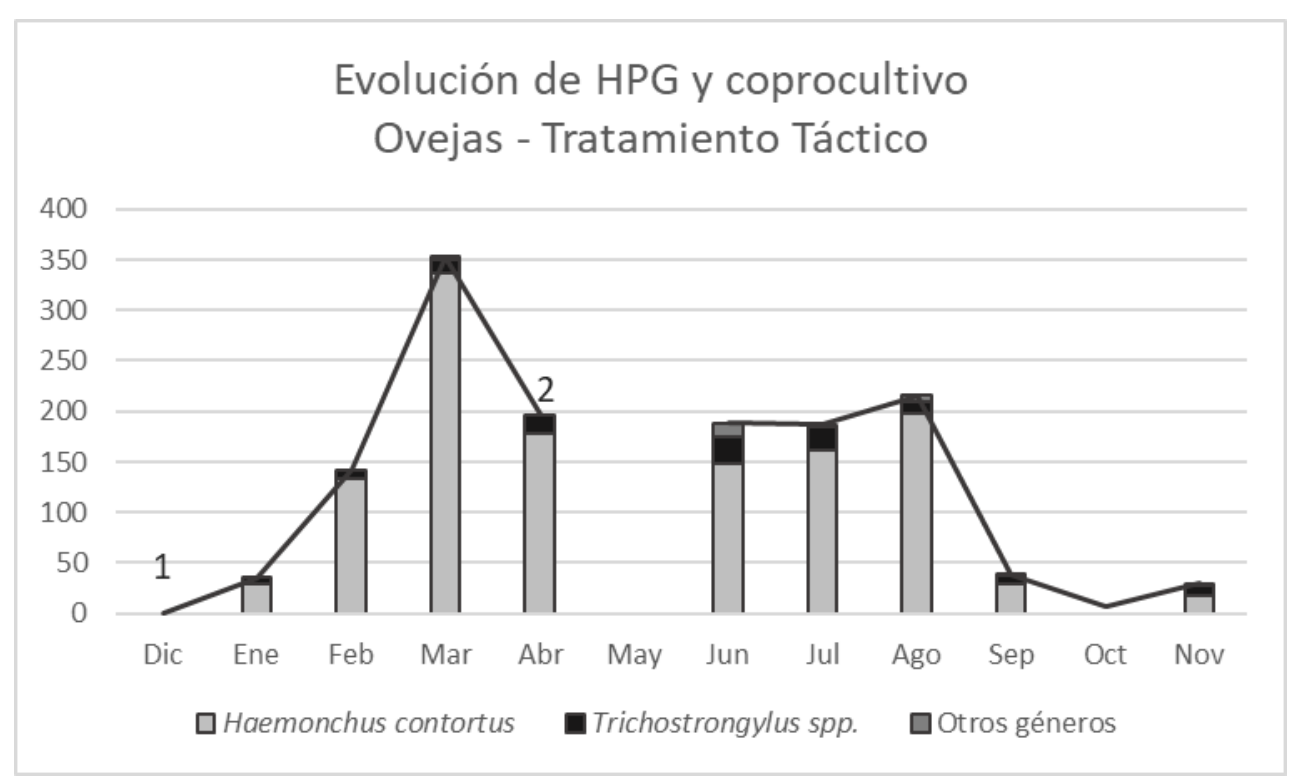

Gráfico 32: evolución de HPG para el grupo táctico. Los tratamientos se indican como: 1: levamisol + ivermectina; 2 : derquantel + abamectina.

\begin{tabular}{lcccccccccccc}
\hline \multicolumn{1}{c}{ Géneros } & D & E & F & M & A & M & J & J & A & S & O & N \\
\hline Haemonchus spp. & - & 29 & 133 & 336 & 179 & & 148 & 162 & 198 & 30 & $*$ & 17 \\
Trichos. spp. & - & 7 & 9 & 13 & 18 & 26 & 23 & 11 & 8 & $*$ & 11 \\
Ostertagia. spp. & - & 0 & 0 & 0 & 0 & 0 & 2 & 2 & 0 & $*$ & 0 \\
Cooperia spp. & - & 0 & 0 & 2 & 0 & 8 & 0 & 0 & 0 & $*$ & 2 \\
Oesoph. spp. & - & 0 & 0 & 2 & 0 & 6 & 0 & 4 & 1 & $*$ & 0 \\
\hline
\end{tabular}

* El HPG promedio fue 7 y no se recuperaron larvas en los coprocultivos.

Tabla 43: recuento de HPG y coprocultivo mensual para el grupo táctico. 


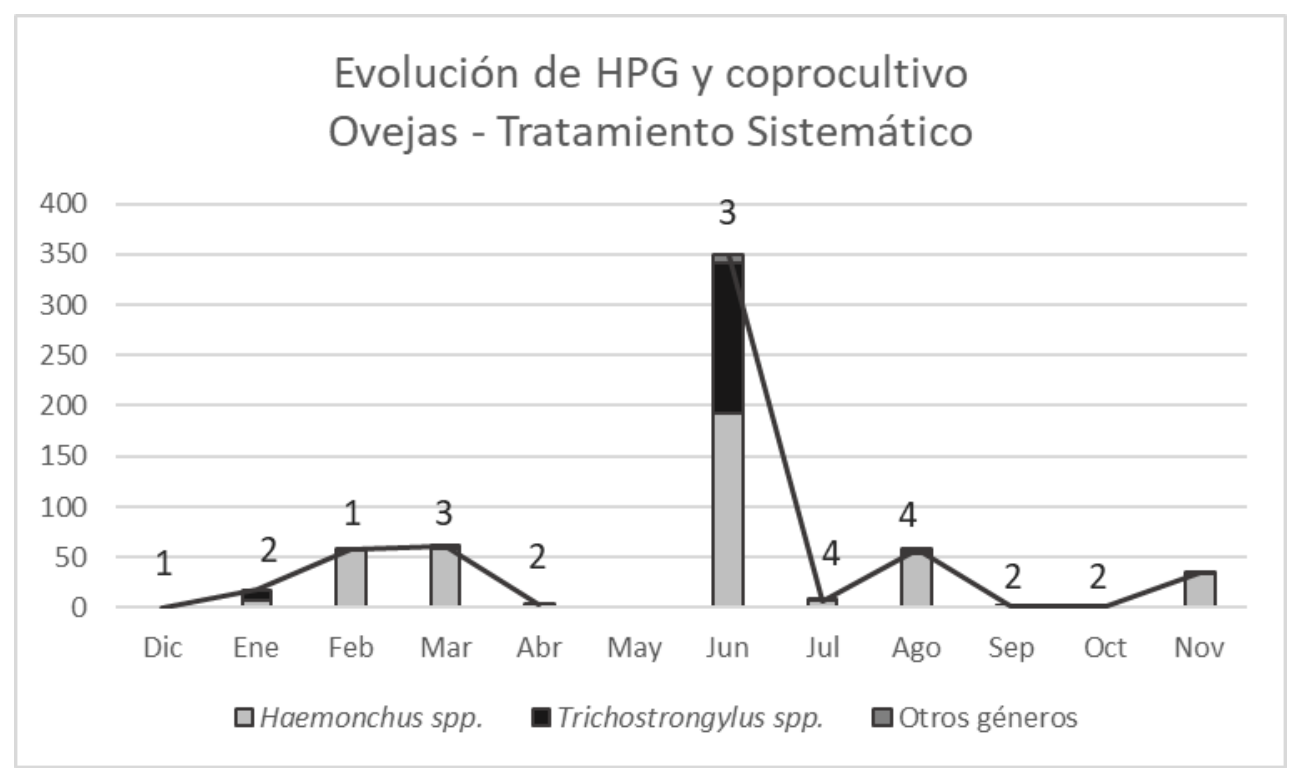

Gráfico 33: evolución de HPG para el grupo sistemático. Los tratamientos se indican como: 1 : levamisol + ivermectina; 2 : derquantel + abamectina; 3: monepantel; 4: closantel + fenbendazol.

\begin{tabular}{lcccccccccccc}
\hline \multicolumn{1}{c}{ Géneros } & D & E & F & M & A & M & J & J & A & S & O & N \\
\hline Haemonchus spp. & - & 7 & 57 & 59 & 1 & & 192 & 7 & 54 & 1 & $*$ & 33 \\
$\begin{array}{l}\text { Trichos. spp. } \\
\text { Ostertagia. spp. }\end{array}$ & - & 10 & 1 & 1 & 0 & 150 & 0 & 2 & 1 & $*$ & 1 \\
Cooperia spp. & - & 0 & 0 & 0 & 0 & 0 & 0 & 1 & 0 & $*$ & 0 \\
Oesoph. spp. & - & 0 & 0 & 0 & 2 & 7 & 0 & 1 & 0 & $*$ & 0 \\
\hline
\end{tabular}

* El HPG promedio fue 2 y no se recuperaron larvas en los coprocultivos.

Tabla 44: recuentos de HPG y coprocultivo mensual para el grupo sistemático.

Los resultados del análisis del score de FAMACHA® (aunque no fue utilizado como criterio de tratamiento), no presentaron diferencias significativas entre grupos, observando una reducción de las frecuencias de score 4 y 5 hacia el parto, que luego aumentaron y se mantuvieron hasta el final del ensayo. 
La evolución de peso podría dividirse en dos períodos (Gráfico 34 y Tabla 45). El primero va desde el servicio hasta el parto y muestra una tendencia a ganar peso igual en los dos grupos. Se registraron variaciones en enero, compensadas en febrero, llegando al parto sin diferencias, en coincidencia con el análisis de las frecuencias de condición corporal.

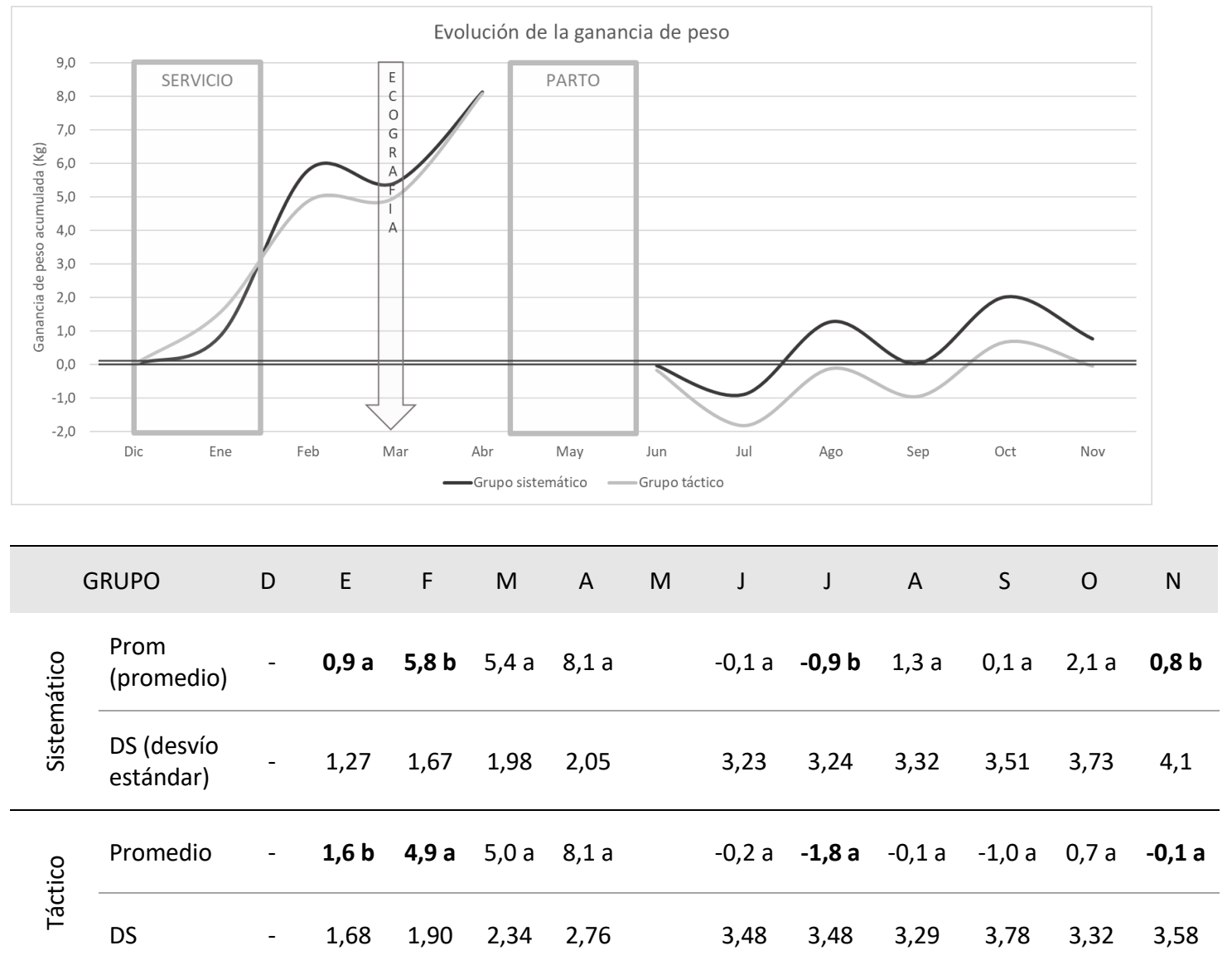

Letras diferentes expresan diferencias significativas $(p<0,05)$.

Gráfico 34 y Tabla 45: evolución de las ganancias de peso promedio acumuladas (detallando el desvío estándar para cada caso) indicando las diferencias significativas entre grupos. 
El segundo período, desde el parto hasta el fin del ensayo, inicia con una pérdida asociada al parto de aproximadamente el $17 \%$ del peso vivo. Se generan diferencias en el mes siguiente (julio) a favor del grupo sistemático, que se sostienen sin cambios en el peso hasta el destete. La evolución y el análisis de la condición corporal, acompaña estas diferencias, como así también una desmejora hasta el destete (octubre). Paralelamente, se observó que los animales en los momentos clave presentaron condición corporal inferior a lo recomendado (Tabla 46).

\begin{tabular}{|c|c|c|c|c|c|}
\hline GRUPO & $\begin{array}{l}\text { SCORE CONDICIÓN } \\
\text { CORPORAL }\end{array}$ & $\begin{array}{c}\text { DICIEMBRE } \\
\text { (inicio del ensayo) }\end{array}$ & $\begin{array}{c}\text { ABRIL } \\
\text { (preparto) }\end{array}$ & $\begin{array}{c}\text { JUNIO } \\
\text { (posparto) }\end{array}$ & $\begin{array}{l}\text { NOVIEMBRE } \\
\text { (fin del ensayo) }\end{array}$ \\
\hline \multirow{3}{*}{ Sistemático } & $<=2$ & $24 \%$ & $8 \%$ & $85 \%$ & $55 \%$ \\
\hline & $>2 y<3$ & $39 \%$ & $35 \%$ & $2 \%$ & $17 \%$ \\
\hline & $>=3$ & $37 \%$ & $56 \%$ & $13 \%$ & $28 \%$ \\
\hline \multirow{3}{*}{ Táctico } & $<=2$ & $38 \%$ & $21 \%$ & $85 \%$ & $56 \%$ \\
\hline & $>2 y<3$ & $29 \%$ & $54 \%$ & $15 \%$ & $30 \%$ \\
\hline & $>=3$ & $33 \%$ & $25 \%$ & $0 \%$ & $14 \%$ \\
\hline
\end{tabular}

Tabla 46: evolución de las proporciones de condición corporal (con diferencias significativas entre grupos en los meses de abril y junio).

Las ovejas vacías, que no parieron o que perdieron el cordero no están incluidas en el análisis anterior. La cantidad de animales no permitió desagregar los grupos por tratamiento y se analizaron en su conjunto. No obstante, se observaron ganancias decrecientes según fueron, vacías, secas, parió y perdió y con cría. 


\section{1) Parámetros productivos y reproductivos}

Los resultados productivos no expresaron diferencias significativas para ninguna de las variables evaluadas y se detallan en los gráficos 35 y 36 y Tabla 47. También se analizó la evolución de la ganancia de peso de los corderos al pie (producción indirecta de leche) sin hallar diferencias entre grupos.

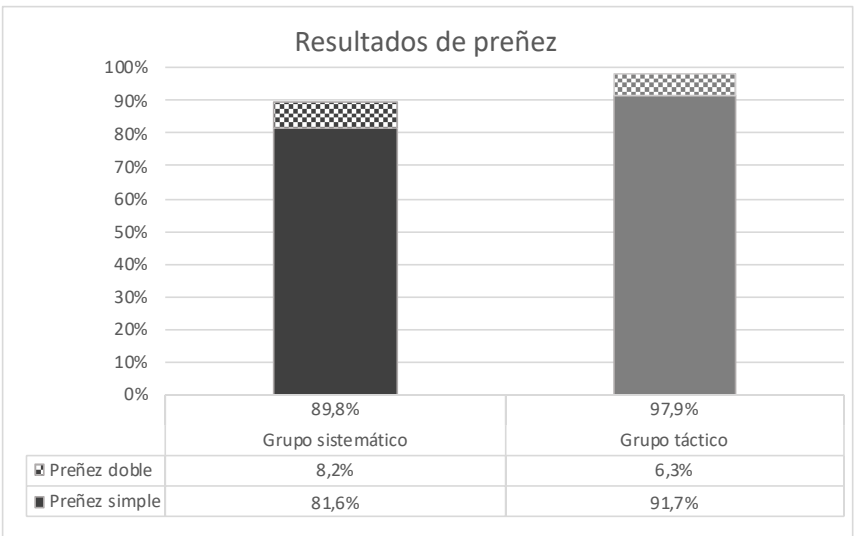

Gráfico 35: porcentajes de preñez, detallando gestaciones múltiples. Los animales vacíos fueron 5 y 1 para el grupo sistemático y táctico respectivamente. 


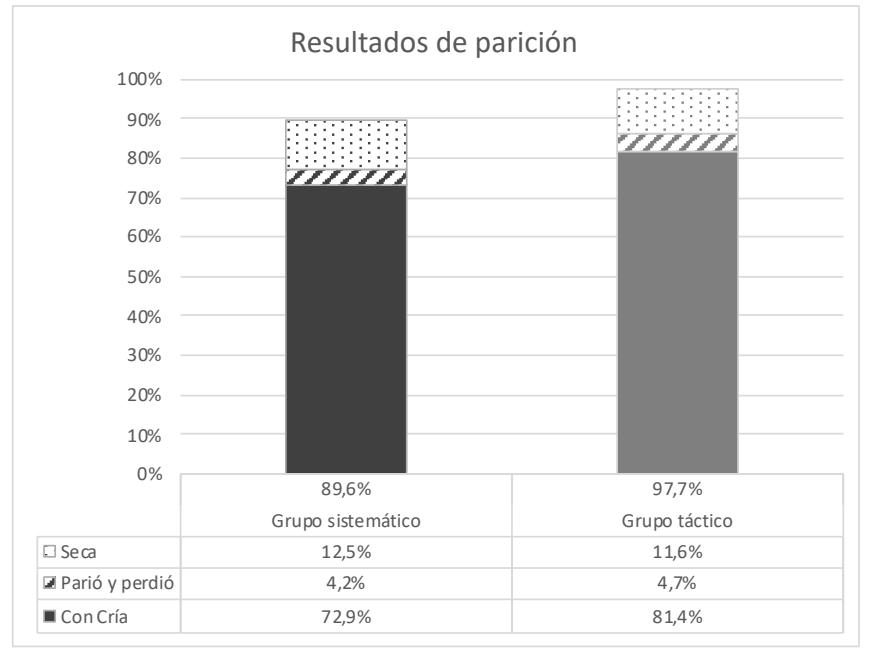

Gráfico 36: porcentajes de parición sobre una base de 43 y 42 ovejas para el grupo sistemático y táctico respectivamente.

\begin{tabular}{lcc}
\hline \multicolumn{1}{c}{ VARIABLE } & GRUPO SISTEMÁTICO & GRUPO TÁCTICO \\
\hline Peso promedio de los corderos $(\mathrm{Kg})$ & 20,4 & 21,0 \\
Kg de cordero destetados por oveja que inicio & 16,6 & 18,0 \\
Producción total (Kg destetados totales) & 715 & 758 \\
Mortalidad de ovejas (\%) * & $2,0 \%$ & $10,4 \%$ \\
Mortalidad neonatal (\%) & $5,4 \%$ & $2,7 \%$ \\
Señalada (\%) & $94,6 \%$ & $97,3 \%$ \\
Producción de lana (Kg) & 2,9 & 2,6 \\
\hline
\end{tabular}

* 1 y 5 animales para los grupos sistemático y táctico respectivamente.

Tabla 47: resultados productivos del ciclo para cada grupo.

\section{3) Seguimiento del control en corderas de recría}

Se descartaron en total 10 animales por causas no atribuibles a los parásitos (no estuvieron en alguno de los muestreos, miiasis, afecciones podales, etc.), de las cuales 2 fueron del grupo sistemático; 
3 del grupo táctico y 5 del grupo control. Finalizado el servicio, se realizó diagnóstico de preñez por ecografía (mayo del segundo año) eliminando los animales vacíos.

Desde el comienzo el grupo control, expresa recuentos crecientes con un pico en junio que se autolimitó. Luego presentó un aumento sostenido hasta el verano siguiente, donde vuelven a reducirse los recuentos hasta el parto. Los animales de este grupo recibieron tratamiento únicamente cuando se inició el ensayo.

Los recuentos del grupo táctico siguen el mismo patrón que el control. En el pico de junio de 2018, se aplicó un tratamiento (800 HPG promedio) motivado además por la presencia de casos clínicos en otros potreros con manejo similar y por el rápido aumento respecto del mes anterior. En diciembre de ese año se realizó el segundo tratamiento, dando por finalizada la etapa de recría (1000 HPG aprox.). Para marzo de 2019, los recuentos de este grupo alcanzaron los 2000 HPG, aplicándose un tratamiento poblacional y otro, según el diseño previsto, en el preparto.

El grupo sistemático, mantuvo valores bajos debido al efecto de los tratamientos, con excepción de los meses de noviembre del 2018 y marzo del 2019. El tratamiento previo en ambos casos fue con closantel y fenbendazol reflejando alguna sobreestimación en la eficacia diagnosticada en el TRCH.

El análisis estadístico, expresa diferencias significativas y la influencia de los tratamientos, especialmente en el grupo sistemático, 
expresando recuentos menores en diferentes períodos (Tabla 48). No obstante, se observa como luego del parto, el grupo control no presentó diferencias respecto de los grupos tratados (Gráfico 37).

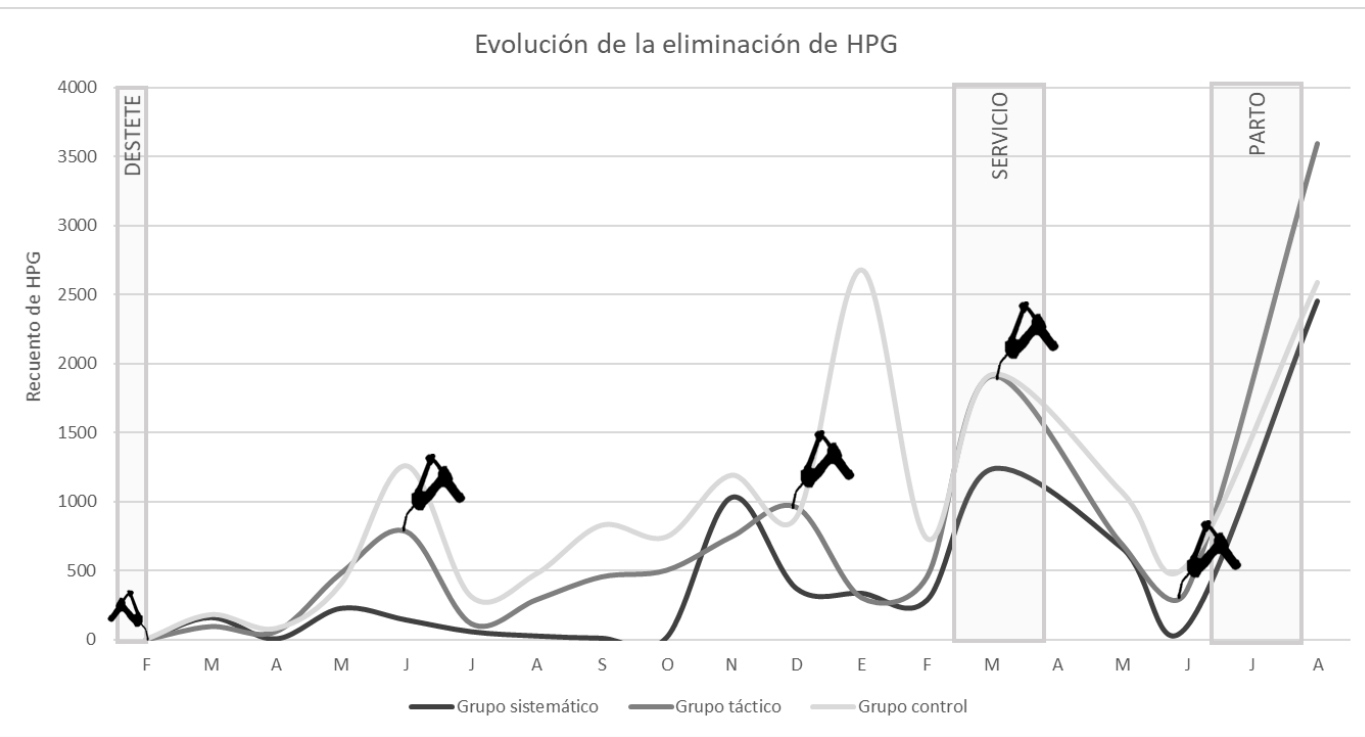

\begin{tabular}{|c|c|c|c|c|c|c|c|c|c|c|c|c|c|c|c|c|c|c|}
\hline GRUPO & $M$ & A & $M$ & J & J & A & $S$ & 0 & $N$ & D & $E$ & $\mathrm{~F}$ & $M$ & A & $M$ & J & $\mathrm{J}$ & $A$ \\
\hline \multirow{2}{*}{ GS } & 162 & 8 & 229 & 145 & 60 & 29 & 13 & 17 & 1031 & 371 & 338 & 287 & 1237 & & 665 & 100 & & 2452 \\
\hline & $a$ & $a$ & a & $a$ & a & $a$ & $a$ & a & $a$ & $a$ & $a$ & a & $a$ & & $a$ & $a$ & & $a$ \\
\hline \multirow{2}{*}{ GT } & 96 & 60 & 483 & 785 & 117 & 290 & 456 & 504 & 747 & 960 & 304 & 455 & 1911 & & 691 & 364 & & 3595 \\
\hline & $a$ & $a b$ & $a$ & b & a & b & b & b & $a$ & $a$ & a & b & $a$ & & a & b & & $a$ \\
\hline \multirow{2}{*}{ GC } & 180 & 80 & 404 & 1259 & 311 & 476 & 828 & 744 & 1191 & 889 & 2680 & 733 & 1921 & & 1068 & 541 & & 2589 \\
\hline & $a$ & b & $\mathrm{a}$ & b & b & b & b & b & $a$ & $a$ & b & b & $a$ & & a & b & & $\mathrm{a}$ \\
\hline
\end{tabular}

Letras diferentes expresan diferencias significativas $(p<0,05)$.

Gráfico 37 y Tabla 48: evolución de HPG promedio para cada grupo (GS: grupo sistemático; GT: grupo táctico y GC: Grupo control), indicando las diferencias significativas. Se señalan los tratamientos aplicados al grupo táctico.

La dinámica parasitaria resultante de los HPG y coprocultivos coincide con lo descripto en el capítulo anterior, con un pico otoñoinvernal en base a $H$. contortus, siendo el segundo género en 
importancia Trichostrongylus spp. En pequeñas proporciones se observaron los géneros Cooperia spp., Ostertagia spp. y más aisladamente Oesophagostomum spp. (<5\%) (Tablas 49 a 51 y Gráficos 38 a 40).

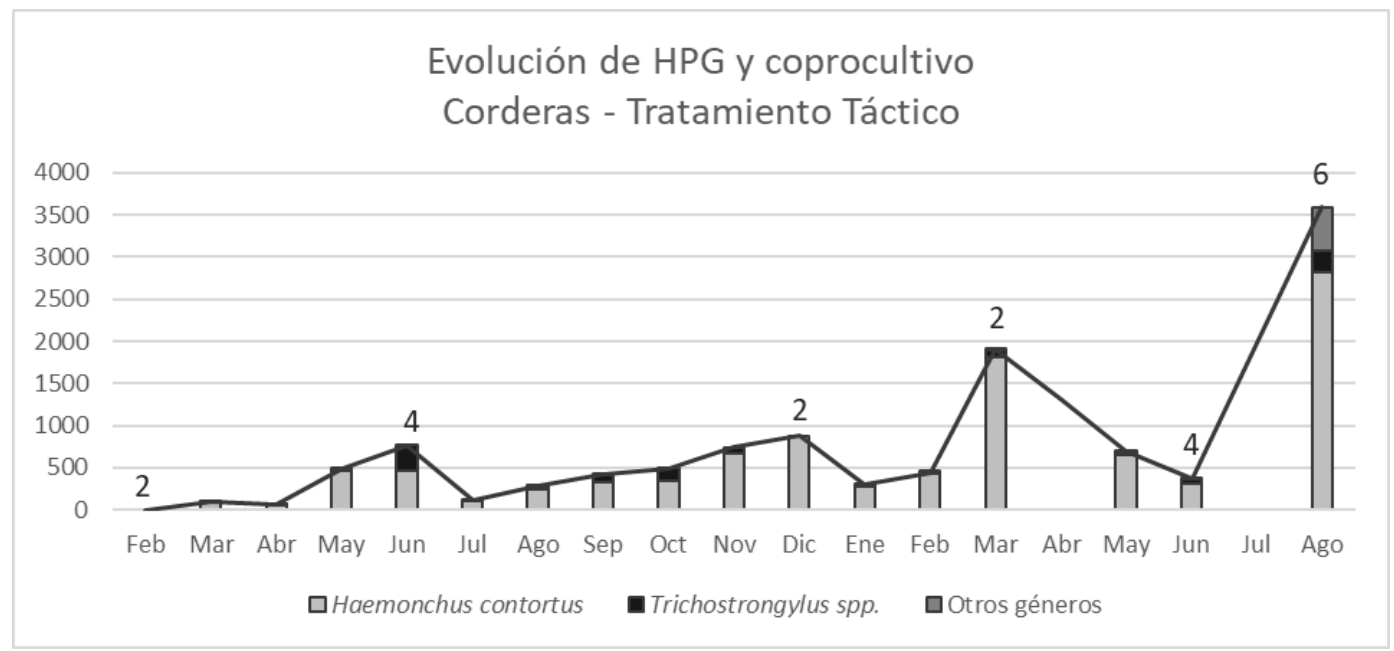

Gráfico 38: recuento de HPG para el grupo táctico, discriminando el proporcional de Haemonchus spp. y Trichostrongylus spp., mientras que el resto de los géneros se agruparon. Los tratamientos aplicados corresponden: 2: derquantel + abamectina; 4 : fenbendazol + closantel y 6 : fenbendazol + levamisol.

\begin{tabular}{lcccccccccccccccccc}
\hline \multicolumn{1}{c}{ GENEROS } & M & A & M & J & J & A & S & O & N & D & E & F & M & A & M & J & J & A \\
\hline Haemonchus spp. & 84 & 61 & 460 & 462 & 104 & 244 & 335 & 349 & 668 & 882 & 284 & 432 & 1816 & 650 & 306 & 2826 \\
Trichos. spp. & 6 & 1 & 15 & 302 & 16 & 39 & 72 & 142 & 77 & 0 & 23 & 8 & 76 & 35 & 55 & 244 \\
Ostertagia spp. & 0 & 0 & 0 & 0 & 0 & 3 & 7 & 0 & 0 & 0 & 0 & 4 & 19 & 0 & 4 & 36 \\
Cooperia spp. & 1 & 1 & 5 & 0 & 2 & 3 & 4 & 0 & 0 & 0 & 0 & 0 & 0 & 0 & 0 & 489 \\
Oesoph-spp. & 0 & 2 & 5 & 0 & 0 & 0 & 0 & 0 & 0 & 0 & 0 & 0 & 0 & 7 & 0 & 0 \\
\hline
\end{tabular}

Tabla 49: recuento de HPG y coprocultivo mensual para el grupo táctico. 


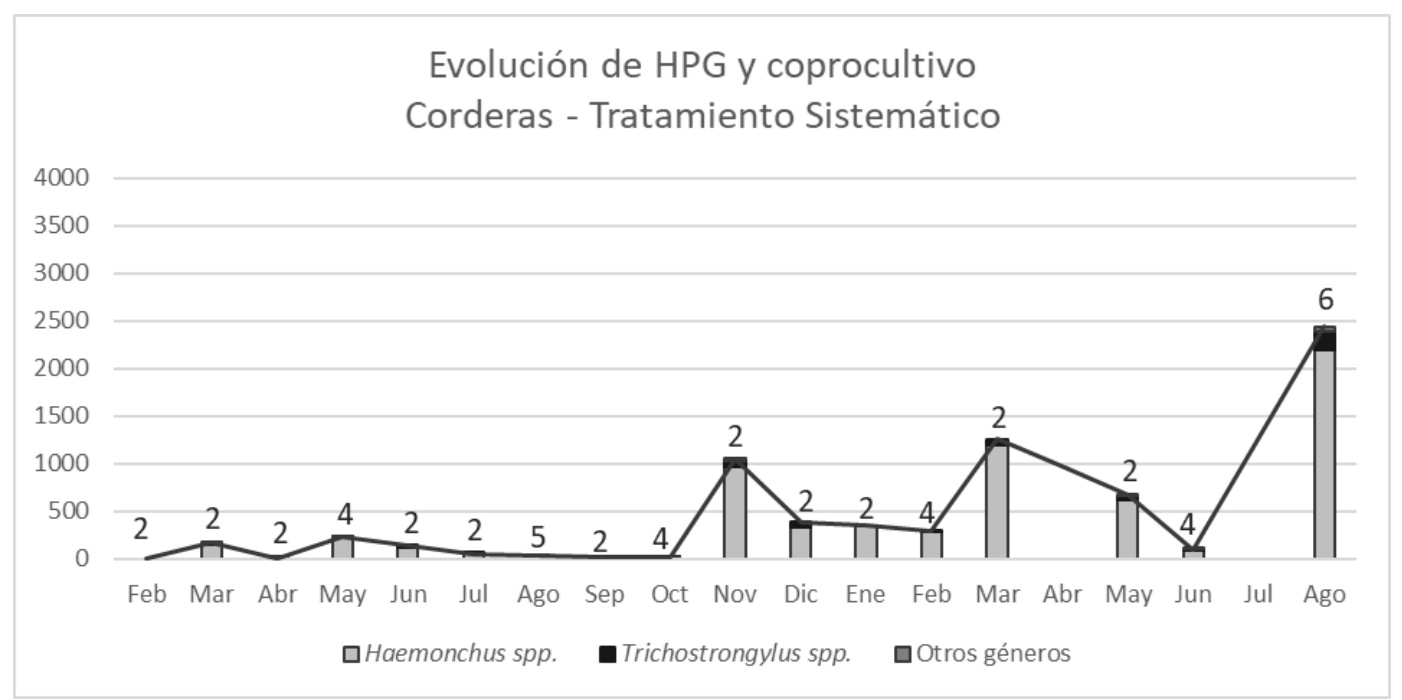

Gráfico 39: recuento de HPG para el grupo sistemático, discriminando el proporcional de Haemonchus spp. y Trichostrongylus spp., mientras que el resto de los géneros se agruparon. Los tratamientos aplicados corresponden: 2: derquantel + abamectina; 4: fenbendazol + closantel; 5: fenbendazol + naftalofos y 6 : fenbendazol + levamisol.

\begin{tabular}{lcccccccccccccccccc}
\hline \multicolumn{1}{c}{ GENEROS } & M & A & M & J & J & A & S & O & N & D & E & F & M & A & M & J & J A \\
\hline Haemonchus spp. & 153 & 9 & 224 & 112 & 52 & 26 & 10 & 16 & 962 & 335 & 347 & 282 & 1199 & & 624 & 91 & 2188 \\
Trichos. spp. & 8 & 0 & 2 & 36 & 5 & 3 & 3 & 1 & 71 & 51 & 0 & 9 & 63 & & 47 & 7 & 205 \\
Ostertagia spp. & 0 & 0 & 7 & 0 & 0 & 1 & 0 & 0 & 21 & 0 & 0 & 0 & 0 & 7 & 0 & 49 \\
Cooperia spp. & 5 & 0 & 0 & 0 & 1 & 1 & 0 & 0 & 0 & 0 & 0 & 0 & 0 & & 7 & 2 & 0 \\
Oesoph. spp. & 2 & 0 & 0 & 0 & 0 & 0 & 0 & 0 & 0 & 0 & 0 & 0 & 0 & 0 & 0 & 0 \\
\hline
\end{tabular}

Tabla 50: recuento de HPG y coprocultivo mensual para el grupo sistemático. 


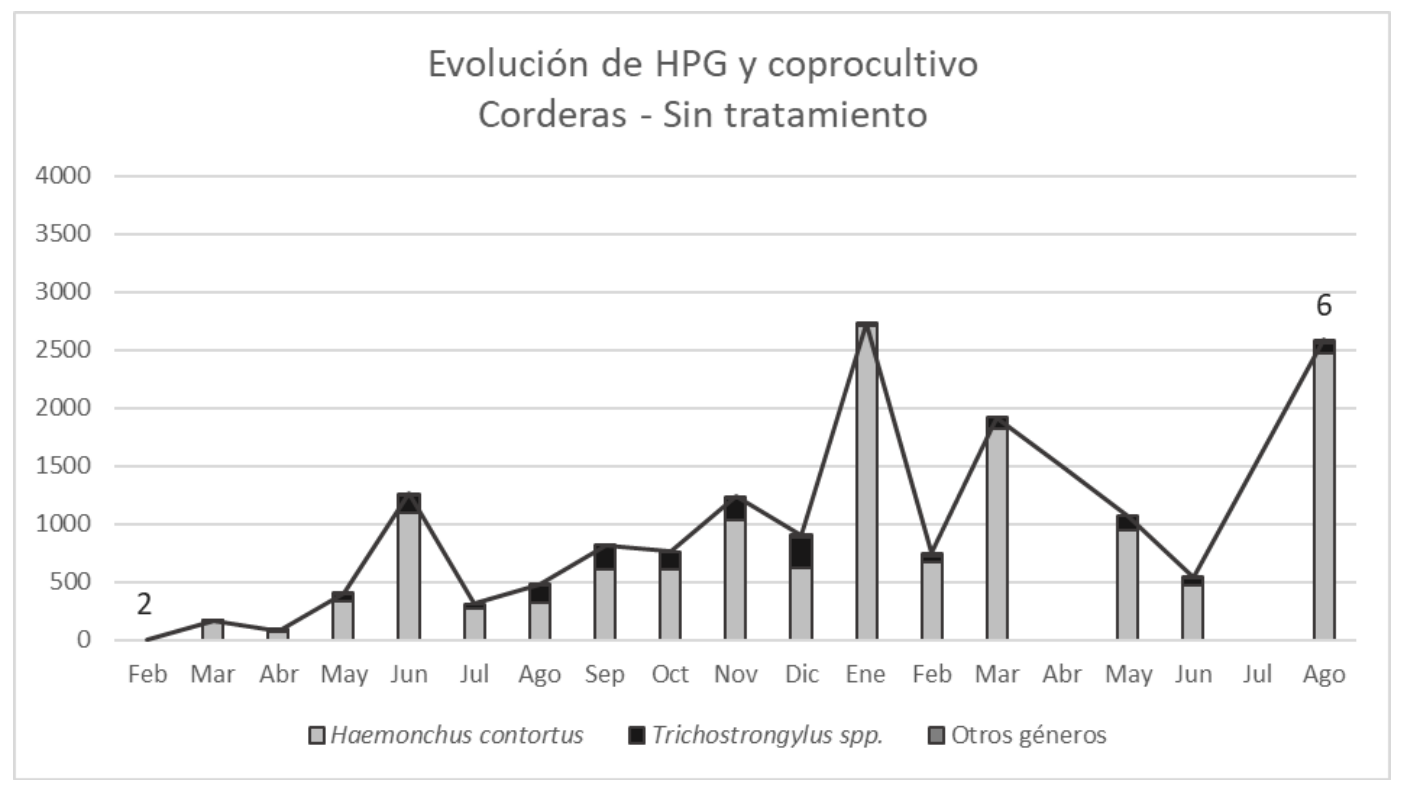

Gráfico 40: recuento de HPG para el grupo control, discriminando el proporcional de Haemonchus spp. y Trichostrongylus spp., mientras que el resto de los géneros se agruparon. Los tratamientos aplicados corresponden: 2: derquantel + abamectina y 6 : fenbendazol + levamisol, al inicio y fin del ensayo respectivamente.

\begin{tabular}{lcccccccccccccccccc}
\hline \multicolumn{1}{c}{ GENEROS } & $\mathrm{M}$ & $\mathrm{A}$ & $\mathrm{M}$ & $\mathrm{J}$ & $\mathrm{J}$ & $\mathrm{A}$ & $\mathrm{S}$ & $\mathrm{O}$ & $\mathrm{N}$ & $\mathrm{D}$ & $\mathrm{E}$ & $\mathrm{F}$ & $\mathrm{M}$ & $\mathrm{A}$ & $\mathrm{M}$ & $\mathrm{J}$ & $\mathrm{J}$ & $\mathrm{A}$ \\
\hline Haemonchus spp. & 155 & 68 & 336 & 1101 & 267 & 321 & 614 & 613 & 1039 & 622 & 2707 & 664 & 1824 & & 940 & 470 & 2475 \\
Trichos. spp. & 7 & 13 & 60 & 150 & 39 & 144 & 205 & 150 & 187 & 265 & 27 & 60 & 96 & 128 & 65 & 91 \\
Ostertagia spp. & 0 & 0 & 0 & 0 & 0 & 5 & 0 & 0 & 12 & 17 & 0 & 6 & 0 & 0 & 5 & 23 \\
Cooperia spp. & 7 & 1 & 0 & 13 & 3 & 0 & 0 & 0 & 0 & 0 & 0 & 18 & 0 & 0 & 0 & 0 \\
Oesoph. spp. & 0 & 0 & 4 & 0 & 0 & 5 & 0 & 0 & 0 & 0 & 0 & 0 & 0 & 0 & 0 & 0 \\
\hline
\end{tabular}

Tabla 51: recuento de HPG y coprocultivo mensual para el grupo control.

Aunque no se aplicaron tratamientos con este criterio, se analizó el score de FAMACHA ${ }^{\odot}$ de los registros mensuales, sin hallar diferencias significativas entre grupos, con una reducción de las frecuencias de score 1 y 2 posparto. 


\section{1) Parámetros productivos y reproductivos}

La ganancia de peso demostró diferencias significativas en los animales del grupo sistemático, respecto de los otros grupos entre noviembre y febrero inclusive. Luego del tratamiento de diciembre fueron compensándolas hasta marzo. El grupo control presentó hasta el parto mayor variabilidad (hasta $1,6 \mathrm{~kg}$ de diferencia en mayo), aunque la diferencia anterior, fue perdiendo significancia estadística (Gráfico 41 y Tabla 52).

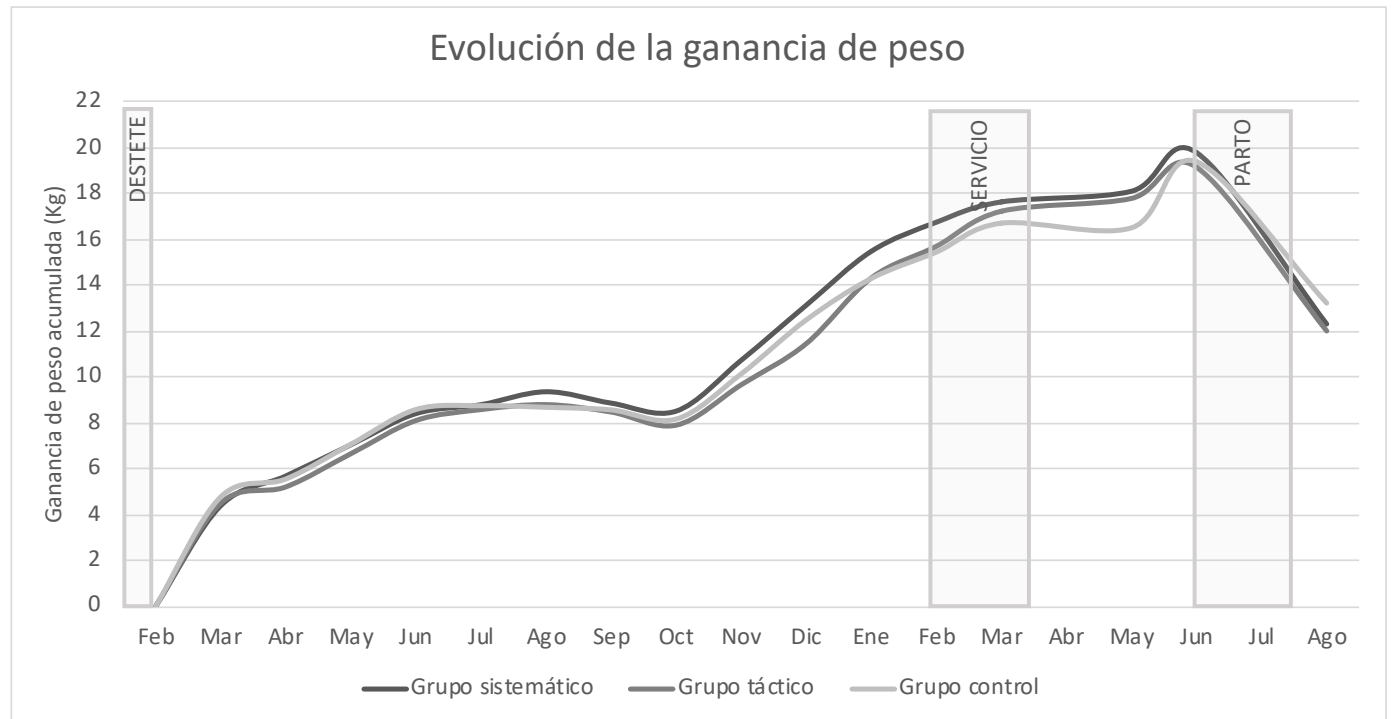

Gráfico 41: evolución de la ganancia de peso de los tres grupos evaluados.

\begin{tabular}{|c|c|c|c|c|c|c|c|c|c|c|c|c|c|c|c|c|c|c|c|}
\hline \multicolumn{2}{|c|}{ GRUPO } & $\mathrm{M}$ & A & $\mathrm{M}$ & J & J & A & $S$ & 0 & $\mathrm{~N}$ & D & $\mathrm{E}$ & $\mathrm{F}$ & M & A & M & J & J & $A$ \\
\hline \multirow{3}{*}{ ऽ } & Prom & 4,4 & 5,7 & 7,0 & 8,4 & 8,8 & 9,3 & 8,8 & 8,5 & 10,7 & 13,1 & 15,4 & 16,7 & 17,6 & & 18,1 & 19,7 & & 12,3 \\
\hline & & a & $a$ & a & $a$ & a & $a$ & a & $a$ & a & $\mathbf{a}$ & $\mathbf{a}$ & $\mathbf{a}$ & a & & $a$ & $a$ & & $a$ \\
\hline & DS & 1,4 & 1,1 & 1,5 & 1,7 & 2,2 & 2,3 & 2,5 & 2,2 & 2,3 & 2,4 & 2,3 & 3,1 & 3,2 & & 3,7 & 3,5 & & 3,6 \\
\hline \multirow{3}{*}{ 厄 } & Prom & 4,5 & 5,2 & 6,6 & 8,1 & 8,6 & 8,8 & 8,5 & 7,9 & 9,7 & 11,5 & 14,3 & 15,7 & 17,2 & & 17,8 & 19,1 & & 12,0 \\
\hline & & a & a & a & a & a & a & a & a & b & b & b & $a b$ & a & & $a$ & a & & a \\
\hline & DS & 1,0 & 1,0 & 1,4 & 1,7 & 2,0 & 2,0 & 2,1 & 2,0 & 2,1 & 2,5 & 2,4 & 2,5 & 2,6 & & 2,8 & 3,1 & & 3,2 \\
\hline
\end{tabular}




\begin{tabular}{|c|c|c|c|c|c|c|c|c|c|c|c|c|c|c|c|c|c|}
\hline \multirow{3}{*}{ ৩ } & Prom & 4,8 & 5,5 & 7,1 & 8,6 & 8,7 & 8,7 & 8,6 & 8,2 & 10,1 & 12,5 & 14,3 & 15,4 & 16,7 & 16,5 & 19,4 & 13,2 \\
\hline & & $a$ & $a$ & $a$ & a & a & $a$ & a & $a$ & $a b$ & $a b$ & b & b & a & a & a & $a$ \\
\hline & DS & 1,6 & 1,0 & 1,9 & 1,5 & 1,7 & 1,7 & 1,8 & 1,8 & 1,9 & 2,0 & 2,3 & 2,8 & 3,1 & 4,1 & 3,2 & 3,0 \\
\hline
\end{tabular}

Letras diferentes expresan diferencias significativas $(p<0,05)$.

Tabla 52: evolución de las ganancias de peso promedio acumuladas (detallando el desvío estándar para cada caso) indicando las diferencias significativas entre grupos.

La condición corporal mejoró hasta el mes de julio y luego desmejoró hasta octubre, sosteniéndose así hasta el preparto en coincidencia con las diferencias en las ganancias de peso entre grupos (Tabla 53).

\begin{tabular}{|c|c|c|c|c|c|c|}
\hline GRUPO & $\begin{array}{l}\text { SCORE CONDICIÓN } \\
\text { CORPORAL }\end{array}$ & $\begin{array}{l}\text { FEBRERO } \\
\text { (inicio) }\end{array}$ & JULIO & OCTUBRE & $\begin{array}{c}\text { JUNIO } \\
\text { (preparto) }\end{array}$ & $\begin{array}{l}\text { AGOSTO } \\
\text { (posparto) }\end{array}$ \\
\hline \multirow{3}{*}{$\begin{array}{c}\text { Grupo } \\
\text { sistemático }\end{array}$} & $<=2$ & $30 \%$ & $0 \%$ & $54 \%$ & $54 \%$ & $70 \%$ \\
\hline & $>2 y<3$ & $50 \%$ & $76 \%$ & $43 \%$ & $37 \%$ & $28 \%$ \\
\hline & $>=3$ & $20 \%$ & $24 \%$ & $2 \%$ & $9 \%$ & $2 \%$ \\
\hline \multirow{3}{*}{ Grupo táctico } & $<=2$ & $24 \%$ & $0 \%$ & $67 \%$ & $67 \%$ & $78 \%$ \\
\hline & $>2 y<3$ & $53 \%$ & $69 \%$ & $33 \%$ & $31 \%$ & $22 \%$ \\
\hline & $>=3$ & $22 \%$ & $31 \%$ & $0 \%$ & $2 \%$ & $0 \%$ \\
\hline \multirow{3}{*}{ Grupo control } & $<=2$ & $30 \%$ & $5 \%$ & $50 \%$ & $75 \%$ & $77 \%$ \\
\hline & $>2 y<3$ & $45 \%$ & $86 \%$ & $48 \%$ & $23 \%$ & $20 \%$ \\
\hline & $>=3$ & $25 \%$ & $9 \%$ & $2 \%$ & $2 \%$ & $2 \%$ \\
\hline
\end{tabular}

Tabla 53: evolución de las proporciones de condición corporal en diferentes momentos del ciclo para los tres grupos. 
Se analizaron parámetros productivos y reproductivos no habiendo diferencias significativas entre grupos (Gráficos 42 a 43 y Tabla 54).

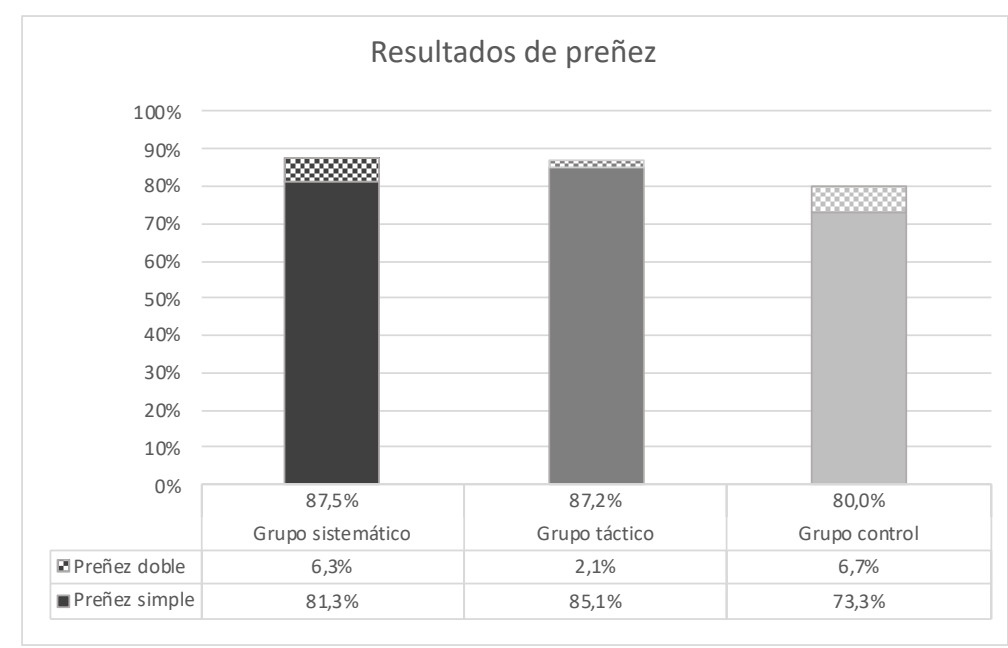

Gráfico 42: porcentajes de preñez, detallando gestaciones múltiples. Los animales vacíos fueron 4, 3 y 7 para los grupos sistemático, táctico y control respectivamente.

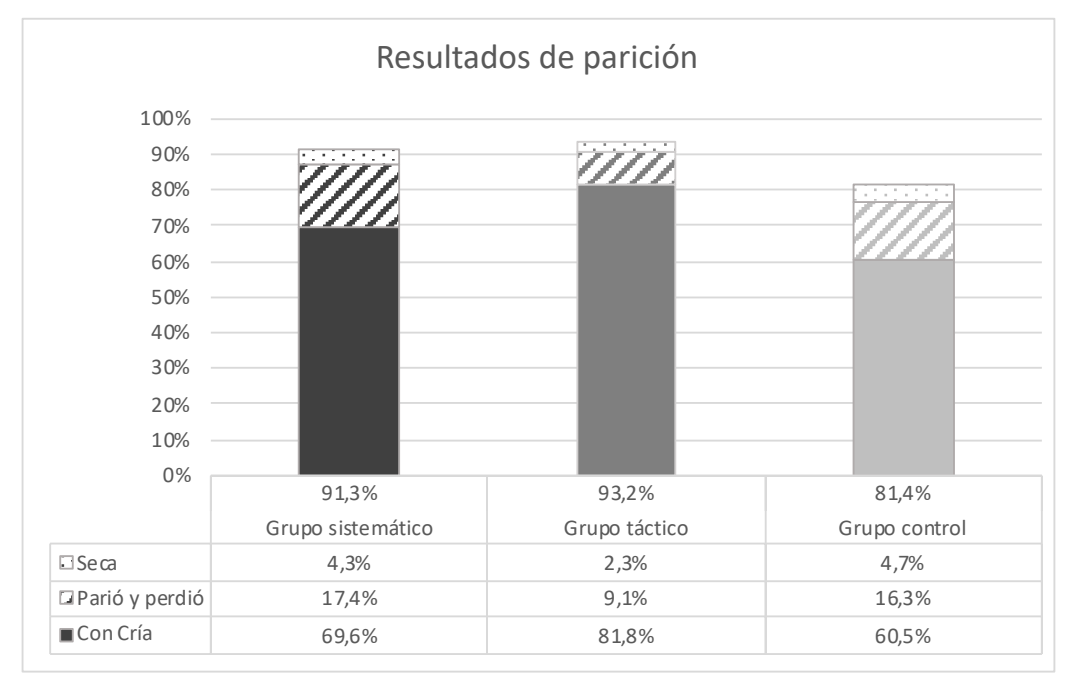

Gráfico 43: porcentajes de parición sobre una base de 42, 41 y 37 animales para el grupo sistemático, táctico y control respectivamente. 


\begin{tabular}{lccc}
\hline \multicolumn{1}{c}{ VARIABLE } & GRUPO SISTEMÁTICO & GRUPO TÁCTICO & GRUPO CONTROL \\
\hline Mortalidad de ovejas (\%) & $4,20 \%$ & $6,40 \%$ & $4,40 \%$ \\
Mortalidad neonatal (\%) & $20 \%$ & $10 \%$ & $21 \%$ \\
Señalada (\%) & $80 \%$ & $90 \%$ & $79 \%$ \\
Producción de lana (Kg) & 2,34 & 2,3 & 2,36 \\
Diámetro medio (micras) & 22,3 & 22,47 & 22,62 \\
Desviación estándar (micras) & 4,87 & 4,89 & 5,02 \\
Coeficiente de variación (\%) & 21,89 & 21,79 & 22,29 \\
Curvatura de ondulación (Grados/mm) & 70,25 & 69,58 & 68,19 \\
Factor de confort (\%) & 94,62 & 93,94 & 93,03 \\
\hline Largo de mecha (mm) & 72,95 & 70,95 & 74,77 \\
\hline
\end{tabular}

Tabla 54: resultado productivo para cada grupo.

Las variables que influyen en el desempeño reproductivo de ovejas y corderas están, por encima de la influencia parasitaria en el contexto presente, lo que queda evidenciado por el contraste del grupo táctico respecto al sistemático o al control sin tratamientos en corderas.

\section{3) Productividad del potrero por índice verde}

Se estimó la disponibilidad materia seca ( $\mathrm{Kg} \mathrm{MS/Ha)} \mathrm{del} \mathrm{potrero}$ donde pastorearon los animales durante el ensayo (potrero 14C), para el período 2000-2017 (utilizada como referencia), 2018 y 2019 (Tabla 55). Se observa para la serie histórica (2000-2017) un patrón estacional, con valores máximos para el trimestre 1 y 4 hallándose 
valores mínimos en el trimestre 2 y 3 . En los años de estudio el trimestre 2 se comportó como intermedio entre el 3 y el 4 . Pese a esto no se hallaron diferencias estadísticas en la producción anual.

\begin{tabular}{cccccccccccccc}
\hline AÑO & E & F & M & A & M & J & J & A & S & O & N & D & ANUAL \\
\hline $2000-2017$ & 655 & 616 & 558 & 375 & 253 & 198 & 113 & 229 & 293 & 452 & 646 & 663 & $\mathbf{5 0 5 0}$ \\
2018 & 676 & 835 & 909 & 706 & 421 & 259 & 68 & 175 & 276 & 567 & 676 & 929 & $\mathbf{6 4 9 8}$ \\
2019 & 944 & 848 & 751 & 597 & 288 & 257 & 97 & 156 & 124 & 330 & 812 & 766 & $\mathbf{5 9 6 9}$ \\
\hline
\end{tabular}

Tabla 55: productividad mensual en $\mathrm{Kg}$ de MS/Ha según índice verde en el potrero $14 \mathrm{C}$.

En el mes de diciembre de 2019, se estudió la composición botánica, clasificando el potrero como representativo de ambiente de pajonal, con buena calidad (valor INTECO ${ }^{14}: 1,3$ ) y cuya disponibilidad de forraje fue adecuada para la época del año, con un $9 \%$ de suelo desnudo. Entre las especies encontradas, no todas son de utilización forrajera (Tabla 56).

\begin{tabular}{lc}
\hline \multicolumn{2}{c}{ COMOPOSICIÓN BOTÁNICA } \\
\hline Eryngium paniculatum & $23,4 \%$ \\
Andropogon lateralis & $20,5 \%$ \\
Paspalum notatum & $11,2 \%$ \\
Desmodium incanum & $10,7 \%$ \\
Setaria geniculata & $6,7 \%$ \\
Piptochaetium montevidensis & $6,6 \%$ \\
Fimbristile complanata & $4,0 \%$ \\
Aristida venustula & $2,7 \%$ \\
Stipa neesiana & $2,4 \%$ \\
Paspalum plicatulum & $2,2 \%$ \\
Indigosfera asperifolia & $2,2 \%$ \\
Paspalum hexastachyum & $1,8 \%$
\end{tabular}

14 Índice de tendencia y condición 


\begin{tabular}{ll} 
Rhynchospora praecinta & $1,5 \%$ \\
Axonopus argentinus & $1,3 \%$ \\
Mimosa strigillosa & $1,1 \%$ \\
Eragrostis bahiensis & $0,4 \%$ \\
Fimbristylis diphylla & $0,4 \%$ \\
Coelorhachis selloana & $0,3 \%$ \\
Schizachyrium microstachyum & $0,3 \%$ \\
Sporobolus indicus & $0,1 \%$ \\
Schizachyrium imberbe & $0,1 \%$ \\
\hline
\end{tabular}

Tabla 56: resultado de composición botánica del pastizal.

La carga del potrero fue de $80,5 \%$ para ovinos, $16,4 \%$ bovinos y 3,1\% de equinos (Gráfico 44).

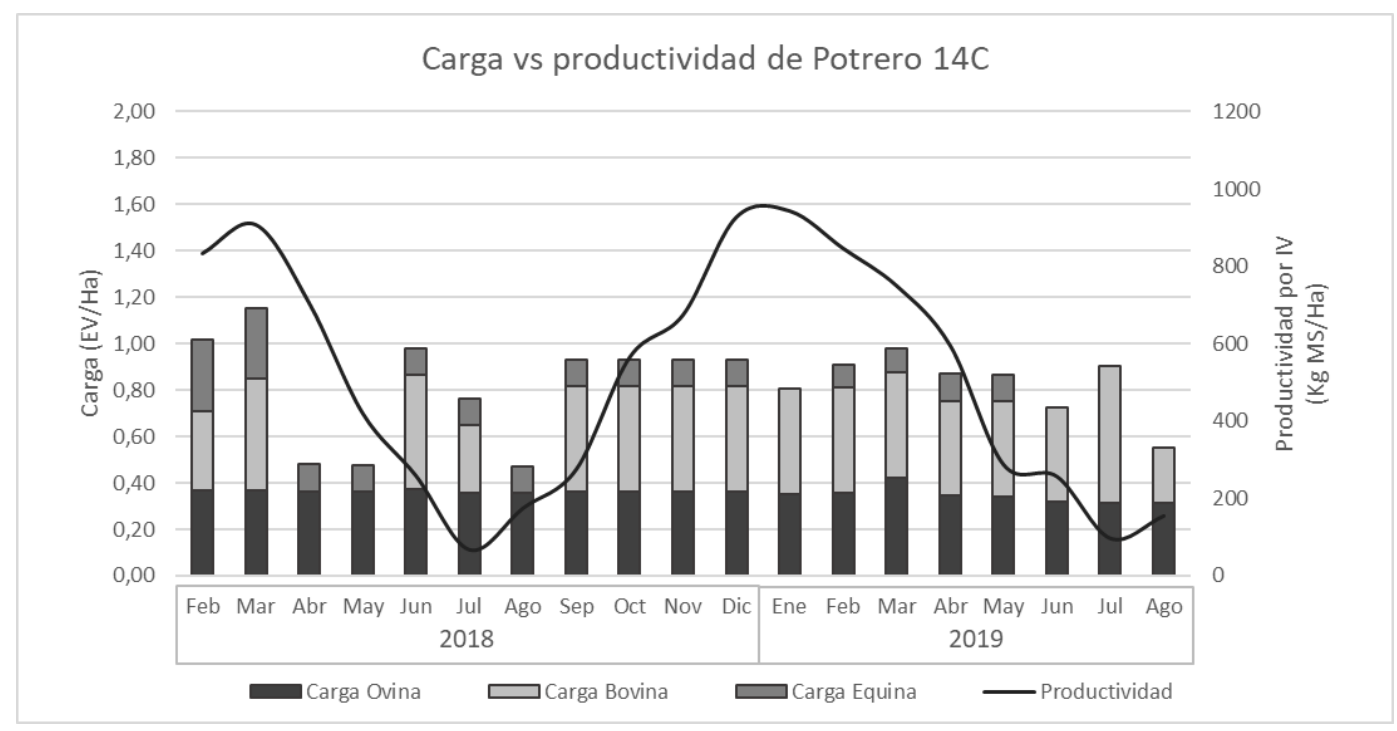

Gráfico 44: composición de la carga y productividad mensual del potrero.

La meseta de ganancia de peso de invierno coincide con la menor producción de forraje. Durante la primavera se normaliza la tasa de crecimiento con altas tasas de infestación (mayor HPG) que explican las ganancias de peso diferenciales entre grupos (Gráfico 45). 


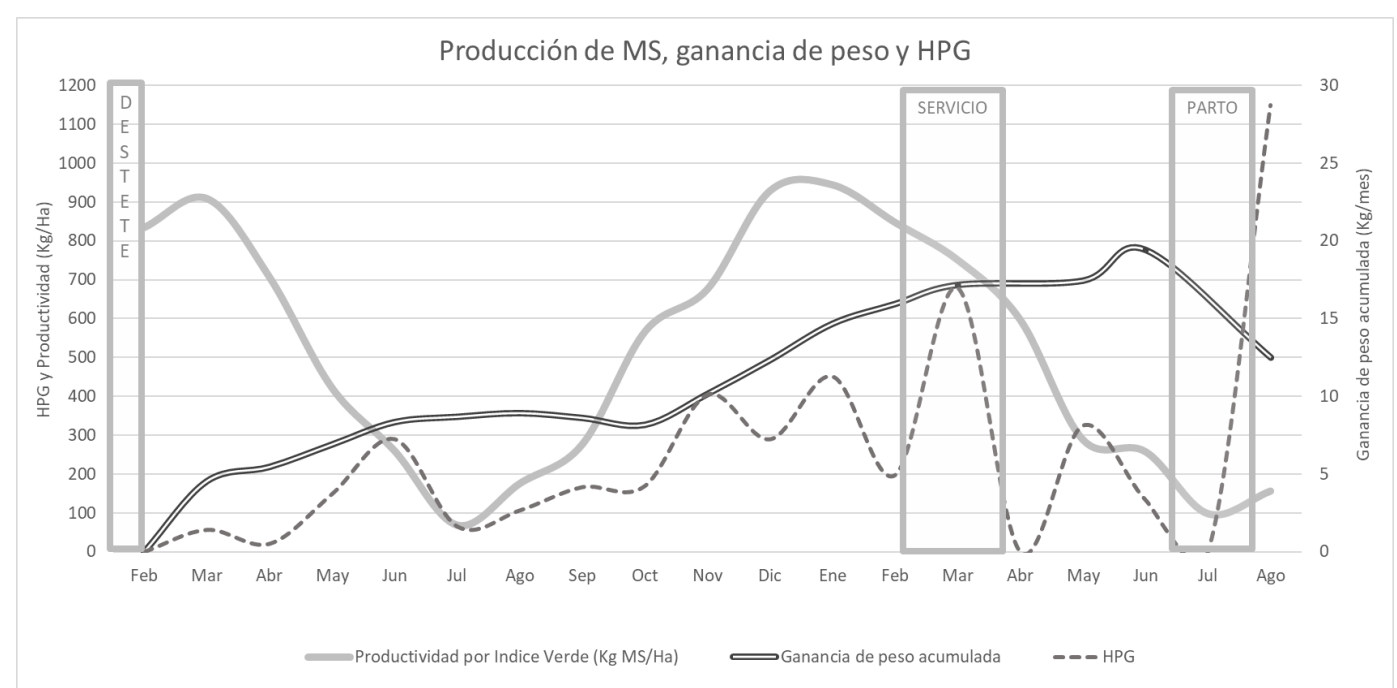

Gráfico 45: productividad del potrero $14 \mathrm{C}$ (en $\mathrm{Kg}$ de $\mathrm{MS} / \mathrm{Ha} / \mathrm{mes}$ ), contrastada con la eliminación de HPG y la ganancia de peso acumulada promedio para los 3 grupos.

Analizando mensualmente la ganancia de peso de cada mes respecto del peso anterior (expresada en porcentaje), en relación a la productividad del potrero resulta el Gráfico 46. El análisis de regresión entre estas dos variables demostró una relación significativa y positiva $\left(p<0,05\right.$, Beta: 0,557, $\left.\mathrm{R}^{2}: 0,309\right)$. 


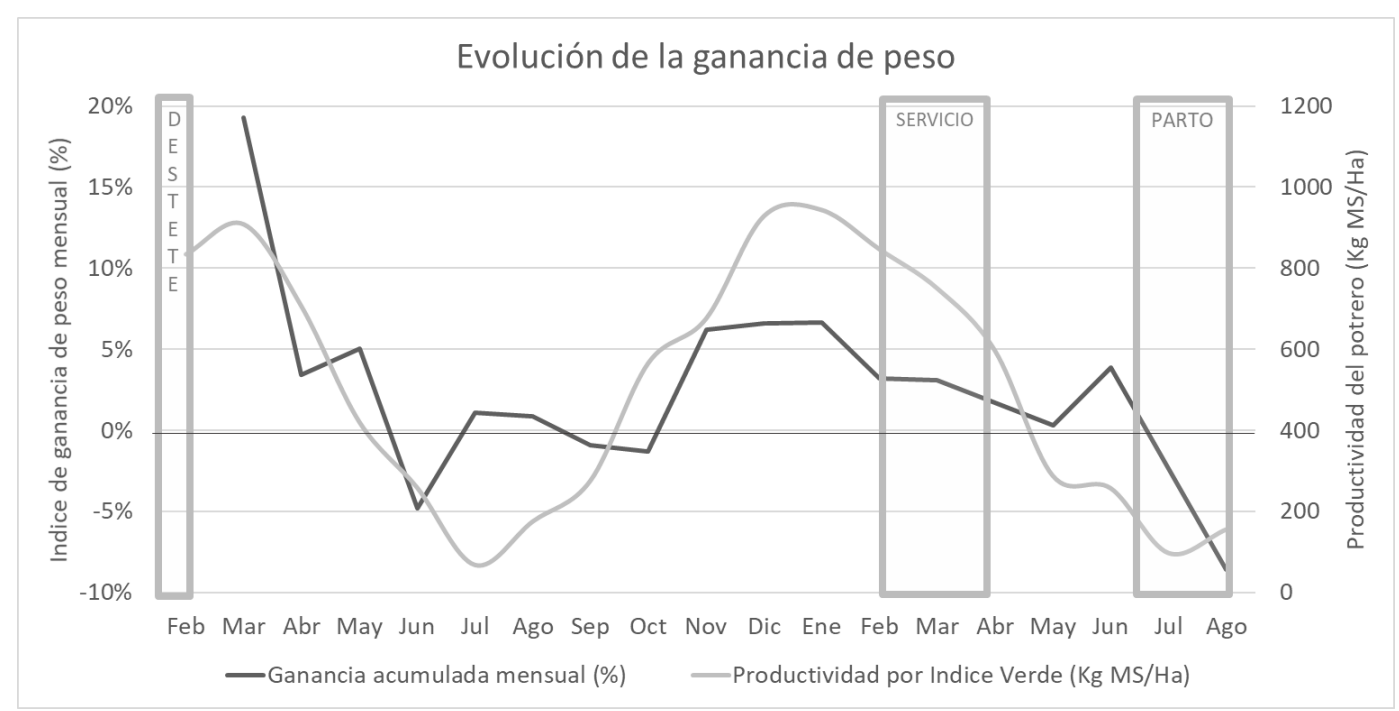

Gráfico 46: productividad en $\mathrm{Kg}$ de $\mathrm{MS} / \mathrm{Ha} /$ mes y tasa de ganancia de peso mensual promedio para los tres grupos.

c. Discusión

En las ovejas, los recuentos de HPG se mantuvieron bajos todo el año. Aumentaron durante el otoño, sin generar pérdidas hasta el preparto (abril). Esto coincide con las diferencias en las frecuencias de animales con menor condición corporal entre grupos. Después del parto (con $200 \mathrm{HPG}$ ), se produjo una diferencia de peso no compensada hasta el final de la lactancia donde la carga parasitaria se redujo. En paralelo, todos los parámetros de productividad no mostraron diferencias significativas, lo que permite afirmar que el sistema de control vigilado mensual, en estas condiciones, fue eficaz. No obstante, aún con baja carga parasitaria se dejan ver los dos períodos críticos (pre y posparto).

En las corderas durante la recría, el entorno también fue de baja carga y hasta entrada la primavera los grupos no mostraron diferencias de peso, aún con 1000 HPG en junio (el grupo sin tratamiento bajó solo). 
Luego, la carga parasitaria se construyó lentamente hasta alcanzar el máximo en marzo. Entre los meses de noviembre y febrero, se observaron diferencias en las ganancias de peso entre grupos que alcanzaron a compensarse en junio, incluso en el grupo sin tratamiento. Esto muestra que HPG superiores a 600 pueden generar pérdidas de aproximadamente $1 \mathrm{~kg}$, siendo éstas compensables. Las pérdidas de peso desde el parto hasta la señalada no mostraron diferencias significativas entre grupos. En ese contexto ninguno de los parámetros productivos fue resentido, pero debe tenerse en cuenta que los porcentajes de preñez y parición fueron menores en el grupo control (aunque sin alcanzar significancia estadística). Resta saber el comportamiento del método de control con mayor desafío parasitario.

El score de FAMACHA $^{\odot}$ no mostró diferencias entre grupos, probablemente por la baja carga de $H$. contortus, aunque en los recuentos de huevos y coprocultivos fue dominante (ya se discutió en el capítulo anterior el impacto de éste al solapar otros géneros).

Habiéndose caracterizado ya el momento del impacto parasitario, destacamos la pérdida de oportunidad de ganancia de peso debida al déficit forrajero y nutricional en el primer invierno de recría, que no se compensa en la primavera siguiente y nuevamente en el segundo invierno, compromete la condición corporal hasta el preparto.

Romero (et al., 2013) sugiere que las parasitosis son el mayor problema sanitario cuando las cargas ovinas son superiores al $10 \%$ del total. En los ensayos realizados fueron del 9,7\% para San Luis del 
Garabatá y 12,3\% para Aguay, demostrando la importancia de la variabilidad entre años, y que no siempre se las cargas parasitarias se relacionan directamente a la carga animal.

Existe una gran variabilidad en la expresión de cargas parasitarias individuales (resistencia) y también en la expresión de resiliencia. Esa variabilidad se neutraliza en grupos tratados, pero se sigue expresando en grupos sin tratamiento, razón por la cual, adquieren valor pequeñas diferencias entre grupos, que se sostienen en el tiempo como pudo apreciarse hasta el preparto en las corderas de recría.

No solo debe destacarse el período de ganancias de peso reducidas asociadas a limitaciones en el forraje, sino que buena parte de las pérdidas se deben a mortandad (extremadamente variable) y/o a lesiones de pietín complicadas con miiasis. Ambas causas no deben solaparse, aunque el interés del presente trabajo se fije en las relacionadas al parasitismo gastrointestinal.

Aunque estadísticamente no pueden atribuirse a la diferencia de tratamientos, se observan diferencias en el desempeño reproductivo entre lotes dignas de tenerse en cuenta en eventuales futuros seguimientos.

Resta por conocer la influencia de las medidas de manejo y especialmente las suplementaciones nutricionales sobre las tasas de infección. 


\section{d. Conclusiones}

Las pérdidas potenciales por causa parasitaria se han documentado en numerosos trabajos, sin embargo existen años en que las condiciones de los animales, del ambiente y manejo, permiten que sean mínimas. Es ahí donde los indicadores objetivos deben retroalimentar y minimizar las intervenciones de los sistemas de control.

En situaciones reales de producción, hay otras causas de pérdidas que pueden coincidir temporalmente con épocas que habitualmente se asocian a parásitos y si objetivamente no se diferencian inducen al uso de antiparasitarios como placebos, con consecuencias en la selección de cepas resistentes y costos innecesarios.

Los sistemas de control que contemplen tratamientos estratégicos, pero que se basen en el seguimiento epidemiológico, pueden detectar las diferencias entre años y generar decisiones sin riesgo de ser superados con pérdidas productivas significativas.

En evaluaciones de pérdidas productivas, la variabilidad individual en las expresiones de los animales incluidos en los estudios, puede minimizar la significación estadística de las diferencias entre grupos ( $\mathrm{n}$ de cada grupo). 


\section{CONCLUSIONES GENERALES}

Los principales parásitos en la región son $H$. contortus y $T$. colubriformis, siendo de mayor importancia clínica el primero al ser más patógeno y con mayor potencial biótico, lo que le permite construir cargas críticas en menor tiempo. No obstante, T. colubriformis puede expresar recuentos parasitarios altos, especialmente en corderas. Esto podría dificultar la interpretación de los resultados de HPG y coprocultivos, ya que este género es soslayado por géneros con mayor nivel de postura, quitando sensibilidad al método de control cuando se aplican tratamientos selectivos $\left(\right.$ FAMACHA $\left.^{\circ}\right)$.

Las condiciones meteorológicas difieren entre años, especialmente la humedad, las precipitaciones y evapotranspiración (modificando el balance hídrico y el almacenaje total), las que resultan críticas y especialmente variables en otoño, influyendo sobre las poblaciones parasitarias.

En determinadas condiciones ambientales (carga real y absoluta, situaciones de manejo especiales, hacinamiento, etc.) pueden aparecer otros géneros como S. papillosus y N. spathiger. Así también, las cargas crecientes de bovinos en pastoreo mixto, aumentan la expresión de los géneros Cooperia spp. y Oesophagostomum spp.

Las pérdidas productivas, son dependientes de las cargas parasitarias y obligan a aplicar sistemas de monitoreo que detecten sus variaciones. Incluso en esta zona, considerada como una de las más propicias del mundo para la presentación de las trichostrongylosis 
ovinas, pueden ser mínimas y los sistemas de control deben tener la sensibilidad suficiente para detectar cuando no son necesarios los tratamientos y los momentos en que las desparasitaciones previas han impactado en las poblaciones de cada especie y permitir tomar decisiones en consecuencia y a tiempo.

La medición de condición corporal, no sólo resulta más práctica que la de peso vivo, especialmente en ovejas (bajo la influencia del ciclo reproductivo), sino que la información obtenida resulta más integral y objetiva para la toma de decisiones (por el peso relativo de la gestación). Debe tenerse en cuenta, que otras causas no parasitarias, pueden asociarse a valores bajos de estos parámetros y el control integrado en la majada debe diferenciarlos. Por ejemplo deficiencias nutricionales invernales, pérdidas por mortandad (tanto de ovejas como de corderos en el periparto), descarte por pietín y miiasis que en este estudio resultaron más importantes que las mermas producidas por parásitos gastrointestinales.

La técnica de $\mathrm{FAMACHA}^{\odot}$ tiene mejor impacto en ovejas que en corderas, posiblemente debido a que el parásito más frecuente en ovejas es el $H$. contortus, y a que su aplicación en verano y otoño (períodos más variables) puede acompañar el manejo racional. En un contexto de fallas en la eficacia de las drogas, reduce el impacto sobre la población en refugio, reduciendo el riesgo ya que es sobre la que se construye la carga del periparto en las ovejas. 
Resulta indispensable conocer el balance nutricional de los animales. El presente estudio demuestra que (especialmente en corderas de recría) la falta de forraje (y posiblemente de proteína en la dieta) impactan negativamente en las tasas de crecimiento, pudiendo confundir el desmejoramiento, con cuadros de parasitosis o predisponer a los mismos por las carencias nutricionales. El volumen de forraje debería tenerse en cuenta al interpretar los parámetros parasitarios (dilución), pudiendo facilitar la infestación en períodos de escases o reducir los riesgos cuando es abundante.

Comentario final: queremos señalar con la experiencia vivida al realizar estudios en campos privados y en entornos con demandas comerciales, que no deben menospreciarse los riesgos respecto a limitaciones del personal, armonización de los protocolos con las condiciones de manejo propias del establecimiento, el entendimiento y disposición del personal y la administración para la demanda del trabajo y el riesgo que implican circunstancias climáticas, imposiciones comerciales eventuales y hasta el abigeato.

Por otro lado, las limitaciones en el número de animales que se pueden sacrificar en estudios lineales como este enfrentan la variabilidad individual en la expresión de parámetros parasitológicos o productivos e imponen limitaciones en la interpretación final de los resultados. 


\section{ANEXO}

Las técnicas de laboratorio utilizadas están ampliamente difundidas en los manuales de procedimientos de diferentes laboratorios e institutos (CEDIVE, INTA, etc.) y están compiladas y detalladas por Steffan y Fiel (2018). En el presente anexo se realizarán aclaraciones que se consideran relevantes.

Condición corporal: técnica sencilla que permite evaluar de modo subjetivo los niveles de engrasamiento de los animales (Murray, 1919). Para ello se califican en una escala de 0 a 5 , en la que los valores más altos corresponden a mayores depósitos de grasa. Según Russel (et al., 1969) podría aumentarse la precisión al dividir cada punto en 2 o en 4 valores intermedios, aunque cuestiona su aplicación. Para la medición en ovinos, se toma la región lumbar ya que es el último lugar en el que se deposita grasa subcutánea y el primero que moviliza (Flores y Mantecón, 1994). En algunas razas puede medirse en la base de la cola, mientras que en caprinos (por la disposición de los depósitos de grasa) es de elección la región esternal.

Huevos por gramo (HPG) de materia fecal: técnica cuantitativa que permite determinar la cantidad de huevos de estrongílidos que son eliminados por gramo de materia fecal. Para su realización en ovinos, se diluye $1 \mathrm{gr}$ de materia fecal en $50 \mathrm{ml}$ de solución salina saturada (densidad >1180) y se completa la cámara de McMáster (cámara INTA). 
Luego se observa y cuentan los huevos de una celda al microscopio con objetivo 5X (Roberts y O'Sullivan, 1949).

Coprocultivo e identificación de larvas: los huevos de distintas especies de estrongílidos que parasitan rumiantes son similares y el conocimiento de su composición específica resulta relevante en infecciones mixtas. Para ello el estudio cuantitativo de la materia fecal se complementa con estudios cualitativos de recuperación de L3 mediante la técnica de Henriksen y Korsholm (1983) e identificación según morfológicas (Niec, 1968).

Test de reducción del conteo de huevos (TRCH): es la prueba de elección para evaluar la eficacia de medicamentos a campo, dado su bajo costo y practicidad de sus resultados. Para ello se realizó un recuento de HPG, seleccionando los animales a incluir en la prueba (HPG >200) y se armaron grupos homogéneos (según peso y HPG) de 10 animales por cada droga a evaluar, sin grupo control. Se realizó un recuento de HPG individual en los animales pretratamiento el día 0 (día de aplicación del tratamiento) y postratamiento entre los 7 y 14 días. En cada caso (pre y postratamiento) se realizó un cultivo por grupo con un pool de materia fecal de los animales para cada caso (igual proporción de materia fecal de cada animal). Los resultados globales y corregidos para cada género con los resultados de los coprocultivos se analizaron según la fórmula propuesta por Coles (et al., 1992) y en las recomendaciones de la 
WAAVP (World Association for the Advancement of Veterinary Parasitology).

$\underline{\text { Recuperación y recuento de nematodes de cuajo, intestino delgado y }}$ grueso: se procede a la ligadura, para facilitar el lavaje por separado de cada uno de los órganos y evitar que su contenido se mezcle. Se realizan 3 ligaduras, una en el cardias, una doble en el píloro y una en la válvula ileocecal. Luego se realizan los cortes correspondientes para la separación de los tres órganos en diferentes bandejas. El cuajo se abre por la curvatura menor, se lava y recupera todo el contenido. Los intestinos se separan del meso (por tracción). El intestino delgado se abre con un enterótomo. El intestino grueso se estira sobre la mesa de trabajo y se corta con tijera por el borde mesentérico. En cada caso, luego de su apertura se lava con abundante agua, recuperándose todo el contenido en un balde graduado. Luego se recupera una alícuota del $10 \%$ del total y se fija con formol al 1\%. Para la identificación y recuento parasitario se utiliza el $2 \%$, pudiendo ampliarse en casos especiales.

Recuperación y recuento de helmintos broncopulmonares: se realiza mediante el lavado interno del pulmón, utilizando una corriente de agua introducida por los vasos sanguíneos (desde la arteria pulmonar). El agua llega a los capilares alveolares y por aumento de presión (resultante por ligadura de venas pulmonares) los rompe y sale a la luz de las vías respiratorias, circulando por el árbol bronquial hasta la tráquea, arrastrando los parásitos que se recogen en un tamiz. 
Para ello se debe extraer el pulmón del animal muerto cuidando de mantener el corazón y la arteria pulmonar intactos y cortando la tráquea a la altura de la laringe. Luego separar el pericardio e incidir el ventrículo derecho para introducir una manguera hacia la arteria pulmonar. Disecarla y fijar la manguera. Ligar las venas pulmonares para evitar el reflujo de agua hacia el corazón. Colocar la abertura de la tráquea sobre el tamiz y comenzar la inyección de agua y mantenerla hasta que hayan pasado por el pulmón no menos de 10 litros. Los nematodes arrastrados por el agua quedarán en el tamiz. Lavar el tamiz recogiendo el líquido en vasos de decantación. Dejar decantar una hora, sifonar el sobrenadante y conservar en solución de Turdyev el sedimento (en formol se rompen con facilidad). La identificación y recuento se realiza sobre el total del material recuperado. Si la cantidad de parásitos fuese muy grande, del mismo modo que se realiza en órganos digestivos, tomar una alícuota del $10 \%$ antes de conservar.

Recuperación y recuento de estadíos inmaduros de la mucosa del cuajo: todos los tricostrongílidos tienen un período de histotropismo en el estado larval. Las larvas 4 de Ostertagia spp., Trichostrongylus spp. y Haemonchus spp. se encuentran en las glándulas de la mucosa del cuajo y no se recuperan en el lavado. En circunstancias especiales, estas larvas 4 permanecen en hipobiosis por períodos prolongados y su recuperación en la necropsia es importante para evaluar la carga parasitaria. La técnica más utilizada y de mayor sensibilidad es la de digestión artificial. Para su realización se debe raspar con un cuchillo la 
mucosa del cuajo y colocar el material resultante en un envase plástico. Por cada $20 \mathrm{gr}$ de material se adicionarán $200 \mathrm{ml}$ de la solución de digestión, preparada con ácido clorhídrico $33 \%(\mathrm{pH} 1)$ y $2,5 \mathrm{gr}$ de pepsina (potencia 1:100.000). Luego llevar a baño María a $37^{\circ} \mathrm{C}$, durante 3 hs., agitando cada 15 minutos hasta la digestión total de la mucosa. Una vez digerido el material se realiza un pasaje por una malla número $10(2 \mathrm{~mm})$ y se fija con formol al $1 \%$. La identificación y recuento parasitario se realiza sobre el $10 \%$ del total. 


\section{BIBLIOGRAFIA}

1. Abbott, K.A.; Taylor, M. y Stubbings, L.A. 2007. Sustainable worm control strategies for sheep 2nd Ed. A technical manual for veterinary surgeons and advisers.

2. Acosta, F.; Gimenez, L.; Richieri, C. y Calvi, M. 2009. Zonas AgroEconómicas Homogéneas Corrientes. Descripción ambiental, socioeconómica y productiva. Instituto Nacional de Tecnología (INTA), Centro Regional Corrientes.

3. Aguirre, D.H.; Viñabal, A.E.; Cafrune, M.M. y Salatin, A.O. 2000. Comparación de la infestación natural por parásitos gastrointestinales en una majada mixta de ovejas y cabras en el noroeste argentino. Dificultades en el control químico de nematodes en los caprinos. Therios 29 (154): 184-192.

4. Albers, G.A.A; Gray, G.D.; Piper, L.R.; Barber, J.S.F.; Le Jambre, L.F. y Barger, I.A. 1987. The genetics of resistance and resilience to Haemonchus contortus infection in young Merino sheep. Int. J. Parasitol. 17: 1355-1367.

5. Ambrústolo, R.; Bulman, G.; Segura, E. Beckwith, B. y Guerrero, J. 1990. El control parasitario y su relación con parámetros de aptitud reproductiva en vaquillonas de reposición en La Pampa Húmeda (Argentina). Veterinaria Argentina 7 (62): 90-98.

6. Anziani, O.; Zimmermann, G.; Guglielmone, A.; Vasquez, R. y Suarez, V.H. 2000. Resistencia a las ivermectinas de bovinos parasitados por Cooperia spp.: comunicación preliminar. 
Veterinaria Argentina Srl. Veterinaria Argentina 17; 164: 6-2000; $280-281$.

7. Archie, E.A. y Ezenwa, V.O. 2011 Population genetic structure and history of a generalist parasite infecting multiple sympatric host species. International Journal for Parasitology 41: 89-98.

8. Arece García, J. 2005. Identificación y comportamiento de los estrongílidos gastrointestinales en ovinos en las provincias de Matanzas. Tesis Doctoral. Ministerio de Educación superior, Centro Nacional de Sanidad Agropecuaria. Estación Experimental de pastos y forrajes "Indio Hatuey".

9. Armour, J. 1980. The epidemiology of helminth disease in farm animals. Vet. Parasitol. Vol. 6 (1-3): 7-46

10. Armour, J.; Bairden, K. Duncan, J.L.; Jennings, F.W. y Parkins, J.J. 1979. Observations on ostertagiasis in young cattle over two grazing seasons with special reference to plasma pepsinogen levels. Veterinary Record 105: 500-503.

11. Artho, R.; Schnyder, M.; Kohler, L.; Torgerson, P.R. y Hertzberg, H. 2007. Avermectin-resistance in gastrointestinal nematodes of Boer goats and Dorper sheep in Switzerland. Vet. Parasitol. 2007; $144: 68-73$.

12. AWEX. Australian Wool Exchange Market. 2019. www.awex.com.au.

13. AWI Australian Wool Innovation. www.wool.com.

14. Bairden, K.; Armour, J. y Duncan, J.L. 1995. A 4-year study on the effectiveness of alternate grazing of cattle and sheep in the 
control of bovine parasitic gastro-enteritis. Veterinary Parasitology 60 (1-2): 119-132.

15. Baker, R.L. 1997. Résistence génétique des petits ruminants aux helminthes en Afrique. INRA, Prod. Anim., Vol. 10 (1): 99-110.

16. Bakunzi, F.R.; Nkomo, L.K.; Motsei, L.E.; Ndou, R.V. y Nyirenda, M. 2013. A survey on anthelmintic resistance in nematode parasites of communally grazed sheep and goats in a rural area of North West Province, Republic of South Africa. Life Sci. J. 2013; 10: 391-393.

17. Balbi A. 1993. Ecología de la fase libre del ciclo de Haemonchus contortus del ovino en la Pampa Húmeda. En "Aportes a la Parasitología Veterinaria" por Eddi, C.; y Caracostantógolo, J. Vol. II. INTA CICV. Castelar.

18. Ballesteros, M.E. 2018. Control frente a los nemátodos gastrointestinales del ganado ovino: Desarrollo de nuevas herramientas para el diagnóstico precoz de la resistencia antihelmíntica. Tesis Doctoral. Universidad de Leon, España.

19. Barger, I.A. 1988. Resistance of young lambs to Haemonchus contortus infection and its loss following anthelmintic treatment. Internationl Journal for Parasitology 18: 1107-1109.

20. Barger, I.A. y Southcott, W.H. 1975. Control of nematode parasites by grazing management: I. Decontamination of cattle pastures by grazing with sheep. International Journal for Parasitology 5: 39-44. 
21. Barger, I.A.; Le Jambre, L.F.; Georgi, J.R y Davies, H.I. 1985. Regulation of Haemonchus contortus populations in sheep exposed to continuous infection. International Journal for Parasitology vol 15 (5): 529-533.

22. Barton, N.J. 1983. Development of anthelmintic resistance in nematodes from sheep in Australia subjected to different treatment frequencies. Int. J. Parasitology, 13: 125-132.

23. Bath, G.F.; Malan, F.S. y van Wyk, J.A. 1996. The "FAMACHA®" Ovine Anemia Guide to assist with the control of haemonchosis. In: Proceedings of the 7th Annual Congress of the Livestock Health and Production Group of the South African Veterinary Association. Port Elizabeth, South África. p. 5.

24. Bendersky, D.; Pizzio, R.; Maidana, C.; Zapata, P. y Durante, M. 2017. Producción y curva de crecimiento de pastizales del Este de Corrientes. INTA Ediciones, Noticias y Comentarios No 542. ISSN Nro. 0327-3059.

25. Brunsdon, R.V. 1964. The effect of infestation by nematodes of the family Trichostrongylidae and the tapeworm, Moniezia expansa, upon the liveweight gain and wool production of young sheep. New Zealand Veterinary Journal, Vol 12(6): 129-134.

26. Brunsdon, R.V. 1966. Further studies of the effect of infestation by nematodes of the family Trichostrongylidae in sheep; an evaluation of a strategic drenching programme. New Zealand Veterinary Journal, Vol 14(7):77-83. 
27. Brunsdon, R.V. 1966. The immunity of sheep to trichostrongyle infestations following reduction of the circulating leucocyte count by oral administration of chlorambucil: A further study of the spring-rise phenomenon, New Zealand Veterinary Journal, 14(10): 161-167, DOI: 10.1080/00480169.1966.33661.

28. Brunsdon, R.V. 1970. Seasonal changes in the level and composition of nematode worm burdens in young sheep. New Zealand Journal of Agricultural Research, 13(1) 126-148, DOI: $10.1080 / 00288233.1970 .10421203$

29. Bueno, L. Fioramonti, J. y Ruckebusch, Y. 1975. Rate of flow of digesta and electrical activity of the small intestine in dogs and sheep. Journal Physiology. 249: 69-85.

30. Bulman, M. 2015. Pérdidas económicas directas e indirectas por parásitos internos y externos de los animales domésticos en Argentina. Veterinaria Argentina, Vol XXXII (330): 1-95.

31. Burkart, R.; Bárbaro, N.O.; Sánchez, R.O. y Gómez, D.A. 1999. Eco-Regiones de la Argentina. Administración de Parques Nacionales, Programa de desarrollo Institucional Ambiental, Secretaría de Recursos Naturales y Desarrollo Sustentable, Presidencia de la Nación. 42 pp.

32. Bush, A.O.; Lafferty, K.D.; Lotz, J.M. y Shostak, A.W. 1997. Parasitology meets ecology on its own terms; Margolis et al. revisited. Journal Parasitology, Vol 83(4): 575-583.

33. Caracostantogolo, J.; Anziani, O.; Romero, J.; Suarez, V. y Fiel, C. 2013. Enfermedades Parasitarias de Importancia Clínica y 
Productiva en Rumiantes. Fundamentos epidemiológicos para su prevención y control - Fiel, C.; Nari, A. Capítulo 11: Resistencia a los antihelmínticos en Argentina. Pp 255-282. ISBN: 978-9974674-35-6.

34. Caracostantogolo, J.; Castaño, R.; Cutullé, Ch.; Cetrá, B.; Lamberti, R.; Olaechea, F.; Plorutti, F.; Ruiz, M.; Schapiro, J.; Martínez, M.; Balbiani, G.; Castro, M.; Morici, G. y Eddi, C. 2005. Evaluación de la resistencia a los antihelmínticos en rumiantes en Argentina. En Resistencia a los antiparasitarios internos en Argentina. Serie FAO Producción y Sanidad Animal. Organización de las Naciones Unidas para la Agricultura y la Alimentación, Roma 2005. ISBN: 92-5-305428-X. ISSN 1014-1200.

35. Cardellino, R.; Peñagaricano, J. y Castells, D. 1994. Central Prueba de Progenie Corridal "Dr. Alberto Gallinal" Generacion 1994, Sociedad de Criadores de Corriedale, №1. 14 pp.

36. Carmichael, I.; Visser, R.; Schneider, D. y Soll, M., 1987. Haemonchus contortus resistance to ivermectin. J. S. Afr. Vet. Assoc., 58: 93.

37. Castaño Zubieta, R. 2005. Estudio de la variación genética entre cepas de nematodos parásitos trichostrongylideos de los rumiantes, resistentes y susceptibles a la ivermectina mediante el empleo de marcadores moleculares. Tesis de Maestría en Biotecnología, Universidad de Buenos Aires.

38. Castells D.; Nari, A.; Risso, E. y Mármol, E. 1995. Efecto de los nematodos gastrointestinales sobre diversos parámetros 
productivos del ovino en la etapa de recría Año II 1991. Producción ovina 8, pp 17-32.

39. Castells, D. 2002. Resistencia genética del ovino a los nematodes gastrointestinales (revisión) "Resistencia genética del ovino y su aplicación en sistemas de control integrado de parásitos" FAO Animal Production and Healt Paper. Ed. Hemisferio Sur. Buenos Aires.

40. Castells, D.; Gayo, V.; Mederos, A.; Martinez, D.; Risso, R.; Rodriguez, A.; Scremini, P.; Olivera, J.; Banchero, G. ; Lima, A.L. ; Larrosa, F.; Casaretto, A.; Bonino, J.; Rosadilla, D.; Franchi, M.; Quintana, S. y Quintans, G. 2011. Epidemiological study of gastro-intestinal nematodes of sheep in Uruguay: Prevalence and seasonal dynamics. Proceedings 2rd. International Conference of the World Association for the Advancement of Veterinary Parasitology. Buenos Aires. Argentina, pp 16.

41. Castells, D.; Romero, J.; Mederos, A. y Nari, A. 2013. Enfermedades Parasitarias de Importancia Clínica y Productiva en Rumiantes. Fundamentos epidemiológicos para su prevención y control - Fiel, C.; Nari, A. Capítulo 9: Control de nematodos gastrointestinales en ovinos pp. 201-221. ISBN: 978-9974-67435-6.

42. Čerňanská, D.; Várady, M. y Čorba, J. 2006. A survey on anthelmintic resistance in nematode parasites of sheep in the Slovak Republic. Veterinary Parasitology 135; 39-45. 
43. Cintra, M.C.R.; Teixeira, V.N.; Nascimiento, L.V y Sotomaior, C.S. 2016. Lack of efficacy of monepantel against Trichostrongylus colubriformis in sheep in Brazil. Veterinary Parasitology, Vol, 216, pp 4-6.

44. Claerebout, E. y Vercruysse, J. 2000. The immune response and the evaluation of acquired immunity against gastrointestinal nematodes in cattle: a review. Parasitology 120: 25-42.

45. Clarke, E.A. 1963. The economic importance of intestinal parasites. New Zealand Veterinary Journal, Vol 11(4): 77-81.

46. Coles, G.C.; Bauer, C.; Borgsteed, F.H.M.; Geerts, S.; Klei, T.R.; Taylor M.A. y Wallerf P.J. 1992 World Association for the Advancement of Veterinary Parasitology (W.A.A.V.P.) methods for the detection of anthelmintic resistance in nematodes of veterinary importance. Veterinary Parasitology, 44 (1992) 35-44.

47. Coles, G.C.; Jackson, F.; Pomroy, W.E.; Prichard, R.K.; von Samson-Himmelstjerna, G.; Silvestre, A.; Taylor, M.A. y Vercruysse, J. 2006. The detection of anthelmintic resistance in nematodes of veterinary importance. Veterinary Parasitology, 136: $167-185$.

48. Comisión Mixta Provincial del Ovino, provincia de Corrientes. 2004. Diagnóstico de la producción ovina de Corrientes. En: IDIA XXI - Ovinos. Año IV, No. 7. Ediciones INTA. 194-200.

49. Coop, R.L. y Holmes, P.H. 1996. Nutrition and parasite interaction. International Journal for Parasitology 26: 951-962. 
50. Coop, R.L. y Kyriazakis, I. 1999. Nutrition-parasite interaction. Veterinary Parasitology 84: 187-204.

51. Cordero del Campillo, M. y Rojo Vázquez, F.A. 1999. Parasitología veterinaria. 1ra Ed. McGraw-Hill-Interamericana de España, S.A.U. España. ISBN: 84-486-0236-6.

52. Cristel, S.; Fiel, C.; Anziani, O.; Descarga, C.; Cetrá, B.; Romero, J.; Fernández, S.; Entrocasso, C.; Lloberas, M.; Medus, D. y Steffan, P. 2017. Anthelmintic resistance in grazing beef cattle in central and norheastern areas of Argentina - An update. Veterinary Parasitology: Regional Studies and Reports.

53. CSIRO. 2007. Nutrient Requirements of Domesticated Ruminants. 270 p. CSIRO Publishing. Australia.

54. Dargie, J.D. y Allonby, E.W 1975. Pathophysiology of single and challenge infections of Haemonchus contortus in Merino sheep; studies on red cell kinetics and the Self-Cure phenomenon. International Journal for Parasitology, Vol 5, pp 147-157.

55. De Gea, G. 2007. El ganado lanar en la Argentina. 2da Ed. Río Cuarto, Córdoba. Universidad Nacional de Río Cuarto. 280p. ISBN $978-950-665-448-1$.

56. De Melo, H.J.H. 1977. Evidencia preliminar de "hipobiose" ou "desenvolvimento interrompido" de nematodeos gastrointestinais em becerros zebus criados extensivamente em zona de Cerrado de Mato Grosso. Pesq. Agrop. Bras. 12: 197:204. 
57. Didan K. 2015. MOD13Q1 MODIS/Terra Vegetation Indices 16Day L3 Global 250m SIN Grid V006. NASA EOSDIS Land Processes DAAC. https://doi.org/10.5067/MODIS/MOD13Q1.006.

58. Dimitrijevic B.; Borozoan, S.; Katic'-Radivojevic', S.; Stojanovic', S. 2012. Effects of infection intensity with Strongyloides papillosus and albendazole treatment on development of oxidative/nitrosative stress in sheep. Veterinary Parasitology 186, $364-375$.

59. Dobson, R.J.; Lejambre, L.F. y Gill, J.H. 1996. Management of anthelmintic resistance: Inheritance of resistance and selection with persistent drugs. Int. J. Parasitology, 26: 993-1000.

60. Domke, A.V.M.; Chartier, C.; Gjerde, B.; Höglund, J.; Leine, N.; Vatn, S. y Stuen S. 2012. Prevalence of anthelmintic resistance in gastrointestinal nematodes of sheep and goats in Norway. Parasitol. Res. 2012; 111:185-193.

61. Dopchiz, M.C.; Parma, A.E. y Fiel, C.A. 2000. Hypobiosis induction alters the protein profile of Ostertagia ostertagi (Nematoda: Trichostrongylidae). Folia Parasitologica 47: 135-140.

62. Drudge, J.H.; Szanto, J.; Wyant, Z.N. y Elam, G., 1964. Field studies on parasitic control in sheep: comparison of thiabendazole, ruelene and phenothiazine. Am. J. Vet. Res., $1512-1518$.

63. Dutruel, F.J. y De Caro, A.E.J. 2019. Producción ovina en la Mesopotamia Argentina; Acciones y políticas desarrolladas para el 
sector. Revista de la Facultad de Agronomía UBA, 39 (1) 45-53, 2019.

64. Eady, S.J. 1998. Worm resistance in Merino breeding objective Influence of genetic correlations between resistance and production traits. 6th world congress on genetic applied to livestock production, pp. 141-144.

65. Echevarria, F.; Borba, M.F.S.; Pinheiro, A.C.; Waller, P.J. y Hansen, J.W. 1996. The prevalence of anthelmintic resistance in nematode parasites of sheep in Southern Latin America: Brazil. Veterinary Parasitology, 62: 199-206.

66. Eddi, C.; Caracostantogolo, J.; Peña, M.; Schapiro, J.; Marangunich, L.; Waller, P.J. y Hansen, J.W. 1996. The prevalence of anthelmintic resistance in nematode parasites of sheep in Southern Latin America: Argentina. Veterinary Parasitology, 62: 189-197.

67. Entrocasso, C.; Lange, R. y Fernández Ripoll. 1988. Resistencia antiparasitaria al oxfendazole en ovinos en un establecimiento de la provincia de Buenos Aires. Memorias del VI Congreso Arg. de Ciencias Vet., Buenos Aires. 1988. Com. libre 208.

68. FAO - Faostat. Enero 2020. Existencias ovinas. Organización de la Naciones Unidas para la Alimentación y la Agricultura. http://www.fao.org/faostat/es/\#data/QA.

69. Federación Lanera Argentina (FLA). Estadísticas laneras Argentinas, a través de consulta web. http://www.flasite.com/index.php/es/; info@flasite.com. 
70. Fernandez Abella, D. 2011. Pérdidas embrionarias y fetales en ovinos en Uruguay. XV Congreso Latinoamericano de Buiatría. XXXIX Jornadas Uruguayas de Buiatría. 8 al 10 de junio de 2011. Paysandú Uruguay.

71. Fernandez Abella, D.; Castells, D.; Piaggio, L. y Deleón, N. 2006. Estudio de la mortalidad embrionaria y fetal en ovinos. I. Efecto de distintas cargas parasitarias y su interacción en la alimentación sobre las pérdidas embrionarias y la fecundidad. Producción ovina vol. 15, 25-31, 2006.

72. Fernández-Long, M.E.; Spescha, L.; Barnatán, I.; Murphy, G. 2012. Modelo de Balance Hidrológico Operativo para el Agro (BHOA). Rev. Agronomía \& Ambiente 32(1-2): 31-47. FA-UBA, Buenos Aires, Argentina.

73. Fernandez, A.; Fiel, C. y Steffan, P. 1999. Study on the inductive factors of hypobiosis of Ostertagia ostertagi in cattle. Veterinary Parasitology, 81: 295-307.

74. Ferreyra, D.A., Steffan, P.E. y Fiel, C.A. 2002. Dinámica estacional y diaria en las pasturas de poblaciones de nematodes trichostrongylideos de bovinos. Revista de Investigaciones Agropecuarias (RIA), Vol 31 (2): 25-38.

75. Fiel, C. A.; Anziani, O.; Suarez, V.; Vazquez, R.; Eddi, C.; Romero, J.; Caracostangolo, J.; Samuell, C.; Mejia, M.; Costa, J. y Steffan, P. 2001. Resistencia antihelmíntica en bovinos: causas, diagnostico y profilaxis. Revista Veterinaria Argentina. 18 (171): 21-23. 
76. Fiel, C. y Nari, A. 2013. Enfermedades Parasitarias de Importancia Clínica y Productiva en Rumiantes. Fundamentos epidemiológicos para su prevención y control. Editorial Hemisferio Sur S.R.L. ISBN: 978-9974-674-35-6.

77. Fiel, C.; Steffan, P.E.; Muchiut, S.M.; Fernandez, A.S.; Bernat, G.; Riva, E.; Lloberas, M.M.; Almada, A. y Homer, D. 2017. An attempt to replace an ivermectin-resistant Cooperia spp. population by a susceptible one on grazing pastures based on epidemiological principles and refugia management. Veterinary Parasitology, 246, pp 53-59.

78. Fiel, C.A.; Saumell, C.A.; Fuse, L.A.; Florez Gálvez, J.; Freije, E.; Iglesias, L. y Steffan, P. 2009. Estudio de la dinámica de la inhibición-desinhibición de Ostertagia ostertagi en terneros del centro de la provincia de Buenos Aires. Resultados preliminares. Revista de Medicina Veterinaria (Buenos Aires) 2009, 90, (1/2): 4-8.

79. Fiel, C.A.; Saumell, C.A.; Steffan, P.E.; Rodriguez, E.M. y Salaberry, G. 2000. Resistencia de los nematodes trichostrongylideos - Cooperia y Trichostrongylus resistentes a tratamientos con avermectinas en bovinos de la Pampa Húmeda, Argentina. Rev Med Vet 81: 4, 310-315, 2000.

80. Fiel, C.A.; Steffan, P.E. y Ferreyra D.A. 2011. Diagnóstico de las parasitosis más frecuentes de los rumiantes: Técnicas de laboratorio e interpretación de resultados. Programa de Control 
Parasitario Sustentable (CPS) Proyecto a cargo de Pfizer. ISBN 978-987-33-1502-2.

81. Fiel, C.A.; Steffan, P.E.; Vercesi, H.M.; Ambrústolo, R.; Catania, P.; Casaro, A.; Entrocasso, C. y Biondani, C. 1988. Variación estacional del parasitismo interno de bovinos en el sudeste de la provincia de Buenos Aires (Argentina) con especial referencia al fenómeno de hipobiosis. Rev Med Vet 81: 4, 57-64, 1988.

82. Frutos, P.; Mantecón, A.R. 1994. Condición corporal en el ganado ovino y caprino en Aspectos sanitarios importantes y análisis de los factores productivos en el ovino-caprino. Ed. Colegio Oficial de Veterinarios de Zamora $15 \mathrm{pp}$.

83. Gibbs, H.C. 1986. Hypobiosis and the periparturient rise in sheep. Veterinary Clinics of North America: Food Animal Practice - Vol, $2,(2): 345-353$.

84. Giudici, C.J. 1999. Correspondances entre les variabilités morphologique et ecologique chez le nematode Haemonchus placei, parasite de bovins. Tesis doctoral. Université Francois Rabelais Tours. Francia pp 76-83.

85. Giudici, C.J.; Entrocasso, C. y Steffan, P. 2013. Enfermedades Parasitarias de Importancia Clínica y Productiva en Rumiantes. Fundamentos epidemiológicos para su prevención y control - Fiel, C.; Nari, A. Capítulo 1: Biología, fisiología e inmunidad de los nematodos gastrointestinales y pulmonares. pp. 1-28. ISBN: 9789974-674-35-6. 
86. Gonzalez Garduño R.; Córdova Pérez C.; Torres Hernández G.; Mendoza de Gives P. y Arece García J. 2011. Prevalencia de parásitos gastrointestinales en ovinos sacrificados en un rastro de Tabasco, México. Vet. Méx. 42 (2).

87. Gordon, H. Mcl. 1948. The epidemiology of parasitic diseases with special reference to studies with nematode parasites of sheep. The Australian Veterinary Journal 24: 17-44.

88. Grigera, G.; Oesterheld, M.; Pacín, F. 2007. Monitoring forage production for farmer's decision making. Agricultural Systems 94, 637-648.

89. Guzmán, M. 2014. Transmisión de Haemonchus contortus de ovino a bovino. Estudio de relaciones interespecíficas ParásitoHospedador aplicando métodos epidemiológicos y moleculares en cepas resistentes y sensibles a benzimidazoles. Tesis doctoral, Facultad de Ciencias Veterinarias, UNCPBA.

90. Hamer, K.; McIntyre, J.; Morrison, A.A.; Jennings, A.; Kelly, R.F.; Leeson, S.; Bartley, D.J.; Chaudhry, U.; Busin, V. y Sargison, N. 2019. The Dynamics of ovine gastrointestinal nematode infections within ewe and lamb cohorts on three Scottish sheep farms. Preventive Veterinary Medicine, 171 (2019), 104752.

91. Hart, J.A. 1964. Observartions on the dry season strongyle infestations of Zebu cattle in Northern Nigeria. Brit. Vet. J. 120: 87-95. 
92. Hauck, V. y Slukwa, M.A. 2013. Corrientes, la puerta de entrada del norte grande para la producción ovina. Instituto Nacional de Tecnología Agropecuaria (INTA) Centro Regional Corrientes.

93. Henriksen, S.A. y Korsholm, H. 1983. A method for culture and recovery of gastrointestinal strongyle larvae. Nord. Vet. Med., 35: 429-430.

94. Houdijk, J.G.M.; Jessop, N.S.; Kyriazakis, I. 2001. Nutrient partitioning between reproductive and immune functions in animals. Proceedings of the Nutrient Society. 60:515

95. Illanes, F.A.; Romero, J.R.; Niño Uribe, A.I. y Pruzzo, C.I. 2018. Primer informe de resistencia antihelmíntica a monepantel en ovinos de la provincia de Corrientes, Argentina. Vet. Arg. Vol. 35 (368) pp 1-7.

96. Instituto Nacional de Investigación Agropecuaria (INIA) Treinta y tres. Estación Experimental del Este. - 2013. Seminario de actualización técnica: Producción de carne ovina de calidad. Ministerio de ganadería agricultura y pesaca. República Oriental del Uruguay.

97. Instituto Uruguayo de Meteorología. www.inumet.gub.uy.

98. International Wool Textile Organization (ITWO). 2018. https://www.iwto.org.

99. Jacquiet, P.; Cabaret, J.; Cheikh, D.; Thiam, E. 1997. Identification of Haemonchus species in domestic ruminants based on morphometrics of spicules. Parasitology Research, $83: 82$ 
100. Johnstone, I.L. 1971. Enfoque ecológico para el control de la parasitosis ovina. Col. Agrop., INTA, No 20, 113 pp.

101. Kaplan, R.M. 2004. Drug resistance in nematodes of veterinary importance: a status report. Trends in parasitology, Vol. 20 (10) pp 477-481.

102. Kaplan, R.M.; Burke, J.M.; Terrill, T.H.; Miller, J.E.; Getz, W.R.; Mobini, S.; Valencia, E.; Williams, M.J.; Williamson, L.H.; Larsen, M.; Vatta, A.F. 2004. Validation of the FAMACHA ${ }^{\odot}$ eye color chart for detecting clinical anemia in sheep and goats on farms in the southern United States. Veterinary parasitology, 123, pp 105120.

103. Le Jambre, L.F. 1978. Host genetic factors in helminth control. En: The epidemiology and control of gastrointestinal parasites of sheep in Australia. Donald, A.D.; Southcott, W.H. and Dinnen, J.K. pp 137-141. CSIRO, Melbourne.

104. Le Jambre, L.F.; Southcott, W.H. y Dash, K.M., 1976. Resistance of selected lines of Haemonchus contortus to thiabendazole, morantel tartrate and levamisole. Int. J. Parasitol., 6: 217-222.

105. Levine, D.N. 1963. Weather, climate and the bionomics of ruminant nematode larvae in: Advances in Veterinary - Science, ed. Academic Fress. New York and London, 8; 215-259.

106. Lloberas, M.M. 2018. Evaluación cinético-dinámica in vivo e in vitro en Haemonchus contortus resistente a lactonas macrocíclicas. Tesis doctoral, Facultad de Ciencias Veterinarias, UNCPBA. 
107. Lombardero, O.; Moriena, R. y Schiffo, H. 1976. Epizootiología de la gastroenteritis verminosa bovina en la zona norte de la provincia de Corrientes. Gac. Vet. 38 (310): 143-169.

108. Lopez Saubidet, C.A. 1987. Manual del ovejero mesopotámico. Estación experimental Agrop. Mercedes, Corrientes, Argentina. Instituto Nacional de Tecnología Agropecuaria (INTA).

109. Love, S. 2007. Worm Test for livestock and guide to egg counts. State Worm Control, Extensive Industries Development, Armidale. Primefact 480. Feb. 2007 in. ISSN 1832-6668. http://www.dpi.nsw.gov.au/ data/assets/pdf file/0016/11007 7/wormtest-for-livestock-and-guide-to-egg-counts.pdf.

110. Love, S. 2011. Drench resistance and sheep worm control. NSW Government, Department of primary industries. Extensive industries development, 2nd edition.

111. Lukovich, R. 1985. Identificación las formas adultas de los nematodos gastrointestinales y pulmonares de los rumiantes en la República Argentina. Instituto de Patología Animal, Centro Nacional de Investigaciones Agropecuarias, Instituto Nacional de Tecnología Agropecuaria (INTA), Secretaría de Estado de Agricultura y Ganadería de la Nación, República Argentina. Disponible en Red de Helmintología de FAO para América Latina y el Caribe.

112. Lyndal-Murphy, M.; Ehrlich, W.K.; Mayer, D.G. 2014. Anthelmintic resistance in ovine gastrointestinal nematodes in 
inland southern Queensland. Australian Veterinary Journal. Vol.92, $11: 415-420$

113. Maciel, S.; Giménez, A.M.; Gaona, C.; Waller, P.J. y Hansen, J.W. 1996. The prevalence of anthelmintic resistance in nematode parasites of sheep in Southern Latin America: Paraguay. Veterinary Parasitology, 62: 207-212.

114. Maciel, W.G.; Felippelli, G.; Zanetti Lopes, W.D.; Pires Teixeira, W.F.; Cayeiro Cruz, B.; Rabelo dos Santos, T.; Buzzulini, C.; Favero, F.; Costa Gomes, L.; Pereira de Oliveira, G.; da Costa, A. y Shigaki de Matos, L.V. 2014. Fauna helmintológica de ovinos provenientes da microrregião de Jaboticabal, estado de São Paulo, Brasil. Ciência Rural, Santa Maria, v.44, n.3, p.492-497. ISSN 0103-8478

115. Martinez, P.R. 1987. Predicción de la estacionalidad de Haemonchus contortus mediante el establecimiento de bioclimatogramas en el estado de Veracruz. Tesis Doctoral. Universidad Veracruzana. México.

116. Mavrot, F.; Hertzberg, H.; Torgerson, P. 2015. Effect of gastrointestinal nematode infection on sheep performance: a systematic review and meta-analysis. Parasites \& Vectors (2015) 8:557.

117. Mc Ewan, J. 1994. Breeding sheep resistant o roundworm infection: Worm FEC. Breeders Manual. Edited by New Zealand Pastoral Agriculture Research Institute. 
118. McKenna, P.B. 2010. Update on the prevalence of anthelmintic resistance in gastrointestinal nematodes of sheep in New Zealand. N.Z. Vet. J. 58, 172-173.

119. McMahon, C.; Bartley, D.J.; Edgar, H.W.J.; Ellison, S.E.; Barley, J.P.; Malone, F.E.; Hanna, R.E.B.; Brennan, G.P. y Fairweather, I. 2013. Anthelmintic resistance in Northern Ireland (I): prevalence of resistance in ovine gastrointestinal nematodes, as determined through faecal egg count reduction testing. Vet. Parasitol. 2013; 195:122-130.

120. Mederos, A.E.; Ramos, Z. y Banchero, G. 2014. First report of monepantel Haemonchus contortus resistance on sheep farms in Uruguay. Parasites \& Vectors. Vol. 7 (598): pp 1-4.

121. Melander, A.L. 1914. Can insects become resistant to spray? J. Econ. Entomol. 7: 167-173.

122. Michel, J.F. 1969. The epidemiology and control of some nematode infections of grazing animals. Advances in parasitology Vol. 7 pp. 211-282.

123. Michel, J.F.; Lancaster, M.B. y Hong, C. 1979. The effect of age, acquired resistance, pregnancy and lactation on some reactions of cattle infection with Ostertagia ostertagi. Parasitolol. 79: 157168.

124. Ministerio Agricultura, Ganadería y Pesca (MAGyP). 2020. Presidencia de la Nación. https://www.agroindustria.gob.ar/sitio/areas/d ovinos/precios/l ana/index.php. 
125. Ministerio de Agroindustria, Presidencia de la Nación - 2016. El contexto actual del sector ovino: La necesidad de planificar hacia donde

ir.

https://agroindustria.gob.ar/sitio/areas/d ovinos/informes/regi onales/ archivos//000000 NEA/000000 El\%20contexto\%20act ual\%20del\%20sector\%200vino.pdf.

126. Ministerio de Agroindustria. 2016. El contexto actual del sector ovino. Ministerio de Agroindustria, Presidencia de la Nación. https://www.agroindustria.gob.ar/sitio/areas/d ovinos/informes /regionales/ archivos//000000 NEA/000001 Disertaciones/00 0003 El\%20contexto\%20actual\%20del\%20sector\%200vino.pdf

127. Ministerio de Agroindustria. 2017. Indicadores anuales carne ovina. Serie histórica 1998-2017. Dirección Nacional de Producción Ganadera. Dirección de Ovinos, Caprinos y Camélidos. Subsercretaría de Ganadería. Secretaría de Agricultura, Ganadería y Pesca. Ministerio de Agroindustria. Presidencia de La Nación.

128. Miranda, A.O., Suarez, V.H., Bedotti, D.O., Fort, M.C. y Busetti, M.R., 2002. Patologías prevalentes en una majada ovina de La Pampa (catorce años de casuística). Vet. Arg., Vol. XIX, 183: 180194.

129. Monteith, J., 1972. Solar radiation and productivity in tropical ecosys- tems. Journal of Applied Ecology 9, 747-766. 
130. Montossi, F., De Barbieri, I., Ciappesoni, G., Ganzabal, A., Banchero, G., Soares de Lima, J.M., Brito, G., Luzardo, S., San Julián, R., Silveira, C., y Vázquez, A. 2011. ¿Es posible con menos ovejas producir más y con mayor valor agregado?: Análisis y aportes del INIA para una ovinocultura uruguaya más innovadora y competitiva. En: Suplemento El País Agropecuario. Diciembre 2011. pp 30-24.

131. Montossi, F.; De Barbieri, I.; Ciappesoni, G.; Ganzábal, A.; Banchero, G.; Luzardo, S. y San Julián, R. 2013. Intensification, diversification, and specialization to improve the competitiveness of sheep production system under pastoral conditions: Uruguay's case. Animal Frontier Vol 3(3): 28-35, 2013.

132. Morales G., Guillen A.T., Pino L.A., Sandoval E., Morales J. 2013. Tratamiento Antihelmíntico Selectivo en Rumiantes: Métodos de Selección de la Fracción de Animales a tratar. Medicina Veterinaria Al día. Maracay, Venezuela. Año 3, Nro 4. Pag. 27.

133. Morales, G.; Pino, L.A. y Sandoval, E. 2006. La estrongilosis digestiva de los ovinos a pastoreo en Venezuela. Revista Electrónica de Veterinaria REDVET. Vol. 8 (11): 1-15. ISSN 16957504.

134. Morgan, E.R. y van Dijk, J. 2012. Climate and the epidemiology of gastrointestinal nematode infections of sheep in Europe. Veterinary Parasitology 189, 8-14.

135. Morris, J.E., Cronin, G.M., y Bush, R.D. 2012. Improving sheep production and welfare in extensive systems through precision 
sheep management. Animal Production Science, 52, 665-670. http://dx.doi.org/10.1071/AN11097.

136. Muchiut, S.; Fernández, A.S.; Lloberas, M.; Steffan, P.; Luque, S.; Cardozo, P.; Bernat, G.; Riva, E. y Fiel, C., 2019. Recovery of fenbendazole efficacy on resistant Haemonchus contortus by management of parasite refugia and population replacement. Veterinary Parasitology, 271 pp. 31-37.

137. Mueller, J.P.; Cueto, M.I. y Robles, C.A. 2015. Actualización en producción ovina 2015. Memorias del IX Curso, San Carlos de Bariloche. 14 al 18 de septiembre, 2015. Departamento de producción animal. Estación experimental Bariloche. Instituto Nacional de Tecnología Agropecuaria (INTA). 1ra Edición. ISBN $978-987-521-651-8$

138. Mufarrege, D. 2005. Los minerales en la alimentación de vacunos para carne en la Argentina. Serie técnica N037. Estación Experimental Agropecuaria Mercedes, INTA Corrientes. Julio 2005.

139. Muller, G.L. 1968. The epizootiology of helminth infestation in sheep in the South-Western districts of the Cape. Ondersterpoort J. Vet. Res. 35: 159-194.

140. Murray, J.A. 1919. Meat production. J. agric. Sci., Camb. 9, 17481.

141. Nari A, Cardozo H, Rizzo E, Solari MA, Petraccia C. 1983. Efecto del parasitismo gastrointestinal en la performance de corderos sometidos a diferentes planos de nutrición y edad de destete. 
Veterinaria. $1983 ; 19(85): 57-63$.

142. Nari, A.; Cardozo, H. y Berddie, J. 1977b. Alza de lactación (spring rise) para nematodos gastrointestinales de ovinos. Veterinaria 12: 65 .

143. Nari, A.; Cardozo, H.; Berdie, J.; Canabez, F. y Bawden, R. 1977a. Dinámica de población para nematodes gastrointestinales de ovinos en Uruguay. Veterinaria 14: 66 pp 11-24.

144. Nari, A.; Petraccia, C.; Solari, M.A. y Cardozo, H. 1982. La inhibición del desarrollo larvario en nematodes gastrointestinales de ovinos con especial referencia a Haemonchus contortus. Veterinaria, 18, (81): 78-88.

145. Nari, A.; Salles, J.; Gil, A.; Waller, P.J. y Hansen, J.W. 1996. The prevalence of anthelmintic resistance in nematode parasites of sheep in Southern Latin America: Uruguay. Veterinary Parasitology, 62: 213-222.

146. Nari, A.; Solari, M.A. y Cuore, U. 2013. Enfermedades Parasitarias de Importancia Clínica y Productiva en Rumiantes. Fundamentos epidemiológicos para su prevención y control - Fiel, C.; Nari, A. Capítulo 29: Bases teóricas y niveles de aplicación del control integrado en parásitos. Pp 689-713. ISBN: 978-9974-674-35-6.

147. Nari, A.H. 2011. Metodología y resultados del control integrado de parásitos en sistemas mixtos de producción. XV Congreso latinoamericano de Buiatría. XXXIX Jornadas Uruguayas de Buiatría. Uruguay. 
148. Newton, L.A.; Chilton, N.B.; Beveridge, I. y Gasser, R.B. 1998. Systematic relationships of some memers of the genera Oesophagostomum and Chabertia (Nematoda; Chabertiidae) based on ribosomal DNA sequence data. International Journal for Parasitology vol. 28; pp 1781-1789.

149. Niec, R. 1968. Cultivo e identificación de larvas infectantes de nematodos gastrointestinales del bovino y ovino. Instituto de Patología Animal, Centro Nacional de Investigaciones Agropecuarias, Instituto Nacional de Tecnología Agropecuaria (INTA), Secretaría de Estado de Agricultura y Ganadería de la Nación, República Argentina. Manual técnico $\mathrm{N}^{\circ}$ 3. INTAArgentina. pp: 1-37. Disponible en Red de Helmintología de FAO para América Latina y el Caribe.

150. Niec, R.; Rosa, W. y Lukovich, R. 1966. Variaciones estacionales del parasitismo gastrointestinal de los ovinos en la zona sud-este de la provincia de Buenos Aires. Instituto Nacional de Tecnología Agropecuaria (INTA) Revista IDIA No 221.

151. Niño Uribe, A.; Cetrá, B.; Pereira, M.; Gómez, S.; Romero, J. e Illanes, F. 2018. Estudio de persistencia de la infectividad en los pastos, de larvas de Haemonchus contortus susceptibles y resistentes a bencimidazoles, en el sur de la provincia de Corrientes. Noticias y comentarios, No 560. INTA EEA, Mercedes. ISSN No 0327-3059

152. Nitor Torres, E.M. 2006. Identificación de los parásitos helmintos gastrointestinales presentes en ovinos, que llegan a mataderos 
de exportación en Chile (Región XII). Tesis Doctoral. Universidad Austral de Chile.

153. O'Connor, L.J.; Walkeden-Brown, W. y Kahn, L.P. 2006. Ecology of the free-living stages of major trichostrongylid parasites of sheep. Veterinary Parasitology 142, 1-15.

154. Ogunsusi, R.A.; Eysker, M. 1979. Inhibited development of trichostrongylids of sheep in Norhtern Nigeria. Res. Vet. Sci. 26: 108-110.

155. Olaechea F.V. y M. Suárez. 1984. Parasitismo gastrointestinal en ovinos de la zona de Pilcaniyeu (Río Negro). Rev. Med. Vet. (Bs.As.) Vol. 65 Nro. 6:310-317. 1984.

156. Olaechea F.V., y Suárez M. 1985. Parasitismo gastrointestinal de los ovinos de Comodoro Rivadavia (Chubut). Vet. Arg. 2 (17): 611-616.

157. Onyali, I.O.; Onwuliri, C.O.E.; Ajayi, J.A. 1989. Strongyloides papillosus infestations of lambs in Plateau State of Nigeria. Revue Élev. Med. Vet. Pays. trop. Vol. 42 (2), pp 223-226.

158. Organización Meteorológica Mundial (OMM). 2014. El Niño/ Oscilación del sur. OMM Nro 1145. ISBN 978-92-63-31145-0. www.wmo.int.

159. ORNL DAAC 2018. MODIS and VIIRS Land Products Global Subsetting and Visualization Tool. ORNL DAAC, Oak Ridge, Tennessee, USA. Accessed janury 1, 2021. Subset obtained for MOD13Q1 product at various sites in Spatial Range: $\mathrm{N}=-$ 29.47977, $S=-29.47413, E=-58.16669, \quad W=-58.16694$, time 
period: february 18, 2000 to December 31, 2019, and subset size: 0,25 x 0,25 km. https://doi.org/10.3334/ORNLDAAC/1379

160. Pereira D.; Castells D.; Deschenaux H. 2006. Infectividad de campo natural contaminado con huevos de Haemonchus contortus en las cuatro estaciones del año. Producción ovina (18) 57-65.

161. Piñeiro, G.; Oesterheld, M.; Paruelo, J.M. 2006. Seasonal variation of aboveground production and radiation use efficiency of temperate rangelands estimated through remote sensing. Ecosystems 9, 1-19.

162. Pinilla, J.C.; Flórez, P.; Sierra, M.; Morales, E.; Sierra, R.; Vásquez, M.C.; Tobon, J.C.; Sánchez, A. y Ortiz, D. 2018. Rev. Inv. Vet. Perú 2018; 29 (1): 278-287.

163. Pizzio, R.; Bendersky, D.; Barbera, P. 2007. Caracterización de Ios pastizales correntinos. VII Congreso Nacional de Manejo de Pastizales Naturales. X Encuentro de Ganaderos del Pastizal del Cono Sur.

164. Pizzio, R.; Bendersky, D.; Barbera, P.; Maidana, E. 2021. Caracterización y manejo de los pastizales correntinos. Ediciones INTA; Estación Experimental Agropecuaria Mercedes, 289 p.

165. Poli, M.A.; Cetrá, B.; Medus, P.D.; Maizón, D.O. 2015. Estimación de parámetros genéticos en respuesta al desafío artificial con L3 de PGI en corderos Corriedale. $44^{\circ}$ Congreso Argentino de Genética. 13 al 16 de septiembre de 2015, Mar del Plata, Argentina. 
166. Prichard, R.K. 1990. Anthelmintic resistance in nematodes extent, recent understanding and future directions for control and research. Int. J. Parasit., 20: 515-523.

167. Prichard, R.K. 1999. Drug resistance. Int. J. Parasitology 29: 137138.

168. Prichard, R.K.; Hall, C.A. ; Kelly, J.D. ; Martin, I.C.A. y Donald, A.D. 1980. The problem of anthelmintic resistance in nematodes. Australian Veterinary Journal. Vol. 56: 239-250.

169. PROLANA. 2017. Informe de fin de zafra 2016-2017. Sistema de Datos y Estadísticas PROLANA. https://prolana.magyp.gob.ar/estadisticas-nacionales/.

170. Ramos, C.I.; Bellato, V.; Pereira de Souza, A.; Silveira de Avila, V.; Coutinho, G.C. y Dalagnol, C.A. 2004. Epidemiologia das helmintoses gastrintestinais de ovinos no Planato Catarinense. Ciencia Rural, nov.-dez; año/vol. 34, número 006 Universidade Federal de Santa Maria. Santa Maria, Brasil pp. 1889-1895.

171. Raza, A.; Lamb, J.; Chambers, M.; Hunt, P.W. y Kotze, A.C. 2016. Larval development assay reveals the presence of subpopulations showing high- and low-level resistance in a monepantel (Zolvix ${ }^{\circledR}$ )-resistant isolate of Haemonchus contortus. Veterinary Parasitology, Vol. 220, pp 77-82.

172. Reynecke, D.P.; Waghorn, T.S.; Oliver, A-M.B.; Miller, C.M.; Vlassoff, A. y Leathwick, D.M. 2011. Dynamics of the free-living stages of sheep intestinal parasites on pasture in the North Island of New Zealand. 2. Weather variables associated with 
development. New Zealand Veterinary Journal, 59:6, 287-292, DOI: $10.1080 / 00480169.2011 .610280$.

173. Rialch, A.; Vatsya, S. y Kumar, R.R. 2013. Detection of benzimidazole resistance in gastrointestinal nematodes of sheep and goats of sub-Himalyan region of northern India using different tests. Vet. Parasitol. 2013; 198: 312-318.

174. Rissi, D.R.; Pierezan, F.; Oliveira Filho, J.C.; Fighera, R.A.; Irigoyen, L.F.; Kommers, G.D. y Barros, C.S.L. 2010. Doenças de ovinos da região Central do Rio Grande do Sul: 361 casos. Pesq. Vet. Bras. 30 (1):21-28, 2010.

175. Roberts, F.H. y O'Sullivan, P.J. 1949. Methods for eggs counts and larval cultures for strongyles infesting the gastrointestinal tract of cattle. Aust. J. Agric. Res., 1:99-103.

176. Robles, C. y Olaechea, F. 2001. Salud y enfermedades de las majadas. Capitulo 11, pp. 223-242. En: Ganadería sustentable en la Patagonia Austral. Instituto Nacional de Tecnología Agropecuaria (INTA). Estación Experimental Bariloche.

177. Romero, J.; Boero, C.; Aristizábal, M.; Baldo, A. y Vasquez, R. 1998. Estudio de resistencia a antihelmínticos en majadas de la mesopotamia argentina. Rev. Med.Vet. 79 (5): 342-346.

178. Romero, J.; Boero, C.A.; Prando, A.J.; Baldo, A.; Griffin, B. y Silvestrini, M. 1999. Selection of trichostrongylid resistant sheep in argentine farms. 17th International conference of the World Association for the Advancement of Veterinary Parasitology. Copenhagen 15-19 august 1999. Abst. f. 304. 
179. Romero, J.R. y Boero C.A. 2001. Epidemiología de la gastroenteritis verminosa de los ovinos en las regiones templadas y cálidas de la Argentina. Revista Analecta Veterinaria 21, 1: 2137. ISSN 1514259-0

180. Romero, J.R.; Anziani, O.; Cetrá, B. y Fiel, C. 2013. Enfermedades Parasitarias de Importancia Clínica y Productiva en Rumiantes. Fundamentos epidemiológicos para su prevención y control - Fiel, C.; Nari, A. Capítulo 4: Epidemiología e impacto productivo de nematodes en la región del NEA. pp. 89-112. ISBN: 978-9974674-35-6.

181. Romero, J.R.; Boero, C.A.; Aristizábal, M.; Baldo, A. y Vazquez, R. 1998. Estudio de resistencia a antihelmínticos en majadas de la Mesopotamia Argentina. Rev. Med.Vet. 79 (5): 342-346.

182. Romero, J.R.; Cetrá, B.; Sanabria, R.; Antonini, A. 2011. Selection of ewes with low and high trichostrongylids eggs count in Argentina. International Conference of the World Association for the Advancement of Veterinary Parasitology. Session A1, Parte 68. Buenos Aires. Argentina, pp 620.

183. Romero, J.R.; Espinosa, G. y Valera, A. 1992. Demostración de resistencia al oxfendazole en trichostrongylidos de ovinos de la zona deprimida del Salado. Rev. Med. Vet. 73 (2): 82-86.

184. Rosa, W.; Niec, R.; Lukovich, R.; Dindart, J. y Barberan, R. 1973. Etiología y variación estacional del parasitismo gastrointestinal de los ovinos y bovinos en la zona de Mercedes (Provincia de 
Corrientes). Revista de Investigaciones Agropecuarias (RIA), 10 (1): $25-40$.

185. Rosa, W.A.J. y Lukovich, R. 1974. Incidencia económica de los parásitos gastrointestinales de los bovinos y ovinos. Rev Med Vet (Bogota). 1974; 55 (4): 327-36.

186. Rossanigo, C. y Page, W. 2017. Evaluación de FAMACHA ${ }^{\odot}$ en el control de nematodes gastrointestinales en cabras de San Luis (Argentina). Revista de investigaciones agropecuarias, vol 43, núm. 3, pp 239-246. ISSN: 0325-8718.

187. Rossanigo, C.E. y Gruner, L. 1995. Moisture and temperature requirements in faeces for the development of free-living stages of gastrointestinal nematodes of sheep, cattle and deer. Journal of Helminthology, 69, 357-362.

188. Russel, J.F.; Doney, J.M. y Gunn, R.G. 1969. Subjective assessment of body fat in live sheep. J. agric. Sci. Camb. 72, 451454.

189. Sagues, M.; Fusé, L.; Fernández, A.; Iglesias, L.; Moreno, F. y Saumell, C. 2011. Efficacy of an energy block containing Duddingtonia flagrans in the control of gastrointestinal nematodos of sheep. Proceedings, 23rd. International Conference of the World Association for the Advancement of Veterinary Parasitology. Bs. As. Argentina, pp. 27.

190. Sales, N. y Love, S. 2016. Resistance of Haemonchus sp. to monepantel and reduced efficacy of a derquantel / abamectina 
combination confirmed in sheep in NSW, Australia. Veterinary Parasitology, Vol, 228, pp 193-196.

191. Salgado, C. 2003. El Cordero Pesado "SUL". Un Ejemplo de Desenvolvimiento Integrado en la Producción de Carne Ovina en Uruguay. 20 Simposio Internacional de Producción de Carne Ovina y Caprina. Joao Pessoa, Paraiba, Brasil.

192. Salles, J.; Castells, D.; Rizzo, E.; Morixe, F.; Nari, A.; van Wyk, J. y Hansen, J. 2002. Evaluación de la eficacia de FAMACHA ${ }^{\odot}$, para el diagnóstico clínico y control de Haemonchus contortus en ovinos en el Uruguay. Reunión de especialistas en Parasitología Veterinarai de Argentina, Brasil, Chile, Paraguay y Uruguay. $11^{\circ}$ Encuentro de Veterinarios Endoparasitólogos Rioplatenses. Fac. Cs. Veterinarias, Tandil, Argentina.

193. Sánchez, R.O. y Romero, J.R. 2005. Observaciones sobre la dinámica del parasitismo gastrointestinal en corderos de destete de la Pampa Húmeda. Rev. Med. Vet 86 (1): 17-26.

194. Sangster, N.C. y Gill, J. 1999. Pharmacology of anthelmintic resistance. Parasitology Today, vol. 15 (4): 141-146.

195. Sani, R.A.; Gray, G.D. y Baker, R.L. 2004. Worm Control for Small Ruminants in Tropical Asia. Australian Centre for International Agricultural Research 2004. 1863204725

196. Santiago, M.A.M.; Benevenga, S.F. y Da Costa, U.C. 1976. Epidemiologia e controle da helmintose ovina no municipio de Itaqui, Rio Grande do Sul. Pesq. agropec. brasi., Sér. Vet. 11: 17. 1976. 
197. Santos, M.C.; Silva, B.F.; Amarante, A.F.T. 2012. Environmental factors influencing the transmission of Haemonchus contortus. Veterinary Parasitology 188: 277-284.

198. Schapiro, J.; Morici, G.; Di Ciaccio, L.; Salvat, A.; Fortunato, R.H. y Caracostantogolo J. 2015. Actividad antihelmíntica de extractos vegetales. Congreso Latinoamericano de Agroecología. La Plata, Argentina, 2015. A1-203.

199. Scott, I.; Pomroy, W.E.; Kenyon, P.R.; Smith, G.; Adlington, B. y Moss, A. 2013. Lack of efficacy of monepantel against Teladorsagia circumcincta and Trichostrongylus colubriformis. Veterinary Parasitology 198 (1-2): 166-171.

200. Secretaria de Ambiente y Desarrollo Sustentable de La Nación; 2007 - Primer inventario nacional de bosques nativos. Informe regional espinal 2da parte. 154 p. ISBN: 978-987-23575-9-7.

201. Servicio Meteorológico Nacional (SMN). 2012. Consulta en el Ministerio de Defensa, Centro de Información Meteorológica, Servicio Meteorológico Nacional. $\quad$ CIM@smn.gov.ar. https://www.smn.gob.ar.

202. Servicio Meteorológico Nacional; www.smn.gob.ar.

203. Servicio Nacional de Sanidad y Calidad Agroalimentaria (SENASA). Enero 2020. Existencias ovinas en Argentina. Dirección de Control de Gestión y Programas Especiales Dirección Nacional de Sanidad Animal - SENASA https://datos.agroindustria.gob.ar/dataset/senasa-existencias- 
ovinas. https://www.argentina.gob.ar/senasa/ovinos-sectorprimario.

204. Servicio Nacional de Sanidad y Calidad Agroalimentaria (SENASA). 2018. Ovinos sector primario. SIGSA - Dirección de Control de Gestión y Programas Especiales - Dirección Nacional de Sanidad Animal - SENASA. Recuperado de https://www.argentina.gob.ar/senasa/mercados-yestadisticas/estadisticas/animal-estadisticas/ovinos.

205. Servicio Nacional de Sanidad y Calidad Agroalimentaria (SENASA). 2018. Ovinos. Cadena Animal. Recuperado de http://www.senasa.gob.ar/cadena-animal/ovinos.

206. Soto, A.T.; Gómez, M.V.; Pastorelli, V. 2020 - Reproducción en pequeños rumiantes: cómo evaluar la eficiencia reproductiva de la majada y el hato caprino - 1ra ed. - La Plata: Universidad Nacional de La Plata; EDULP, 2020 (Libros de cátedra). Archivo Digital: ISBN 978-950-34-1867-3.

207. Späth, E.J.A.; Manazza, J.; Entrocasso, C.; Brusca, G.; Plorutti, F.; Faverín, C. y Frade, V. 2009. Enfermedades de los ovinos diagnosticadas por veterinarios rurales en la provincia de Buenos Aires. Revista Argentina de Producción Animal Vol 29 Supl. 1:5782 (2009).

208. Steffan, P.E. 1991. Efectos de la parasitosis gastrointestinal sobre la aptitud reproductiva de vaquillonas. VI o Simposio Argentino de Producción Animal, AAPA, Tandil, Junio de 1991. 
209. Steffan, P.E. y Fiel, C. 1994. Efectos en producción y control de nematodes gastrointestinales en bovinos. Enfermedades Parasitarias de Importancia Económica en Bovinos. Capítulo 7. Editado por A. Nari y C. Fiel. Editorial Hemisferio Sur.

210. Steffan, P.E. y Fiel, C. 2018. Diagnóstico de los parásitos internos más frecuentes en rumiantes. Técnicas e interpretación clínica de resultados. Primera edición especial, Tandil. Programa CPS (120 pag.). ISBN 978-987-42-6751-1.

211. Suarez VH, Larrea S, Busetti MR, Bedotti DO, Bulman MG, Ambrustolo R.R. 1990. Nematodes gastrointestinales ovinos: Su control y efectos sobre los parametros epizootiologicos, hematologicos y productivos en la region semiarida pampeana (Argentina). Therios. 1990;15(73):156-73.

212. Suárez, V.H. 1985(a). Parasitosis gastrointestinal en ovinos Corriedale en la región semiárida pampeana. I Resultados de los primeros 16 meses de observaciones. Rev. Med. Vet. 66 (3): 140149.

213. Suárez, V.H. 1985(b). Parasitosis Gastrointestinal en ovinos Corriedale en la región semiárida pampeana. II resultados período 1981-1983. Rev Prod. An. 5 (3-4): 243-55.

214. Suárez, V.H. 1986. Epizootiología de los parásitos gastrointestinales en ovejas en la región semiárida pampeana. Rev. Med. Vet. 67 (4): 190-202. 8.

215. Suarez, V.H. 1990a. Variación estacional de las poblaciones de helmintos parásitos de bovinos en sistemas de invernada en la 
Región Semiárida y Subhúmeda Pampeana. Revista de Medicina Veterinaria (Bs. As.) 71 (1): 6-18.

216. Suárez, V.H. 2004. Lechería Ovina y Raza Pampinta. En: IDIA XXI - Ovinos. Año IV, No. 7. Ediciones INTA. 194-200.

217. Suarez, V.H. 2007a. Enfermedades parasitarias de los ovinos y otros rumiantes menores en el cono sur de América - Suarez, V.H.; Olaechea, F.V.; Romero, J.R.; Rossanigo, C.E. Ovinos. Nematodes. Sistemática y binomia de los principales nematodes de los lanares. Publicación técnica nº 70. Instituto Nacional de Tecnología Agropecuaria (INTA) pp 15-32. ISBN: 0325-2132.

218. Suárez, V.H. 2007b. Epidemiología y control de los nematodos gastrointestinales en el oeste de la región Pampeana. En Enfermedades parasitarias de los ovinos y otros rumiantes menores en el cono sur de América. Por Suarez, V.H.; Olaechea, F.V.; Romero, J.R.; Rossaingo, C.E. (2007). Ed. Instituto Nacional de Tecnología Agropecuaria. ISSN: 0325-2132. 295 pp. Cap. 1.3.2 pp 43-62.

219. Suárez, V.H. 2007c. Producción ovina e importancia de los nematodes gastrointestinales en la Argentina. En Enfermedades parasitarias de los ovinos y otros rumiantes menores en el cono sur de América. Por Suarez, V.H. (2007). Ed. Instituto Nacional de Tecnología Agropecuaria. ISSN: 0325-2132. 295 pp. Cap. 1.1 pp 9-14. 
220. Suarez, V.H. 2011b. Buenas Prácticas de Manejo Sanitario para el Tambo Ovino. Instituto Nacional de Tecnología Agropecuaria (INTA). Estación Experimental Salta.

221. Suarez, V.H.; 2010b. Manejo sanitario de la majada en a región semiárida pampeana. Instituto Nacional de Tecnología Agropecuaria (INTA). Estación Experimental Anguil.

222. Suárez, V.H.; Busetti, M. y Real Ortellado, M. 2010a. Encuesta descriptiva sobre prácticas de manejo y producción en sistemas ovinos de lana y carne en la región semiárida pampeana. Rev. Arg. Prod. Anim. Vol. 30, N 1, 81-96.

223. Suarez, V.H.; Busetti, M.R. y Real Ortellado, M. 2011 a. Prevalencia de enfermedades y manejo sanitario en los sistemas de producción ovina de lana y carne de La Pampa, Argentina. Veterinaria Argentina.

224. Suárez, V.H.; Fondraz, M.; Viñabal, A.; Martinez, G.M.; Salatin A. 2013. Epidemiología de los nematodes gastrointestinales en caprinos lecheros en los valles templados del NOA, Argentina. Revista de investigaciones agropecuarias, vol 39, núm. 2, pp 191197.

225. Suárez, V.H.; Fondraz, M.; Viñabal, A.; Salatin A. 2014. Validación del método $\mathrm{FAMACHA}^{\odot}$ para detectar anemia en caprinos lecheros en los valles templados del noroeste argentino. Revista de Medicina Veterinaria. Vol 95 (2) 4-11. ISSN 1852$771 X$. 
226. Suárez, V.H.; Larrea, S.; Busetti, M.R.; Bedotti, D.O.; Bulman, G.M. y Ambrústolo, R.R. 1990b. Nematodes Gastrointestinales de ovinos: Su control y efectos sobre los parámetros epizootiológicos y productivos en la región semiárida pampeana (Argentina). Therios 15:156-173.

227. Suárez, VH. 1990c. Inhibition patterns and seasonal availability of nematodes for beef cattle grazing on Argentina's Western Pampas. Int. J. Parasitol. 1990; 20: 1031-1036.

228. Symons, L.E.A. y Hennessey, D.R. 1981. Cholecystokinin and anorexia in sheep by the intestinal nematode Trichostrongylus colubriformis. International Journal for Parasitology 11: 55-58.

229. Taira, N.; Nakamura, Y.; Tsuji, N.; Kubo, M.; Ura, S. 1992. Sudden death of calves by experimental infection with Strongyloides papillosus. I. Parasitological observations. Veterinary parasitology, 42, 247-256.

230. Torres-Acosta, J.F.; Jacobs, D.E.; Aguilar, A.; Sandoval, C.; May, M.; Cob, L.A. 2004. The effect of supplementary feeding on the resilience and resistance of browsing Criollo kids against natural gastrointestinal nematode infections during the rainy season in tropical Mexico. Veterinary Parasitology, 124:217.

231. Tothill, J.C.; Hargreaves, J.N.G; Jones, R.M. 1978. BOTANAL - A comprehensive sampling and computing procedure for estimating pasture yield and composition. 1. Field sampling. CSIRO Australia. Division of Tropical Crops and Pastures. Tropical Agronomy Technical Memorandum No8. 
232. Tsotetsi; A.M.; Njiro, S.; Katsande, T.C.; Moyo, G.; Baloyi, F. y Mpofu, J. 2013. Prevalence of gastrointestinal helminths and anthelmintic resistance on small-scale farms in Gauteng Province, South Africa. Trop. Anim. Health Prod. 45:751-761.

233. Ueno, H. y Gonçalves, P.C. 1988. Manual de laboratorio para el diagnóstico de helmintos en rumiantes. $2^{\circ}$ ed. Japan International Cooperation Agency Tokyo, Japan P.O. Box 216 Mitsui Bldg. Shinjuku, Tokyo 163, Japan. 166 pp.

234. Van den Brom, R.; Moll, L.; Kappert, C y Vellema, P. 2015. Haemonchus contortus resistance to monepantel in sheep. Veterinary Parasitology 209, pp 278-280.

235. Van Wyk, J. 2001. Refugia-overlooked as perhaps the most potent factor concerning the development of anthelmintic resistance. Onderstepoort Journal of Veterinary Research 68: 55-67.

236. Van Wyk, J. y Schalkwyk, P., 1990. A novel approach to the control of anthelmintic-resistant Haemonchus contortus in sheep. Vet. Parasitol. 35, 61-69.

237. Van Wyk, J.A. y Bath, G.F. 2002. The FAMACHA ${ }^{\odot}$ system for managing haemonchosis in sheep and goats by clinically identifying individual animals for treatment. Vet. Res. 33: 509529.

238. Vatta, A.F.; Waller, P.J.; Githiori, J.B. y Medley G.F. 2012. Persistence of the efficacy of copper oxide wire particles against Haemonchus contortus in grazing South African goats. Veterinary Parasitology, Vol., 190, pp. 159-166. 
239. Vazquez, R. 1995. Avances en la resistencia de los parásitos a los antiparasitarios en ovinos de la Mesopotamia Argentina. Noticias y Comentarios, INTA, EEA Mercedes. 306: 104.

240. Viljoen, J.H. 1969. Further studies on the epizootiology of nematodes parasites of sheep in the Karao. Onderstpoort. J. Vet. Res. 36: 233-264

241. Vlassoff, A. 1982. Biology and population dynamics of the free living stages of gastrointestinal nematodes of sheep. In: Ross AD (ed). Control of internal parasites of sheep - an Animal Industries Workshop. Pp 11-20. Lincoln College, Lincoln, 1982.

242. Vlassoff, A.; Leathwick, D.M. y Heath A.C.G. 2001. The epidemiology of nematode infections of sheep New Zealand Veterinary Journal, 49:6, 213-221, DOI: $10.1080 / 00480169.2001 .36235$.

243. Voigt, K.; Scheuerle, M. y Hamel, D. 2012.Triple anthelmintic resistance in Trichostrongylus spp. in a German sheep flock. Small Rumin. Res. 2012; 106:30-32.

244. Waghorn, T.S.; Reynecke, D.P.; Oliver, A-M.B.; Miller, C.M.; Vlassoff, A.; Koolaard, J.P. y Leathwick, D.M. 2011. Dynamics of the free-living stages of sheep intestinal parasites on pasture in the North Island of New Zealand. 1. Patterns of seasonal development. New Zealand Veterinary Journal, 59:6, 279-286, DOI: $10.1080 / 00480169.2011 .610279$

245. Waller, P.J.; Echevarria, F.; Eddi, C.; Maciel, S.; Nari, A. y Hansen, J.W. 1996. The prevalence of anthelmintic resistance in 
nematode parasites of sheep in Southern Latin America: General overview. Veterinary Parasitology, 62: 181-187.

246. Webb, R.F. y Ottaway, S.J. 1986. The prevalence of anthelmintic resistance in sheep nematodes on the central tablelands of New South Wales. Australian Veterinary Journal, Vol. 63 (1): 13-16.

247. Wolstenholme, A.J.; Fairweather, I.; Prichard, R.; von SamsonHimmelstjerna, G. y Sangster, C. 2004. Drug resistance in veterinary helminths. Trends in Parasitology. Vol. 20 (10) 469476.

248. Woolastone, R.R. 1994. Preliminary evaluation of strategies to breed Merinos for resistance to roundworms. 5th world congress on genetic applied to livestock production, pp. 4.

249. Zúñiga Loaiza, A.E. 2003. Identificación de los helmintos parásitos en abomaso e intestino delgado de ovinos faenados en la ciudad de Coyhaique, Región XI, Chile. Tesis Doctoral. Universidad Austral de Chile.

250. Zvinorova, P.I.; Halimani, T.E.; Muchadeyi, F.C.; Matika, O.; Riggio, V. y Dzama K. 2016. Breeding for resistance to gastrointestinal nematodes - the potential in low-input/output small ruminant production systems. Veterinary Parasitology 30 (225): 19-28. 
"Mucha gente pequeña en lugares pequeños, haciendo cosas pequeñas, puede cambiar el mundo." Eduardo Galeano

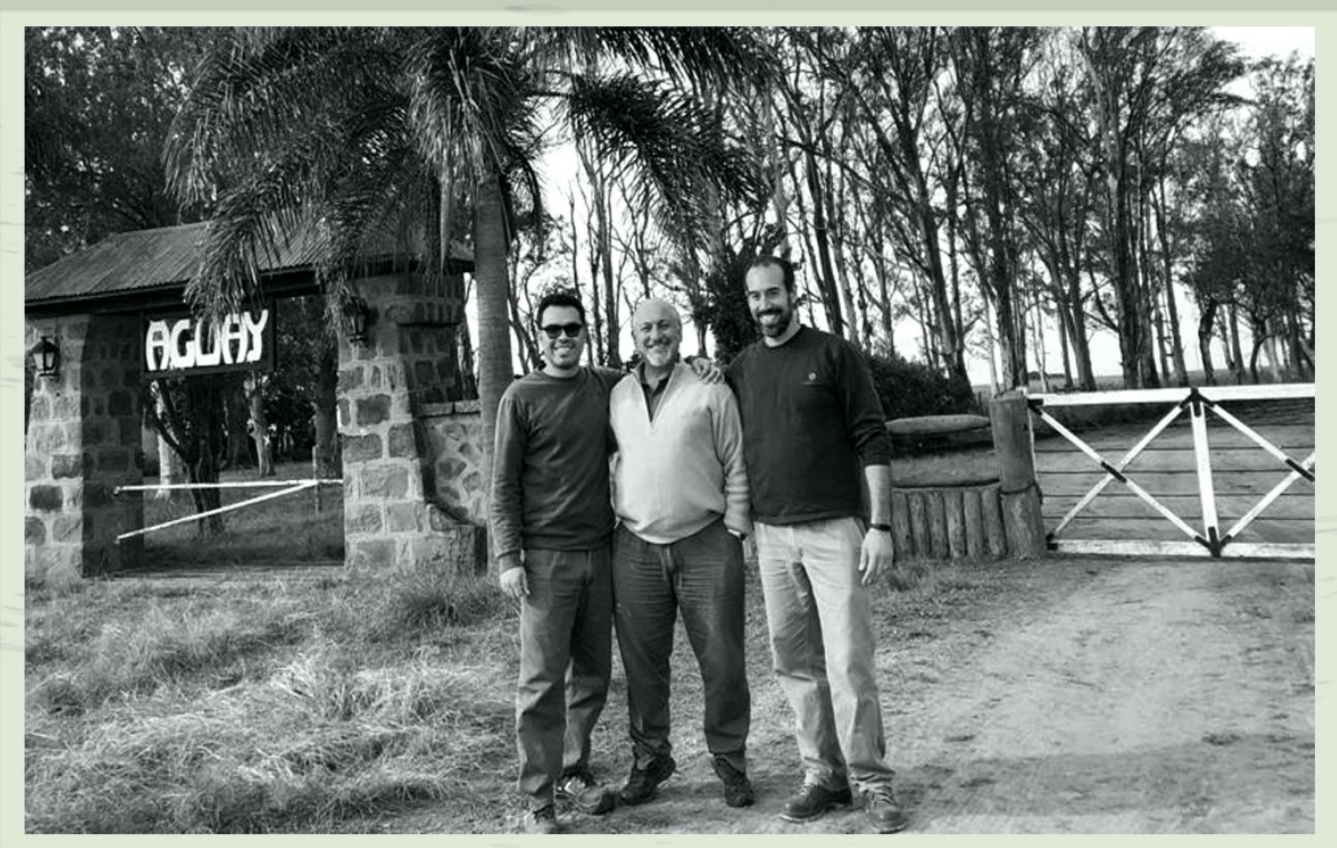

"El equipo de trabajo en uno de los últimos muestreos" (De izquierda a derecha Alvaro Niño Uribe, Jorge Romero, Federico Illanes) 